\title{
Prevention and Control of Microbiologically Influenced Concrete Deterioration in Wastewater Concrete Structures Using E.coli Biofilm
}

By

\section{Sahar Soleimani}

A thesis submitted to the Faculty of Graduate and Post Doctoral Affairs in partial fulfillment of the requirements for the degree of

Doctor of Philosophy

in

Environmental Engineering

Department of Civil and Environmental Engineering Carleton University

Ottawa-Carleton Institute for Environmental Engineering May 2012

(C) 2012 Sahar Soleimani 
Library and Archives

Canada

Published Heritage

Branch

395 Wellington Street

Ottawa ON K1A ON4

Canada
Bibliothèque et

Archives Canada

Direction du

Patrimoine de l'édition

395 , rue Wellington

Ottawa ON K1A ON4

Canada
Your file Votre référence

ISBN: 978-0-494-89320-3

Our file Notre référence

ISBN: $978-0-494-89320-3$

\section{NOTICE:}

The author has granted a nonexclusive license allowing Library and Archives Canada to reproduce, publish, archive, preserve, conserve, communicate to the public by telecommunication or on the Internet, loan, distrbute and sell theses worldwide, for commercial or noncommercial purposes, in microform, paper, electronic and/or any other formats.

The author retains copyright ownership and moral rights in this thesis. Neither the thesis nor substantial extracts from it may be printed or otherwise reproduced without the author's permission.
AVIS:

L'auteur a accordé une licence non exclusive permettant à la Bibliothèque et Archives Canada de reproduire, publier, archiver, sauvegarder, conserver, transmettre au public par télécommunication ou par l'Internet, prêter, distribuer et vendre des thèses partout dans le monde, à des fins commerciales ou autres, sur support microforme, papier, électronique et/ou autres formats.

L'auteur conserve la propriété du droit d'auteur et des droits moraux qui protege cette thèse. $\mathrm{Ni}$ la thèse ni des extraits substantiels de celle-ci ne doivent être imprimés ou autrement reproduits sans son autorisation.
In compliance with the Canadian Privacy Act some supporting forms may have been removed from this thesis.

While these forms may be included in the document page count, their removal does not represent any loss of content from the thesis.
Conformément à la loi canadienne sur la protection de la vie privée, quelques formulaires secondaires ont été enlevés de cette thèse.

Bien que ces formulaires aient inclus dans la pagination, il n'y aura aucun contenu manquant. 


\begin{abstract}
One of the most important deterioration mechanisms in wastewater infrastructure is microbial influenced concrete deterioration (MICD). MICD is a process in which microbial organisms accelerate the concrete deterioration by producing sulphuric acid on the surface of concrete. Sulphur oxidizing bacteria (SOB) are aerobic bacteria that convert the sulphur compounds into sulphuric acid on the concrete surface which results in biogenic sulphuric acid deterioration.
\end{abstract}

This study was proposed to investigate the use of E.coli DH5 $\alpha$ bacterial biofilm as an environmentally friendly alternative to inhibit MICD. MICD was simulated with sulphuric acid solution as well as biogenic acidification using two species of SOB. E.coli biofilm with high amount of extracellular polymeric substance coverage was successfully grown on the mortar surface. All evidence from calcium leach-out concentration, scanning electron microscopy (SEM) and X-ray diffraction (XRD) analyses suggests that the presence of biofilm prevented or controlled the chemically and biologically induced mortar deterioration. SEM and XRD analysis of mortar specimens under biogenic acidification showed the presence of gypsum crystals on the control mortar without biofilm, which is one of the indicators of concrete deterioration due to sulphate attack; however, there was no sign of gypsum crystals on the biofilm-covered mortar surface. The confocal laser scanning microscopy and volatile suspended solid analyses indicated that the biofilm sustained and was growing during both acidification processes.

Comparing the mechanism of chemical sulphuric acid deterioration with the biogenic sulphuric acid deterioration illustrated that the chemical acidification changes the 
structure of the mortar by dissolution of $\mathrm{C}-\mathrm{S}-\mathrm{H}$; however, biogenic acidification causes cracking, spalling, loss of coherence and expansion due to gypsum formation. It was also revealed that the biogenic acidification at an elevated temperature (i.e., $37 \pm 1^{\circ} \mathrm{C}$ ) leads to a more severe deterioration comparing with the room temperature biogenic acidification. As shown by the XRD analysis, the biogenic acidification at elevated temperatures resulted in the formation of gypsum in the biofilm-covered mortar which was not a case for the room temperature experiment. 


\section{ACKNOWLEDGEMENTS}

I would like to sincerely thank both my supervisors Dr. Banu Ormeci and Dr. O. Burkan Isgor for their continuous support, thoughtful advice and warm encouragement throughout my doctoral study. They inspired me in every step of my work from the very early stages to the end and enhanced my knowledge as a researcher. I am so honoured for having the experience of working with them which trained me for my future career and life. I have been extremely lucky to have these two persons as my supervisors and mentors in my life.

I would like to express my appreciation to Dr. Jim Beaudoin (Researcher Emeritus at NRC and Adjunct Professor at the University of Ottawa) who provided me with his expertise in very specialized areas of work. I am also very thankful for the technical help provided by Mr. Gordon Chan during my experimental studies at NRC. Special thanks must be extended to Ms. Rahil Khoshnazar for her assistance in the XRD investigation.

I would like to express my gratitude to the staff of Civil and Environmental Engineering laboratory at Carleton University with special thanks to Mr. Stanley Conley and Dr. Marie Jose Tudoret-Chow for their assistance throughout these years. I gratefully acknowledge the assistance of Dr. Jianqun Wang, the technical director of SEM laboratory at Carleton University, in preparing the SEM images. I should also acknowledge the assistance of Mr. Raed Hanania at the Image Acquisition Core Facility of University of Ottawa for his assistance in taking the CLSM images. I would also like to thank my fellow graduate student, Burak Gunay, for his help in preparing some graphs for this thesis. 
I am grateful to Dr Sankara Papavinasam for his collaboration in the biosensor study and the technical help of staffs, Dr. Reeta Sooknah and Mr. Alex Doiron during my experimental studies at CANMET/MTL. Special thanks go to Dr. Thomas K. Wood from Texas A\&M University for providing the antibiotic resistance strain of E.coli DH5 $\alpha$.

Words cannot express how I am indebted to my family. I feel a deep sense of gratitude for my family, specially my father and mother who formed part of my vision and have been unconditionally supporting me from the beginning of my life. Without doubt, none of my success would have been possible without their dedication and support. I also would like to thank all my friends in Ottawa for the enjoyable moments they provided for me during the writing of this thesis.

I would like to give my special appreciation to my husband, Pouria Ghods, whose love and support enabled me to complete this work. He unwaveringly encouraged me to pursue my academic studies in the doctoral level. Without his understanding and help, it would have been impossible for me to finish this work.

I would like to acknowledge the financial supports provided in the forms of Natural Sciences and Engineering Research Council of Canada (NSERC) Scholarship, Ontario Graduate Scholarships (OGS), and Carleton University's financial assistance, including several scholarships, fellowship, and teaching assistantship. 


\section{TABLE OF CONTENTS}

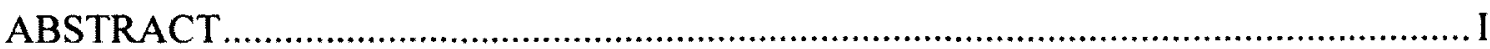

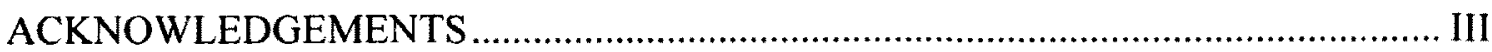

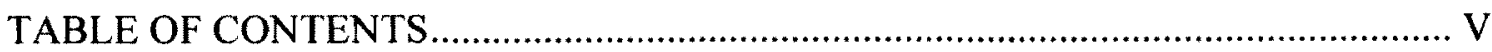

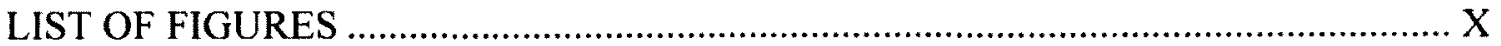

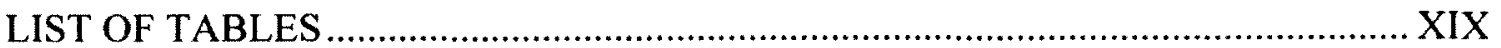

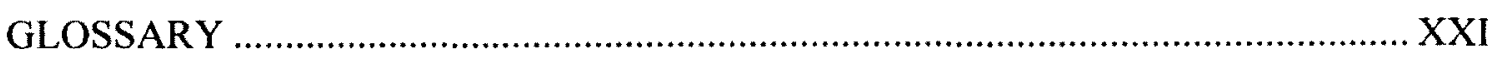

CHAPTER 1. INTRODUCTION AND OBJECTIVES ..................................... 1

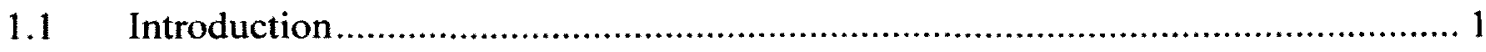

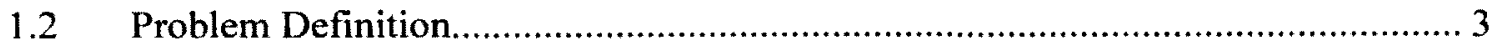

1.3 Objectives and Scope

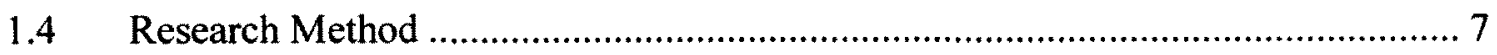

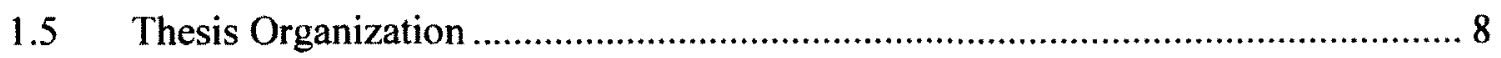

CHAPTER 2. LITERATURE REVIEW ............................................................. 10

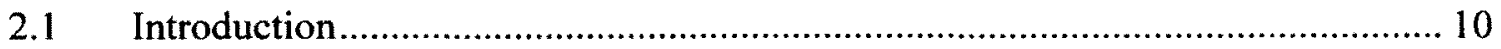

2.2 Microbiologically Influenced Corrosion of Metals ......................................... 11

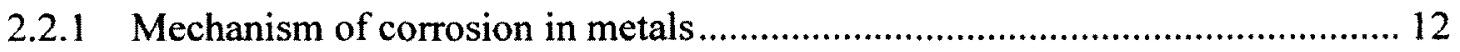

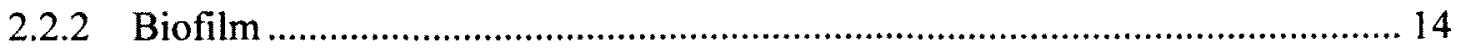

2.2.3 Corrosion control by biofilm formation................................................... 15

2.3 Microbiologically Influenced Concrete Deterioration (MICD)........................ 20

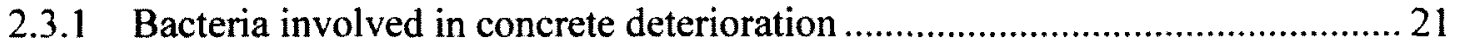

2.3.2 Test procedures for biogenic sulphuric acid attack simulation...................... 24

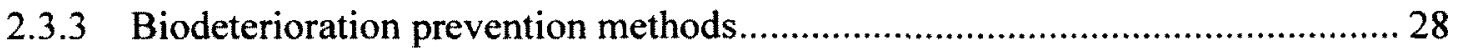


2.4 Sulphate Attack: Mechanism and Differences................................................... 34

2.4.1 Forms of sulphate attack ............................................................................ 35

2.4.2 Mechanism of sulphate attack on concrete microstructure ............................... 36

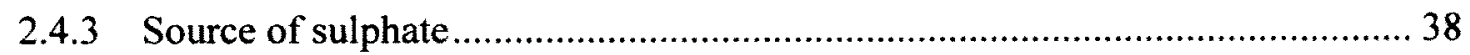

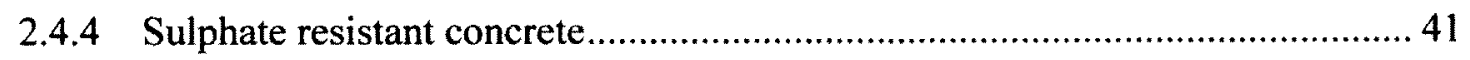

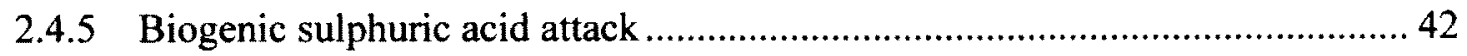

CHAPTER 3. MATERIALS AND METHODS ........................................................4 44

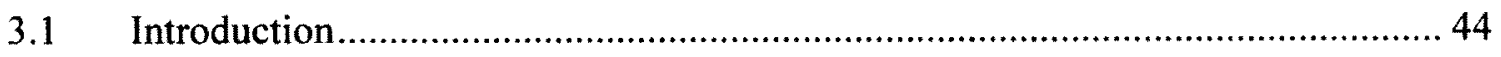

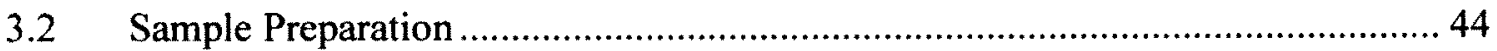

3.3 Phase 1: Biofilm Formation on Mortar Specimens.............................................. 45

3.3.1 Bacterial strain and growth medium ............................................................. 45

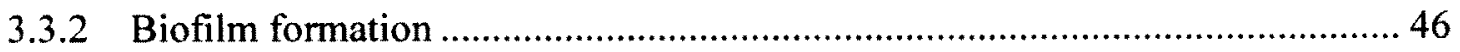

3.4 Phase 2: Chemical Sulphuric Acid Deterioration .................................................. 49

3.4.1 Chemical acidification on mortar disk ......................................................... 49

3.4.2 Chemical acidification on mortar cubes ........................................................ 50

3.5 Phase 3: Biogenic Sulphuric Acid Deterioration ................................................. 50

3.5.1 Bacterial strains and their growth media ......................................................... 50

3.5.2 Selection of modified broth used for the growth of SOB strains...................... 51

3.5.3 Biogenic acidification on mortar disks ........................................................... 52

3.5.4 Biogenic acidification on small mortar cubes.................................................5 53

3.6 Phase 4: High Temperature Biogenic Sulphuric Acid Deterioration..................... 53

3.7 Calcium and Sulphate Analysis ………………............................................ 53

3.8 Adenosine Triphosphate Measurement.............................................................. 54

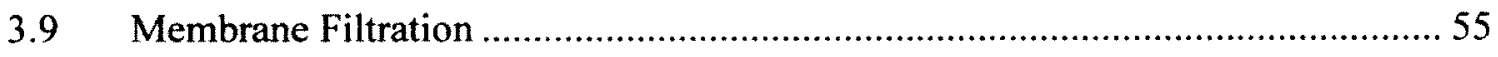

$3.10 \quad$ Volatile Suspended Solids ............................................................................... 56

3.11 Scanning Electron Microscopy and Energy-Dispersive X-ray Spectroscopy ...... 56

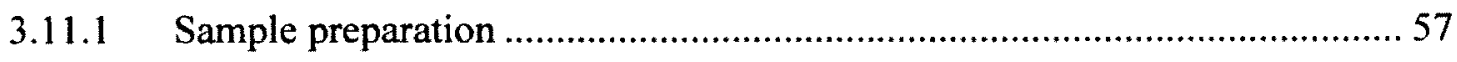

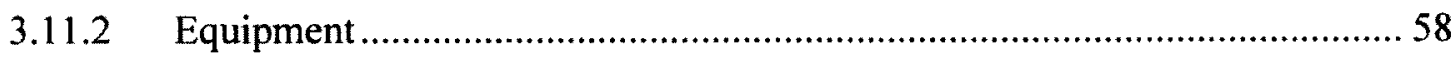

3.12 Confocal Laser Scanning Microscopy ……….................................................. 58

3.13 Fluorescence In Situ Hybridization (FISH) ……............................................. 59 


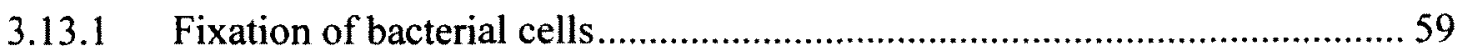

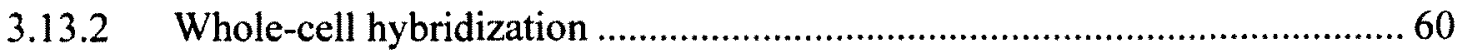

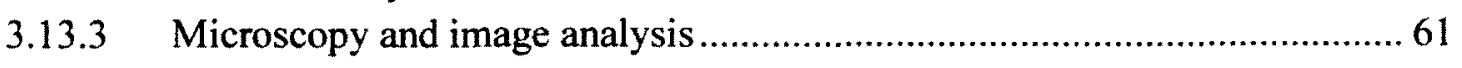

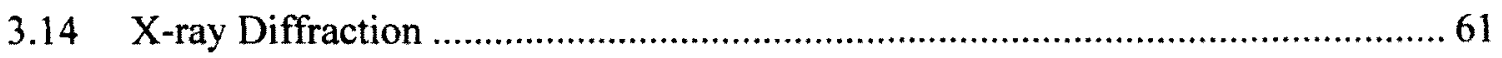

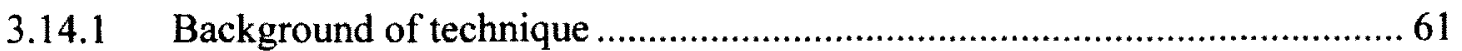

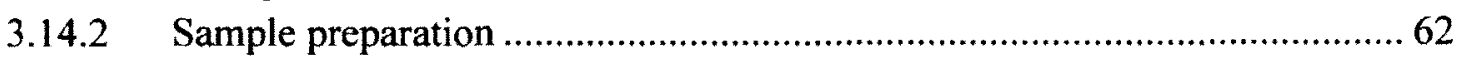

CHAPTER 4. BIOFILM FORMATION ON MORTAR SURFACE ..................... 63

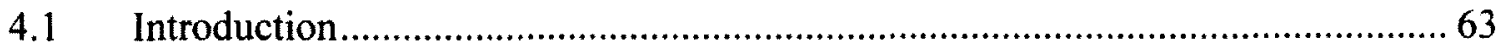

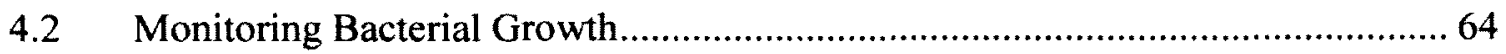

4.3 Monitoring Biofilm Formation ....................................................................... 65

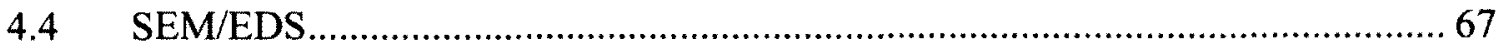

4.5 Fluorescence In Situ Hybridization ............................................................. 70

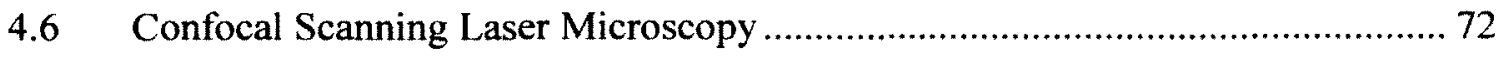

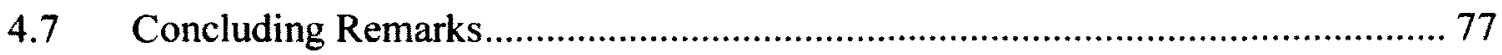

CHAPTER 5. CHEMICAL SULPHURIC ACID DETERIORATION.................. 79

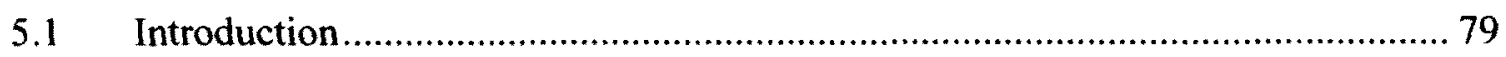

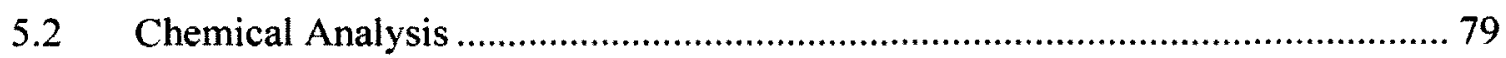

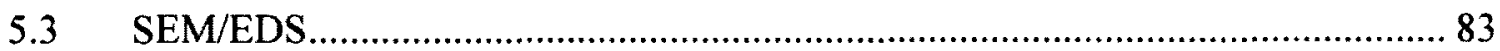

5.4 Confocal Laser Scanning Microscopy ………................................................... 88

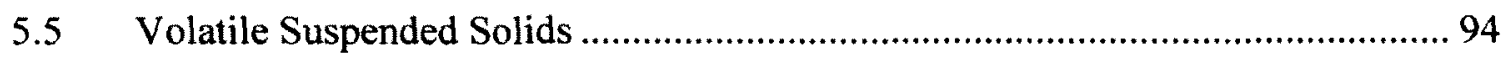

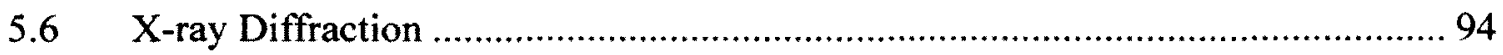

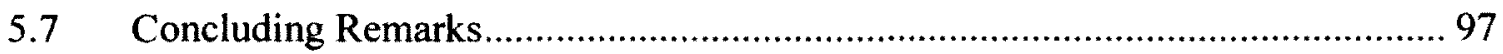

CHAPTER 6. BIOGENIC SULPHURIC ACID DETERIORATION..................... 99

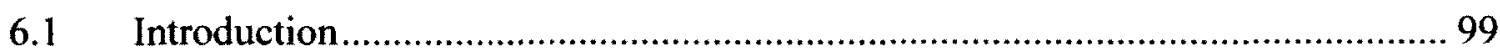


6.2 Selection of Medium for SOB Growth …………......................................... 100

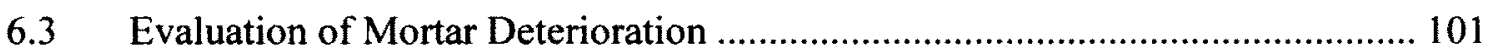

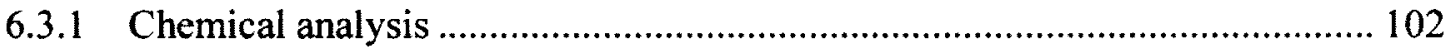

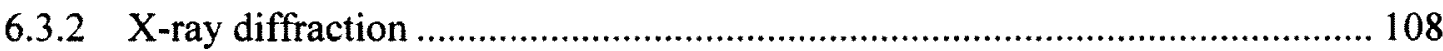

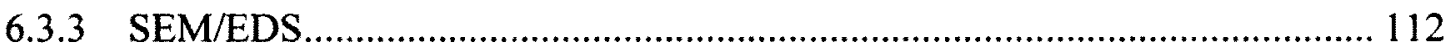

6.4 Biofilm Properties After Biogenic Acidification............................................. 116

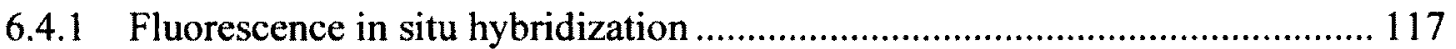

6.4.2 Confocal laser scanning microscopy ........................................................ 118

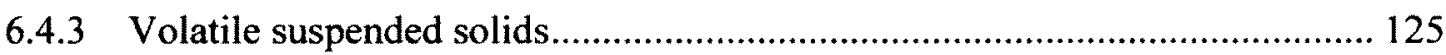

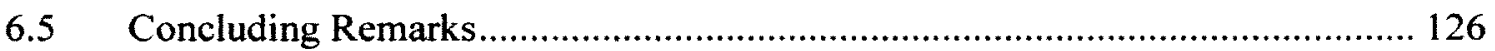

CHAPTER 7. EFFECT OF HIGH TEMPERATURE AND MECHANISMS OF DETERIORATION .................................................................................................................... 128

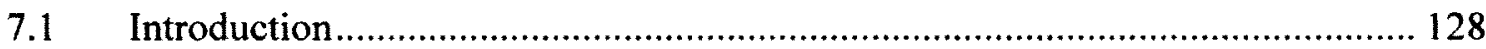

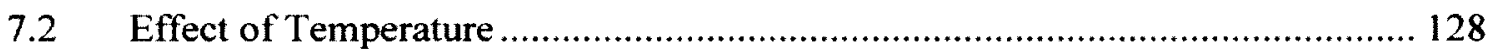

7.2.1 Chemical analysis ................................................................................. 129

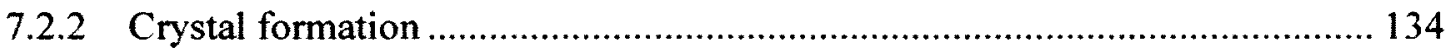

7.2.3 Visual inspection................................................................................. 138

7.3 Mechanisms of Deterioration: Chemical vs. Biogenic Acidification ................. 140

7.4 Concluding Remarks................................................................................... 144

CHAPTER 8. BIOFILM PERFORMANCE EVALUATION USING AN ENZYME ELECTRODE ................................................................................................. 146

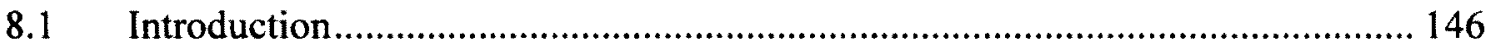

8.2 Materials and Methods............................................................................. 148

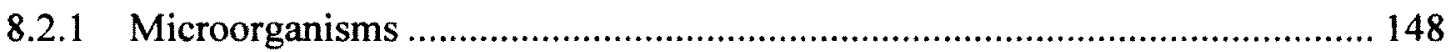

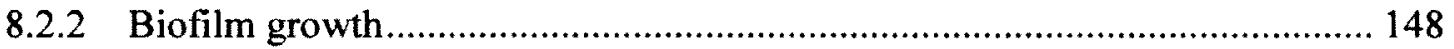

8.2.3 Production and purification of sulphide oxidase enzyme ……………........... 149

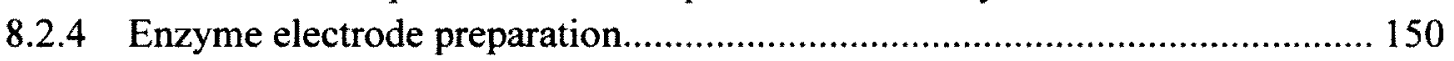

8.2.5 Electrochemical measurements............................................................ 150

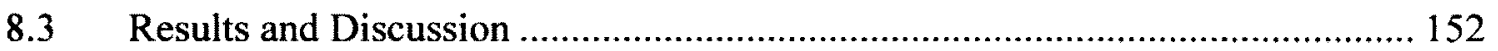

8.3.1 Electrochemical measurements.............................................................. 152 


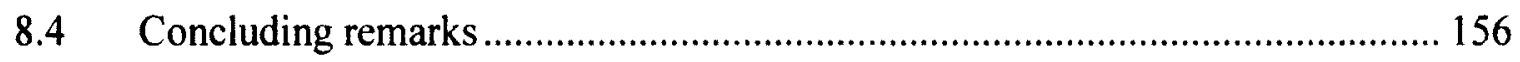

CHAPTER 9. CONLUSIONS AND FUTURE WORK .......................................... 157

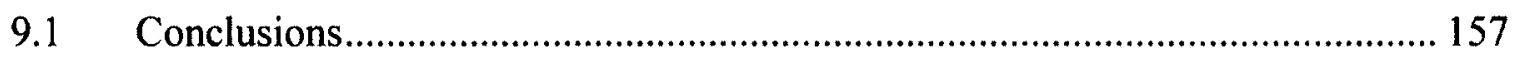

9.2 Recommendations for Future Work ........................................................... 160

REFERENCES........................................................................................................................... 164

APPENDIX A： SUPPLEMENTARY XRD ANALYSIS ........................................ 175

APPENDIX B: SUPPLEMENTARY CLSM IMAGES .......................................... 178

APPENDIX C: TABULAR DATA USED FOR DRAWING GRAPHS ................. 184 


\section{LIST OF FIGURES}

Figure 2.1: Representative proposed mechanisms of corrosion inhibition employing beneficial bacterial biofilms. a) Aerobic respiration of biofilms decreases oxygen concentration on metal surface. b) Antimicrobials generated in situ by biofilms (such as Bacillus brevis) eliminate corrosion-causing bacteria (e.g., SRB). c) Biofilm-secreted protective layers of corrosion inhibitors decrease contact of corrosive agents with metal surface (taken from Zuo, 2007). 17

Figure 2.2: Schematic representation of microbial induced concrete deterioration....... 21

Figure 2.3: MICD simulation chamber by Sand et al. (1987) (taken from Sand et al., 1987). 25

Figure 2.4: Experimental setup for MICD simulation by Hormann et al. (1997) (taken from Hormann et al., 1997). 27

Figure 2.5: Lab-scale simulation system for MICD by Mori et al. (1992) (taken from Mori et al., 1992).

Figure 3.1: Schematic and image of the reactor used for biofilm growth on mortar disks.

Figure 3.2: Schematic of biofilm growth setup. 47

Figure 3.3: Schematics of atomic planes in a crystalline structure and representation of Bragg's law.

Figure 4.1: The optical density of bacteria grown in biofilm reactor as measured by absorbance reading at $600 \mathrm{~nm}$ at room and elevated temperature.

Figure 4.2: Biomass concentration on the mortar surfaceas measured by the coliform forming unit at different time of biofilm growth; biomass concentration after 8 days was $18 \times 10^{5} \mathrm{CFU}$. 66

Figure 4.3: ATP of biomass on mortar surface at differnt days of biofilm growth as measured by ATP analysis. 66

Figure 4.4: SEM micrographs of mortar surface covered with biofilm; a) $1 \mathrm{~K}$ magnification image, b) area with high concentration of bacterial cells, 
magnification: $5 \mathrm{~K} ; \mathrm{c}$ ) area with low bacterial cell concentration, magnification $10 \mathrm{~K}$.

Figure 4.5: EDS analysis of biofilm-covered mortar on area with no bacterial cell; a) SEM micrograph showing the area used for EDS analysis, b) the corresponding EDS spectrum of the area with no bacterial concentration.. 69

Figure 4.6: Images of pure E.coli DH5a; a) differential interference contrast (DIC) image showing all the present bacteria, b) florescent image showing the hybridized E.coli bacteria.

Figure 4.7: FISH Images for identification of E.coli in biofilm attached on the mortar surface; (a) Total bacteria present stained with DAPI (blue), (b) Same viewing of the sample hybridized with probe EC-1531(green) to identify E.coli.

Figure 4.8: Confocal laser scanning microscope images of 8 days grown biofilm of E.coli DH5a on mortar surface stained for live and dead cells; a) section of biofilm at $20 \mu \mathrm{m}$ distance from the mortar surface, b) projected image of all the subsections in the same position. Scale bar represents $10 \mu \mathrm{m}$. The green areas are live cells and red areas are dead cells.

Figure 4.9: Confocal laser scanning microscope images of 8 days grown biofilm on mortar surface stained for live cells (green), dead cells (red) and polysaccharide (cyan); image of biofilm at (a) $10 \mu \mathrm{m}$, (b) $20 \mu \mathrm{m}$, (c) $30 \mu \mathrm{m}$, (d) $40 \mu \mathrm{m}$ distance from the mortar surface, e) projected image of all the subsections in the same view. Scale bar represents $10 \mu \mathrm{m}$. 75

Figure 4.10: Live and dead cell distribution profiles of 8 day grown E.coli biofilm developed on mortar surface. Measurements are the average of two representative positions in the biofilm. 76

Figure 4.11: EPS and void distribution profiles of 8 day grown E.coli biofilm developed on mortar surface. Measurements are the average of two representative positions with the same biofilm thickness.

Figure 5.1: Solution $\mathrm{pH}$ in the reactor with biofilm-covered mortar and control mortar specimen without biofilm under chemical acidification.

Figure 5.2: Accumulative calcium concentration in the reactor with biofilm-covered mortar and reactor with control mortar specimen without biofilm under chemical acidification. 
Figure 5.3: Accumulative calcium concentration of the replica experiment in the reactor with biofilm-covered mortar and reactor with control mortar specimen without biofilm.

Figure 5.4: a) SEM micrograph with 1000x magnification of biofilm-covered mortar before acidification; $b$ \& c) SEM micrograph of biofilm-covered mortar specimen after exposure to $\mathrm{pH}$ of 5 ; b) $1000 \mathrm{x}$ magnification showing biofilm with less bacterial concentration, c) $5000 \times$ magnification showing high concentration of bacteria in biofilm. 84

Figure 5.5: $\quad$ SEM image of mortar surface without biofilm after exposing to $\mathrm{pH} 5$ shows formation of cracks on the surface; $1000 \mathrm{x}$ magnification. 85

Figure 5.6: SEM image of biofilm-covered mortar surface after the last cycle of acidification; a) $1000 \mathrm{x}$ magnification of the mortar surface; b) $5000 \mathrm{x}$ magnification of the bacterial cell in biofilm. 86

Figure 5.7: SEM image of control mortar surface without biofilm after exposure to $\mathrm{pH}$ value of 3 .

Figure 5.8: CLSM images of biofilm on mortar surface after chemical acidification stained with calcoflour for polysaccharide (cyan); image of biofilm at (a) $10 \mu \mathrm{m}$, (b) $20 \mu \mathrm{m}$, (c) $31 \mu \mathrm{m}$, (d) $45 \mu \mathrm{m}$, (e) $59 \mu \mathrm{m}$ distance from the mortar surface, $f$ ) projected image of all the subsections in the same view. Scale bar represents $10 \mu \mathrm{m}$. 90

Figure 5.9: CLSM images of biofilm on mortar surface after chemical acidification stained for live cells (green) and dead cells (red); image of biofilm at (a) 10 $\mu \mathrm{m}$, (b) $20 \mu \mathrm{m}$, (c) $30 \mu \mathrm{m}$, (d) $40 \mu \mathrm{m}$, (e) $50 \mu \mathrm{m}$ distance from the mortar surface, $f$ ) projected image of all the subsections in the same view. Scale bar represents $10 \mu \mathrm{m}$. 91

Figure 5.10: Spatial distribution of bacterial viability within the E.coli biofilm attached to mortar surface after chemical acidification; a) first field of view, b) second field of view.

Figure 5.11: Comparison of spatial distribution of EPS coverage within the E.coli biofilm before and after chemical acidification. 93

Figure 5.12: Volatile suspended solids measurement of biomass attached to mortar specimens (the values are the average of two VSS measurement on the surface of two mortar cubes). 94 
Figure 5.13: XRD of mortar powder taken from top $0.5 \mathrm{~mm}$ surface of mortar surface before any treatment; dolomite (D), gypsum (G), quartz (Q), magnesium calcite (C), winchitte potassium (W).

Figure 5.14: XRD of mortar powder taken from top $0.5 \mathrm{~mm}$ surface of mortar without biofilm after chemical acidification; dolomite (D), gypsum (G), quartz (Q), magnesium calcite $(\mathrm{C})$, magnesium sulphate hydroxide $(\mathrm{MH})$, winchitte potassium (W). 96

Figure 5.15: XRD of mortar powder taken from top $0.5 \mathrm{~mm}$ surface of biofilm-covered mortar after chemical acidification; calcium carbonate (CC), dolomite (D), gypsum (G), quartz (Q), magnesium calcite (C), magnesium sulphate hydroxide $(\mathrm{MH})$, winchitte potassium $(\mathrm{W})$.

Figure 6.1: The $\mathrm{pH}$ decrease in different modified broths due to the growth of T.thiooxidans and T.neapolitanus. 101

Figure 6.2: The sulphate generation in different modified broths due to the growth of T.thiooxidans and T.neapolitanus; data points are the average of three readings with the standard deviation of less than $250 \mathrm{mg} / \mathrm{L}$. 101

Figure 6.3: $\mathrm{pH}$ in the reactor with biofilm-covered mortar and control mortar specimen without biofilm under biogenic acidification. 103

Figure 6.4: Sulphate concentration in the reactor with biofilm-covered mortar and reactor with control mortar specimen without biofilm.

Figure 6.5: Accumulative calcium concentration in the reactor with biofilm-covered mortar and reactor with control mortar specimen without biofilm under biogenic acidification. 105

Figure 6.6: $\mathrm{pH}$ in the reactor with biofilm-covered mortar and control mortar specimen without biofilm under biogenic acidification for the duplicate set of experiment. 107

Figure 6.7: Sulphate concentration in the reactor with biofilm-covered mortar and reactor with control mortar specimen without biofilm for duplicate experiment.

Figure 6.8: Accumulative calcium concentration in the reactor with biofilm-covered mortar and reactor with control mortar specimen without biofilm under biogenic acidification. 108 
Figure 6.9: XRD pattern of sand sample used for constructing the mortar specimens; dolomite (D), quartz (Q), magnesium calcite (C), winchite potassium (W), magnesium sulphate hydroxide $(\mathrm{MH})$. 109

Figure 6.10: XRD of mortar powder taken from top $0.5 \mathrm{~mm}$ surface of mortar surface before any treatment; dolomite (D), quartz (Q), magnesium calcite (C), winchite potassium $(\mathrm{W})$, magnesium sulphate hydroxide $(\mathrm{MH})$. 109

Figure 6.11: XRD analysis of top $0.5 \mathrm{~mm}$ surface of mortar without biofilm after biogenic acidification; dolomite (D), quartz (Q), calcite (C), winchite potassium $(\mathrm{W})$, magnesium sulphate hydroxide $(\mathrm{MH})$, gypsum $(\mathrm{G})$

Figure 6.12: XRD analysis of top $0.5 \mathrm{~mm}$ surface of biofilm-covered mortar after biogenic acidification; dolomite (D), gypsum (G), quartz (Q), magnesium calcite $(\mathrm{C})$, magnesium sulphate hydroxide $(\mathrm{MH})$, winchitte potassium $(\mathrm{W})$.

Figure 6.13: XRD analysis of second layer of mortar without biofilm after biogenic acidification; dolomite (D), gypsum (G), quartz (Q), magnesium calcite (C), magnesium sulphate hydroxide $(\mathrm{MH})$, winchitte potassium (W).

Figure 6.14: SEM micrographs of biofilm-covered mortar specimen after biogenic acidification; a) 200x magnification showing biofilm covering the surface in big patches, b) 500x magnification of biofilm-covered biofilm after removing the biofilm showing the formation of calcium carbonate crystals. .

Figure 6.15: SEM micrographs of control mortar specimen after biogenic acidification; a) $200 x$ magnification showing a layer of SOB bacterial film on top of some crystals , b) $200 x$ magnification showing cracks and gypsum crystals. ... 115

Figure 6.16: Image of bacteria collected from biofilm-covered mortar specimen after biogenic acidification a) DAPI stained image showing all the present bacteria in blue b) FISH image of the same view showing only the E.coli bacteria in green.

Figure 6.17: Bacterial viability analysis and the percent EPS coverage of biofilm before and after biogenic acidification experiment.

Figure 6.18: CLSM images of biofilm on mortar surface after biogenic acidification stained with calcoflour for polysaccharide (cyan); image of biofilm at (a) $20 \mu \mathrm{m}$, (b) $30 \mu \mathrm{m}$, (c) $40 \mu \mathrm{m}$, (d) $55 \mu \mathrm{m}$, (e) $70 \mu \mathrm{m}$ distance from the mortar 
surface, f) projected image of all the subsections in the same view. Scale bar represents $10 \mu \mathrm{m}$.

Figure 6.19: CLSM images of biofilm on mortar surface after biogenic acidification stained for live cells (green) and dead cells (red); image of biofilm at (a) $20 \mu \mathrm{m}$, (b) $30 \mu \mathrm{m}$, (c) $40 \mu \mathrm{m}$, (d) $55 \mu \mathrm{m}$, (e) $70 \mu \mathrm{m}$ distance from the mortar surface, f) projected image of all the subsections in the same view. Scale bar represents $10 \mu \mathrm{m}$

Figure 6.20: Spatial distribution of bacterial viability within the E.coli biofilm attached to mortar surface after biogenic acidification at two different location. ... 123

Figure 6.21: Comparison of profile of EPS coverage within the E.coli biofilm before and after biogenic acidification.

Figure 6.22: Volatile suspended solids measurement of biomass attached to mortar specimens after biogenic acidification (the values are the average of two VSS measurement on the surface of two mortar cubes).

Figure 7.1: $\mathrm{pH}$ in the reactor with biofilm-covered mortar and control mortar specimen without biofilm under biogenic acidification at elevated temperature of $37 \pm 1^{\circ} \mathrm{C}$

Figure 7.2: Sulphate concentration in the reactor with biofilm-covered mortar and control mortar specimen without biofilm under biogenic acidification at elevated temperature of $37 \pm 1^{\circ} \mathrm{C}$ (data points are the average of at least 3 readings with the maximum standard deviation of $225 \mathrm{mg} / \mathrm{L}$ ).

Figure 7.3: Accumulative calcium concentration in the reactor with biofilm-covered mortar and control mortar specimen without biofilm under biogenic acidification at elevated temperature of $37 \pm 1^{\circ} \mathrm{C}$. 132

Figure 7.4: $\mathrm{pH}$ in the reactors of the second replica experiment under biogenic acidification at an elevated temperature of $37 \pm 1^{\circ} \mathrm{C}$ 133

Figure 7.5: Sulphate concentration in the reactors in second replica experiment under biogenic acidification at an elevated temperature of $37 \pm 1^{\circ} \mathrm{C}$ (data points are the average of at least 3 readings with the maximum standard deviation of $200 \mathrm{mg} / \mathrm{L}$ ). 134

Figure 7.6: Accumulative calcium concentration of reactors in duplicate experiments under biogenic acidification at an elevated temperature of $37 \pm 1^{\circ} \mathrm{C}$. 134 
Figure 7.7: XRD pattern of mortar powder taken from top $0.5 \mathrm{~mm}$ surface after biogenic acidification at elevated temperature; a) control mortar, b) biofilmcovered mortar; dolomite (D), gypsum (G), quartz (Q), magnesium calcite (C), magnesium sulphate hydroxide(MH), winchitte potassium (W), aluminate (A). 136

Figure 7.8: XRD pattern of second layer of mortar powder after biogenic acidification at elevated temperature; a) control mortar, b) biofilm-covered mortar; dolomite $(D)$, gypsum $(\mathrm{G})$, quartz $(\mathrm{Q})$, magnesium calcite $(\mathrm{C})$, magnesium sulphate hydroxide( $\mathrm{MH})$, winchitte potassium $(\mathrm{W})$, aluminate $(\mathrm{A})$.......... 137

Figure 7.9: Visual inspection of mortar surface after biogenic acidification at elevated temperature; a) first control mortar without biofilm, b) second control mortar without biofilm c) first biofilm-covered mortar showing the attached biofilm, d) first biofilm-covered mortar after removing the biofilm layer, e) second biofilm-covered mortar showing the attached biofilm, f) second biofilm-covered mortar after removing the biofilm layer. 139

Figure 7.10: Comparison of mortar deterioration due to biogenic acidification with chemical acidification as measured by calcium concentration and $\mathrm{pH}$ measurement; a) calcium concentration and, b) $\mathrm{pH}$ measurement in reactors under chemical and biogenic acidification at room temperature.

Figure 7.11: SEM micrographs of mortar surface; a) after chemical acidification (1000x magnification), b) after biogenic acidification (200x magnification)....... 143

Figure 7.12: XRD analysis of powder taken from the top $0.5 \mathrm{~cm}$ surface of mortar under chemical (bottom XRD pattern) and biogenic (top XRD pattern) acidification. 144

Figure 8.1: Body of the electrode used for placement of enzyme paste; the tip of the electrode is covered with the biofilm-covered membrane where needed.. 150

Figure 8.2: Schematic of the setup for amperometric measurements. 152

Figure 8.3: Current densities measured using a sulphide oxidase enzyme electrode, at ambient temperature, with a potential hold of $0.3 \mathrm{~V}$ (vs. SCE); concentration of sulphide reported on the graph as $\mathrm{mg} / \mathrm{mL}$ 154

Figure 8.4: Current densities measured using a sulphide oxidase enzyme electrode with a membrane on the tip, at ambient temperature, with a potential hold of 0.3 $\mathrm{V}$ (vs. SCE); concentration of sulphide reported on the graph as $\mathrm{mg} / \mathrm{mL}$. 155 
Figure 8.5: Current densities measured using a sulphide oxidase enzyme electrode with a biofilm grown membrane on the tip, at ambient temperature, with a potential hold of $0.3 \mathrm{~V}$ (vs. SCE); concentration of sulphide reported on the graph as $\mathrm{mg} / \mathrm{mL}$ 155

Figure 8.6: Calibration lines for enzyme electrodes with and without the membrane and steady-state current density reading for the enzyme electrode with the biofilm grown membrane. 156

Figure A.1: XRD of mortar powder taken from second layer of mortar surface (the powder was collected from the top $0.5-1 \mathrm{~mm}$ of the mortar surface) before any treatment; dolomite $(\mathrm{D})$, gypsum $(\mathrm{G})$, quartz $(\mathrm{Q})$, magnesium calcite $(\mathrm{MC})$, winchitte potassium $(\mathrm{W})$, aluminate phase $(\mathrm{A})$ 175

Figure A.2: XRD analysis of second layer of mortar with biofilm after biogenic acidification; dolomite (D), gypsum (G), quartz (Q), magnesium calcite (C), magnesium sulphate hydroxide $(\mathrm{MH})$, winchitte potassium (W), aluminate phase (A). 176

Figure A.3: XRD analysis of second layer of mortar without biofilm after chemical acidification; dolomite (D), gypsum (G), quartz (Q), magnesium calcite (C), magnesium sulphate hydroxide $(\mathrm{MH})$, winchitte potassium $(\mathrm{W})$, aluminate phase (A). 176

Figure A.4: XRD analysis of second layer of mortar with biofilm after chemical acidification; dolomite (D), gypsum (G), quartz (Q), magnesium calcite (C), magnesium sulphate hydroxide( $\mathrm{MH})$, winchitte potassium $(\mathrm{W})$, aluminate phase (A) 177

Figure A.5: XRD of concrete powder taken from top $0.5 \mathrm{~cm}$ surface of biofilm-covered mortar after chemical acidification; calcium carbonate (CC), dolomite (D), gypsum $(\mathrm{G})$, quartz $(\mathrm{Q})$, magnesium calcite $(\mathrm{C})$, magnesium sulphate hydroxide $(\mathrm{MH})$, winchitte potassium $(\mathrm{W})$. 177

Figure B.1: CLSM images of biofilm-covered mortar before acidification stained with calcoflour for polysaccharide (cyan); image of biofilm at, a) $10 \mu \mathrm{m}$, b) 20 $\mu \mathrm{m}$, c) $26 \mu \mathrm{m}$ distance from the mortar surface, d) projected image of all the subsections in the same view. Scale bar represents $10 \mu \mathrm{m}$. 178

Figure B.2: CLSM images of biofilm-covered mortar before acidification stained for live cells (green) and dead cells (red); image of biofilm at, a) $5 \mu \mathrm{m}$, b) 10 $\mu \mathrm{m}$, c) $15 \mu \mathrm{m}$, d) $20 \mu \mathrm{m}$, e) $26 \mu \mathrm{m}$ distance from the mortar surface, f) 
projected image of all the subsections in the same view. Scale bar represents $10 \mu \mathrm{m}$.

Figure B.3: CLSM images of biofilm-covered mortar after chemical acidification stained with calcoflour for polysaccharide (cyan); image of biofilm at, a) 20 $\mu \mathrm{m}$, b) $40 \mu \mathrm{m}$, c) $60 \mu \mathrm{m}$, d) $82 \mu \mathrm{m}$, e) $110 \mu \mathrm{m}$ distance from the mortar surface, $f$ ) projected image of all the subsections in the same view. Scale bar represents $10 \mu \mathrm{m}$ 180

Figure B.4: CLSM images of biofilm-covered mortar after chemical acidification stained for live cells (green) and dead cells (red); image of biofilm at, a) 5 $\mu \mathrm{m}$, b) $10 \mu \mathrm{m}$, c) $15 \mu \mathrm{m}$, d) $20 \mu \mathrm{m}$, e) $22 \mu \mathrm{m}$ distance from the mortar surface, f) projected image of all the subsections in the same view. Scale bar represents $10 \mu \mathrm{m}$. 181

Figure B.5: CLSM images of biofilm-covered mortar after biogenic acidification stained with calcoflour for polysaccharide (cyan); image of biofilm at, a) $11 \mu \mathrm{m}$, b) $15 \mu \mathrm{m}$, c) $20 \mu \mathrm{m}$, d) $30 \mu \mathrm{m}$ distance from the mortar surface, e) projected image of all the subsections in the same view. Scale bar represents $10 \mu \mathrm{m}$...

Figure B.6: CLSM images of biofilm-covered mortar after chemical acidification stained for live cells (green) and dead cells (red); image of biofilm at, a) 20 $\mu \mathrm{m}$, b) $32 \mu \mathrm{m}$, c) $51 \mu \mathrm{m}$, d) $64 \mu \mathrm{m}$, e) $91 \mu \mathrm{m}$ distance from the mortar surface, f) projected image of all the subsections in the same view. Scale bar represents $10 \mu \mathrm{m}$. 183 


\section{LIST OF TABLES}

Table 4.1: Percentage atomic fraction of elements on the mortar surface before and after biofilm formation, area of analysis was $250 \times 250 \mu \mathrm{m}$.

Table 4.2: Analysis of the biofilm components using the projected CLSM images... 73

Table 5.1: Percentage atomic fraction of elements on mortar surface under different conditions

Table 5.2: Live, dead and EPS coverage of biofilm on the mortar surface before and after chemical acidification.

Table 6.1: Percentage atomic fraction of elements on mortar surface as obtained by EDS analysis under different conditions.

Table 6.2: Biofilm thickness, live to dead cell ratio and total cell coverage on the mortar surface before and after biogenic acidification.

Table C.1: Data points of Figure 4.1; bacterial growth at elevated temperature of $37 \pm 1^{\circ}$ C.

Table C.2: Data points of Figure 4.1; bacterial growth at room temperature. 184

Table C.3: Data points of Figure 4.2; biomass concentration as measured by membrane filtration.

Table C.4: Data points of Figure 4.3; biomass concentration as measured by ATP analysis.

Table C.5: Data points of Figure 4.10; live/dead cell coverage on biofilm-covered mortar.

Table C.6: Data points of Figure 4.11; EPS and void space coverage on biofilmcovered mortar.

Table C.7: Data points of Figure 5.1 and 5.2; accumulative calcium and $\mathrm{pH}$ measurement in biofilm-covered and control reactors after chemical acidification.

Table C.8: Data points of Figure 5.10; live/dead cell coverage on biofilm-covered mortar after chemical acidification. 
Table C.9: Data points of Figure 5.11; comparison of EPS coverage on biofilm-covered mortar.

Table C.10: Data points of Figure 6.1 and $6.2 ; \mathrm{pH}$ and sulphate concentration of SOB growth media, MB1 188

Table C.11: Data points of Figure 6.1 and $6.2 ; \mathrm{pH}$ and sulphate concentration of SOB growth media, MB2.

Table C.12: Data points of Figure 6.3 and 6.5; accumulative calcium and $\mathrm{pH}$ measurement in biofilm-covered and control reactors during biogenic acidification.

Table C.13: Data points of Figure 6.4; sulphate concentration in biofilm-covered and control reactors during biogenic acidification; units are in $\mathrm{mg} / \mathrm{L}$.

Table C.14: Data points of Figure 6.17; comparison of biofilm components at different condition. 190

Table C.15: Data points of Figure 6.20; biofilm viability profile after biogenic acidification.

Table C.16: Data points of Figure 6.21; comparison of EPS coverage on biofilm-covered mortar after biogenic acidification. 190

Table C.17: Data points of Figure 7.1 and 7.3; accumulative calcium and $\mathrm{pH}$ measurement in biofilm-covered and control reactors during biogenic acidification at an elevated temperature.

Table C.18: Data points of Figure 7.2; sulphate concentration in biofilm-covered and control reactors during biogenic acidification at an elevated temperature; units are in $\mathrm{mg} / \mathrm{L}$ 192 


\section{GLOSSARY}

\section{Abbreviations}

ASOB Acidophilic Sulphur Oxidizing Bacteria

ATCC American Type Culture Collection

ATP Adenosine Triphosphate

ATP Adenosine triphosphate

CLSM Confocal Laser Scanning Microscopy

C-S-H Calcium-Silicate-Hydrate

DI Deionised Water

EE Enzyme Electrode

EDS Energy Dispersive Spectroscopy

EIS Electrochemical Impedance Spectroscopy

EPS Extracellular Polymeric Substances

FISH Fluorescence In Situ Hybridization

FITC Fluorescein Isothiocyanate

GY Glucose-Yeast Extract

ICDD International Center for Diffraction Data

LB Luria-Bertani

MIC Microbiologically Influenced Corrosion

MICD Microbiologically Influenced Concrete Deterioration

NSOB Neutrophilic Sulphur Oxidizing Bacteria

PF Pseudomonas fragi

PP Paenibacillus polymyxa

SEM Scanning Electron Microscopy

SO Sulphide Oxydase

SOB Sulphur Oxidizing Bacteria

SRB Sulphate Reducing Bacteria

VSS Volatile Suspended Solid

XRD X-ray Diffraction 


\section{Variables}

A Surface area of mortar cube in $\left(\mathrm{cm}^{2}\right)$

B Weight of dish with filter after drying at $105^{\circ} \mathrm{C}(\mathrm{mg})$

C Weight of dish with filter after ignition at $550^{\circ} \mathrm{C}(\mathrm{mg})$

d Distance between the atomic planes (A)

$\mathrm{RLU}_{\mathrm{tATP}}$ Total ATP reading of sample (RLU or relative light unit)

$\mathrm{RLU}_{\mathrm{UCl}}$ Total ATP reading of $1(\mathrm{ng} / \mathrm{mL})$ standard solution (RLU)

tATP Total ATP of sample $\left(\frac{\mathrm{pg} \text { ATP }}{\mathrm{cm}^{2}}\right)$

$\theta \quad$ Angle of incidence

$\lambda \quad$ Wavelength of the X-ray (A) 


\section{CHAPTER 1. INTRODUCTION AND OBJECTIVES}

\subsection{INTRODUCTION}

In North America, more than 75 percent of the population is served by wastewater collection systems and treatment plants for which concrete is a key construction material because of its low cost and ability to take forms that are important to the building of these facilities (USEPA, 2004). However, in cases where the structure is exposed to sulphurrich water such as wastewater, concrete may become vulnerable to premature deterioration, causing service interruptions, and in extreme cases, catastrophic failures that may affect the general population. Therefore, mitigation of concrete deterioration due to exposure to wastewater is critical and forms the basic motivation of this research.

In order to explain the mechanisms of concrete deterioration due to exposure to wastewater, it is important to introduce the sulphur cycle, which is one of the major microbial activities that are present in many stages of the treatment process. The sulphate ion is naturally present in most water supplies and wastewater. Sulphur is required for the synthesis of proteins, and it is released upon the degradation of proteins. Under anaerobic conditions, sulphate ion is biologically reduced to sulphide and converted to hydrogen sulphide in the presence of hydrogen via (Metcalf and Eddy, 2003): 
Organic matter+ $\mathrm{SO}_{4}{ }^{2-} \longrightarrow \mathrm{S}^{2-}+\mathrm{H}_{2} \mathrm{O}+\mathrm{CO}_{2}$

$\mathrm{S}^{2-}+2 \mathrm{H}^{+} \longrightarrow \mathrm{H}_{2} \mathrm{~S}$

Although many external agents can cause concrete to deteriorate, within the scope of wastewater collection and treatment processes, the effect of hydrogen sulphide $\left(\mathrm{H}_{2} \mathrm{~S}\right)$ is particularly important. Hydrogen sulphide attacks concrete in three ways:

1. Conventional acid attack on concrete and rebar that is caused by the low $\mathrm{pH}$ of wastewater. This type of attack occurs below the waterline where concrete is in contact with sulphate containing water (e.g., wastewater), and it deteriorates the concrete cover and the steel reinforcement (Parande et al., 2006).

2. Biogenic sulphuric acid attack that is caused by the microbial activity of aerobic bacteria which convert hydrogen sulphide to a more corrosive agent, sulphuric acid. The biogenic sulphuric acid reduces the $\mathrm{pH}$ of concrete to as low as $0.5-1$. This type of attack occurs above the waterline and heavily deteriorates concrete (Monteny et al., 2000).

3. Deterioration of internal steel reinforcement due to the corrosion by continuous exposure to hydrogen sulphide: Hydrogen sulphide can be detrimental to concrete by directly attacking the concrete and converting the calcium hydroxide in the hydration products of concrete to calcium bisulphide, reducing the alkalinity of the medium. In this type of attack, reinforcement corrosion generally starts before any serious deterioration of concrete (Idriss et al., 2001).

Biogenic sulphuric acid attack, which is known as microbiologically influenced concrete deterioration (MICD), causes the main damage to concrete of sewer pipes or wastewater treatment facilities. In the worst case scenarios, the rate of degradation can reach several millimetres of concrete per year (De Belie et al., 2004; Mori et al., 1992). The attachment 
and growth of aerobic sulphur oxidizing bacteria ( $\mathrm{SOB})$ on the surface of concrete is the key factor in the concrete deterioration. These bacteria use hydrogen sulphide or any sulphur compounds as a food source to produce (biogenic) sulphuric acid.

The biogenic sulphuric acid attack on concrete structures and corrosion of the metallic equipment are costly problems in wastewater treatment plants and sewer pipelines worldwide. The results of a study conducted by National Association of Corrosion Engineers (NACE) estimated the annual economic impact of corrosion to the economy of the United States at $\$ 276$ billion or approximately 3.1\% of the Gross Domestic Product (GDP). Of this total, the corrosion cost of drinking water and sewer infrastructures and sewer pipelines accounts for approximately $\$ 36$ billion; this includes the costs of replacing aging infrastructure, water leaking from pipelines, corrosion inhibitors, internal mortar linings and external coatings and cathodic protection (NACE International, 2002). The overall cost of the restoration of sewer pipes in Germany that are damaged by bacteria was estimated to be $\$ 1.1$ million (Little and Lee, 2007). In Japan, it is estimated that the biodeterioration of concrete sewer pipes is approximately 4.3 to $4.7 \mathrm{~mm} / \mathrm{yr}$ equivalent to approximate life of 20 years (Little and Lee, 2007).

\subsection{Problem Definition}

Hydrogen sulphide exists in wastewater solution as either hydrogen sulphide gas $\left(\mathrm{H}_{2} \mathrm{~S}\right)$ or in the ionized form as hydrosulphide ion (HS) or sulphide ion $\left(\mathrm{S}^{2-}\right)$ depending on the $\mathrm{pH}$ of the solution. Aerobic deterioration of concrete initiates by the oxidation of $\mathrm{H}_{2} \mathrm{~S}$ with atmospheric oxygen which results in the production of compounds such as thiosulphate, sulphate and elemental sulphur. These compounds are more readily digestible for many 
SOB such as Thiobacilli species (Thiobacillus thiooxidans, Thiobacillus neapolitanus, and Thiobacillus intermedius) (De Belie et al., 2004). SOB are strictly aerobic bacteria which convert the sulphur compounds into sulphuric acid on the surface of the concrete and initiate the biogenic sulphuric acid attack of concrete.

Three elemental factors are responsible for the biogenic sulphuric acid attack: elevated $\mathrm{H}_{2} \mathrm{~S}$ concentrations, moisture, and oxygen in the atmosphere (Roberts et al., 2002). To inhibit the metal corrosion or concrete deterioration due to microbial attachment and biofouling, different approaches have been suggested including: a) chemical coating of concrete, b) biocide addition, c) eliminating the $\mathrm{H}_{2} \mathrm{~S}$ emission by adding other oxidizing agents such as nitrate or nitrite, d) limiting the growth of hydrogen sulphide producing bacteria by adding chlorine and potassium permanganate into the solution, e) using the beneficial biofilm on the surface of the materials under corrosion. Among these alternatives, the use of biofilm as a protective layer on the concrete surface has shown promising results in reducing corrosion of many types of metal (Jayaraman et al., 1998 and 1997a, b; Zuo and Wood, 2004; Ornek et al., 2002a, b; Hernandez et al., 1994; Guiamet et al., 1999; Zuo, 2007; Zuo et al., $2004 \&$ 2005). However, this approach has not been used for the deterioration inhibition of concrete; therefore, it is a new method for the reduction of concrete deterioration due to the microbial assimilation.

In this new approach, a layer of favourable biofilm that is not detrimental to the concrete is grown on the concrete surface. The main hypothesis of this research is that the biofilm layer protects the concrete by depleting the oxygen from the concrete surface and decreasing the growth of unfavourable aerobic sulphur oxidizing bacteria on the surface. Moreover, this protective layer inhibits the growth of unfavourable biofilm by reducing 
the nutrient availability and in some cases by secreting antimicrobial agents. The byproducts of the assimilation of bacteria in the biofilm also provide a protective layer acting as a physical barrier on the surface of the concrete and reducing the permeability of concrete.

To the best of the author's knowledge, at the time of this research, these hypotheses have not been tested in a systematic approach, and the proof of the concept that a beneficial biofilm on the concrete surface can be grown to resist deterioration due to biogenic acid attack has not been made.

\subsection{OBJECTIVES AND SCOPE}

The general objective of the proposed study is to investigate the effectiveness of Escherichia coli DH5 $\alpha$ biofilm on the mortar surface for MICD inhibition. The specific objectives of the research can be summarized as follows:

1. To demonstrate that a beneficial biofilm can be grown on mortar surface, which is an unfavourable environment for bacterial growth due to its high $\mathrm{pH}$, complex chemical composition, and its heterogeneous porous surface texture.

2. To investigate the effectiveness of the biofilm to reduce mortar deterioration exposed to chemical acidification that is induced by external addition of sulphuric acid.

3. To investigate the effectiveness of the biofilm to reduce mortar deterioration exposed to biogenic acidification that is induced by natural acidification of the medium with SOB.

4. To investigate the effect of temperature on the biofilm performance. 
5. To evaluate the effectiveness of biofilm to prevent the passage of deleterious sulphide ion in MICD.

It should be noted that the current research is the first of its kind to prove the concept that a beneficial biofilm on the concrete surface can be grown to resist deterioration due to biogenic acid attack. It is acknowledged that in order to use beneficial biofilms to resist concrete deterioration caused by biogenic acidification in real-life applications, largescale experiments and demonstration projects are required to address the practical issues related to the growth and maintenance of a healthy biofilms on concrete. However, these studies cannot start before bench-scale experiments are completed and the idea is proven to have potential for further investigation. Therefore, the large-scale experiments and demonstration projects were not within the scope of the current investigation, and the study only focused on bench-scale experiments.

In addition, it should be noted that concrete is a versatile material that shows a variety of chemical and microstructural properties. Many different types of concrete can be produced using different types of cement, water-to-cement ratios, and aggregate and cement contents. The goal of this research was not to investigate the effects of different concrete types on the performance of biofilm as MICD inhibitor. Because of the small scale of the surface on which biofilm is grown, concrete with large aggregates was not used; instead cement mortar produced with ordinary portland cement, sand and water was used as the representative material with similar cementitious properties.

The beneficial biofilm of E.coli DH5a was chosen for this study based on its proven ability to provide a protective barrier against the microbial influenced corrosion of metals. The good performance of E.coli biofilm in preventing the sulphide ion passage 
which was evaluated initially and demonstrated in Chapter 8 was the second reason for the selection of this bacterium.

\subsection{RESEARCH METHOD}

In order to achieve the objectives of the research outlined in Section 1.3, the investigation is divided into five phases:

Phase 1: growing E.coli biofilm on the mortar specimens and monitoring the biofilm growth by quantification of bacteria using membrane filtration and adenosine triphosphate (ATP) measurement.

Phase 2: simulating chemical deterioration using sulphuric acid solution and evaluating the mortar deterioration by X-ray diffraction (XRD), microscopic techniques and chemical analysis.

Phase 3: simulating biogenic sulphuric acid deterioration using two strains of sulphur oxidizing bacteria and evaluating the performance of E.coli biofilm by microscopic techniques and chemical analysis.

Phase 4: investigatiing the effect of temperature on biogenic sulphuric acid attack.

Phase 5: using the enzyme electrode (biosensor) to investigate the biofilm properties in terms of sulphide ion passage inhibition.

Different microscopy methods such as confocal laser scanning microscope (CLSM) and scanning electron microscopy (SEM) were employed to assess the biofilm growth, biofilm attachment and surface structures of mortar specimens before and after deterioration. The microbiological techniques such as adenosine tri-phosphate 
measurement, biomass measurement as well as some chemical analysis such as $\mathrm{pH}$, and sulphate concentration measurement were used to predict the bacterial growth rate and biofilm formation in the reactor. Fluorescence in situ hybridization (FISH) was employed to assess the purity of E.coli biofilm and to evaluate the competence of SOB for attachment to biofilm layer during biogenic acidification. XRD was used mainly to evaluate the formation of gypsum and ettrengite crystals on the mortar surface and compare the performance of biofilm-covered mortar with the mortar without biofilm after the acidification process.

\subsection{Thesis Organization}

Apart from the current introduction, the thesis is divided into the following sections:

Chapter 2 provides a review of the literature on the subject of microbiologically influenced corrosion of metal, microbiologically influenced concrete deterioration, the accelerated test methods to simulate biogenic deterioration, and mechanisms of sulphate attack in concrete.

Chapter 3 provides a brief background on some of the experimental tools and presents the materials and methodologies adopted for this study.

Chapter 4 provides the result of the phase one of the study in which the monitoring of E.coli growth and biofilm formation, and the evaluation of the E.coli biofilm characteristics grown on the mortar specimens are presented.

Chapter 5 presents the result of the phase two of the study including the results of chemically induced deterioration as simulated by exposure to the sulphuric acid solution. 
Chapter 6 provides the result of the phase three of the study in which the effectiveness of biofilm against the biogenic sulphuric acid deterioration is evaluated.

Chapter 7 presents the results of the phase 4 of the study in which the effectiveness of biofilm against the biogenic sulphuric acid deterioration at an elevated temperature is evaluated.

In Chapter 8 the results of the enzyme electrode to evaluate the effectiveness of a biofilm as a protective barrier against the passage of sulphide ions is provided.

The main conclusions of this study along with recommendations for future work are presented in Chapter 9. Supplementary XRD analysis and CLSM images are provided in Appendix A and B, respectively. 


\section{CHAPTER 2. LITERATURE REVIEW}

\subsection{INTRODUCTION}

This chapter provides a review of the existing literature on microbiologically influenced concrete deterioration and relevant topics around it as they relate to the scope of this thesis. At the onset, it should be clarified that the mechanism of MICD is different from the widely-studied mechanism of microbiologically influenced corrosion (deterioration) of metals (MIC) (Jayaraman et al., 1998 and 1997 a, b; Zuo and Wood, 2004; Ornek et al., 2002 a, b; Hernandez et al., 1994). The corrosion of metals is an electrochemical process while MICD is the chemical deterioration of the hydrated products of concrete (e.g., calcium hydroxide) by external contaminants. Both deterioration mechanisms, on the other hand, have one common aspect: the presence and activity of bacteria that cause the deterioration. Hence, the prevention and inhibition of deterioration in both materials (i.e., concrete and metal) are similar and mostly involve the removal of the harmful bacteria. Due to the similarity of these two mechanisms in terms of the prevention strategies, in this chapter, a literature review on the MIC of metals and the prevention method using biofilm is presented first. The literature review is then followed by the mechanism of MICD and its prevention methods. Due to the similarity of MICD with the 
chemically induced sulphate attack of concrete, this chapter is concluded with a review of sulphate attack mechanisms in concrete.

\subsection{MiCROBIOLOGICALLY INFLUENCED CORROSION OF METALS}

Steel and reinforced concrete are largely used in water and wastewater treatment plants to build tanks, pipes, purification basins, and operating components such as blades and pumps. The contact of these units with biologically active liquid (e.g. wastewater) causes biological formations of unfavourable ions and inorganic charge changes on the metal/solution interface, which can result in MIC. The parts of the treatment facilities frequently experiencing MIC are filtration systems, different type of pipes, potable water distribution systems, storage tanks, and aerobic and anaerobic digesters.

Microbiologically influenced corrosion is a process in which the metabolic activity of microorganisms results in corrosion acceleration by the production of aggressive metabolites and the enhancement of the corrosion reaction. The accumulation of inorganic ions and organic compounds in the absence of dissolved oxygen forms a thin layer of corrosion causing biofilm. The biofilm layer causes corrosion by altering the electrostatic charges on the metal surface, dissolving the protective metal oxide layer on the surface (i.e., passive layer), enhancing the transport of chemical species from or towards the metal surface, and stimulating oxidation-reduction potential (Videla and Herrera, 2005). The breakdown of the passive layer is the first step in the MIC reaction which is caused by the production of final methabolites of sulphate reducing bacteria (SRB) such as sulphides, bisulphites, hydrogen sulphides and thiosulphate (Videla and Herrera, 2005; Videla and Characklis, 1992). The mature biofilm consisting of microbial 
cells and their extracellular polymeric substances (EPS) is the key factor to explain the physical/chemical and biological alterations at the metal/solution interface.

\subsubsection{Mechanism of corrosion in metals}

Corrosion is the dissolution of a metal due to the interaction of the metal with the environment. The typical dissolution of a metal with two valance electrons proceeds as follows (Zuo, 2007):

$\mathrm{M} \leftrightarrow \mathrm{M}^{2+}+2 \mathrm{e}^{-}$

The above reaction is the anodic reaction that produces the electron that is consumed in the cathodic reactions, which may take a number of forms depending on the availability of oxygen. Two typical cathodic reactions are oxygen reduction (Eq. 2-2) and hydrogen evolution (Eq.2-3):

$1 / 2 \mathrm{O}_{2}+\mathrm{H}_{2} \mathrm{O}+2 \mathrm{e}^{-} \leftrightarrow 2 \mathrm{OH}^{-} \quad$ (cathodic reaction, with oxygen)

$2 \mathrm{H}^{+}+2 \mathrm{e}^{-} \leftrightarrow \mathrm{H}_{2} \quad$ (cathodic reaction, without oxygen)

Several environmental factors such as chemical composition of liquid exposed to metal, metal type, electrochemistry and presence and type of microorganisms influence the rate of corrosion. Corrosion initiated by the activity of microorganisms results in a severe form of corrosion damage and is known as MIC. Microorganisms responsible for MIC include sulphate reducing bacteria (SRB), iron-reducing bacteria, acid-producing bacteria, and fungi (Zuo, 2007). In anaerobic conditions, the most common bacteria for metal corrosion are sulphate reducing bacteria which produce acidic hydrogen sulphide (Perego et al., 1997). The involvement of SRB in the MIC of anaerobic treatment facilities is largely documented (Videla and Characklis, 1992; Hamilton, 1985). 
Kuhr and Van der Vlugt equations suggested for MIC of iron in the presence of SRB are commonly used to study MIC mechanisms (Sheng et al., 2007; Stott, 1993):

$$
\begin{array}{ll}
4 \mathrm{Fe} \rightarrow 4 \mathrm{Fe}^{2+}+8 \mathrm{e}^{-} & \text {(anodic reaction) } \\
8 \mathrm{H}_{2} \mathrm{O} \rightarrow 8 \mathrm{H}^{+}+8 \mathrm{OH}^{-} & \text {(water dissociation) } \\
8 \mathrm{H}^{+}+8 \mathrm{e}^{-} \rightarrow 8 \mathrm{H} & \text { (cathodic reaction) } \\
\mathrm{SO}_{4}{ }^{2+}+8 \mathrm{H} \rightarrow \mathrm{S}^{2-}+4 \mathrm{H}_{2} \mathrm{O} & \begin{array}{l}
\text { (bacterial consumption with the aid of } \\
\text { hydrogenase enzyme) }
\end{array}
\end{array}
$$

In this process, the biological reaction is initiated in the cathodic reaction (Eq. 2-6) which produces atomic hydrogen and is followed by Eq. 2-7, through which the SRB removes a hydrogen atom as the electron donor with sulphate as electron acceptor. The removal of atomic hydrogen by Eq. $2-7$ boosts the anodic reaction (Eq. 2-4) and speeds up the dissolution of iron. The anodic reaction can be accelerated by the formation of iron sulphide as the corrosion product via (anodic depolarization):

$\mathrm{Fe}^{2+}+\mathrm{S}^{2-} \rightarrow \mathrm{FeS} \quad$ (corrosion product)

Similarly, cathodic reaction can be accelerated by the cathodic reduction of $\mathrm{H}_{2} \mathrm{~S}$ (cathodic depolarization) (Sheng et al., 2007). Then the overall reaction can be written as follows:

$$
4 \mathrm{Fe}+\mathrm{SO}_{4}{ }^{2-}+4 \mathrm{H}_{2} \mathrm{O} \rightarrow 3 \mathrm{Fe}(\mathrm{OH})_{2}+\mathrm{FeS}+2 \mathrm{OH}^{-}
$$

Based on the theory presented above, SRB consume the atomic hydrogen at the cathodic reaction by releasing a hydrogenase enzyme (Stott, 1993). The hydrogenase enzyme catalyses the oxidation of molecular hydrogen and exists in a number of anaerobes, specially SRB. Booth and Tiller (1960) studied the potential changes of steel electrodes due to the development of two species of SRB to evaluate the capability of SRB in 
corrosion acceleration. They concluded that only the SRB containing hydrogenase enzyme are capable of affecting the reduction of sulphate with hydrogen (i.e. the corrosion rate increases in the presences of SRB with the hydrogenase enzyme).

\subsubsection{Biofilm}

Microorganisms require water, nutrients, and electron acceptors for their survival. A microorganism can withstand long periods of starvation and desiccation without any growth. The size of microorganisms is from two tenths to several hundred micrometres in length and 2-3 $\mu \mathrm{m}$ in width (Little and Lee, 2007). This small size of microorganisms allows them to penetrate porous materials and small spaces to cause biofouling or biodeterioration of materials. Biofouling is an undesirable form of biological growth on material surfaces which decreases material performance (Borenstein, 1994). An example of biofouling is MIC or MICD that causes corrosion or deterioration of materials, respectively. Biofouling is initiated by the growth of a layer of microorganisms called biofilm. Biofilm is a microbial community consisting of microorganisms confined in extracellular polymeric substances (EPS) that are able to grow with low levels of nutrients. A highly hydrated EPS matrix is essential to keep the cells together, retain water, and provide nutrients for biofilm organisms.

Biofilms are a preferred way of microbial existence as they provide protection against existing physical forces and chemical attack, if necessary (Geoghegan et al., 2008). Bacteria in biofilm experience a different growth mode than growth in suspension, resulting in distinct physiological characteristics such as cell morphology, improved resistance to antibiotics, different responses to environmental stimuli, and increased production of EPS (Zuo, 2007). Formation of a biofilm is desirable in some cases 
(wastewater treatment, biochemical production), whereas in other cases it poses severe problems (marine equipment fouling, biomaterial-related infections, deterioration and corrosion of materials). Being able to quantitatively describe biofilms, for instance, in terms of volume, wet weight, number of species present, or thickness, allows for better systems engineering and reduction in damage and operational costs.

The internal structure of biofilms, which affects internal nutrient transfer and the microbial activity within the biofilm, is not uniform. The internal structure of the biofilm matrix is dependent on the flow velocity at which they are grown (Beyenal and Lewandowski, 2008; Peyton, 1996). A biofilm grown at a lower flow velocity or at stationary conditions is less dense and less resistant to shear stress than those grown at higher flow rates. The less dense biofilm has a higher diffusivity at the interfacial liquid/biofilm layer which will further alter the mass transport rate (Peyton, 1996). Beyenal and Lewandowski (2008) hypothesized that the biofilm attempts to increase its mechanical strength to resist the shear stress at the expense of nutrient transfer rate to the internal layers. Hence, the increase in the substrate loading rate increases the biofilm thickness but decreases the uniformity of the biofilm (Peyton, 1996).

\subsubsection{Corrosion control by biofilm formation}

The role of microorganisms in corrosion is very critical since they can either accelerate or inhibit corrosion (Zuo, 2007). The bacterial biofilm can fill the pore space and protect the metal surface or alter the surroundings of the surface and lead to corrosion. The use of biofilm as a corrosion inhibitor has been widely investigated by different researchers (Jayaraman et al., 1997 a, b, 1998 and 1999 a, b, c; Zuo and Wood, 2004; Ornek et al., 2002 a, b; Hernandez et al., 1994; Guiamet et al., 1999; Zuo, 2007). 
Biofilms can inhibit corrosion thorough: 1) removal of corrosive agents (Zuo, 2007) (Figure 2.1a), 2) growth inhibition of SRB by antimicrobial compounds secreted within the biofilm (Zuo, 2007) (Figure 2.1b), 3) formation of protective corrosion products (Akid et al., 2008) (Figure 2.1c), 4) uptake of water by the bacteria within the biofilm as a result of metabolic activity (Akid et al., 2008).

Corrosion inhibition by the biofilm through the removal of corrosive cathodic agents performs differently depending on particular conditions. For instance, the biofilm under aerobic conditions inhibits corrosion through the removal of cathodic agents such as oxygen (cathodic protection) (Zuo, 2007). Under anaerobic conditions, the chemoorganotrophic bacteria such as Fe(III)-reducing bacteria can inhibit corrosion by converting ferric corrosion products to soluble $\mathrm{Fe}$ (III) compounds and result in the destruction of ecological niches suitable for SOB growth (Potekhina et al., 1999). Akid et al. (2008) reported Pseudomonas fragi (PF), Escherichia coli DH5a, Pseudomonas flava, and Paenibacillus polymyxa (PP) as the beneficial bacterial biofilm that help mitigate corrosion. Bacillus subtilis has been shown to inhibit the corrosion of metal by secreting polyglutamate and polyaspartate (antimicrobial compounds), while P.flava inhibits corrosion by forming phosphate (Sheng et al., 2007). Biofilm of aerobic bacteria such as PF inhibits corrosion by reducing the oxygen concentration and biofilm of PP inhibits corrosion by secreting an antimicrobial compound against SRB and hindering the anaerobic growth of SRB at the metal surface (Akid et al., 2008). 

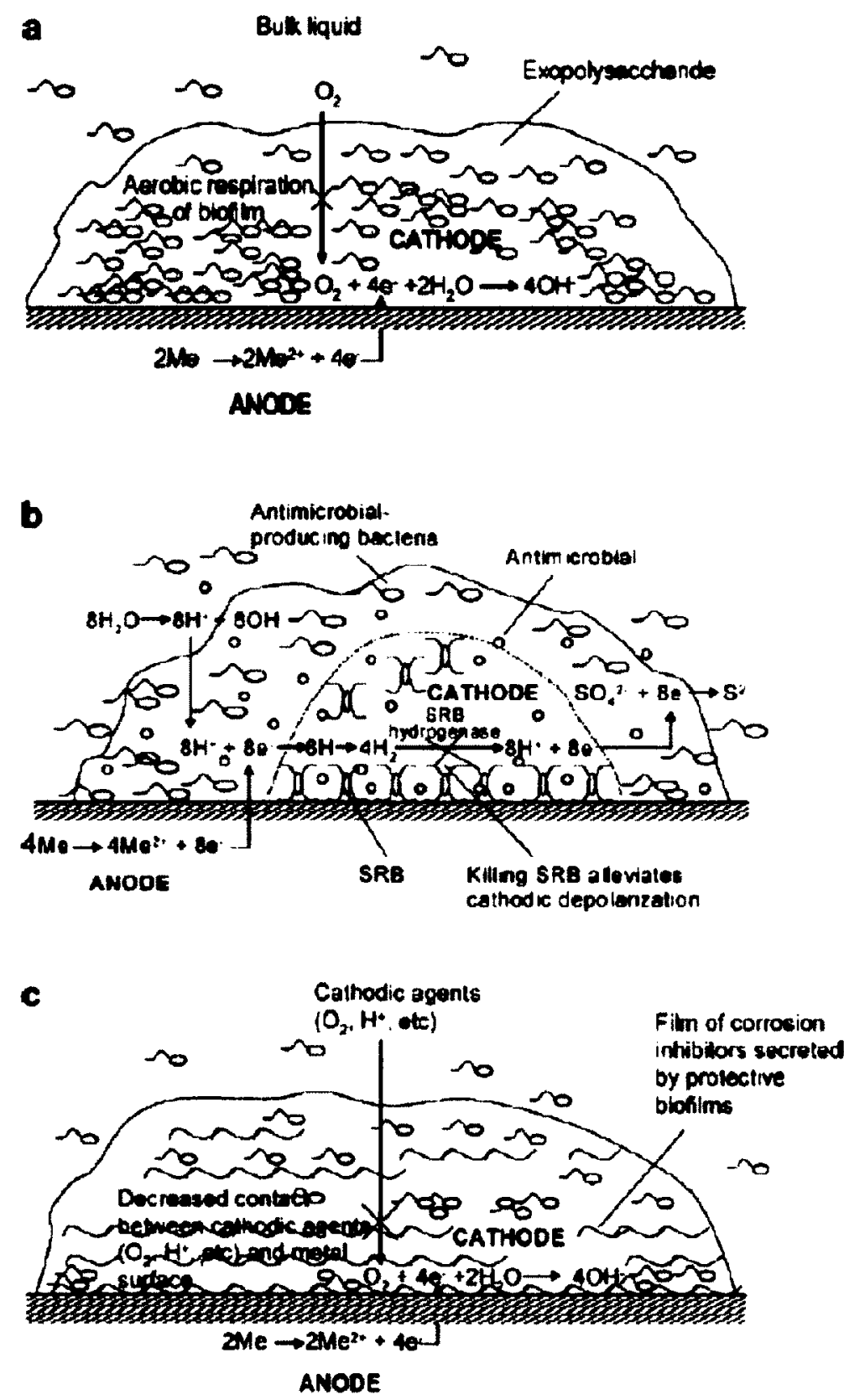

Figure 2.1: Representative proposed mechanisms of corrosion inhibition employing beneficial bacterial biofilms. a) Aerobic respiration of biofilms decreases oxygen concentration on metal surface. b) Antimicrobials generated in situ by biofilms (such as Bacillus brevis) eliminate corrosion-causing bacteria (e.g., SRB). c) Biofilm-secreted protective layers of corrosion inhibitors decrease contact of corrosive agents with metal surface (taken from Zuo, 2007).

Because of the disadvantages of traditional corrosion inhibitors (i.e., being hazardous and subject to degradation and dilution by the bulk fluid), biofilms can play an important role 
for secreting the corrosion inhibitors, as they can be generated adjacent to the surfaces under corrosion and within the biofilm. Ornek et al. (2002 a, b) investigated the corrosion inhibition of aluminium and brass using the biofilm of genetically engineered Bacillus subtilis that produces polyaspartate or Bacillus licheniformis that produces $\gamma$ polyglutamate. $\gamma$-Polyglutamate and polyaspartate are naturally produced corrosion inhibitors which have an aluminum-chelating carboxylic group. Ornek et al. (2002 a) observed a $90 \%$ reduction in the MIC inhibition of aluminium by B.licheniformis compared to the non-engineered biofilm (i.e., biofilms that do not secrete corrosion inhibitors) and a significant corrosion reduction by B.subtilis. In another attempt, Jayaraman et al. (1999 a) constructed the genetically engineered B.subtilis secreting antimicrobial peptide of indolicidin, bactenecin and probactenecin to inhibit the growth and proliferation of SRB. B. subtilis expressing bactenecin in biofilms inhibited the SRBinduced corrosion of stainless steel 6 to 12-fold in continuous reactors as observed by EIS spectra and by the reduction in hydrogen sulphide and iron sulphide in batch fermentations with mild steel. Zuo and Wood (2004) used the gramicidin-S producing Bacillus brevis to reduce the corrosion of mild steel due to the presence of iron-oxidizing and sulphate reducing bacteria. Gramicidin-S is an antimicrobial peptide, effective in killing a range of bacteria and fungi. They observed about a 20 -fold reduction in corrosion by the protective and antimicrobial secreting biofilm of B.brevis.

Jayaraman et al. (1997 a, b, 1998) used the biofilm forming aerobic bacteria of P.fragi and facultative anaerobic E.coli $\mathrm{DH} 5 \alpha$ to reduce corrosion by removing the oxygen from the corrosion site in carbon steel SAE 1018. By measuring mass loss, they observed a 210 fold reduction in corrosion in the presence of these bacterial biofilms compared to 
sterile conditions (biofilm free). Using confocal laser scanning microscopy and by staining the bacteria with Live/Dead Baclight stain, they showed that increasing the cellular content and the thickness of the biofilm led to further corrosion reduction. By killing the bacteria using antibiotics, they concluded that the dead bacterial biofilm is not effective in reducing the corrosion because of the lack of bacterial assimilation. Jayaraman et al. (1997 b) extended their study to further investigate if oxygen depletion is the only reason for the corrosion inhibition by the E.coli and P.fragi biofilm. They were able to reduce the corrosion of steel in the presence of the aerobically grown biofilm of E.coli and $P$. fragi in a continuous reactor by 4 - to 20 -fold in an LB medium. However, as the corrosion rate in the presence of anaerobically grown biofilm of E.coli was always lower than the sterile anaerobic control, they could not completely attribute the corrosion reduction to oxygen depletion alone. It is likely that some other activities might be involved rather than oxygen depletion alone in the corrosion inhibition by E.coli biofilm (Zuo, 2007). Akid et al. (2008) produced a ready-made biofilm of the Pseudomonas fragi and Paenibacillus polymyxa bacteria encapsulated in a sol-gel coating and inoculated the gel close to the metal substrate. The electrochemical measurement of the polarization resistance, the impedance spectroscopy and the electrochemical noise studies carried out by Akid et al. (2008) demonstrated at least a 10-fold inhibition in metal corrosion coated with bacteria infused sol-gel coating compared to sol-gel coating with no bacteria. 


\subsection{Microbiologically INFLUENCED CONCRETE DETERIORATION (MICD)}

The occurrence of MICD has been widely reported in wastewater collection systems such as sewer pipes (O’Dea, 2007; Parande et al., 2006; Kulpa and Baker, 1990; Diercks et al., 1991), and treatment facilities such as digesters (Estoup and Cabrillac, 1997) or clarifiers (Basu et al., 2001; Bruce and Freitag, 2005). Fresh sewage contains abundant amounts of sulphate ions $\left(\mathrm{SO}_{4}{ }^{2-}\right)$ which are reduced to hydrogen sulphide in anaerobic conditions. The responsible bacteria for this conversion is anaerobic sulphate reducing bacteria (SRB), e.g. Desulfovibrio, which use the sulphate ion as an oxygen source for the assimilation of organic matter and release back the sulphide ion $\left(\mathrm{S}^{2-}\right)$ as the by product of this assimilation (Figure 2.2). Depending on the $\mathrm{pH}$ and the temperature of the wastewater, the sulphide ion exists either in the form of bisulphide ion ( $\mathrm{HS}^{-}$) or hydrogen sulphide gas $\left(\mathrm{H}_{2} \mathrm{~S}\right)\left(\mathrm{O}^{\prime}\right.$ Dea, 2007). For example at a pH value of 7 and at $30^{\circ} \mathrm{C}$ about 60 percent of $\mathrm{H}_{2} \mathrm{~S}$ is present as dissolved $\mathrm{H}_{2} \mathrm{~S}$ (Metcalf and Eddy, 2003). In the headspace above the wastewater, part of the $\mathrm{H}_{2} \mathrm{~S}$ reacts with atmospheric oxygen to produce elemental sulphur, sulphite, and thiosulphate which are deposited on the surface of the concrete structures and are more readily digestible by sulphur oxidizing bacteria (Nica et al., 2000). SOB convert the sulphur compounds to sulphuric acid which is corrosive and causes concrete deterioration.

The concrete deterioration is initiated by the reaction of sulphuric acid with calcium hydroxide in the concrete to produce gypsum and is followed by the reaction between gypsum and calcium aluminate hydrate in the concrete to form ettringite (Monteny et al., 2000, 2001). Both gypsum and ettringite are expansive which leads to the increase of 
internal pressure and deterioration of the concrete matrix. Deterioration worsens when the $\mathrm{H}_{2} \mathrm{~S}$ gas also reacts with the concrete reinforcement through cracks and corrodes the steel reinforcements (Parande et al., 2006; Abdelmseeh et al., 2005, 2006).

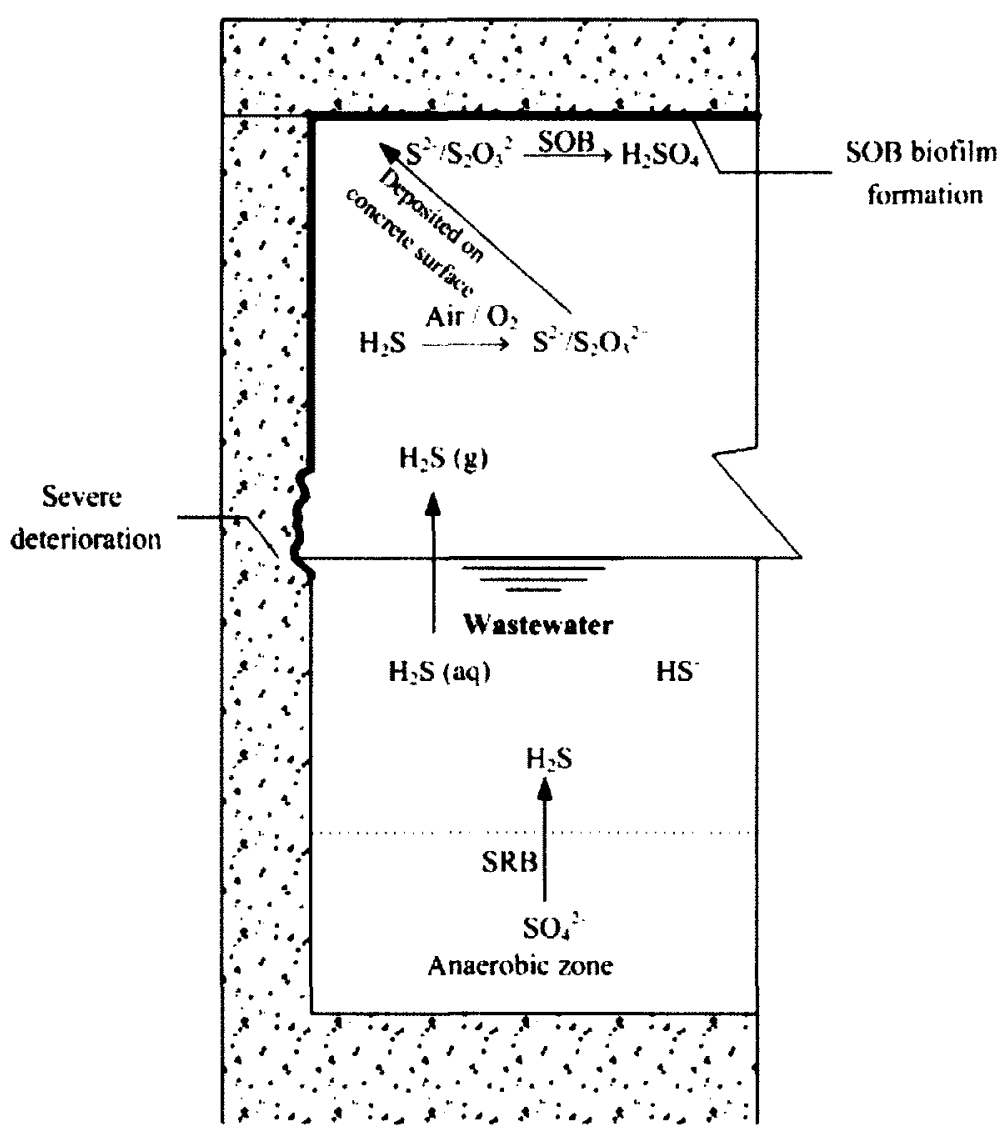

Figure 2.2: Schematic representation of microbial induced concrete deterioration.

\subsubsection{Bacteria involved in concrete deterioration}

Microbial induced concrete deterioration has been studied since 1945 when Parker discovered that the sulphur oxidizing bacteria of Thiobacillus thiooxidans are involved in accelerating the concrete deterioration process by utilizing inorganic sulphur compounds in the presence of oxygen and forming sulphuric acid (Parker, 1945). 
Concrete is a highly alkaline material with high surface $\mathrm{pH}$ of approximately 13 , which is not suitable for the growth of SOB. Hence, a succession of several species capable of oxidizing sulphur compounds is involved in MICD to enable their colonization on the concrete surface (Sand et al., 1987; Islander et al., 1991; Diercks et al., 1991; Okabe et al., 2007; Mori et al., 1992; Bielefeldt et al., 2010). Islander et al. (1991) divided the various SOB involved in MICD into two main groups of neutrophilic (NSOB) and acidophilic sulphur oxidizing bacteria (ASOB) based on the $\mathrm{pH}$ range for the growth, and the form of sulphur they use as substrate. The NSOB are capable of growth at $\mathrm{pH}$ levels up to 9 and can reduce the $\mathrm{pH}$ to 5 which becomes self-inhibitory for their growth. T.thioparus, T.neapolitanus, and T.novellus are categorized in the NSOB group. As the $\mathrm{pH}$ reduces to 5, the second group of $\mathrm{SOB}, \mathrm{ASOB}$ such as T. thiooxidans, T.intermedius start their activity and reduce the $\mathrm{pH}$ to as low as 0.5 (Islander et al., 1991; Nica et al., 2000). The ASOB, which can survive at very low $\mathrm{pH}$, are responsible for the structural failure of concrete structures due to their ability to create a highly acidic environment. The microbial succession is ultimately dominated by the aerobic autotrophic sulphur oxidizing bacteria of $T$. thiooxidans which can survive at a very low $\mathrm{pH}$. Bielefeldt et al. (2010) studied the kinetics of different $\mathrm{SOB}$ species and their biodeterioration rate associated with $\mathrm{pH}$ decrease, calcium release, and sulphate production. They concluded that the biodeterioration rate of concrete exposed to the mixed culture of ASOB and NSOB was faster than the concrete exposed only to NSOB.

Apart from SOB, the lithoautotrophic nitrifying bacteria are other acid producing microorganisms involved in deterioration of concrete structures exposed to ammonia and acidic air pollutants such as $\mathrm{NO}_{\mathrm{x}}$ or $\mathrm{SO}_{2}$ (Diercks et al., 1991). The reaction of ammonia 
with $\mathrm{NO}_{\mathrm{x}}$ or $\mathrm{SO}_{2}$ provides the appropriate substrate for the growth of nitrifying bacteria to produce nitric acid. However, since this type of bacteria cannot grow at acidic $\mathrm{pH}$ of less than 5 , the severity of biodeterioration is much less than SOB; hence the biodeterioration caused by nitrifying bacteria might be neglected in wastewater treatment systems.

Gu et al. (1998) suggested that fungi are also involved in the biodeterioration of concrete and compared the MICD caused by the SOB of Tintermedius with MICD caused by the fungus, Fusarium sp. They reported that Fusarium sp. is equally capable of biodeteriorating concrete as T.intermedius. T.intermedius attacks concrete by etching and spalling the concrete but Fusarium sp. penetrates to a deeper depth in concrete and deteriorates the concrete by organic acid production. Nica et al. (2000) characterized the microorganisms involved in the biodeterioration of concrete in sewer pipes. They were able to isolate nine heterotrophic bacteria, two autotrophic bacteria and four fungi from a corroding concrete sewage pipe in Houston, USA. Vincke et al. (2001) studied the microbial community on a corroded sewer pipe in Belgium using DNA-based identification techniques such as denaturing gradient gel electrophoresis and polymerase chain reaction. The results of their study revealed the presence of sulphur oxidizing bacteria such as T.thiooxidans, T.novellus, T.neapolitanus, acidithiobacillus sp. and nonsulphur oxidizing bacteria of Mycobacteria sp. as well as different heterotrophs belonging to $\alpha$-, $\beta$ - and $\gamma$-proteobscteria, acidobacteria, and actinobacteria. Vinke et al. (2001) also showed apart from the diversity of bacteria attached to the deteriorated concrete, the density of SOB was higher in locations with higher levels of deterioration. The diverse community of bacteria that has been observed on the concrete surface of 
deteriorating sewer pipes may not be directly involved in the deterioration of concrete, but they may facilitate the presence and activity of deterioration causing bacteria by increasing the surface area for their growth and by lowering $\mathrm{pH}$ and redox potentials of the deterioration causing bacteria (Santo Domingo et al., 2011; Vinke et al., 2001). Satoh et al. (2009) studied the in situ microbial communities of SOB and SRB using molecular techniques on concrete specimens placed in a manhole. They categorized the biofilm formed on the concrete into two main biofilm groups. In the non-deteriorated parts of concrete, they observed a gel-like biofilm introduced as SRB which was covered with a white filamentous biofilm of SOB, whereas, in the deteriorated sections of concrete above the water line, just the biofilm of SOB was observed. As Satoh et al. (2009) stated in their paper, the reason why the concrete was not deteriorated in the middle section was that "the corrosive compound generated in the upper filamentous biofilm were reduced in the deeper gel-like biofilm".

\subsubsection{Test procedures for biogenic sulphuric acid attack simulation}

Since the discovery of the bacterial involvement in concrete deterioration, several experiments have focused on comparing the resistance of different types of concrete to MICD. Hence, different researchers have tried to develop an accelerated test method that can better simulate biogenic sulphuric acid attack which is different from chemical sulphuric acid attack (Sand et al., 1987; Mori et al., 1992; Hormann et al., 1997; Vincke et al., 1999). To evaluate concrete resistance to SOB, Sand et al. (1987) constructed a control stainless steel chamber where temperature, humidity, hydrogen sulphide concentration, thiobacillus concentration were controlled (Figure 2.3). The concrete blocks were placed inside the chamber with $10 \mathrm{~cm}$ water (Figure 2.3 ), at $100 \%$ humidity 
and $\mathrm{H}_{2} \mathrm{~S}$ concentration of $10 \mathrm{ppm}$. The concrete samples were periodically sprayed with a mixture of Thiobacilli to accelerate the corrosion rate.

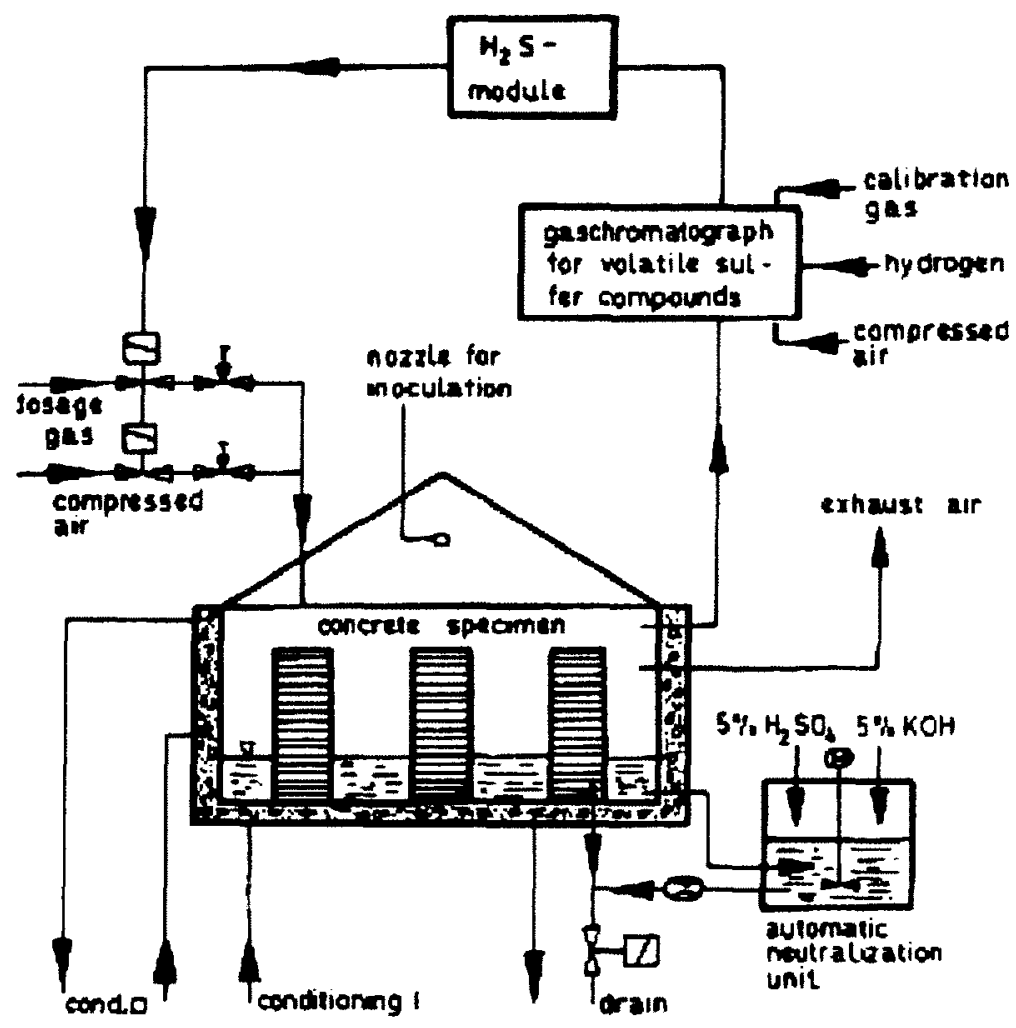

Figure 2.3: MICD simulation chamber by Sand et al. (1987) (taken from Sand et al., 1987).

Sand et al. (1987) monitored the deterioration rate of concrete by measuring the weight loss, the number of cells of different types of Thiobacilli attached to the concrete samples and $\mathrm{pH}$ of the concrete surface. Even though they observed a $\mathrm{pH}$ reduction from 11 to 2-3 after 70 days and accelerated the deterioration process by up to 8 times in comparison with the in situ situation, the investigation took almost one year to finish.

Hormann et al. (1997) created a new test setup to simulate MICD utilizing optimal growth for T.thiooxidans to accelerate the deterioration process of 5-10 years in the field to 3-5 months in the lab experiments. Since the optimal growth medium for T.thiooxidan 
has a $\mathrm{pH}$ below 3 and in order not to expose the concrete samples to a low $\mathrm{pH}$ medium for a long time, they used a two step process consisting of: 1) fermentation of T.thiooxidans and 2) reaction process as illustrated in Figure 2.4. In the first step, the T.thiooxidans was cultivated to its maximum cell count in a fermentor, and in the second step, the concrete specimens placed in a stainless steel reactor were exposed to the content of fermentor for 5 minutes followed by one hour break. Hormann et al. (1997) observed a weight loss of $18-31 \%$ for the concrete specimens after 5 months of exposure to their simulated condition.

Mori et al. (1992) investigated the effect of nutrient availability, and moisture on the MICD of sewer pipes. Their lab-scale simulation system is illustrated in Figure 2-5. The concrete specimens were placed on an enclosed plastic chamber inside different media and exposed to a high $\mathrm{H}_{2} \mathrm{~S}$ concentration of $400 \mathrm{ppm}$ as shown in Figure 2.5. The experiment lasted for 6 months and specimens were inoculated with T.thiooxidans every two weeks for the first two months. They investigated the deterioration of samples using scanning electron microscopy considering the reduction in cross-section as an indication for deterioration.

Vincke et al. (1999) proposed a very simple test procedure for biogenic sulphuric acid attack of concrete in sewer pipes. Their procedure consists of the following steps: 1) sorption of $\mathrm{H}_{2} \mathrm{~S}$ to clean concrete samples and concrete samples covered with SOB biofilm by incubating the concrete specimens in an $\mathrm{H}_{2} \mathrm{~S}$ incubation chamber for 3 days, 2) biogenic sulphuric acid production on the specimens by incubating the specimens in a SOB suspension at neutral $\mathrm{pH}$ for 10 days, 3) simulating a rainy day with high loading rate by rinsing the specimen with deionised water for 2 days 4 ) simulating a dry weather 
period by exposing the concrete to $\mathrm{H}_{2} \mathrm{~S}$ for 2 days. They were able to observe a weight loss of $9-11 \%$ after running the test for three cycles or 51 days.

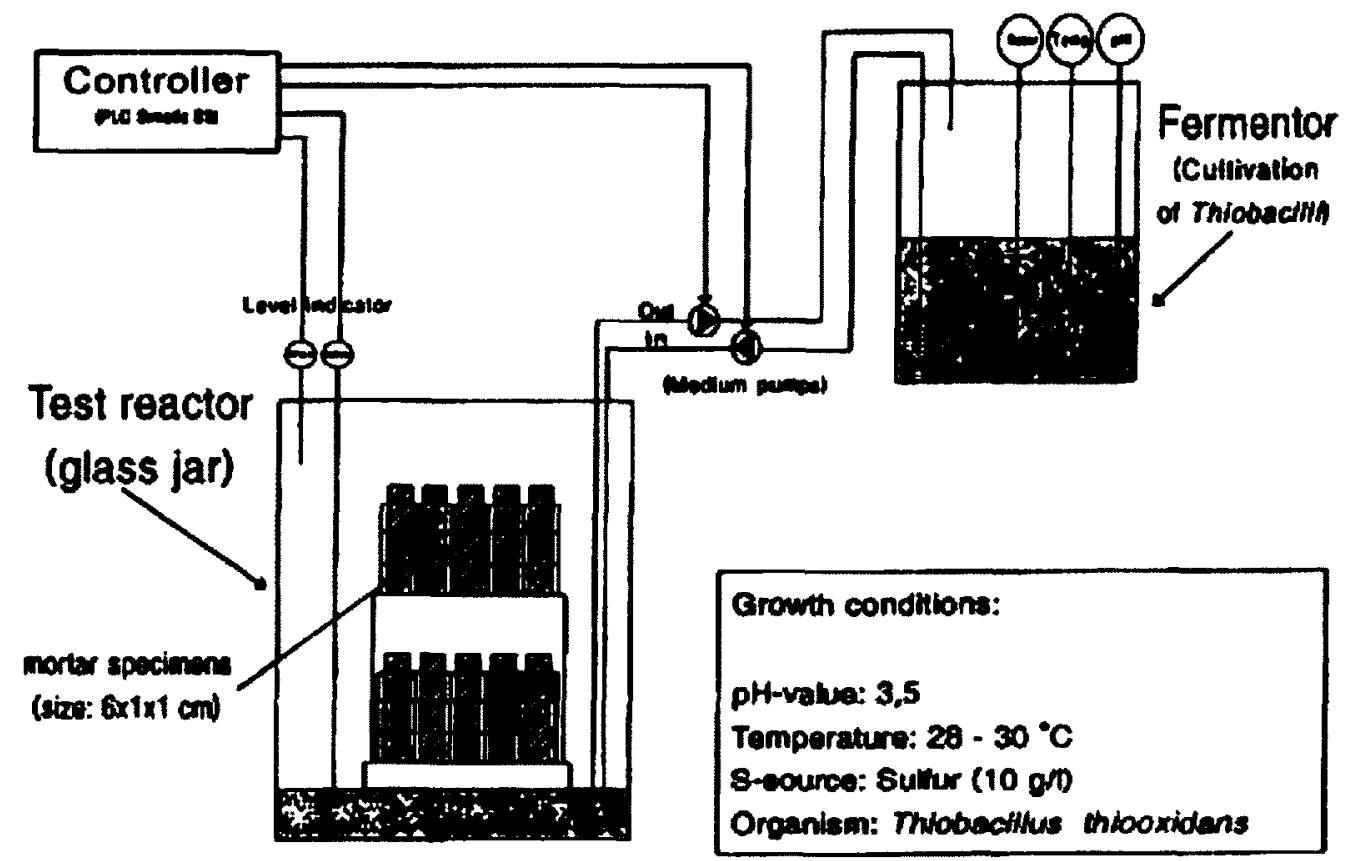

Figure 2.4: Experimental setup for MICD simulation by Hormann et al. (1997) (taken from Hormann et al., 1997).

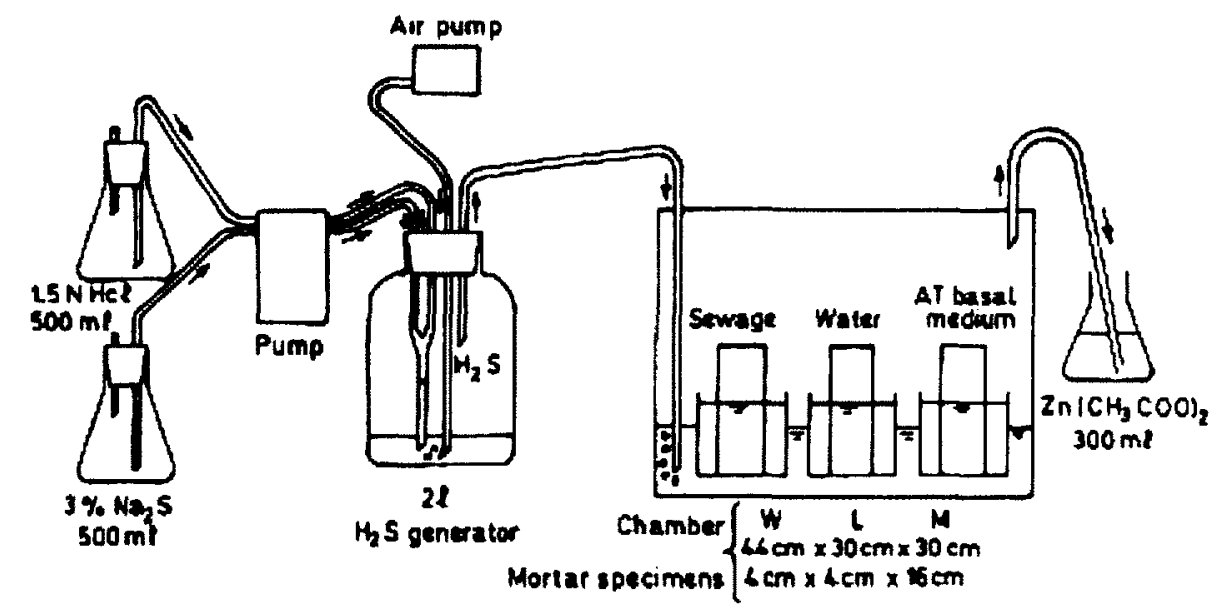

Figure 2.5: Lab-scale simulation system for MICD by Mori et al. (1992) (taken from Mori et al., 1992). 


\subsubsection{Biodeterioration prevention methods}

Keeping the material clean is the best way to prevent or control biocorrosion (Videla, 2002). Cleaning removes the bacterial biofilm and corrosive deposits on the surfaces. Increasing the fluid velocity or adding a dispersive agent causes the detachment of chemical deposits or bacteria resulting in the cleaning of the materials under deterioration. Different methods for the prevention and the control of biodeterioration have been suggested: chemical or antimicrobial coating, chemical addition, biocides treatment, and coating with beneficial biofilm (Shock and Bell, 2003; Videla, 2002). These methods prevent or inhibit sulphide production by inhibition of biological activity and prevention of anaerobic conditions (septic condition) or provide a protective layer that hinders the contact of the surface with the corrosive solution.

\subsubsection{Chemical or antimicrobial coating}

Chemical coating is a common approach to protect from any type of corrosion; therefore it could also be helpful for the mitigation of MICD. Coating is achieved through nontoxic products consisting of the following compounds: silicone, epoxy-resins, and fluorinated compounds (Videla and Herrera, 2005). Coating is a good method for the prevention of MICD; however any discontinuity (e.g. cracks and defects) in coating will make a preferential pathway for localized deterioration. Moreover, microbial activities of some microorganisms deteriorate the coating and utilize it as the nutrient resulting in the reduction of the coating protection properties (Zuo, 2007). The coating for concrete structures in the wastewater and water treatment should resist the permeation of $\mathrm{H}_{2} \mathrm{~S}$ and other wastewater gases and also sulphuric acid. In addition, it should not release the corrosive substances or be altered by bacterial attack (O’Dea, 2007). Shock and Bell 
(2003) incorporated an antimicrobial material as an admixture in concrete and also brushapplied it to the surface of concrete samples to investigate the MICD inhibition. They concluded that the test material was capable of $100 \%$ removal of thiobacillus thiooxidans from the concrete surface. Haile et al. $(2008,2009)$ mixed silver loaded zeolite in an epoxy resin and brush-applied the resin on concrete samples to evaluate the resistance to MICD and bacterial survival. Their hypothesis is that the antimicrobial characteristics of silver in the coating prevents or reduces the growth and proliferation of SOB on the concrete surface, resulting in the reduction of MICD. De Muynck et al. (2009) studied two types of antimicrobial admixtures (i.e., copper/silver zeolite or antimicrobial fiber) and four types of surface coatings (i.e., plyurea coating, epoxy coating, cementitious coating and silicate coating) regarding their effectiveness to prevent biogenic sulphuric acid deterioration by means of chemical and microbiological tests. They observed the best resistance to both chemical and microbiological tests in epoxy coating and the worst performance in the cementitious coatings. The addition of antimicrobial admixtures into the concrete was not very effective in preventing the deterioration.

\subsubsection{Use of admixtures and supplementary cementitious materials in concrete}

Another method of inhibiting the MCID is the use of concrete admixtures (e.g., polymers, antimicrobial chemicals) and supplmentary cementitious materials (e.g., silica fume, fly ash) (Cao et al., 1997; Vincke et al., 2002). The mechanism of protection is either by reducing the permeability of concerte or improving the antimicrobial properties of concrete to inhibit SOB attachment (Vincke et al., 2002; De Muynck et al., 2009). Addition of silica fume or fly ash not only reduces permeability and diffusivity of 
concrete, but also reduces the amount of free calcium hydroxide of concrete leading to less expansive reaction (Torri and Kawamura, 1994).

Polymer addition improves the durability of concrete to sulphuric acid by preventing the big crystal formation due to interaction of the cement hydrate with polymer particles (Beeldens et al., 2001). Vincke et al. (2002) evaluated the influence of four different types of polymer and silica fume addition on the resistance of concrete to microbilogical and chemical sulphuric acid attack. Among polymers, the addition of the styrene acrylic ester has shown a better performance in terms of the weight loss, $\mathrm{pH}$ reduction and calcium release. However, they did not observe any resistance improvement toward biologically produced sulphuric acid by addition of the acrylic polymer or silica fume. Torri and Kawamura (1993) studied the effect of fly ash and silica fume on resistance of concrete immersed in $2 \% \mathrm{H}_{2} \mathrm{SO}_{4}, 10 \% \mathrm{Na}_{2} \mathrm{SO}_{4}$ and $10 \% \mathrm{MgSO}_{4}$ solutions for 3 years. The results of their experiments showed that the effectiveness of fly ash and silica fume to sulphate solution varies depending on the type of cation involved in sulphate solution $\left(\mathrm{Mg}^{2+}\right.$ or $\left.\mathrm{Na}^{+}\right)$and the percentage of pozollan used. They also concluded that fly ash and silica fume could not prevent the more severe deterioration caused by sulphuric acid which results in the softenning of the mortar by dissolusion of calsium silicate hydrate.

\subsubsection{Biocide treatment}

The most common chemical method for controlling biofouling is biocide addition (Videla and Herrera, 2005). Biocides are oxidizing or non-oxidizing compounds capable of killing microorganisms or inhibition of their growth (Videla, 2002; Videla and Herrera, 2005). Prevention of biodeterioration with biocide addition is mainly based on avoiding or minimizing the development of corrosion causing biofilms (Guiamet and Gomez de 
Saravia, 2005). Biocides are inorganic oxidizing agents such as chlorine, ozone and bromine, or organic non-oxidizing agents such as isothiazolones, quarternary ammonium compounds, and aldehydes.

The efficiency of a biocide depends on the nature of microorganisms being treated and environmental conditions. The combination of oxidizing and non-oxidizing biocides or two non-oxidizing biocides may be used to increase the efficiency of the biocide treatment (Videla and Herrera, 2005). Non-oxidizing biocides are more effective to control bacteria, algae and fungi (Videla and Herrera, 2005). Oxidizing biocides are less persistent because of their dependence to $\mathrm{pH}$ of solution. Their negative effects include interaction with other chemicals used in the treatment which reduces their effectiveness, and also their potential for causing corrosion. Environmental concern encourages the replacement of conventional biocides, widely used in the past (e.g. chlorine), with more readily degradable antimicrobial chemicals that are more degradable and less toxic to the environment (Guiamet and Gomez de Saravia, 2005). An effective biocide generally has the following criteria: 1) high efficacy against a wide range of microorganisms, 2) capable of penetration and dispersion into microbial slime, 3) chemical and physical compatibility with other products (e.g. corrosion inhibitors) and the environment (e.g. pH effects), 4) safe storage and easy use, 5) appropriate biodegradability, 6) cost effectiveness (Guiamet and Gomez de Saravia, 2005).

\subsubsection{Nitrate or nitrite addition}

Eliminating sulphate from the water source or addition of more thermodynamically favourable compounds such as oxygen, nitrate or nitrite prevent anaerobic conditions and sulphate reduction. Hubert et al. (2005) and De Lomas et al. (2006) added both nitrate 
and nitrite to control the production of sulphide via microbial competition of thermodynamically favourable reactions. Nitrate can remove more oxidisable material than nitrite due to its higher oxidative characteristics (Little et al., 2007). In anaerobic reactors, nitrate or nitrite is preferentially reduced as an oxidizing agent and eliminates hydrogen sulphide production (Hubert et al., 2005). Nitrate or nitrite-reducing, sulphide oxidizing bacteria (NR-SOB) use nitrate or nitrite to reoxidize produced sulphide to elemental sulphur and sulphate (Hubert et al., 2005). Nitrite is also capable of hindering the reduction of sulphite to sulphide by assimilation of sulphite reductase enzyme. Hubert et al. (2005) assessed the effect of nitrate and nitrite addition on the corrosion inhibition in anaerobic bioreactors. Their results indicated that the introduction of $17.5 \mathrm{mM}$ of nitrate causes the sulphide concentration to drop to $0-1 \mathrm{mM}$ for the entire time of the experiment.

De Lomas et al. (2006) investigated the efficiency of nitrate addition to wastewater at plant-scale by dosing concentrated calcium nitrate (Nutriox) in the inlet location and analyzing the species in the bulk water before grit removal, at primary effluent leaving primary sedimentation and the final effluent discharge point. They observed a sharp decrease of sulphide, both in the air and in the bulk water, to a maximum reduction of $98.7 \%$ and $94.7 \%$, respectively. They attributed the reduction of sulphide concentration to the activity of nitrate-reducing, sulphide-oxidizing bacteria which are only able to oxidize sulphides in the presence of nitrate. They also reported that nitrate or nitrite addition did not remove the SRB; however, the produced $\mathrm{H}_{2} \mathrm{~S}$ by the SRB was also consumed by the production of NR-SOB which oxidized the produced $\mathrm{H}_{2} \mathrm{~S}$. De Lomas et al. (2006) reported the microorganisms involved in the reduction of $\mathrm{H}_{2} \mathrm{~S}$ as 
Thiomicrospira denitrificans, an epsilon-proteobacteria, and Thiobacillus denitrificans, a beta-proteobacteria. Results obtained in their experiments showed an increase in the nitrate and ammonium concentrations at the early stage of treatment; however, the added nitrate was completely consumed after the primary sedimentation tank.

\subsubsection{Efficiency of different inhibition methods}

Different methods, with both advantages and disadvantages, have been suggested for the mitigation of MICD. Coatings are subjected to abrasion resulting in cost increase due to the reapplication of coating. Biocide addition as a more common method of biofouling inhibition is very cost effective and simple to use (Videla and Herrera, 2005), but they are toxic and may also inhibit the growth of the beneficial microorganism for the treatment processes. Moreover, the persistent use of a single biocide may reduce its effectiveness in removing the corrosion causing bacteria and may develop the more resistant corrosion microorganism (Little et al., 2007). Microorganisms in the biofilm are more resistant to biocides because of their protection by EPS. Therefore, higher concentrations of biocides are required to inactivate the biofilm induced corrosion which increases the cost of operation.

Addition of electron acceptors such as nitrate/nitrite has been introduced as a means of MICD control. It is recognized that the efficiency of nitrate addition as a corrosion control relies on the amount of NR-SOB grown in the system which is related to the ratio of sulphide to nitrate (De Lomas et al., 2006). Since the injection of ex-situ grown microorganisms into the existing water solution is difficult (Little et al., 2007), the efficiency of this method in the solution with higher sulphide to nitrate ratio decreases. 
Due to the increase of sludge production, the cost associated with nitrate or nitrite addition is high.

MIC inhibition using beneficial biofilm has been extensively discussed; however, further investigation has to be performed for these strategies to be successfully implemented in the field. The interaction between biofilm and metal is complicated since the same organisms and mechanisms that cause MIC can also inhibit corrosion. Little et al. (2007) cited work by Pedersen et al. $(1988,1989)$ in which Pseudomonas sp. S9 and Serratia marcescens EF 190 increased the corrosion of iron and nickel, while the same bacterial species provided a protective layer on carbon steel. The environmental friendly strategy of using biofilm as a protective barrier or as means of secreting antimicrobial substances to deactivate the deterioration-causing bacteria (e.g., SOB) to inhibit MICD has not been studied so far. There seems to be a potential of using this strategy to control or inhibit MICD, since the use of biofilm for MIC inhibition was found to be rather successful. Moreover, the interaction between biofilm and concrete is not as sophisticated as the interaction of biofilm and metals because of the lack of electrochemical processes between the two.

\subsection{SUlPhate ATtACK: MeChanisM ANd DIfFERENCES}

Due to the complexity of simulation of accelerated biogenic sulphuric acid attack, extensive studies performed on assessing the resistance of a concrete design specification to biogenic sulphuric acid attack usually consider simulating the deterioration with either sulphate attack or sulphuric acid attack (Attiogbe and Rizkalla, 1988; O'Connell et al., 2010). Therefore, it is important to review the current state of research in sulphate and 
sulphuric acid attack of concrete and how they relate to biogenic sulphuric acid attack considering the severe environmental conditions that exists in wastewater infrastructure.

\subsubsection{Forms of sulphate attack}

Sulphate attack is defined as the chemical reaction between any form of sulphate ions and constituents of cement pastes which causes expansion, chemical degradation, and loss of cement paste adhesion leading to consequent cracking, spalling or delamination of concrete (Mehta, 2000; Skalny et al., 2002). Sulphate attack mechanisms are divided into two mechanisms: formation of gypsum and formation of ettrengite (ACI, 2008). These two mechanisms cause expansion, softening of concrete, progressive loss of strength and loss of mass of concrete.

Several studies on sulphate attack of concrete showed that deterioration can be as a result of chemical or physical attacks, and the source of the sulphates can be external or internal. The chemical sulphate attack is considered as the chemical reaction of cement constituents with the sulphate anion, $\mathrm{SO}_{4}{ }^{2-}$. The characteristic of chemical sulphate attack is the formation of ettrengite and gypsum (Mehta, 2000). Physical attack involves recrystallization of different salts penetrated or present inside the concrete pores which results in pressure increase due to the expansion of crystals (Mehta, 2000). For instance, the prevalent form of physical attack is the transformation of sodium sulphate anhydrate $\left(\mathrm{Na}_{2} \mathrm{SO}_{4} \mathrm{H}_{2} \mathrm{O}\right)$ into sodium sulphate decahydrate $\left(\mathrm{Na}_{2} \mathrm{SO}_{4} \cdot 10 \mathrm{H}_{2} \mathrm{O}\right)$ which accompanies significant volume expansion. In physical sulphate attack, the microstructure of concrete, such as porosity, plays an important role in delaying the attack. 
External sulphate attack is caused due to an external sulphate source such as groundwater, soil, wastewater, or from the atmosphere whereas for internal sulphate attack the source of sulphate is inside the concrete (e.g., from cement, supplementary material such as fly ash or slag). The external sulphate attack initiates at the surface of the concrete and moves gradually inwards by migration of the sulphate ions into the concrete (Attigobe and Rizkall, 1988). Hence the rate of this attack is dependent on the porosity of concrete and its permeability to the liquid (Gospodinova and Kazandjiev, 1999).

\subsubsection{Mechanism of sulphate attack on concrete microstructure}

Some or all of the chemical or physical processes including adsorption-desorption, dissolution of ions, precipitation of coloides and crystallization are the invisible processes that may be involved in the severe damage of concrete under sulphate attack. Dissolution or removal of calcium hydroxide from the cement phase (decalcification) is one of the first manifestations of sulphate attack. Leaching of the calcium and hydroxyl ions is the consequence of such dissolution. As the result of the calcium leaching, a decrease in alkalinity of the paste and further reaction of released $\mathrm{Ca}^{2+}$ ion with sulphate ions to form expansive products such as gypsum or ettrengite would be possible. Decomposition of the previously formed hydration products such as calcium silicate hydrate (C-S-H) and calcium hydroxide leads to loss of cementing properties (paste cohesion, paste to aggregate bond and durability). According to Taylor and Gollop (1997), expansion and cracking are caused by ettrengite formation while the disintegration, loss of adhesion and softening of paste is caused by destruction of C-S-H. The authors also emphasized that the latter phenomena appears to be as important as the expansion and cracking. 
Gypsum formation is another manifestation of sulphate attack that is associated with a limited increase in volume and is of concern at sulphate concentrations above $3000 \mathrm{ppm}$ (Skalny et al., 2002). Wang (1994) studied the deterioration of hardened cement paste with varying water to cement $(\mathrm{w} / \mathrm{c})$ ratios under $5 \%$ sodium sulphate solution of $\mathrm{pH}=6$. According to his finding, gypsum formation is the primary cause of sulphate attack because ettrengite is not stable when alkalinity of the paste reduces $\mathrm{pH}$ to below $\mathrm{pH}=10$ 11. At $\mathrm{pH}$ values lower than 10-11, ettrengite decomposes to gypsum (Neville, 2004; Skalny et al., 2002). There is a controversial discussion through the literature on whether gypsum formation deteriorates the cement paste through expansion or softening (Wang, 1994). Cohen and Mather (1991) suggested that crystallization of gypsum from solution is not expansive.

Ettrengite formation is a more prevalent mechanism of deterioration mostly because it can form at relatively low sulphate concentrations. In chemical sulphate attack, the most important expansion reaction is ettrengite formation due to the reaction of monosulphate with gypsum as follow:

$\underbrace{\mathrm{C}_{4} \mathrm{~A} \overline{\mathrm{S}} \mathrm{H}_{12}}_{\text {Monosulphate }}+\underbrace{2 \mathrm{C} \overline{\mathrm{S}} \mathrm{H}_{2}}_{\text {Gypsum }}+16 \underbrace{\mathrm{H}}_{\text {Water }} \Rightarrow \underbrace{\mathrm{C}_{6} \mathrm{~A} \overline{\mathrm{S}}_{3} \mathrm{H}_{32}}_{\text {Ettringite }}$

where $\mathrm{C}$ is $\mathrm{CaO}, \mathrm{A}$ is $\mathrm{Al}_{2} \mathrm{O}_{3}, \overline{\mathrm{S}}$ is $\mathrm{SO}_{3}$, and $\mathrm{H}$ is $\mathrm{H}_{2} \mathrm{O}$. It is also important to know that sufficiently high amounts of calcium hydroxide should be present in the liquid phase to bring about the topochemical reaction resulting in an oriented growth of ettrengite crystals to cause expansion (Alunno Rossettia et al., 1982; Min and Mingshu, 1994). At low $\mathrm{Ca}(\mathrm{OH})_{2}$ concentration, aluminate, which is required for ettrengite formation, can migrate more freely and ettrengite precipitates out of the solution without causing any 
expansive stresses. The concentration of calcium hydroxide present in the paste also affects the morphology and size of ettrengite crystals. At very low concentrations or in the absence of $\mathrm{Ca}(\mathrm{OH})_{2}$, usually larger ettrengite crystals of $6 \mu \mathrm{m}$ are formed; however, at high $\mathrm{Ca}(\mathrm{OH})_{2}$ concentrations, small collodial particles of only $1 \mu \mathrm{m}$ size are formed (Mehta, 1973).

Formation of hydrous silica (silica gel) in the presence of magnesium ions and thaumasite formation at the low temperatures of $5-10^{\circ} \mathrm{C}$ are other indications of sulphate attack.

\subsubsection{Source of sulphate}

Accelerated chemical tests are widely used to assess the mechanism of sulphate attack in laboratory settings. Since the low concentration of sulphate present in groundwater is not sufficient to deteriorate concrete in a reasonable time, a high sulphate concentration is used for accelerated sulphate attack tests. The actual behaviour of sulphate attack is not predictable under accelerated tests by increasing the sulphate concentration (Cohen and Mather, 1991). The increase in sulphate concentration increases the intensity of sulphate attack and changes the type of deterioration. For example, it is well known that ettrengite formation leads to expansion and microcracking in an actual sulphate attack. However, it was proposed by Mehta (1983) that not all types of ettrengite are expansive, and certain morphological characteristics depending on the sulphate concentration and other environmental conditions are necessary to induce expansive ettrengite formation. Therefore, researchers concluded that there could be other operational mechanisms other than expansion that impose the deterioration (Mehta, 2000; Taylor and Gollop, 1997). 
The accelerated chemical tests to investigate resistance of materials against sulphate attack have been performed mainly using sulphate solution such as magnesium, sodium or calcium sulphate, and sulphuric acid. The principal reaction of hydrated cement paste with each of these solutions and the mechanism of deterioration are slightly different. However, the test results can be used to interpret the overall impression of sulphate resistance of cement.

\subsubsection{Reaction with sulphate solution}

In the test with sulphate solution, test specimens are usually submerged in a $5-10 \%$ concentration of sodium or magnesium sulphate and the $\mathrm{pH}$ of the medium is either replenished or controlled automatically to stay at a constant level (Monteny et al., 2000). Cohen and Mather (1991) categorized the deterioration mechanism of sodium sulphate solution based on the concentration of sodium sulphate. They suggested that at low $\mathrm{SO}_{3}$ concentration (i.e., $\mathrm{SO}_{3}$ concentration of less than $830 \mathrm{mg} / \mathrm{L}$ ) the deterioration mechanism is by ettrengite formation and at high $\mathrm{SO}_{3}$ concentration the damage mechanism is dominated by gypsum formation.

Sulphate attack is more damaging in the presence of magnesium sulphate rather than calcium or sodium sulphate because the magnesium itself is leading some deleterious reaction such as replacement of calcium with magnesium in C-S-H (Skalny et al., 2002). Monteny et al. (2000) reported that the sodium sulphate solution only reacts with the $\mathrm{Ca}(\mathrm{OH})_{2}$ or tricalcium aluminate $\left(\mathrm{C}_{3} \mathrm{~A}\right)$ of the cement; however, the magnesium sulphate attacks all cement minerals including $\mathrm{C}-\mathrm{S}-\mathrm{H}$ and causes complete destruction of $\mathrm{C}-\mathrm{S}-\mathrm{H}$ with silica gel formation. The formation of magnesium hydroxide (brucite) from the reaction of $\mathrm{C}-\mathrm{S}-\mathrm{H}$ with magnesium sulphate and formation of magnesium silicate hydrate 
from the reaction of brucite with silica gel are other indicators that are only present in magnesium-sulphate attack (Gollop and Taylor, 1992, 1995; Cohen and Mather, 1991). However, only a minor amount of ettrengite and monosulphate is formed in the attack with $\mathrm{Mg}\left(\mathrm{SO}_{4}\right)$ in comparison with the $\mathrm{Na}\left(\mathrm{SO}_{4}\right)_{2}$ solution (Gollop and Taylor, 1992; Bonen and Cohen, 1992).

\subsubsection{Reaction with sulphuric acid solution}

The test methodology in case of using sulphuric acid as the deteriorating solution is similar to sulphate solution tests in which the specimens are submerged in the sulphuric acid solution of $1-5 \%$ and the solution is replenished at regular time intervals. Durnning and Hicks (1991) studied the effectiveness of silica fume addition on concrete resistance to sulphuric acid using $1 \%$ and $5 \%$ sulphuric acid solution. The results of their study showed that in more concentrated sulphuric acid, the resistance increase due to the addition of silica fume (as measured by the number of acid immersion cycles to failure of specimen) was less. They attributed this difference to the aggressive nature of the solution which is high enough to start attacking the C-S-H before even destroying the calcium hydroxide; hence, the reduction in calcium hydroxide due to addition of silica fume was not effective at higher acid concentrations.

Unlike sulphate attack with sulphate salt, the chemical reaction of cement paste with sulphuric acid is a combined acid attack and sulphate attack. The sulphuric acid attack in which the hydrogen ion causes dissolution of cement constituents in addition to the sulphate ion participation is a more severe attack compared to sulphate attack (Torii and Kawamura, 1993). During the sulphuric acid attack, as the $\mathrm{pH}$ of the concrete goes lower than 12.6 , the calcium hydroxide is the first constituent of the cement starting dissolution. 
Therefore, gypsum formation is the initial step of sulphuric acid reaction which will be ultimately converted to amorphous hydrous silica (silica gel):

$$
\begin{aligned}
& \mathrm{Ca}(\mathrm{OH})_{2}+\mathrm{H}_{2} \mathrm{SO}_{4} \rightarrow \underbrace{\mathrm{CaSO}_{4} \cdot 2 \mathrm{H}_{2} \mathrm{O}}_{\text {gypsum }} \\
& x{\mathrm{Cao} . \mathrm{SiO}_{2} . \mathrm{aq}}+x \mathrm{H}_{2} \mathrm{O}+x \mathrm{H}_{2} \mathrm{SO}_{4} \rightarrow x \underbrace{\mathrm{CaSO}_{4} \cdot 2 \mathrm{H}_{2} \mathrm{O}}_{\text {gypsum }}+x \underbrace{\mathrm{SiO}_{2} \cdot \mathrm{aq}}_{\text {silica gel }}
\end{aligned}
$$

After complete dissolution of $\mathrm{Ca}(\mathrm{OH})_{2}$ and at lower $\mathrm{pH}$, cement hydrates such as calcium silicate, calcium aluminate and calcium-alumino-ferrite hydrate decompose by losing their calcium and converting to the amorphous hydrogel as silica, alumina and ferric hydrogel (Allahverdi and Skvara, 2000; Zivica and Bajza, 2000). A limited amount of ettrengite may be formed in deeper sections of the concrete where the $\mathrm{pH}$ remains high enough (Skalny et al., 2002).

\subsubsection{Sulphate resistant concrete}

Research studies and field experiences have shown that the sulphate resistance of concrete increases by lowering the $\mathrm{C}_{3} \mathrm{~A}$ content of the cement known as type $\mathrm{V}$ cement in which the $\mathrm{C}_{3} \mathrm{~A}$ is replaced by alumina-poor, ferric-rich $\mathrm{C}_{4} \mathrm{AF}$ (Neville, 2004; Skalny et al., 2002). The hypothesis behind using the low $\mathrm{C}_{3} \mathrm{~A}$ content cement is reducing the aluminum source as $\mathrm{C}_{3} \mathrm{~A}$ to limit the ettrengite formation and consequent expansion. Another requirement for achieving a good sulphate resistant concrete is its low permeability which is achieved by good compaction, effective curing and proper mix ingredients. A low permeability concrete can be achieved by lowering the water-cement (w/c) ratio. To see the possible interaction of type of cement and w/c ratio, Stark (2002) investigated the influence of cement composition at different $w / c$ ratio in an alternate 
wetting and drying or a continuous immersion in sodium sulphate. He reported that at $\mathrm{w} / \mathrm{c}=0.4$, the concrete made with portland cement showed worse performance as assessed by visual appearance than the type $\mathrm{V}$ cement. The $\mathrm{w} / \mathrm{c}$ ratio was a significant factor in evaluating the performance of different cement types. As Stark (2002) reported, at w/c ratio of 0.65 , all cement types led to a poor performance. Interestingly, he observed less deterioration on the concrete with continuous immersion in sulphate solution regardless of its cement properties or w/c ratio. Therefore, he attributed the severity of sulphate attack mechanism in the case of wetting and drying to the initiation of cyclic sodium sulphate recrystallization (physical attack).

\subsubsection{Biogenic sulphuric acid attack}

Most of the available research on the resistance of material to biogenic sulphuric acid attack is using chemical testing to analyze biological deterioration in a wastewater environment. The chemical tests (i.e., sulphuric acid or sulphate solution) alone do not consider the bacterial aspects of the deterioration and may lead to irrelevant conclusions (Monteny at al., 2000; Sand et al., 1994; O'Connell et al., 2010). One of the controversial topics has been the classification of the calcium aluminate cement as a poorly resistant material in pure chemical acid attack. This contradicts what was reported by Skalny et al. (2002) and Sand et al. (1994) that calcium aluminate cement is more stable in a sewage environment than the portland cement as its $\mathrm{pH}$ bearing capacity and neutralization capacity is higher than portland cement. Another note is the use of silica fume as an additive to concrete to improve the resistance of concrete to chemical attack (Cao et al., 1997) which is not the case in biogenic sulphuric acid attack (Vincke et al., 2002). The process of biogenic acid attack depends on the rate of acid produced by bacteria, and the 
density, or permeability of the material. Debates also exist on the different mechanisms of chemical and biological sulphuric acid attack and that the resistance to the former does not result in resistance to the latter (Vincke et al. 2002, O'Connell et al. 2010, De Belie et al. 2004). Vincke et al. (2002) claimed that the source of this difference is the colonization of the bacteria in deeper and smaller pores resulting in sulphuric acid production in the deeper microenvironment of the crevices in concrete. In a contradicting statement, Yamanaka et al. (2001) who observed less concentration of ATP in the deeper section of deteriorated concrete suspected that it is the sulphuric acid itself that penetrates deeper into the concrete. 


\section{CHAPTER 3. MATERIALS AND METHODS}

\subsection{INTRODUCTION}

The experimental study of the effectiveness of using biofilm as a prevention method for microbiologically influenced concrete deterioration in sewer and treatment plant structures has been divided into four main phases: 1) biofilm formation on mortar; 2) chemical sulphuric acid deterioration; 3) biogenic sulphuric acid deterioration; and 4) high temperature biogenic sulphuric acid deterioration. In this chapter, first the general experimental setup and procedures used to accomplish each phase of the study are described; then, a detailed description of the methodology and techniques that have been employed during all the study phases is given.

\subsection{SAMple Preparation}

Biofilm formation and effect of different deterioration mechanisms have been investigated on the surfaces of mortar specimens. Two types of mortar specimens were used in the investigation: $1-\mathrm{cm}$-thick mortar disks with $10 \mathrm{~cm}$ diameter, and mortar cubes with $1 \mathrm{~cm}$ dimension. Mortar disks were cut out from mortar cylinders with $10 \mathrm{~cm}$ diameter and $15 \mathrm{~cm}$ height; Mortar cubes were cut out of the mortar disks. The mortar mixture of the cylinders had a w/c ratio of 0.45 and was composed of $540 \mathrm{~g}$ portland 
cement and $1360 \mathrm{~g}$ sand. After mixing, the mortar cylinders were cast in cylindrical moulds and were kept in a curing room with a relative humidity of $95-100 \%$ at $30-35^{\circ} \mathrm{C}$ for 24 hours. After de-moulding, the cylinders were placed in a water bath at $35^{\circ} \mathrm{C}$ for further curing of 28 days before cutting them into $1-\mathrm{cm}$-thick disks and cubes.

The mortar disks were mainly used for chemical analysis (e.g., $\mathrm{pH}$, calcium, and sulphate concentration measurement), and XRD analysis. Mortar cubes were used mainly for microscopic analysis (e.g., CLSM, SEM, and EDS) and biomass concentration measurements (e.g., membrane filtration and volatile suspended solid measurement).

The leaching of $\mathrm{Ca}(\mathrm{OH})_{2}$ from the cement paste when it is placed in water is a common phenomenon due to the high solubility of $\mathrm{Ca}(\mathrm{OH})_{2}$ in water, particularly shortly after the setting of the cement paste (Skalny et al., 2002). The leaching of $\mathrm{Ca}(\mathrm{OH})_{2}$ may be considered as an obstacle for the growth of bacteria. In order to reduce the excessive leaching during biofilm formation, the cut mortar specimens (i.e., mortar disks and cubes) were first immersed in DI water for at least 7 days with daily water replenishment. This process may have also helped to reduce slightly the high surface $\mathrm{pH}$ of the concrete which inhibits biofilm formation (Sand, 1997).

\subsection{Phase 1: BIofilm Formation On MORTAR SPECIMENS}

\subsubsection{Bacterial strain and growth medium}

A tetracycline-resistant enteric bacterium of Escheria coli DH5 $\alpha$ (pKMY319) which is a facultative aerobic bacterium was used based on its ability to form biofilm (Jayaraman et al., 1997 a, b). The strain of E.coli DH5 $\alpha$ (pKMY319) was obtained from Dr. T. K. Wood (Jayaraman et al. $1997 \mathrm{a}, \mathrm{b})$. The bacteria was streaked from the agar plate into 100 
$\mathrm{mL}$ of Luria-Bertani (LB) broth (made of $10 \mathrm{~g} / \mathrm{L}$ tryptone, $5 \mathrm{~g} / \mathrm{L}$ yeast extract and $10 \mathrm{~g} / \mathrm{L}$ $\mathrm{NaCl}$ ) and grown overnight at $37^{\circ} \mathrm{C}$. One $\mathrm{mL}$ of overnight grown bacteria was used to prepare bacterial stock solution by adding $10 \% \mathrm{v} / \mathrm{v}$ glycerol and kept frozen at $-25^{\circ} \mathrm{C}$ for later use. E.coli $\mathrm{DH} 5 \alpha$ from the frozen stock was then grown in $100 \mathrm{~mL}$ of LB broth supplemented with $25 \mu \mathrm{g} / \mathrm{mL}$ of tetracycline. The bacteria were grown over night at $37^{\circ}$ C with no mixing. A $0.1 \%$ inoculum from the overnight grown sample was used as the seed for biofilm growth. The preparation of bacterial stock solutions and inoculums were done under a biological safety cabinet (1300 Series A2, Thermo Scientific) to eliminate contamination.

\subsubsection{Biofilm formation}

\subsubsection{Biofilm growth on mortar disk}

A continuous reactor was designed and built for growing biofilm on mortar disks. In the setup, a mortar disk (with $10 \mathrm{~cm}$ diameter) was placed at the bottom of the reactor, which was formed with a glass cylinder $(6.5 \mathrm{~cm}$ inside diameter, $0.6 \mathrm{~cm}$ thick) covered at both ends with two $1-\mathrm{cm}$-thick teflon plates $(12 \mathrm{~cm} * 12 \mathrm{~cm})$ as illustrated in Figure 3.1. The teflon plates were tightened by screws to create a closed container to prevent leakages and contamination from air.

The biofilm formation set-up as illustrated in Figure 3.2 consists of the biofilm reactor and a mixing reservoir. The mixing reservoir was used to add the required nutrients for bacterial growth and to reduce disturbance during medium replacement inside the reactor. The reactor was filled with $150 \mathrm{~mL}$ of $\mathrm{LB}$ broth supplemented with $25 \mu \mathrm{g} / \mathrm{mL}$ tetracycline to prevent contamination from other bacteria. A $0.1 \% \mathrm{v} / \mathrm{v}$ of the E.coli inoculum from the overnight grown culture was injected into the medium. 


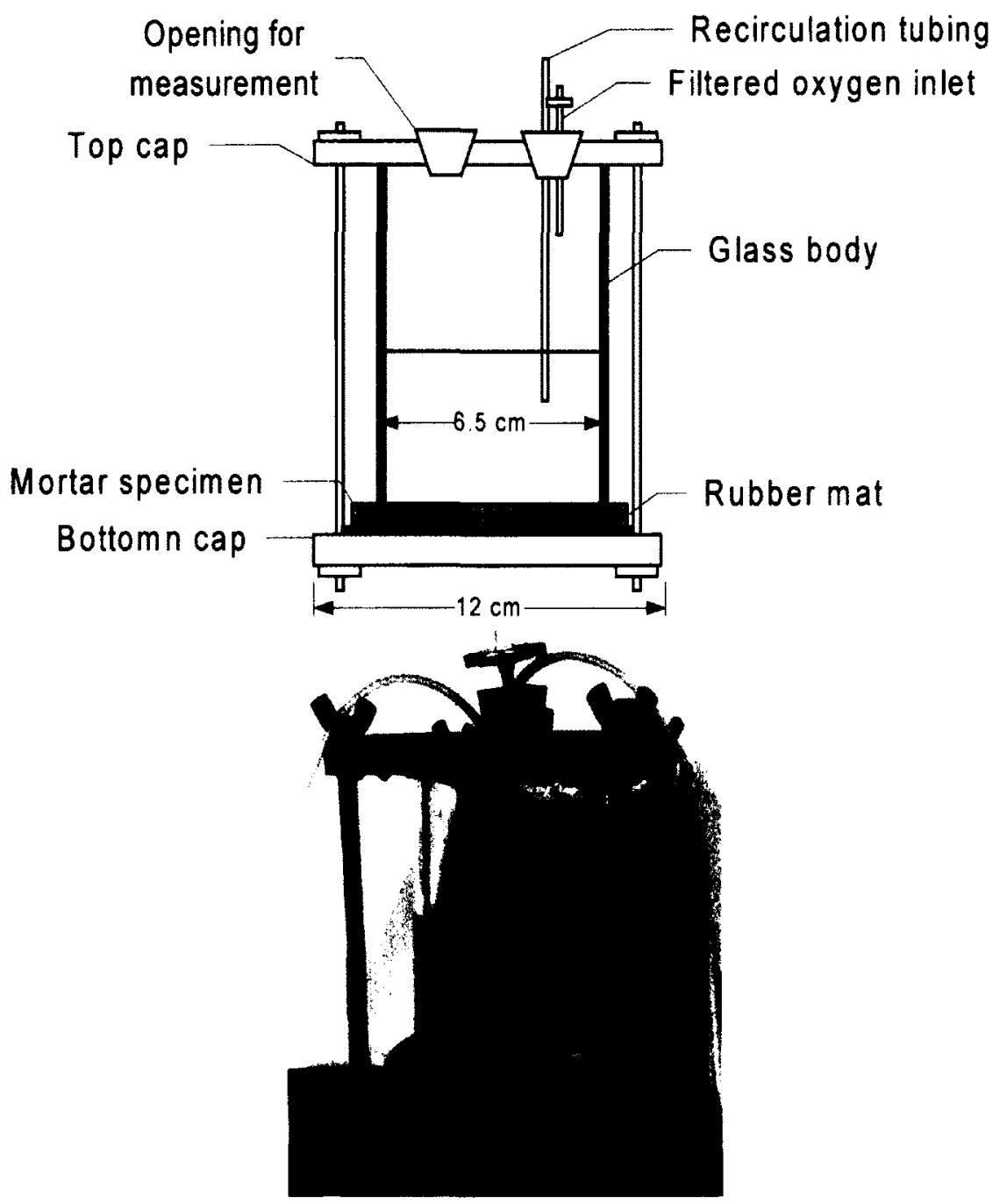

Figure 3.1: Schematic and image of the reactor used for biofilm growth on mortar disks.

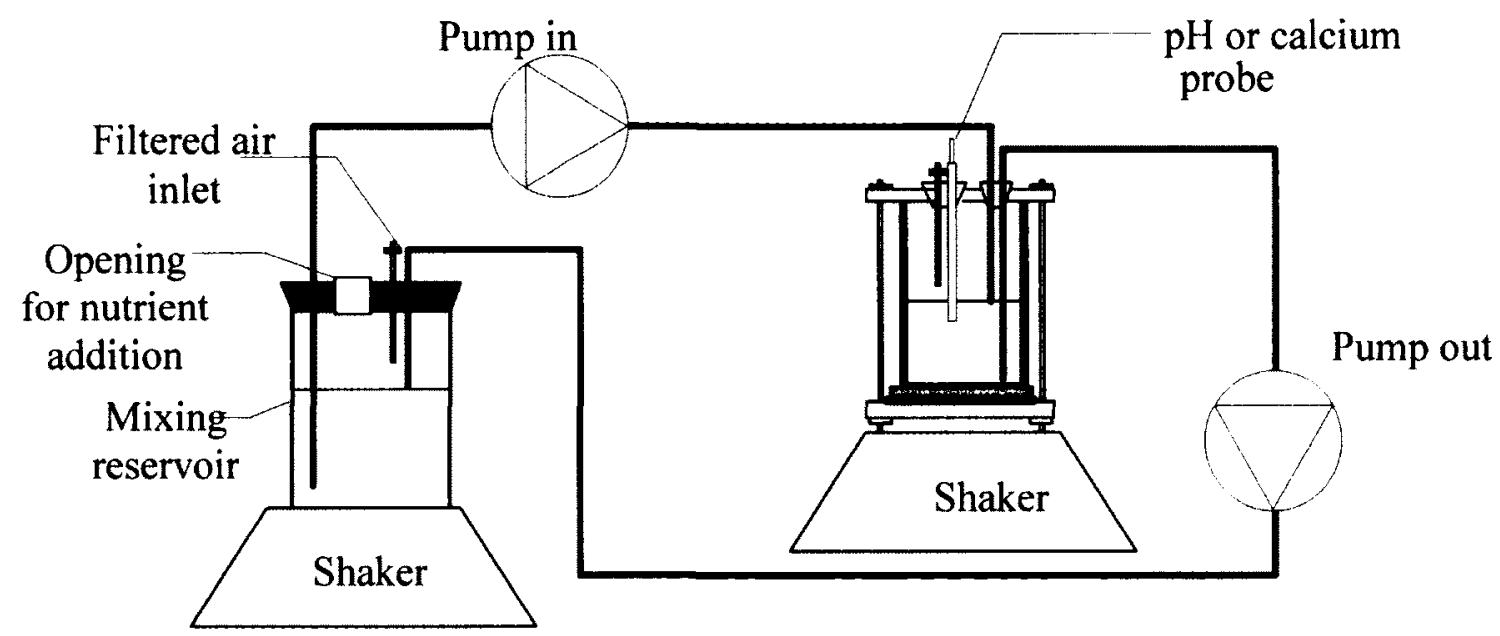

Figure 3.2: Schematic of biofilm growth setup. 
The mixing reservoir was also filled with $150 \mathrm{ml}$ of fresh LB supplemented with tetracycline. Bacteria were allowed to grow for $12 \mathrm{~h}$ in batch mode inside the biofilm reactor, then the growth medium plus the bacteria were circulated at a flow rate of 12 $\mathrm{mL} / \mathrm{h}$ according to Jayaraman et al. (1997 a) (Figure 3.2). A peristaltic pump was used for recirculation of the medium plus the inoculum inside the reactor. In order not to change the total volume of media inside the reactors significantly, LB broth was prepared in 4times concentrated solution and used as the nutrients for the biofilm growth. From the third day of growth, $5 \mathrm{~mL}$ of 4-times concentrated LB broth was added to the mixing reservoir on a daily basis as the nutrient source for biofilm growth. Both mixing reservoir and reactor were placed on a rotary shaker at $60 \mathrm{rpm}$ to provide enough oxygen for bacterial assimilation. The biofilm growth took 8 days under this condition. During this experiment, the calcium concentration and $\mathrm{pH}$ of the solution were monitored. The optical density of the bacteria in the solution was monitored using a UV visible spectrophotometer (CARY-100Bio, Agilent Technologies) at wavelength of $600 \mathrm{~nm}$. For optical density measurement, duplicate samples with three readings for each sample were used.

\subsubsection{Biofilm growth on mortar cubes}

A similar setup to the one illustrated in Figure 3.2 was used for the biofilm growth on mortar cubes. In this setup, a $250 \mathrm{ml}$ Erlenmeyer flask was used as the biofilm reactor. The mortar cubes were placed inside the flask and immersed in $150 \mathrm{~mL}$ of $\mathrm{LB}$ broth supplemented with tetracycline. The ratio of mortar specimen surface area to solution volume was kept approximately the same in both reactors (the reactor for biofilm growth on mortar disks and the reactor for biofilm growth on mortar cubes) to keep the growth 
conditions, $\mathrm{pH}$, and calcium concentrations similar; hence, 8 cubes were placed in each flask. Cubes were taken out on days 3,5 and 8 to perform ATP assay and biomass measurement using membrane filtration. After 8 days of biofilm growth, the cubes were used for additional analyses including FISH, energy-dispersive X-ray spectroscopy (EDS), SEM, confocal laser scanning microscopy (CLSM), and volatile suspended solid (VSS) measurement.

\subsection{Phase 2: Chemical Sulphuric Acid Deterioration}

\subsubsection{Chemical acidification on mortar disk}

The biofilm reactor shown in Figure 3.2 was employed for the acidification of mortar disks. To acidify the mortar specimens, the reactor was filled with acidified LB broth with the $\mathrm{pH}$ adjusted to $6,5,4$ and 3 . The acidified LB broth with the adjusted $\mathrm{pH}$ was prepared by adding $1 \mathrm{M}$ sulphuric acid. The acidification process consists of four fourday cycles of immersion in acidified solution of fresh $\mathrm{LB}$ at $\mathrm{pH} 6,5,4$ and 3. The acidification started with four-day immersion in $\mathrm{pH} 6$ followed by incremental reduction of $\mathrm{pH}$ in each cycle to finish with four-day immersion in $\mathrm{pH} 3$. In order to change the medium with a lower $\mathrm{pH}$ medium, the entire medium inside the mortar container was moved to the mixing reservoir and the medium inside the mixing reservoir was replaced with the fresh acidified LB broth. The fresh LB with desired $\mathrm{pH}$ was then pumped into the reactor containing the mortar specimens. Due to the release of hydroxide ions from the mortar specimens, the $\mathrm{pH}$ of the solution was increased slightly. Hence on the second day of each cycle, the $\mathrm{pH}$ of the medium was controlled by reducing the $\mathrm{pH}$ to the initial $\mathrm{pH}$ of the cycle by adding $1 \mathrm{M}$ sulphuric acid solution. 
This test was conducted with four replicates of mortar disk specimens; two of them covered with biofilm and the other two without biofilm as controls. During the chemical acidification experiments, the calcium concentration and $\mathrm{pH}$ of the solution inside the reactor were monitored. At the end of the experiment, the disks were used for XRD analysis.

\subsubsection{Chemical acidification on mortar cubes}

The same procedure, as described in section 3.4.1, was used to investigate the effect of chemical acidification on mortar cubes inside the flask. The mortar cubes were used for EDS, SEM, CLSM, and VSS measurements.

\subsection{Phase 3: Biogenic Sulphuric ACid Deterioration}

\subsubsection{Bacterial strains and their growth media}

Pure cultures of two types of sulphur oxidizers, Thiobacillus thiooxidans and Thiobacillus neapolitanus, were purchased from American type culture collection (ATCC). T.thiooxidans (ATCC 19703) is an acidophilic sulphur oxidizer that reduces $\mathrm{pH}$ from 4-5 to 1-2. T.thiooxidans was cultivated in the medium suggested by Starkey (1925)

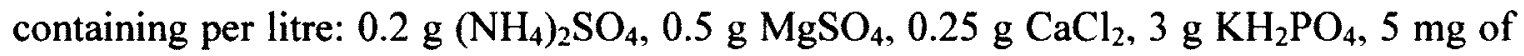
$\mathrm{FeSO}_{4}$ and 10 grams of sublimed sulphur. The sublimed sulphur powder was first autoclaved three times for thirty minutes on three consecutive days, then $0.22 \mu \mathrm{m}$ filtersterilized solution medium was added to the autoclaved sulphur powder. A $-25^{\circ} \mathrm{C}$ glycerol stock strain of T.thiooxidans was grown in $100 \mathrm{~mL}$ of medium under static conditions at room temperature. $5 \% \mathrm{v} / \mathrm{v}$ of the pure culture of T.thiooxidans at its 
exponential growth rate (i.e., after two weeks of growth according to ATCC) was used as seed for the biogenic deterioration experiment.

T.neapolitanus (ATCC 23641) is a neutrophilic sulphur oxidizer that grows well in the $\mathrm{pH}$ of 6-7 and can reduce the $\mathrm{pH}$ to around 4. For the growth and revival of T.neapolitanus the medium of Vishniac \& Santer (1957) containing per litre: $10 \mathrm{~g}$ $\mathrm{Na}_{2} \mathrm{~S}_{2} \mathrm{O}_{3}, 1.2 \mathrm{~g} \mathrm{Na}_{2} \mathrm{HPO}_{4}, 1.8 \mathrm{~g} \mathrm{KH}_{2} \mathrm{PO}, 0.1 \mathrm{~g} \mathrm{MgSO}_{4}-7 \mathrm{H}_{2} \mathrm{O}, 0.1 \mathrm{~g}\left(\mathrm{NH}_{4}\right)_{2} \mathrm{SO}_{4}, 0.03 \mathrm{~g}$ $\mathrm{CaCl} 2,0.02 \mathrm{~g} \mathrm{FeCl}_{3}, 0.02 \mathrm{~g} \mathrm{MnSO}_{4}$ was used at an initial $\mathrm{pH}$ of 6.6 and $28^{\circ} \mathrm{C}$ temperature. The medium was sterilized by autoclaving for 30 minutes at $121^{\circ} \mathrm{C} . \mathrm{A}-25^{\circ}$ C glycerol stock strain of T.N was grown in $100 \mathrm{~mL}$ of medium at static condition and temperature of $30^{\circ}$ C. $5 \% \mathrm{v} / \mathrm{v}$ of the pure culture of T.neapolitanus at its exponential growth rate (i.e., after 4 days of growth) was used as seed for the biogenic deterioration experiment.

\subsubsection{Selection of modified broth used for the growth of SOB strains}

A modified broth that promotes the growth of both SOB bacteria and includes the wastewater nutrients was used for the biogenic deterioration experiments. In order to simulate a solely biogenic acidification, and to distinguish the deterioration caused by biologically produced acid from deterioration by exposure to the acidic medium, the modified broth was made with a neutral $\mathrm{pH}$. Two different recipes used for the modified broth are as follows:

Modified broth 1 (MB1): $5 \mathrm{~g} / \mathrm{L} \mathrm{Na}_{2} \mathrm{~S}_{2} \mathrm{O}_{3} .5 \mathrm{H}_{2} \mathrm{O}, 3 \mathrm{~g} / \mathrm{L} \mathrm{KH}_{2} \mathrm{PO}_{4}, 3 \mathrm{~g} / \mathrm{L} \mathrm{K}_{2} \mathrm{HPO}_{4}, 0.1 \mathrm{~g} / \mathrm{L}$ $\mathrm{MgCl} .6 \mathrm{H}_{2} \mathrm{O}, 0.1 \mathrm{~g} / \mathrm{L}\left(\mathrm{NH}_{4}\right) \mathrm{Cl}, 0.14 \mathrm{~g} / \mathrm{L} \mathrm{CaCl} 2,1.25 \mathrm{~g} / \mathrm{L} \mathrm{LB}$ 
Modified broth 2 (MB2): $0.1 \mathrm{~g} / \mathrm{L}\left(\mathrm{NH}_{4}\right)_{2} \mathrm{SO}_{4}, 0.8 \mathrm{~g} / \mathrm{L} \mathrm{MgCl} 2.6 \mathrm{H}_{2} \mathrm{O}, 0.25 \mathrm{~g} / \mathrm{L} \mathrm{CaCl} 2,3 \mathrm{~g} / \mathrm{L}$ $\mathrm{KH}_{2} \mathrm{PO}_{4}, 3 \mathrm{~g} / \mathrm{L} \mathrm{K} 2 \mathrm{HPO}_{4}, 5 \mathrm{mg} / \mathrm{L}$ of $\mathrm{FeSO}_{4}$ and $10 \mathrm{~g} / \mathrm{L} \mathrm{Na} \mathrm{S}_{2} \mathrm{O}_{3} .5 \mathrm{H}_{2} \mathrm{O}, 1.25 \mathrm{~g} / \mathrm{L} \mathrm{LB}$

In order to identify which modified broth is better in terms of promoting SOB growth and accelerating acidification, a $5 \% \mathrm{v} / \mathrm{v}$ solution of pure T.thiooxidans and T.neapolitanus in the exponential growth phase was injected into $200 \mathrm{~mL}$ of each modified broth in separate containers. The mixtures of SOB bacteria were grown for 12 days under static condition at room temperature. The activity of the bacteria were analysed by measuring the $\mathrm{pH}$ and sulphate concentration in each broth during 12 days of growth. SOB quantitatively oxidize sulphur into sulphates and reduce the $\mathrm{pH}$ of the solution, hence measuring the sulphate concentration and $\mathrm{pH}$ are direct indications of SOB growth (Waksman and Joffe, 1921; Kuenen, et al., 1992). Both broths were investigated and results are shown in Chapter 6. Based on these results, MB2 was used in the rest of the experiments.

\subsubsection{Biogenic acidification on mortar disks}

To biologically acidify the mortar disks, the same reactor as shown in Figure 3.2 was used for biogenic acidification. A mortar disk was placed on the bottom of the reactor and the reactor was filled with $200 \mathrm{~mL}$ of a modified broth (MB2) which has a neutral $\mathrm{pH}$ and promotes the growth of both SOB. The medium was inoculated with $5 \% \mathrm{v} / \mathrm{v}$ solution of T.thiooxidans and $5 \% \mathrm{v} / \mathrm{v}$ solution of T.neapolitanus at their exponential growth phase. The reactor was placed on a rotary shaker $(60-\mathrm{rpm})$ at room temperature for two weeks to promote bacterial growth and acidification. After two weeks, the reactor was emptied and then filled with fresh MB2 solution and new $5 \% \mathrm{v} / \mathrm{v}$ solution of each T.thiooxidans and T.neapolitanus bacteria for another 2 weeks. Hence the whole process of biogenic 
acidification was performed in two 14-day cycles of SOB growth (i.e., T.thiooxidans and T.neapolitanus growth) on mortar specimens. During this experiment, the $\mathrm{pH}$, calcium and sulphate concentration of solution inside the reactor were measured.

\subsubsection{Biogenic acidification on small mortar cubes}

The mortar cubes were placed in a flask filled with $200 \mathrm{~mL}$ of MB2 and $5 \% \mathrm{v} / \mathrm{v}$ solution of T.thiooxidans and T.neapolitanus at their exponential growth phase. The same procedures of acidification, as described in section 3.5.3, were also applied to the mortar cubes inside the flask. The mortar cubes were used for FISH, EDS, SEM, CLSM, and VSS measurements.

\subsection{Phase 4: High Temperature Biogenic Sulphuric ACid DETERIORATION}

The same procedures as described for biogenic sulphuric acid deterioration in sections 3.5 were performed in the fourth phase of the study but at an elevated temperature of $\left.37 \pm 1^{\circ} \mathrm{C}\right)$. The experimental setup was kept inside an environmental incubator to keep the temperature at $37 \pm 1^{\circ} \mathrm{C}$ during the experiments.

\subsection{Calcium and Sulphate Analysis}

A calcium ion selective electrode (ISE) with a reference electrode incorporated in the body of the electrode (PY-I07IS Combination Electrode, Sartorius Mechatronics) connected to a VWR ISE reader (SP90M5, VWR Symphony) was used for calcium concentration measurement. The calcium ISE was calibrated once before each measurement. It was immersed in the solution containing the calcium ions for about 3-5 
minutes for measurement. The $\mathrm{pH}$ was measured using a Thermo Scientific Orion 5 Star pH meter.

For sulphate concentration measurement, $\mathrm{HACH}$ spectrophotometric method (Method No. 8051, concentration range of 2-70 mg/L, DR2800 Spectrophotometer, $\mathrm{HACH}$ ) which was adopted from Standard Methods for the Examination of Water and Wastewater (APHA et al., 2005) was used. The samples were diluted 100 times to be in the range of the acceptable concentration for the measurement.

\subsection{Adenosine Triphosphate Measurement}

To measure the concentration of biofilm forming on mortar cubes, the adenosine triphosphate (ATP) content of attached biofilm was measured on days 3, 5 and 8 of growth. ATP which is present in the body of viable bacterial cells and is used for transmitting energy is a direct indicator of total living biomass. Mortar cubes were first dipped into sterile DI water to remove the loose bacterial biofilm and the LB solution. Then, the biofilm was extracted by immersing the cube in $5 \mathrm{~mL}$ of ATP reagent and vigorously vortexing for one minute. The solution with extracted biofilm was then used for total ATP analysis using an ATP luminometer (Kikkoman Lumitester C-110, LuminUltra) and an ATP kit (\# DSA-25, LuminUltra) specific for biofilm analysis. ATP was analysed for two mortar cubes in triplicate readings and the averages were employed.

The principle of ATP measurement is based on the reaction of luciferase enzyme with luciferin attached to ATP which produces light. The emitted light intensity is measured by luminometer as relative light unit (RLU). Following completion of the ATP 
measurement, RLU values were converted to ATP concentrations by using a $1(\mathrm{ng} / \mathrm{mL})$ ATP standard solution and the following equation:

tATP $\left(\frac{\text { pg ATP }}{\mathrm{cm}^{2}}\right)=\frac{\text { RLU }_{\text {tATP }}}{\operatorname{RLU}_{\text {UCl }}} \times \frac{50000(\mathrm{pg} \text { ATP })}{\mathrm{A}\left(\mathrm{cm}^{2}\right)}$

where tATP is the total ATP of sample with the unit of $\left(\frac{\mathrm{pg} \text { ATP }}{\mathrm{cm}^{2}}\right), \mathrm{RLU}_{\mathrm{tATP}}$ is the total ATP reading of sample in relative light unit, $R U_{U C I}$ is the total ATP reading of 1 $(\mathrm{ng} / \mathrm{mL})$ standard solution in RLU, and A is the surface area of mortar cube in $\left(\mathrm{cm}^{2}\right)$.

\subsection{Membrane Filtration}

The membrane filtration technique for measurement of total coliform was performed as a different method of monitoring biomass accumulation on the mortar surfaces. To extract the biomass from the mortar surface, one mortar cube from the Erlenmeyer flask was immersed in $5 \mathrm{~mL}$ of autoclaved DI water and the solution was vortexed for 1 minute. The supernatant solution containing bacterial biofilm was used for the membrane filtration. The membrane filtration was performed by several dilution of supernatant using the dilution factor in the range of $10^{3}$ to $10^{8}$. The membrane filtration procedure was adopted from APHA et al. (2005) in which $25 \mathrm{~mL}$ of the diluted solution was filtered through a $0.45 \mu \mathrm{m}$ membrane filter $(0.45 \mu \mathrm{m}$, Membrane Filter, Milipore Corporation) under vacuum. The filter was then placed on m-Endo agar (DIFCO ${ }^{\mathrm{TM}}$, Fisher Scientific) and incubated for 22 -hours at $35^{\circ} \mathrm{C}$. The number of colonies formed was counted with a colony counter (\# 3326 Darkfield colony counter, Reichert). Three replicates were used for membrane filtration for each dilution. 


\subsection{Volatile SUSPENDED SOLIDS}

Volatile suspended solids were analysed to evaluate the presence and growth of biofilm and its condition after each acidification process. VSS is the measure of volatile organic matters suspended in the solution and can be used to estimate the amount of biomass present. To perform VSS analysis, the cubic mortar specimens were placed in $10 \mathrm{~mL}$ of sterile DI water inside a centrifuge tube. Then the tube was vortexed for one minute to detach the biofilm bacteria from mortar surface to the solution. The $10 \mathrm{~mL}$ solution was analysed for VSS measurement using the procedure described in APHA et al. (2005). The $10 \mathrm{~mL}$ solution containing the biofilm cells was passed through the filter (Glass Microfibere Filters, $70 \mathrm{~mm}$, Whatman) and the filter was first dried at $105^{\circ} \mathrm{C}$ then ignited at $550^{\circ} \mathrm{C}$. The volatile solids concentration was calculated as follows:

$\frac{\mathrm{mg} \text { volatile solids }}{\mathrm{cm}^{2}}=\frac{\mathrm{B}-\mathrm{C}}{\mathrm{A}}$

where, $\mathrm{B}$ is the $\mathrm{mg}$ weight of dish with filter after drying at $105^{\circ} \mathrm{C}, \mathrm{C}$ is the $\mathrm{mg}$ weight of dish with filter after ignition at $550^{\circ} \mathrm{C}$ and $\mathrm{A}$ is the surface area of mortar cube in $\mathrm{cm}^{2}$. For each VSS measurement, 2 cubic samples were used and the average was reported.

\subsection{SCANNING ELECTRON MicrosCopy AND ENERGY-DiSPERSIVE X-RAY SPECTROSCOPY}

SEM was used to study the biofilm growth as well as the mortar surface characteristics for crystal formation, roughness and cracking. EDS was used for the elemental analysis and chemical characterization of samples. SEM scans the sample surface in sequential rectangular strips by a high-energy beam of electrons. The interaction of the electron beam with the atoms that make up the sample emits secondary and backscattered 
electrons as well as X-ray signals. These electrons which contain information about the surface topography, composition and other properties such as electrical conductivity of the sample are collected and converted to the image of the surface. Elemental analysis is also possible through energy dispersive spectroscopy that enables a qualitative estimate of the proportion of each atom in the mixture.

\subsubsection{Sample preparation}

Mortar cubes with attached surface biofilm were removed from Erlenmeyer flasks and dipped in autoclaved DI water to remove bulk supernatant cells and loose biofilm. During SEM, the specimen is under a high vacuum pressure; hence the biological specimens such as biofilms should be first fixed to preserve their structure and then dried (Little and Lee, 2007; Videla, 1996). The mortar cubes were immersed in $2.5 \%$ glutaraldehyde in $0.1 \mathrm{M}$ potassium phosphate buffer for two and half hours to fix the biofilm cells. The fixation was followed by ethanol dehydration through subsequent ten minutes immersions in each $35 \%, 50 \%, 70 \%$, and $100 \%$ ethanol solution. The samples were airdried over night in a desiccator. When possible, the air-dried samples were then sputter coated with conductive gold-palladium coating with a low vacuum sputter coater. Due to the porosity of the mortar samples, the complete drying of samples could not always be achieved; hence some samples could not be coated. Therefore, a lower vacuum pressure was used for uncoated samples and the high resolution imaging (i.e., magnification more than $10000 \mathrm{x}$ ) was not possible. 


\subsubsection{Equipment}

Scanning electron microscopy (Vega-II XMU VPSEM, Tescan) capable of using variable pressure and wet operation was used for SEM imaging in this study. The images were collected at a scanning speed of $148 \mu \mathrm{s} /$ pixel and a working distance of $6-8 \mathrm{~mm}$. The SEM was operated at acceleration voltage of $20 \mathrm{kV}$ using either secondary detector or backscatter electron detector depending on the required image quality. For uncoated samples, the low vacuum with backscatter electron detector was used. The SEM was connected to an Energy-dispersive X-ray spectrometer (INCAX-act, Oxford) which was used for elemental mapping of the surface. The EDS spectra were acquired using the acceleration voltage of $20 \mathrm{kV}$ and X-ray acquisition rate of 3000 counts/s. An acquisition time of $60 \mathrm{~s}$ was selected for EDS analysis.

\subsection{CONFocal LaSer SCANNing Microscopy}

Confocal laser scanning microscope was employed to examine the properties of biofilm formed on mortar cubes at different stages of treatment (i.e., after biofilm formation, after chemical or biogenic acidification). The biofilm components were analysed for the relative proportion of live cells, dead cells, extracellular polymeric substance (EPS) and void spaces.

Mortar cubes with attached surface biofilm were removed from Erlenmeyer flasks and dipped in autoclaved DI water to rinse off the loose cells and biopolymers. The bacterial cells on the mortar cubes were first stained for $30 \mathrm{~min}$ in $400 \mu \mathrm{l}$ of staining solution using the Live/Dead biofilm viability kit (Film Tracer ${ }^{\mathrm{TM}}$ LIVE/DEAD Biofilm Viability kit, Molecular Probes, Invitrogen). The Live/Dead staining solution contains $10.02 \mu \mathrm{M}$ 
SYTO 9 green-fluorescent stain to stain the live cells and $60 \mu \mathrm{M}$ propidium iodide (PI) red-fluorescent stain to stain the dead cells based on membrane integrity of the cells. The specimens were then exposed for another 30 minutes to $400 \mu \mathrm{L}$ of calcoflour white stain (composition: $0.5 \mathrm{~g} / \mathrm{L}$ calcofluor white $\mathrm{M} 2 \mathrm{R}$, and $0.25 \mathrm{~g} / \mathrm{L}$ evans blue, Sigma Aldrich) to stain the polysaccharides, which are the main component of extracellular polymers. The stained coupons were immersed in sterile DI water to visualize under confocal laser scanning microscope (LSM 510/AxioImager.M1, Zeiss) equipped with an Argon laser $(458,488,514 \mathrm{~nm})$, and a $63 \mathrm{x}$ water-immersion objective (Plan-Apochromat 1.0 VISIR). The specimens were excited at $488 \mathrm{~nm}$ with LP and BP filter sets for Live and Dead stains, respectively; and at $458 \mathrm{~nm}$ with BP filter set for calcoflour stain. The images of biofilm were taken over the complete biofilm thickness by focusing on different depths within the biofilm with the focus distance of $0.5-2.0 \mu \mathrm{m}$ from each other. The biofilm thickness was found by focusing on the top and bottom of the biofilm at five different locations and reported as the average of five readings.

\subsection{FLUORESCENCE IN SITU HyBRIDIZATION (FISH)}

Fluorescence in situ hybridization was performed on the biofilm that was grown on the mortar cubes. FISH was used to confirm that the protective biofilm was formed by $E$. coli and not by competing bacteria, and to evaluate the interaction of E.coli with SOB after biogenic acidification.

\subsubsection{Fixation of bacterial cells}

Mortar cubes with attached surface biofilm were removed from Erlenmeyer flasks and immersed in $5 \mathrm{~mL}$ of $1 \mathrm{x}$ phosphate buffer solution (PBS) $(130 \mathrm{mM} \mathrm{NaCl}, 7 \mathrm{mM}$ 
$\mathrm{Na}_{2} \mathrm{HPO}_{4}, 3 \mathrm{mM} \mathrm{NaH} 2 \mathrm{PO}_{4} \cdot \mathrm{H}_{2} \mathrm{O}$ ) in a centrifuge tube. The tube was vortexed for 1 minute to extract the bacterial cells from the mortar sample. For cell fixation, $5 \mathrm{ml}$ sample of bacterial cells was mixed with $15 \mathrm{~mL}$ of $4 \%$ paraformaldehyde solution. After 4 hours fixation at $4^{\circ} \mathrm{C}$, cells were washed three times with $1 \mathrm{x}$ PBS by sequential centrifugation for 10 minutes at 10,000 rpm and resuspension (Amann, 1995). The fixed cells stored in equal volume of $70 \%$ ethanol at $-20^{\circ} \mathrm{C}$ for later analysis.

\subsubsection{Whole-cell hybridization}

In situ hybridization was adopted from Amann (1995) and Zarda et al. (1997) with some modifications to enhance the probability of the hybridization. $8 \mu \mathrm{L}$ of the fixed cell was immobilized on each well of a gelatin-coated glass slide with six glass surface wells where the hybridization process was performed. The $23 \mathrm{~S}$ rRNA- oligonucleotide probes used in this study was EC1531 (5'-CACCGTAGTGCCTCGTCATCA-3') specific for E.coli supplied from Sigma-Aldrich, Ltd. The probe was stained with fluorescein isothiocyanate (FITC). Immobilized cells were hybridized on the slides by adding $8 \mu$ of hybridization solution $(0.9 \mathrm{M} \mathrm{NaCl}, 20 \mathrm{mM}$ Tris- $\mathrm{HCl}, 10 \%$ formamide, $0.01 \%$ sodium dodecyl sulphate(SDS)) and $1 \mu \mathrm{L}$ of each $100 \mathrm{ng} / \mathrm{L}$ oligo probe and $200 \mathrm{ng} / \mu \mathrm{L}$ DAPI stain and keeping in a moist chamber for 3 hours at $43^{\circ} \mathrm{C}$. Cells were counterstained with DAPI in order to visualize other bacteria such as SOB. Then, the slides were rinsed and washed by immersing in prewarmed $\left(43^{\circ} \mathrm{C}\right)$ wash buffer solution $(0.215 \mathrm{M} \mathrm{NaCl}, 20$ $\mathrm{mM}$ Tris- $\mathrm{HCl}, 0.01 \% \mathrm{SDS}, 5 \mathrm{mM}$ EDTA) for $20 \mathrm{~min}$. The washed slides were rinsed in DI water and air dried for imaging. $1 \mu \mathrm{L}$ of antifade reagent (Fluorgaurd Antifade, Sigma-Aldrich, Ltd.) was added in each well. 


\subsubsection{Microscopy and image analysis}

An epifluorescence inverted microscope (Eclipse Ti-E with TI-FL Epi-fl illuminator, Nikon) was used to visualize the FISH slides. To minimize the damage to the cells when placed on the stage of the inverted microscope, a $24 \mathrm{~mm} \times 40 \mathrm{~mm}$ cover slip (circles no. 1, 0.13-0.17 cm thick, Fisher Scientific Co.) was placed on the slides. The microscope was equipped with single band filter block for DAPI and GFP-B filter for visualizing FITC. A 100x H/1.4 plan Apo VC oil immersion objective was used for phase contrast microscopy as well as florescence microscopy. Image analysis was done with NIS Elements imaging software version 3.20 .

\subsection{X-RAY DIFFRACTION}

\subsubsection{Background of technique}

$\mathrm{X}$-ray diffraction is one of the established techniques to study the compositional changes in concrete and cementitous material. It is widely used in the study of concrete deterioration to identify different deterioration mechanisms (Ramachandran and Beaudoin, 2001). The technique is used to determine the type and abundance of crystalline phases of materials. In this technique, the scattered intensity and angle of the diffracted X-ray beam is measured as it encounters a plane of atoms in a material. In a crystalline material, the atoms are arranged in a regular pattern with a distance called the d-spacing or basal spacing (Figure 3.3). As the X-ray beam hits the atoms, it will be diffracted with the same frequency as the incoming beam if they are in phase. This occurs according to Bragg's law: 
$\mathrm{n} \lambda=2 \mathrm{~d} \sin \theta$

where $\lambda$ is the wavelength of the X-ray $(\sim 0.15 \mathrm{~nm}$ for the $\mathrm{Cu}$ source $), \mathrm{d}$ is the distance between the atomic planes, $\theta$ is the angle of incidence and $\mathrm{n}$ is an integer.

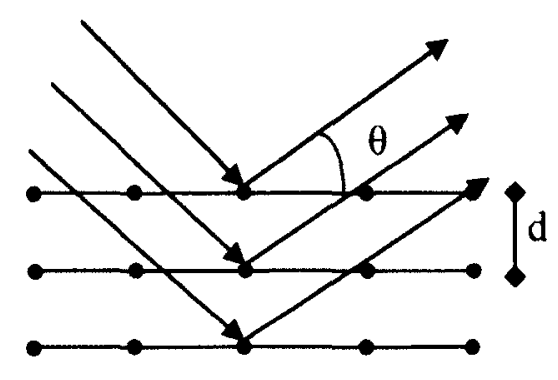

Figure 3.3: Schematics of atomic planes in a crystalline structure and representation of Bragg's law.

In order to identify an unknown crystal, the diffraction pattern of the substance with the list of d-spacing are compared with the standard line patterns available for various compounds. The standard XRD patterns of different crystals are released by the International Center for Diffraction Data (ICDD).

\subsubsection{Sample preparation}

In this study, XRD was employed to quantitatively assess the formation of ettringite, and gypsum crystals as these crystals are the expansive sulphate crystals that are formed during the biodeterioration of concrete (Monteny et al., 2000, 2001).

Using a profile grinder (Metabo Ge700, ACE Tool), the acidified area of the mortar disks with the diameter of $6 \mathrm{~cm}$ were grinded at $0.5-\mathrm{mm}$ thick layers in two layers. The collected powder was used for XRD analysis. The X-ray diffraction measurements were performed using a Scintag XDS 2000 diffractometer and $\mathrm{CuK} \alpha$ radiation. Spectra were obtained in the range of $4<2 \theta<65^{\circ} u$ sing a step size of $0.03^{\circ}$ at $5 \mathrm{sec}$. intervals. 


\section{CHAPTER 4. BIOFILM FORMATION ON MORTAR SURFACE}

\subsection{INTRODUCTION}

In this chapter, the results of the Phase one of this study including the monitoring of E.coli growth and biofilm formation, and the evaluation of the E.coli biofilm characteristics grown on the mortar specimens are presented. The characteristics of the biofilm formed on the mortar surface were studied using several microscopic techniques such as SEM and CLSM. FISH was used to confirm that the biofilm on the mortar specimens was an $E$. coli biofilm after it was exposed to a mixed culture of SOB bacteria.

Biofilm formation on the mortar surface was a challenge due to the high surface $\mathrm{pH}$ of mortars, typically greater than 13 . The calcium hydroxide $(\mathrm{CaOH})$ leach-out from the mortar specimens leading to an increase in the $\mathrm{pH}$ of the bulk solution was another obstacle for the bacterial growth in suspension. To overcome the difficulties of biofilm formation on a high $\mathrm{pH}$ surface, the specimens were first immersed in DI water with regular water replenishment for at least one week to promote leaching of excess $\mathrm{CaOH}$ from the surface of the mortar before the mortar specimens are exposed to biofilmproducing bacteria. In a concrete structure exposed to wastewater, this process is accomplished by the release of carbon dioxide and a slight carbonation of the concrete 
surface. In order to have a more resistant biofilm toward agitation and shear stresses; the biofilm growth was performed under flowing conditions by media recirculation.

Biofilm growth on metal surfaces to inhibit metal corrosion has been studied in numerous literatures. This is the first study of its kind to grow E.coli DH5a biofilm on a cement mortar surface and to propose it as an inhibition method for MICD. It is also the first labscale study to grow the biofilm on a mortar surface using a unique setup that permitted the biofilm growth under continuous flow condition adjacent to the mortar surface.

\subsection{MONITORING BACTERIAL GROWTH}

To monitor the suspended growth of E.coli, the optical density of the bacteria or turbidity of the LB broth inside the biofilm reactor was measured over the phase of biofilm formation. The optical density of the bacteria grown for 8 days in the biofilm reactor at room temperature $\left(25 \pm 1^{\circ} \mathrm{C}\right)$ and elevated temperature of $37 \pm 1^{\circ} \mathrm{C}$ is shown in Figure 4.1. The optical density was measured at the wavelength of $600 \mathrm{~nm}$ which is a commonly used wavelength for indirect measurement of suspended E.coli cell concentration (Lin, 1995; Sezonov, 2007). As it is depicted in Figure 4.1, the growth rate of E.coli was higher at elevated temperature and after 8 days of growth, the optical density reached 1.74 for the elevated temperature compared to 1.24 for room temperature experiment. This is expected since the optimal temperature for E.coli growth is $37^{\circ} \mathrm{C}$. According to this figure, the optical density of bacteria slightly decreased on the second day which was due to the initiation of media circulation and mixing of $150 \mathrm{~mL}$ of fresh $\mathrm{LB}$ broth from the mixing reservoir into the biofilm reactor. This figure also shows that during the 8 days of biofilm formation the bacterial growth in suspension started with the exponential 
growth phase and ended with the stationary growth phase, while the dead phase did not occur (Figure 4.1). The dead phase starts when all the nutrients are exhausted, hence the absence of this phase indicated that proper growth and feeding conditions were selected for the bacterial growth.

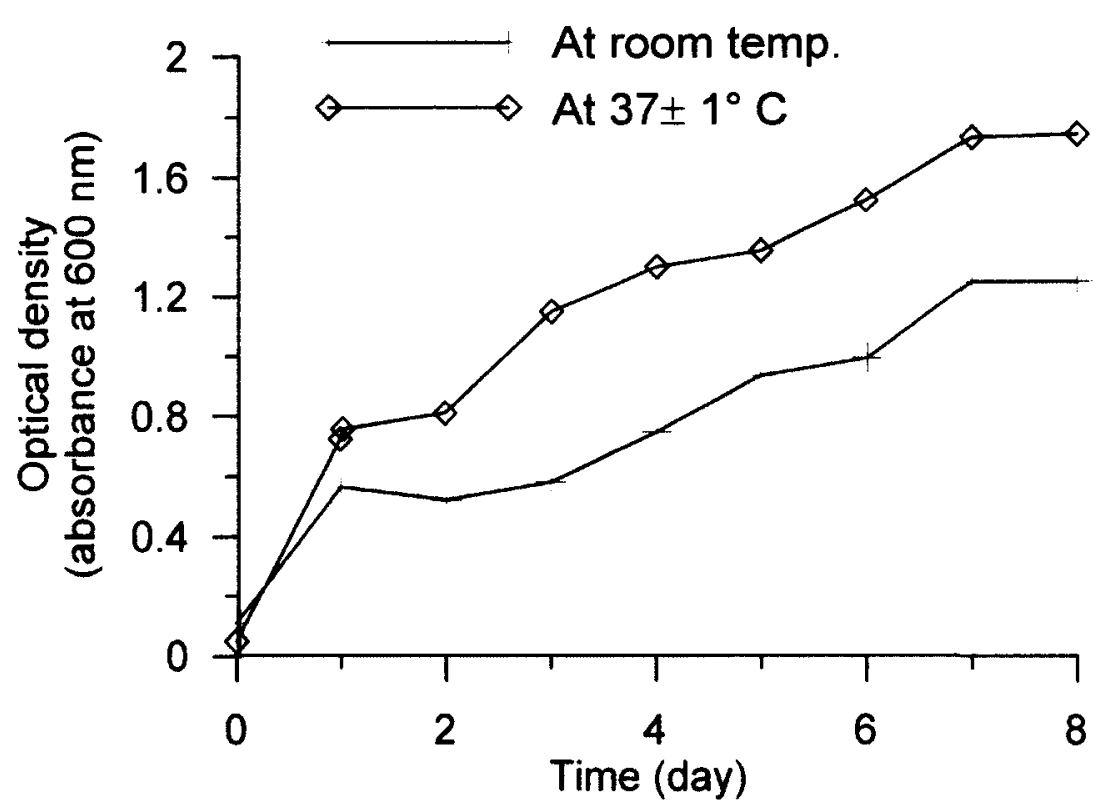

Figure 4.1: The optical density of bacteria grown in biofilm reactor as measured by absorbance reading at $600 \mathrm{~nm}$ at room and elevated temperature.

\subsection{MONITORING BIOFILM FORMATION}

The concentration of biomass on mortar cubes for biofilm grown at room temperature was monitored during the 8 days of biofilm formation using membrane filtration and ATP measurement. The results of biomass concentration on mortar specimens using membrane filtration and ATP assay are shown in Figure 4.2 and Figure 4.3, respectively. Both tests showed the progressive growth of biofilm on the mortar surfaces during the 8 days of biofilm growth (Figure 4.2 and Figure 4.3). According to Figure 4.2 and Figure 4.3, there was a low biomass concentration of $3 \times 10^{4} \mathrm{CFU} / \mathrm{cm}^{2}$ or $1.5 \times 10^{3} \mathrm{pg} \mathrm{ATP} / \mathrm{cm}^{2}$ 
on the mortar surface at the third day of growth. After 8 days of growth, the biomass concentration increased to $18 \times 10^{5} \mathrm{CFU} / \mathrm{cm}^{2}$ of mortar surface area equivalent to $43 \times 10^{3}$ $\mathrm{pg} \mathrm{ATP} / \mathrm{cm}^{2}$ of biomass formed on the surface of mortar specimens. The large error bar on Day 8 is likely caused by the differences in mortar specimens and vortex extraction used to detach the bacteria from the surface of the mortar samples prior to enumeration.

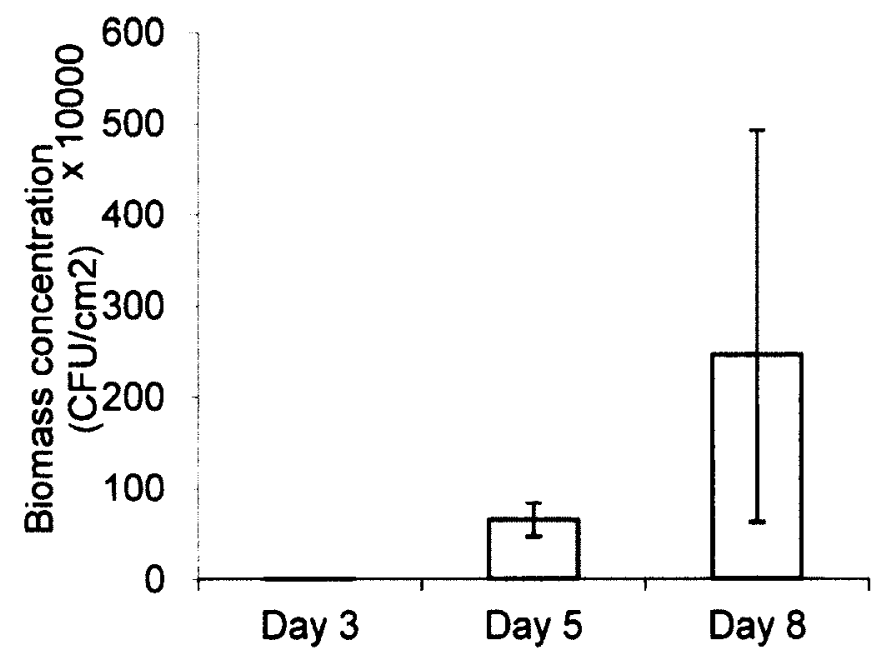

Figure 4.2: Biomass concentration on the mortar surfaceas measured by the coliform forming unit at different time of biofilm growth; biomass concentration after 8 days was $18 \times 10^{5} \mathrm{CFU}$.

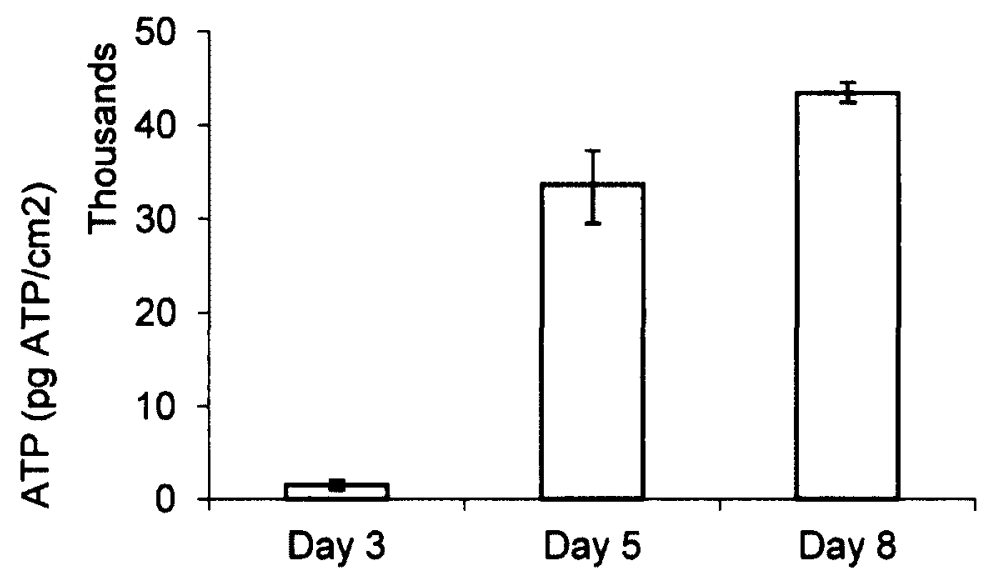

Figure 4.3: ATP of biomass on mortar surface at differnt days of biofilm growth as measured by ATP analysis. 


\subsection{SEM/EDS}

The SEM micrographs of the mortar cubes were taken after 8 days of the biofilm growth. In Figure 4.4, the SEM micrographs of mortar surface after 8 days of biofilm growth are shown at different magnification. Figure $4.4 \mathrm{a}$ shows that the biofilm is fairly well distributed over the mortar surface only after 8 days. The images of Figure $4.4 \mathrm{~b}$ and $\mathrm{c}$ with the higher magnification of $5 \mathrm{~K}$ and $10 \mathrm{~K}$, respectively, show that the biofilm did not have a uniform thickness over the entire surface. A high concentration of bacterial cells was observed at some areas (Figure 4.4a, and b) and at some other locations, only a few bacterial cells were attached (Figure $4.4 \mathrm{a}$ and $\mathrm{c}$ ). Figure $4.5 \mathrm{~b}$ which is the EDS analysis of the $20 \times 20 \mu \mathrm{m}$ mortar surface area with no bacterial cell coverage (the area is shown in Figure 4.5a) confirmed the presence of phosphorus as the main components of EPS and bacterial cells (Todar, 2008). This might be due to the presence of EPS or bacterial cells inside the mortar pores or due to a thin EPS layer that was present before and washed off during the rinsing of the samples.

The elemental composition of E.coli consists of $50 \%$ carbon (C), $20 \%$ oxygen (O), $14 \%$ nitrogen $(\mathrm{N}), 8 \%$ hydrogen $(\mathrm{H}), 3 \%$ phosphorus $(\mathrm{P})$ and traces of sulphur, potassium, magnesium, calcium and iron (Todar, 2008). The abundant concentrations of $\mathrm{C}$, and $\mathrm{O}$ and $\mathrm{Ca}$ already present on the mortar surface made it difficult to distinguish their origin and because there was no sign of the presence of $\mathrm{N}$ or $\mathrm{H}$ the only element indicating the presence of E.coli biofilm was phosphorus. Table 4.1 shows the results of EDS analysis on $250 \times 250 \mu \mathrm{m}$ area of a control mortar specimen without biofilm and a mortar specimen covered with biofilm. Comparing the EDS results before and after biofilm formation 
showed that the biofilm formation increased the amount of phosphorus on the mortar surface (Table 4.1 ).

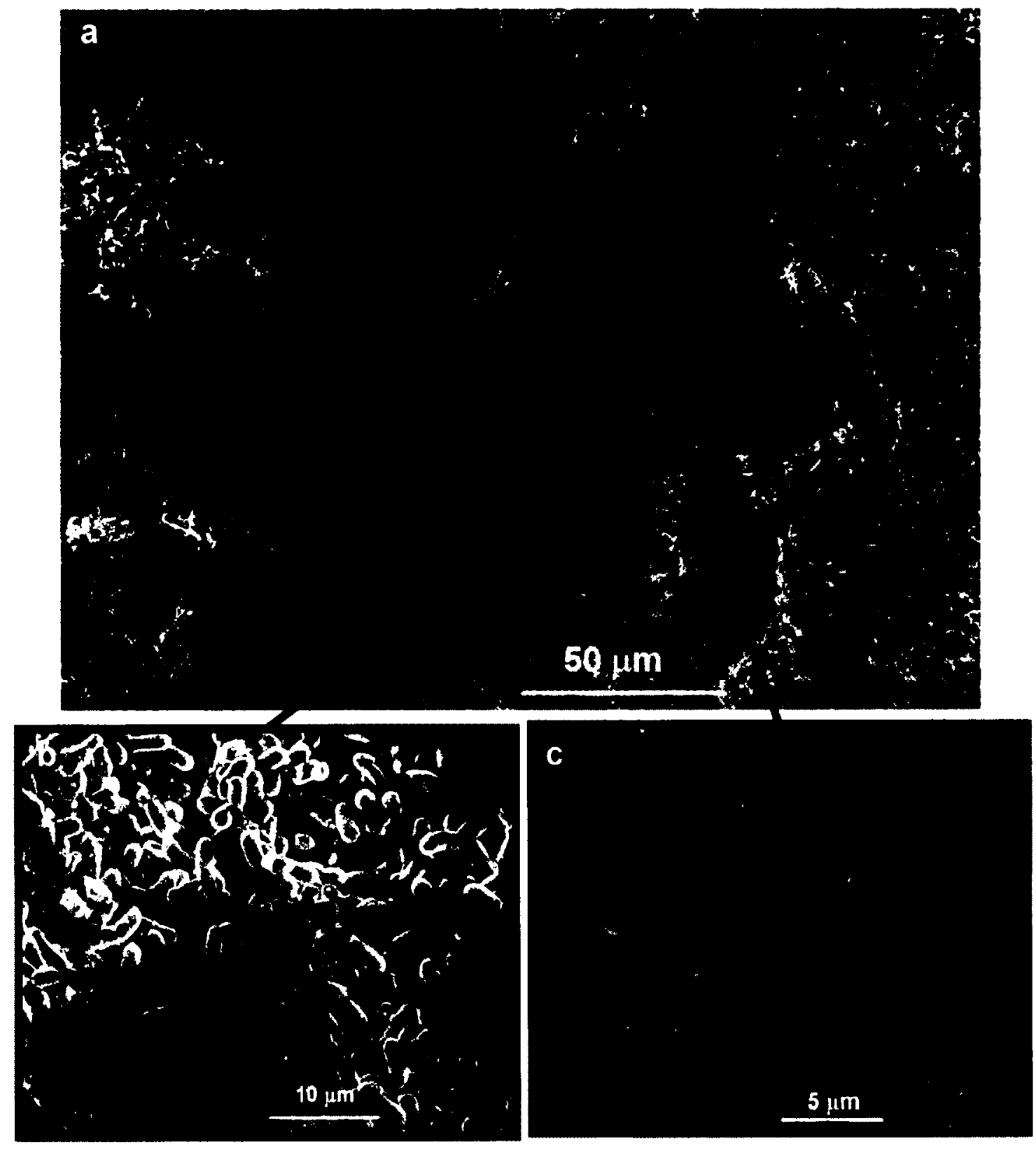

Figure 4.4: SEM micrographs of mortar surface covered with biofilm; a) $1 \mathrm{~K}$ magnification image, b) area with high concentration of bacterial cells, magnification: $5 \mathrm{~K} ; \mathrm{c}$ ) area with low bacterial cell concentration, magnification $10 \mathrm{~K}$. 


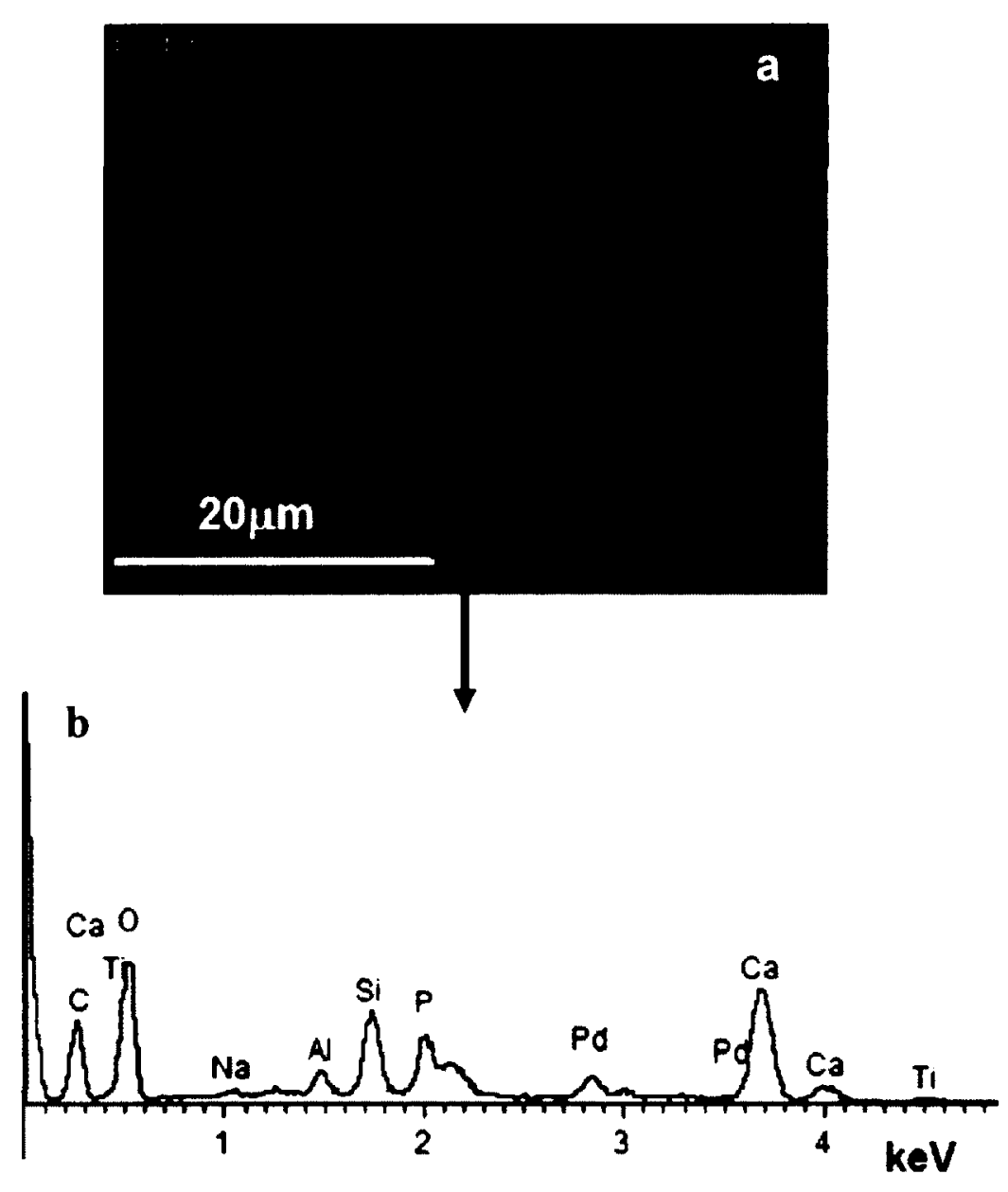

Figure 4.5: EDS analysis of biofilm-covered mortar on area with no bacterial cell; a) SEM micrograph showing the area used for EDS analysis, b) the corresponding EDS spectrum of the area with no bacterial concentration.

Table 4.1: Percentage atomic fraction of elements on the mortar surface before and after biofilm formation, area of analysis was $250 \times 250 \mu \mathrm{m}$.

\begin{tabular}{lll}
\hline Element & $\begin{array}{l}\text { Before biofilm } \\
\text { formation }\end{array}$ & $\begin{array}{l}\text { After 8 days of } \\
\text { biofilm growth }\end{array}$ \\
\hline $\mathrm{P}$ & 0 & 2.41 \\
$\mathrm{C}$ & 29.76 & 38.86 \\
$\mathrm{O}$ & 51.46 & 41.65 \\
$\mathrm{Na}$ & 0.39 & 0 \\
$\mathrm{Mg}$ & 0.14 & 0 \\
$\mathrm{Al}$ & 0.75 & 0.56 \\
$\mathrm{Si}$ & 3.03 & 3.48 \\
$\mathrm{Ca}$ & 13.8 & 10.91 \\
$\mathrm{Fe}$ & 0.16 & 0 \\
\hline
\end{tabular}




\subsection{FluORESCENCE IN Situ Hybridization}

The presence of E.coli bacteria in the attached biofilm and its purity was verified using a FISH probe designed to hybridize E.coli bacteria. The specificity of the probe was confirmed with the pure overnight grown culture of E.coli DH5a (Figure 4.6). Comparison of Figure 4.6a and $\mathrm{b}$ shows that all of the E.coli bacteria were hybridized hence the selected hybridization technique and FISH probe was appropriate for imaging the E.coli DH5 $\alpha$. Five additional images taken at other locations (not shown in this thesis) that are similar to images in Figure 4.6 also suggested the suitability of the FISH probe for E.coli bacteria.

Figure 4.7 is the image of attached bacteria extracted from the mortar surface after biofilm formation stained with DAPI to visualize total bacteria (Figure 4.7a) and hybridized with EC-1531 probe (Figure 4.7b) to distinguish the E.coli bacteria. By comparing Figure 4.7a with Figure 4.7b, it was concluded that biofilm was composed of E.coli bacteria since the DAPI stained cells with blue color were aligned with the hybridized bacterial cells with green color. The purity of E.coli biofilm was also confirmed by analysis of five other FISH images taken at other locations but not shown in this thesis for brevity. 


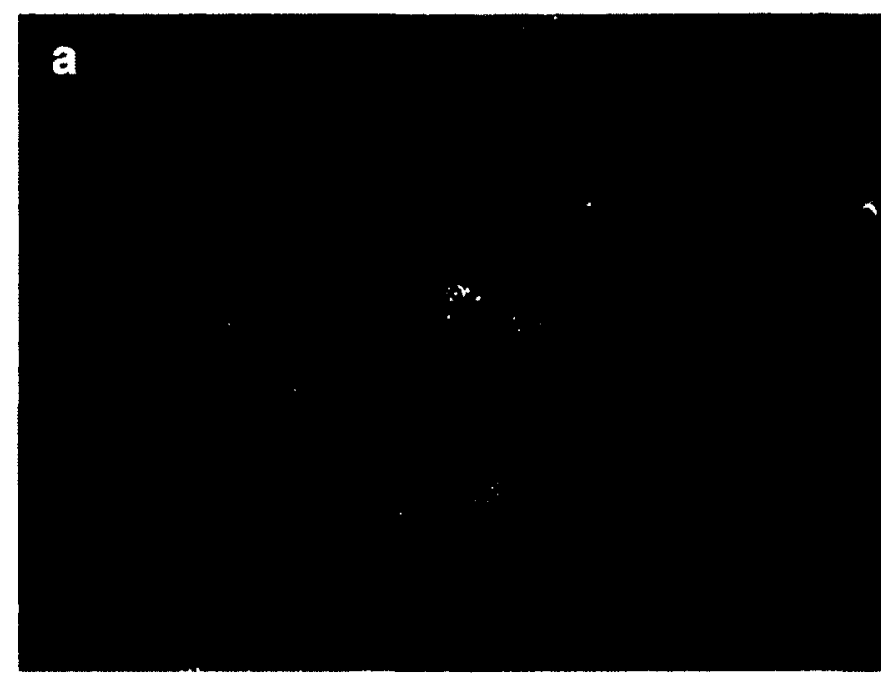

b

Figure 4.6: Images of pure E.coli DH5 $\alpha$; a) differential interference contrast (DIC) image showing all the present bacteria, b) florescent image showing the hybridized E.coli bacteria. 

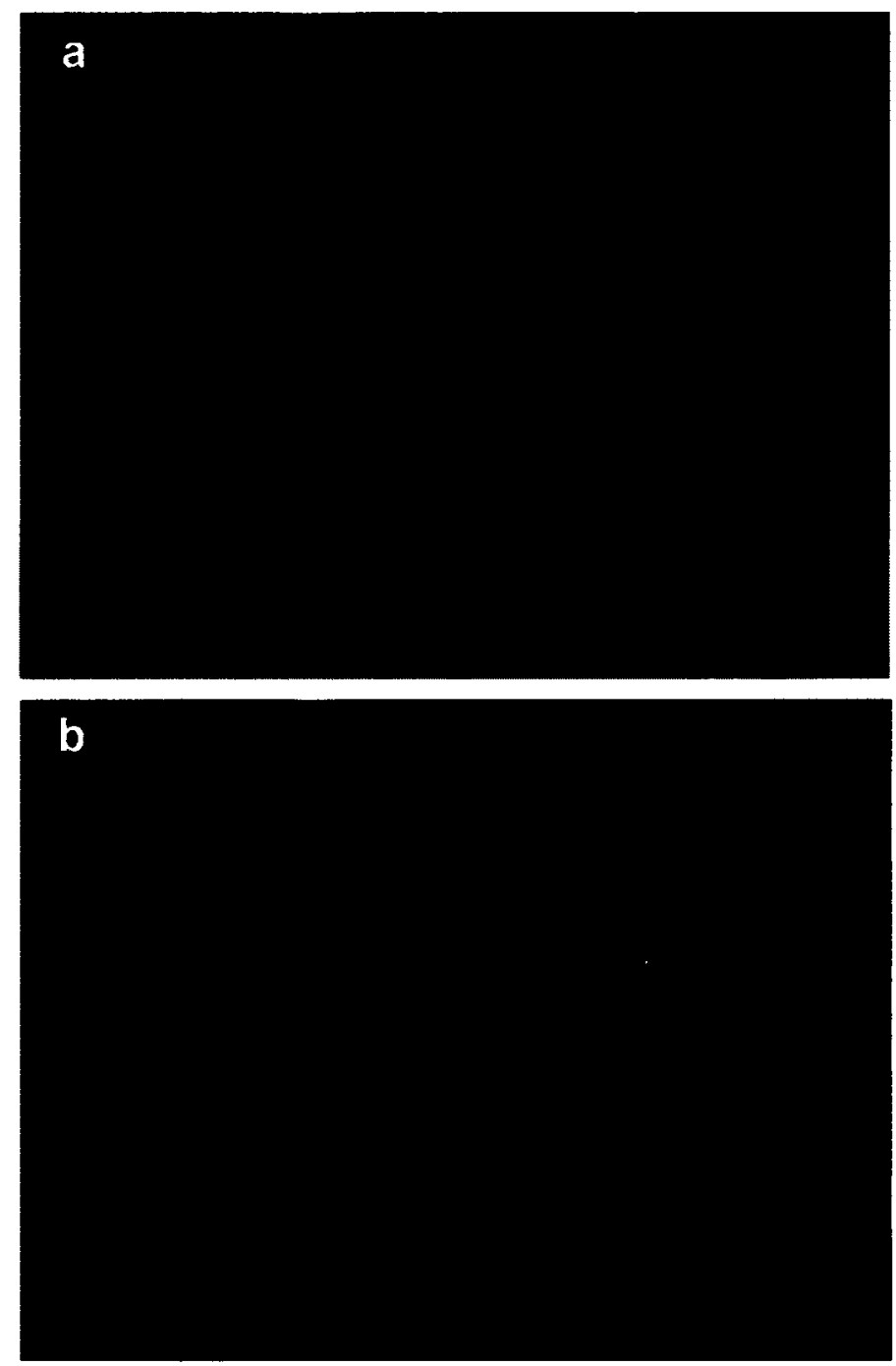

Figure 4.7: FISH Images for identification of E.coli in biofilm attached on the mortar surface; (a) Total bacteria present stained with DAPI (blue), (b) Same viewing of the sample hybridized with probe EC-1531(green) to identify E.coli.

\subsection{CONFocal SCANNING LASER Microscopy}

CLSM images of the attached biofilm layer were taken in 0.5-1 $\mu \mathrm{m}$ thick sections over the entire thickness of biofilm for the analysis of percentage of live, and dead cell coverage as well as percentage of voids and EPS coverage. The $0.5-1 \mu \mathrm{m}$ subsections of each view were projected on top of each other to prepare a new image that was used for analysing the total proportion of live and dead cells and EPS. NIS Elements image 
analysis software was used to obtain the relative proportion of each component of biofilm using a range of pixel intensities with color restriction to distinguish live and dead cells, EPS and void spaces. Where needed a cell size restriction was applied to minimize the artefact of the images due to bacterial clump formation and to accurately measure the proportions of live and dead cells. Figure 4.8 shows the CLSM image of the live and dead cells on the mortar surface taken at a distance of $20 \mu \mathrm{m}$ from the mortar surface and the projected image of the same view. Figure $4.9 \mathrm{a}, \mathrm{b}, \mathrm{c}$, and $\mathrm{d}$ are a series of images taken from a single view at different depths of biofilm stained with calcoflour white to show the EPS layer. Figure $4.9 \mathrm{e}$ is the projected image of biofilm on the mortar surface of the same view. Figure 4.9 shows that the EPS coverage had the lowest density close to the mortar surface and its density increased as going toward the biofilm-liquid interface. This observation was also confirmed by analysis of the images for EPS using an image analysis software (i.e., NIS Elements imaging software). Supplementary CLSM images of biofilm-covered mortar at different locations are provided in Appendix B. Five similar images like the image shown in Figure 4.8b and five images similar to the one shown in Figure $4.9 \mathrm{~d}$ taken at different views were used to obtain the total percentage coverage of live and dead cells, and EPS proportions, respectively (Table 4.2).

Table 4.2: Analysis of the biofilm components using the projected CLSM images.

\begin{tabular}{lccc}
\hline & \%live & \%dead & \%EPS \\
\hline Image 1 & 5.3 & 3.2 & 71.3 \\
Image 2 & 15.5 & 6.4 & 76.8 \\
Image 3 & 8.2 & 1.7 & 69.0 \\
Image 4 & 6.9 & 3.0 & 64.2 \\
Image 5 & 4.2 & 0.3 & 34.2 \\
\hline Average & 8.0 & 2.9 & 63.1 \\
Standard Deviation & 3.1 & 1.5 & 11.6 \\
\hline
\end{tabular}


As reported in Table 4.2, total percentage of live cells was always higher than total percentage of dead cells and on average, the total live cells was 2.7 times higher than total dead cells. Extra polymeric substances mostly covered more than $50 \%$ of the surface area resulting in average EPS coverage of $63.1 \%$.

The biofilm thickness was obtained by focusing on the top and bottom of the stained biofilm and the distance between the two focused points was considered as the thickness. The E.coli biofilm grown for 8 days had a varying thickness in a range of 20 to $40 \mu \mathrm{m}$. The average thickness of the biofilm as measured from 8 different views in 4 different mortar cubes was $29.7 \mu \mathrm{m}$.
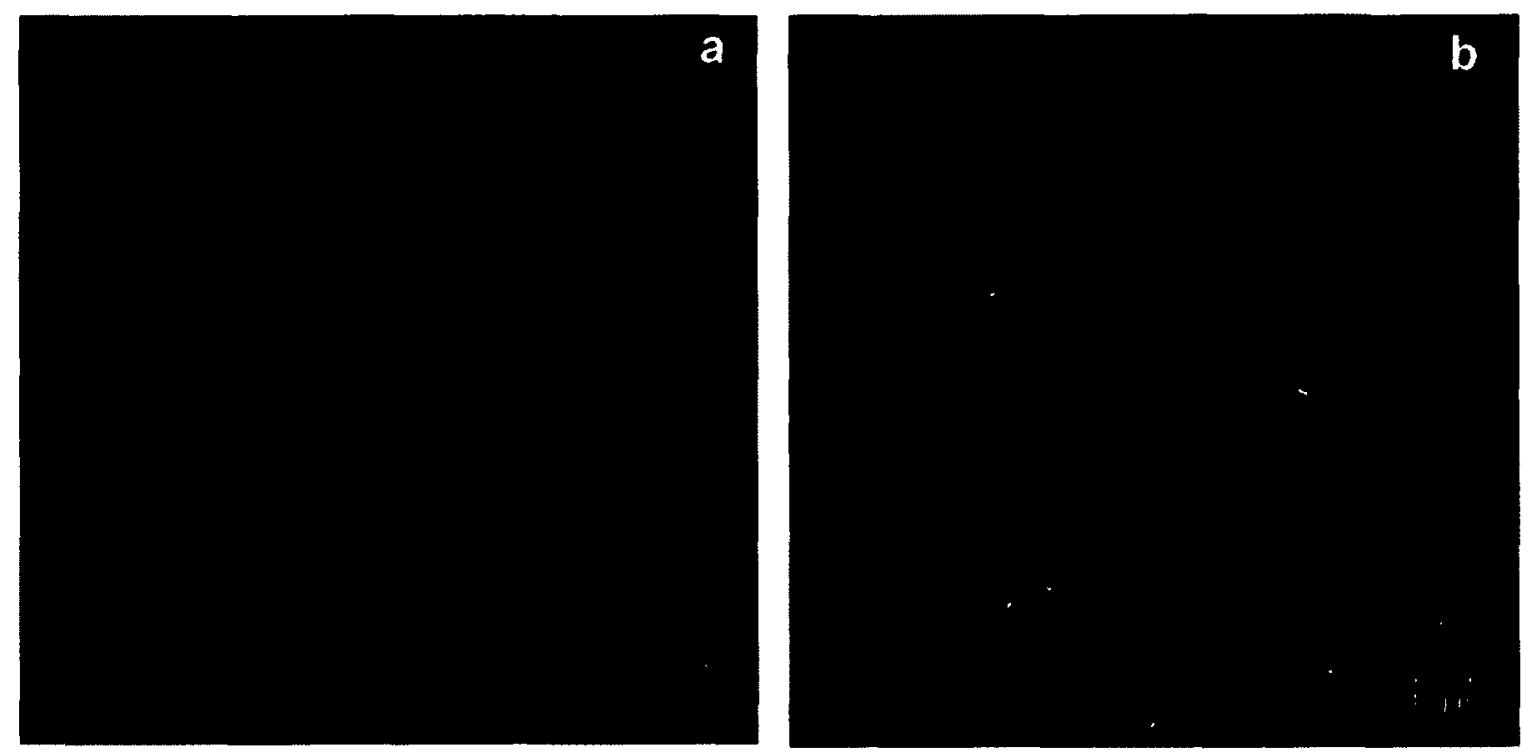

Figure 4.8: Confocal laser scanning microscope images of 8 days grown biofilm of E.coli DH5a on mortar surface stained for live and dead cells; a) section of biofilm at $20 \mu \mathrm{m}$ distance from the mortar surface, b) projected image of all the subsections in the same position. Scale bar represents $10 \mu \mathrm{m}$. The green areas are live cells and red areas are dead cells. 

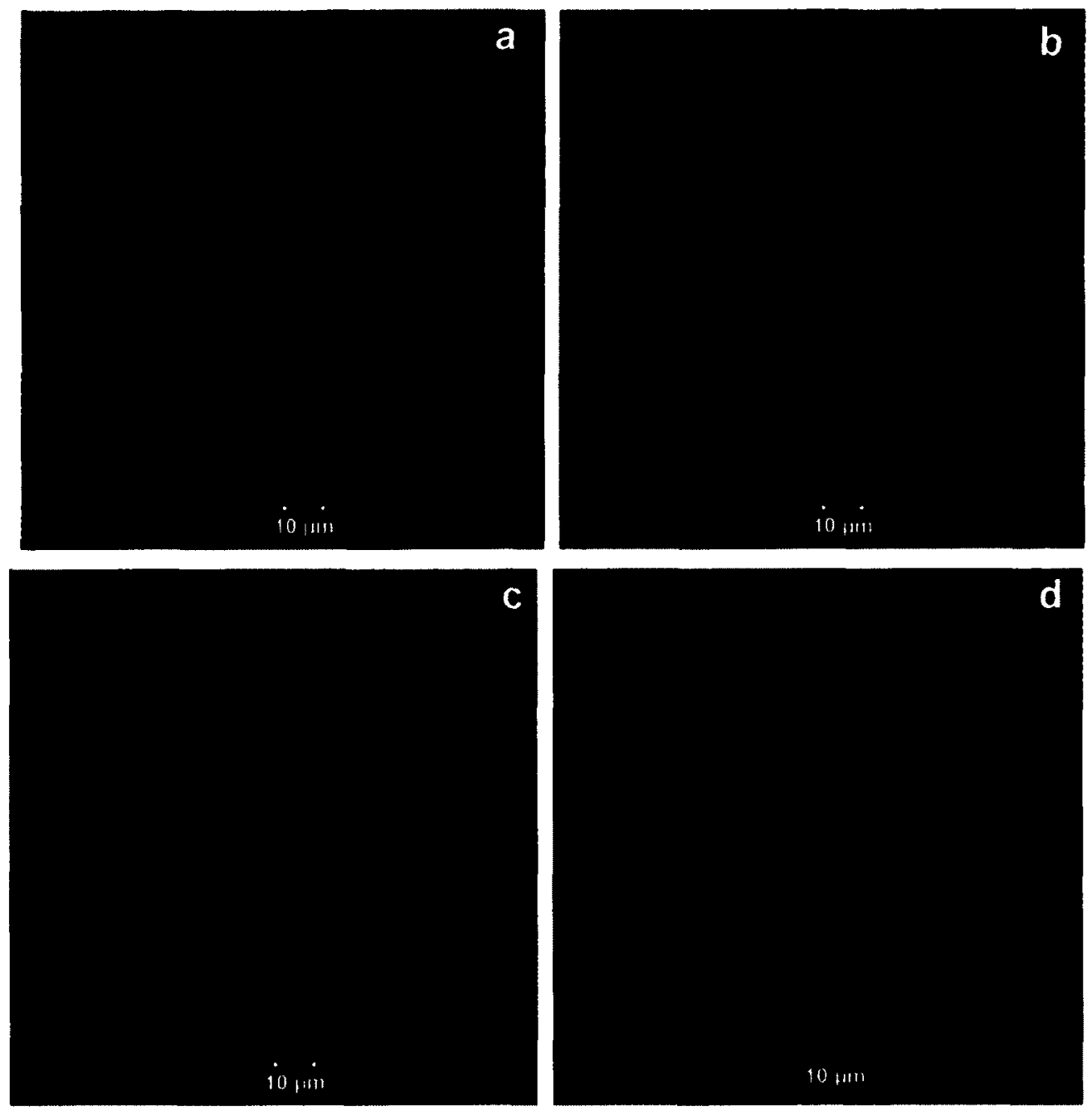

d
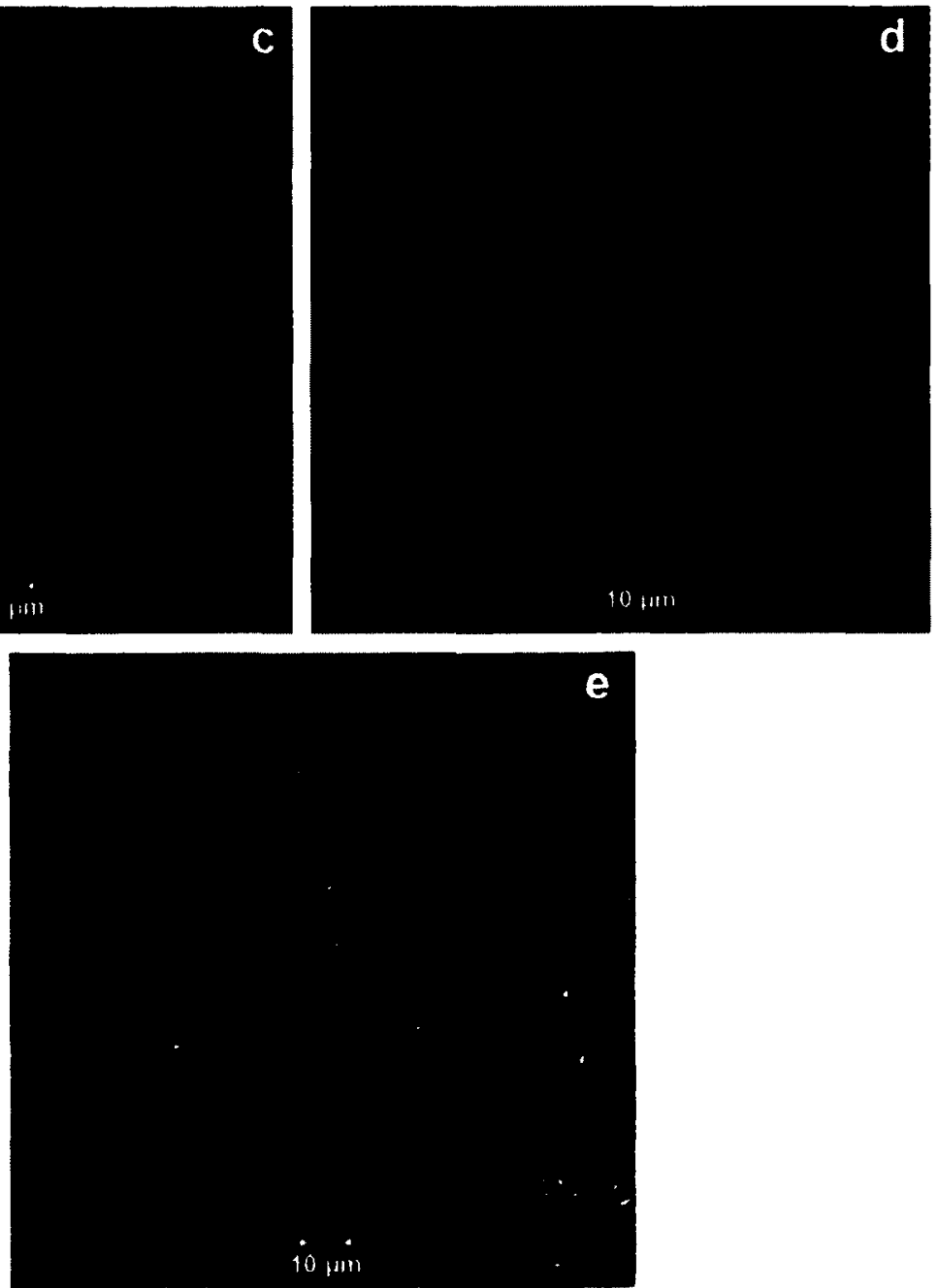

Figure 4.9: Confocal laser scanning microscope images of 8 days grown biofilm on mortar surface stained for live cells (green), dead cells (red) and polysaccharide (cyan); image of biofilm at (a) $10 \mu \mathrm{m}$, (b) $20 \mu \mathrm{m}$, (c) $30 \mu \mathrm{m}$, (d) $40 \mu \mathrm{m}$ distance from the mortar surface, e) projected image of all the subsections in the same view. Scale bar represents $10 \mu \mathrm{m}$. 
The depth profile of biofilm layer was obtained by analysing the images of $0.5-1 \mu \mathrm{m}$ thick sections over the entire biofilm thickness (Figure 4.10 and Figure 4.11). Depth profile analysis of all biofilm images are not shown for reasons of brevity; analysis of all depths at two representative positions with the same biofilm thickness is averaged in Figure 4.10 and Figure 4.11. For all the images, the ratio of cellular (live and dead cells) to non-cellular matter (polysaccharide and water channels) varied with depth. The bacterial population near the mortar surface was the lowest. The population increased to the highest concentration at $3 / 4$ of the biofilm thickness, then decreased to a sparse distribution of cells near the biofilm-liquid interface (Figure 4.10). This biofilm structure is in agreement with Jayaraman et al. (1998) who observed a similar bacterial distribution for E.coli and Pseudomonas fragi biofilm developed on steel coupons. In all the biofilm images, the concentration of the live cells was 2-3 times higher than the concentration of dead cells (Figure 4.10).

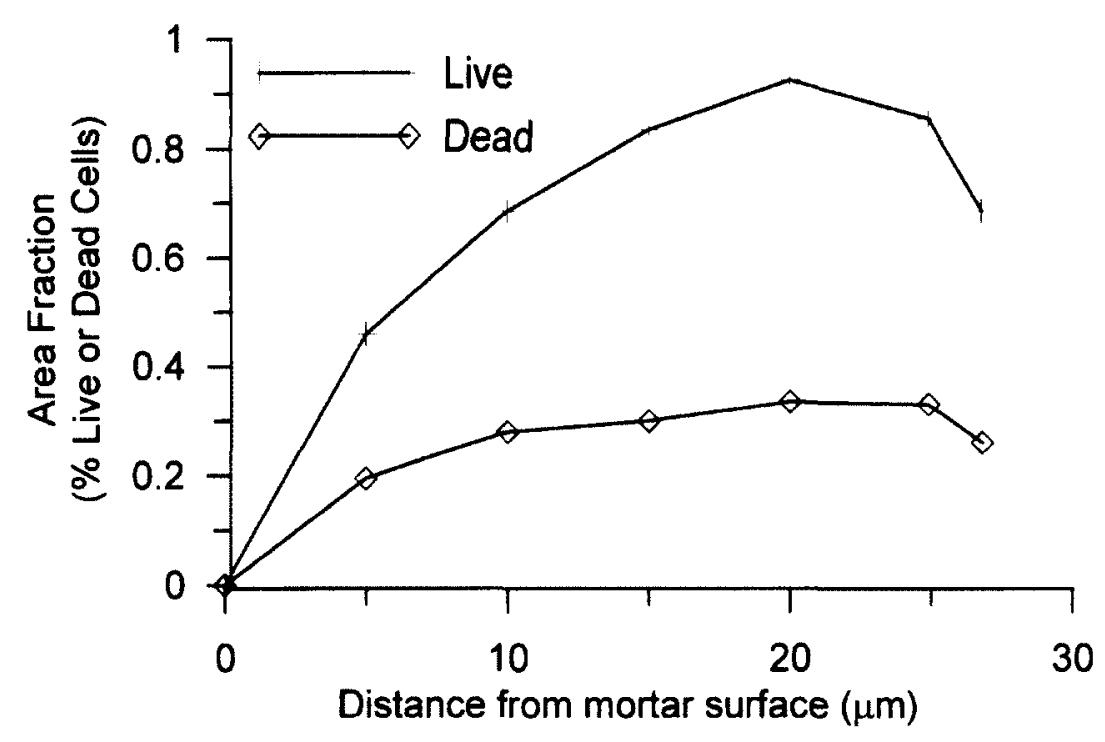

Figure 4.10: Live and dead cell distribution profiles of 8 day grown E.coli biofilm developed on mortar surface. Measurements are the average of two representative positions in the biofilm. 
The EPS was less detected near the biofilm-mortar interface and increased over the biofilm thickness to reach the highest percentage coverage of $65 \%$ at the biofilm-liquid interface (Figure 4.11).

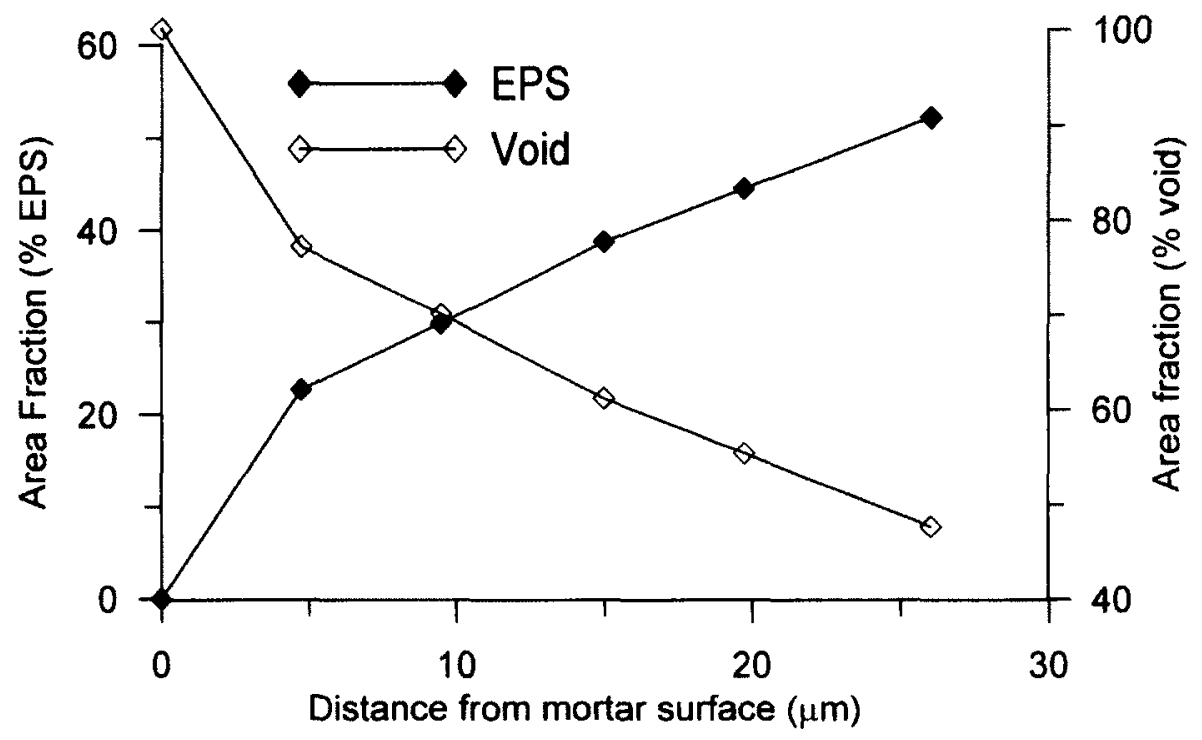

Figure 4.11: EPS and void distribution profiles of 8 day grown E.coli biofilm developed on mortar surface. Measurements are the average of two representative positions with the same biofilm thickness.

The biofilm was also covered with a thin layer of slime composed of loose live and dead cells which could not be retained on top of the mortar specimens during the staining procedure. EPS accounted for approximately 10-78 \% of the E.coli biofilm over the entire depth of biofilm whereas the bacterial cells were detected at $0.2-2.5 \%$ coverage (Figure 4.10 and Figure 4.11).

\subsection{COnCluding Remarks}

Biofilm was successfully grown on the mortar specimens. CLSM image analysis of the biofilm and quantification of the relative proportions of live cells, dead cells, EPS and void space revealed that the biofilm was not uniformly covering the surface after 8 days 
of growth. It would be necessary to grow biofilm for a longer time to generate a biofilm layer with higher number of cell coverage and EPS formation. However, the presence of a fairly high quantity of EPS indicated the formation of a stable and good resistant biofilm with fewer tendencies for cell detachment (Jayaraman et al., 1998).

The SEM micrographs of the mortar surface also confirmed the presence of a nonuniform biofilm; however, the presence of a thin layer of materials with the presence of phosphorus was detected at the void spaces. FISH images of the biofilm also confirmed that the biofilm was composed of E. coli bacteria and not taken over by another bacteria present in the environment. 


\section{CHAPTER 5. CHEMICAL SULPHURIC ACID DETERIORATION}

\subsection{INTRODUCTION}

In this chapter, the results of chemically induced deterioration as simulated by exposure to the sulphuric acid solution are presented. The severity of the mortar deterioration was evaluated by measuring the concentration of calcium leach-out, microscopic analysis such as SEM and EDS, crystal analysis using XRD. After the acidification, the biofilm condition in terms of its spatial distribution and structure was evaluated on the biofilmcovered specimens by CLSM. VSS measurement was employed to compare the concentration of biomass before and after acidification.

\subsection{Chemical Analysis}

Mortar disks were chemically acidified in the reactor shown in Figure 3.1 by incremental exposure to acidic solution of LB broth at $\mathrm{pH}$ of $6,5,4$, and 3 . The incremental acidification was applied in order not to introduce a sudden shock to the biofilm bacteria. The solution $\mathrm{pH}$ and calcium concentration were measured during the acidification process to compare the severity of deterioration in the control mortar specimens (i.e., mortar specimen without biofilm) and in the biofilm-covered mortar specimens; these 
measurements were also used to evaluate the effectiveness of biofilm as an alternative method for the inhibition of deterioration of mortar in an acidic environment. Figure 5.1 shows the results of $\mathrm{pH}$ measurement in two separate reactors containing mortar specimens without biofilm and biofilm-covered mortar specimens. As shown in Figure 5.1 , after each acidification cycle the $\mathrm{pH}$ of the broth increased for both control and biofilm-covered mortars; however, the increase in $\mathrm{pH}$ was considerably higher in the biofilm-covered mortar than that of the control sample. For example, in the second cycle with the desired $\mathrm{pH}$ reduction of 5 , the solution $\mathrm{pH}$ after two days of exposure in the container with biofilm-covered mortar increased to 6.8 while the $\mathrm{pH}$ of the broth in the control sample container increased to 5.8. If the increase in the $\mathrm{pH}$ for the control sample can be attributed to the minor leaching of $\mathrm{Ca}(\mathrm{OH})_{2}$ from the mortar as will be discussed later and shown in Figure 5.2, it can be hypothesized that the E.coli bacteria resisted the acidification most likely by increasing the buffering capacity of the solution. This hypothesis is supported by other researchers who reported that bacteria grown in acidic environment have a tendency to keep their internal $\mathrm{pH}$ at a more alkaline $\mathrm{pH}$ than that of the environment by controlling the movements of cations through their membrane and increasing the extracellular buffering capacity (Slonczewski, 2009; Booth, 1999). It should also be noted that higher $\mathrm{pH}$ increase due to the bacterial assimilation may have lessened the influence of $\mathrm{pH}$ reduction on deterioration of biofilm-covered mortar specimens since the biofilm-covered specimens were exposed to the lower $\mathrm{pH}$ for a shorter period of time. Figure 5.2 shows that the incremental acidification increased the calcium leach-out in both the control specimens without biofilm and the biofilm-covered specimens. However, higher calcium leach-out was observed in the control specimen 
than the biofilm-covered specimen (Figure 5.2). The biofilm was more effective in preventing the calcium leach-out at $\mathrm{pH}$ values higher than 5. As it is shown in Figure 5.2, the amount of calcium leached out during the second cycle of exposure to $\mathrm{pH}$ of 5 was 21 $\mathrm{ppm}$ in biofilm-covered specimen compared to $42 \mathrm{ppm}$ in control specimen. The rate of calcium leach-out during the last acidification cycle by exposure to $\mathrm{pH}$ of 3 was increased by 8.4 and 5.5 times compared to second cycle at $\mathrm{pH}$ of 5 for biofilm-covered and control specimen, respectively (Figure 5.2).

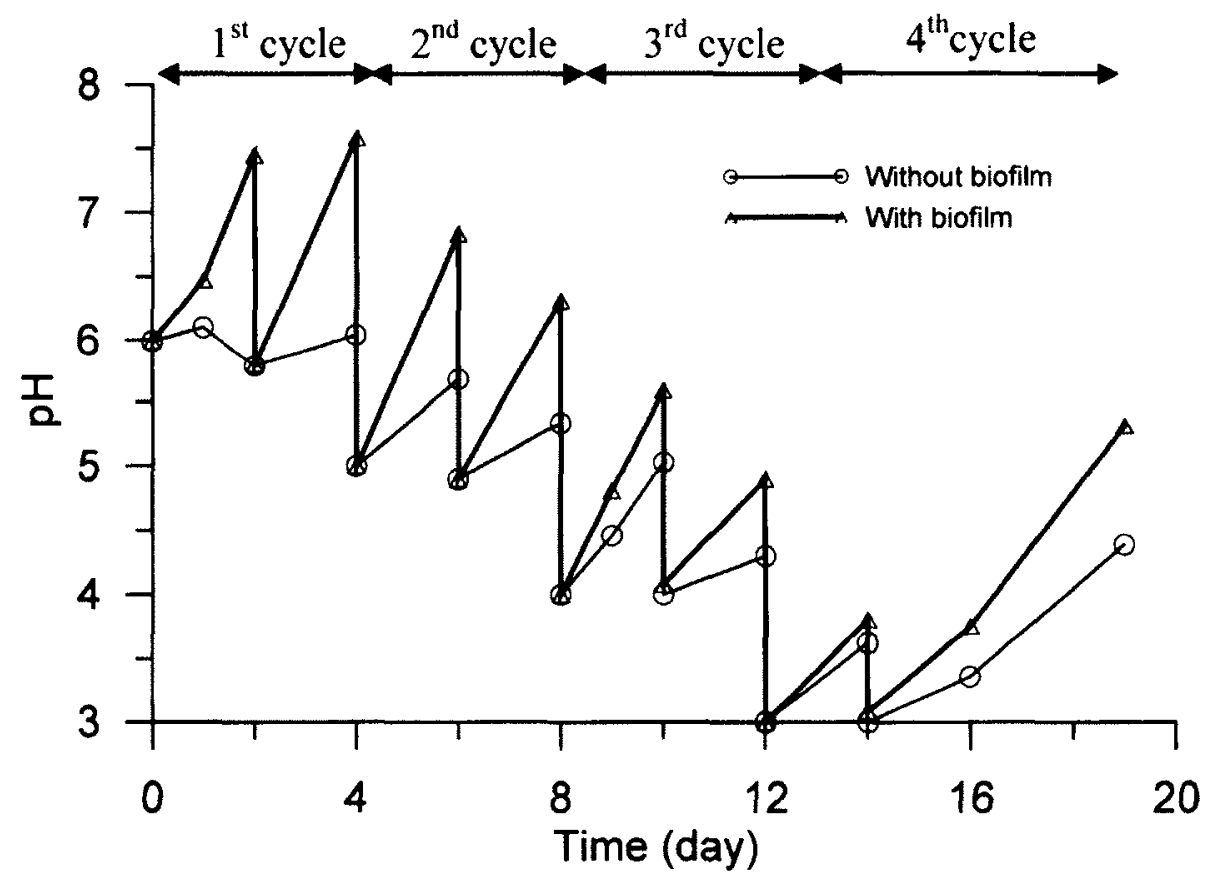

Figure 5.1: Solution $\mathrm{pH}$ in the reactor with biofilm-covered mortar and control mortar specimen without biofilm under chemical acidification.

Extending the last cycle of acidification to 7 days showed that the solution $\mathrm{pH}$ in the reactor with the biofilm-covered mortar has increased considerably from 3 to 5.3 (Figure 5.1) while the calcium concentration was about to reach a plateau (Figure 5.2). However, in the control reactor the calcium concentration was still increasing and the $\mathrm{pH}$ increased to 4.3 due to the high calcium hydroxide leaching (Figure 5.1 and Figure 5.2). These 
observations also support the previous observation that the $\mathrm{pH}$ increase in the container with the biofilm-covered mortar was mainly due to the protective action of the E.coli bacterial biofilm causing an increase in the buffering capacity of the solution.

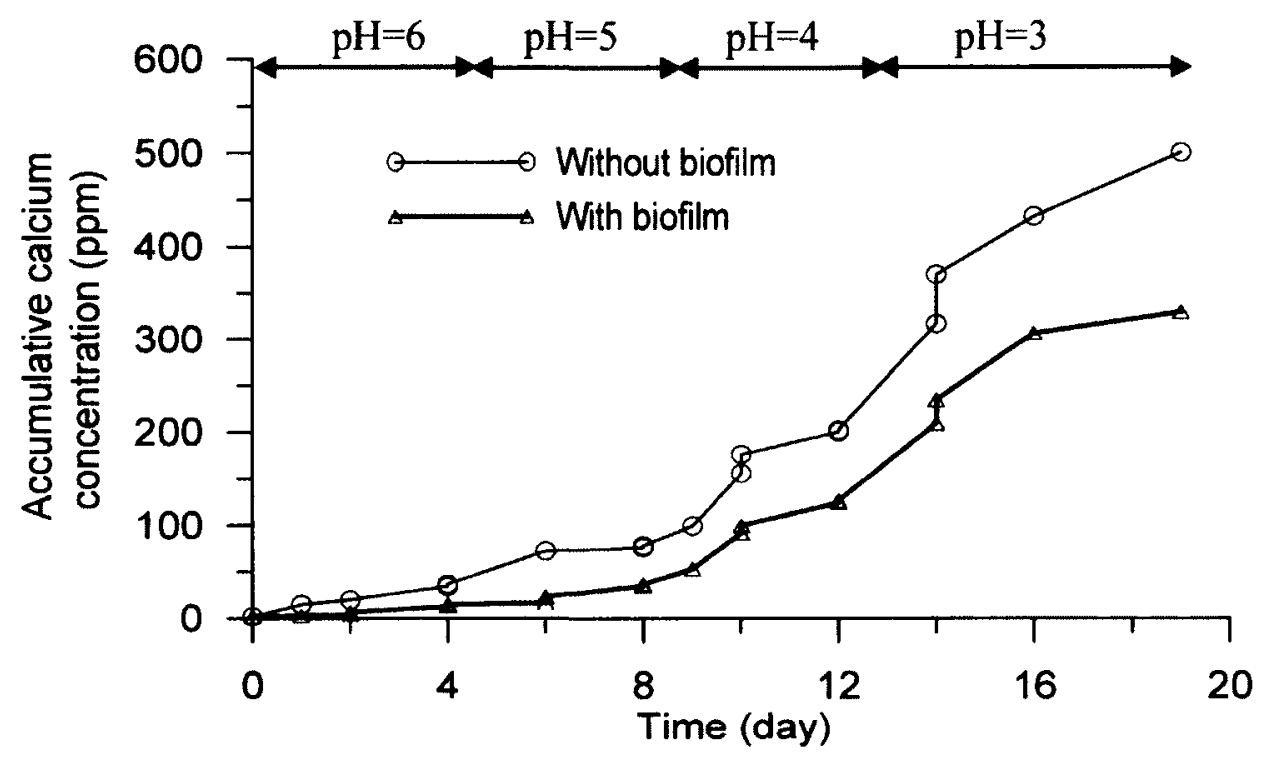

Figure 5.2: Accumulative calcium concentration in the reactor with biofilm-covered mortar and reactor with control mortar specimen without biofilm under chemical acidification.

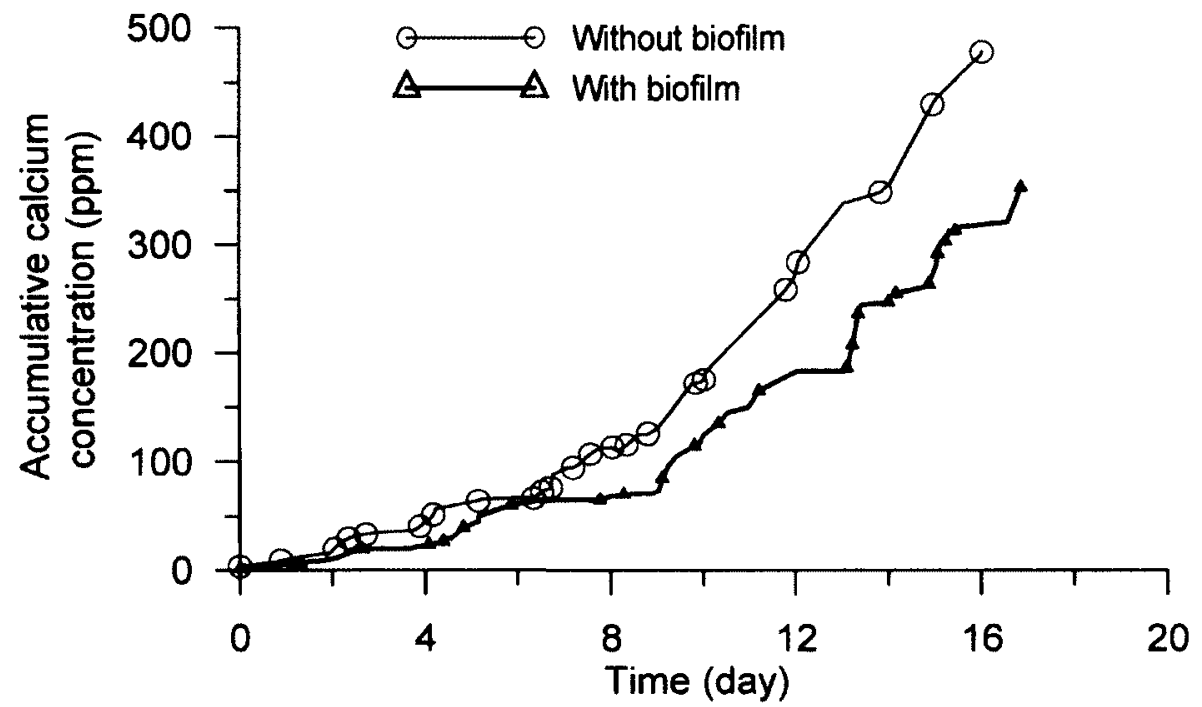

Figure 5.3: Accumulative calcium concentration of the replica experiment in the reactor with biofilm-covered mortar and reactor with control mortar specimen without biofilm. 
A replica experiment was performed to confirm the results presented in Figure 5.2. The same trend for the calcium concentration was observed in the replica reactors as shown in Figure 5.3.

\subsection{SEM/EDS}

The SEM micrographs of the control mortar specimen and biofilm-covered mortar was collected after each acidification cycle. Figure 5.4 shows the SEM images of biofilmcovered mortar after the second cycle of acidification by exposure to $\mathrm{pH}$ of 5 . Comparing Figure 5.4a which is the image of biofilm-covered mortar before acidification with Figure $5.4 \mathrm{~b}$ which is the image of biofilm-covered mortar after the second cycle of acidification indicates that reducing the $\mathrm{pH}$ of the solution from the initial $\mathrm{pH}$ of 7 to 5 decreased the concentration of the bacteria in the biofilm-covered specimen (Figure 5.4a). However, the biofilm was still thick and dense in some areas with good coverage of bacteria (Figure 5.4c) and was thinner and less dense in other places where fewer bacteria were visible (Figure 5.4b). The SEM micrograph of control mortar sample without biofilm after exposure to $\mathrm{pH}$ of 5 is shown in Figure 5.5. This image shows the formation of some micro cracks and deterioration initiation after the exposure to $\mathrm{pH}$ of 5 (Figure 5.5). Comparing Figure 5.4 with Figure 5.5, a smoother surface was observed in the control mortar than the biofilm-covered mortar. This may be due to the formation of a layer of silica gel on top of the mortar surface so the surface seems to be smoother especially at the beginning of the acidification. 


\section{a}

\section{$50 \mu \mathrm{m}$}

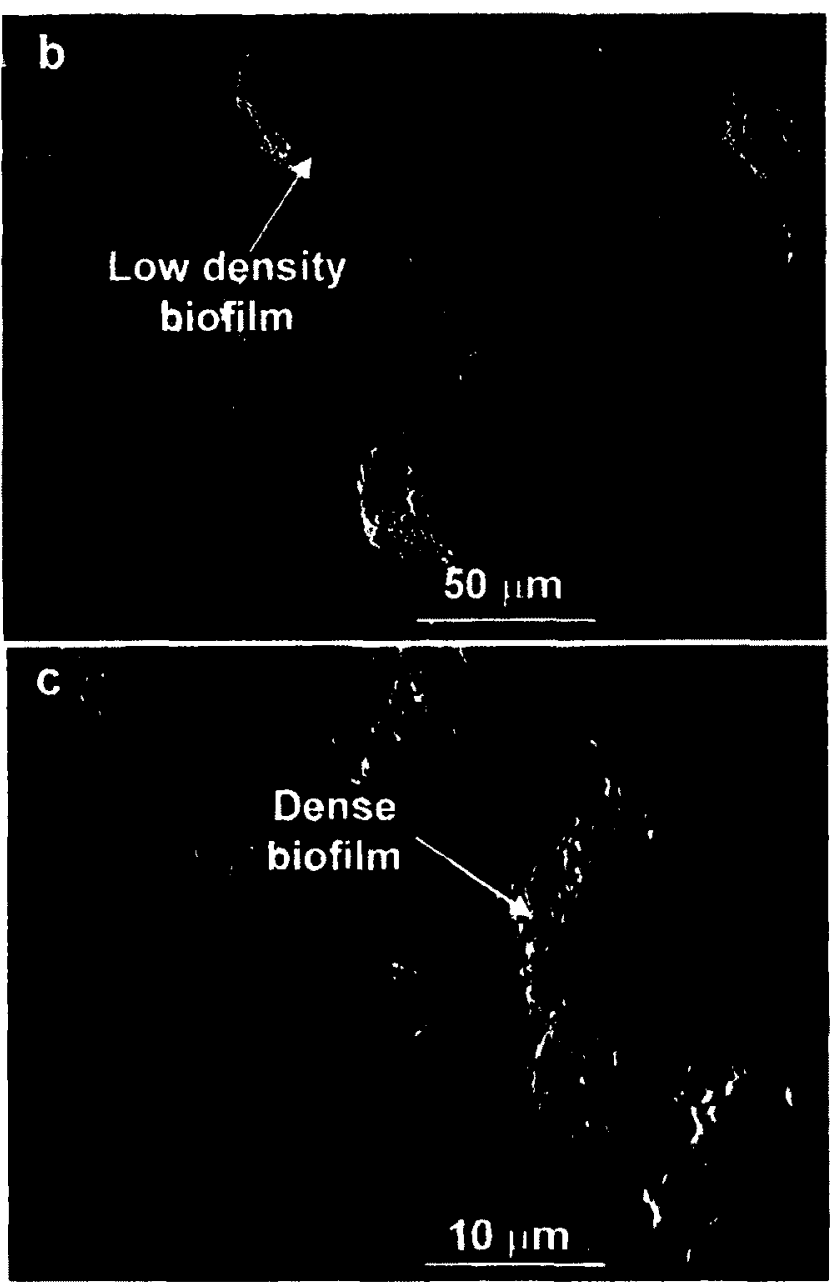

Figure 5.4: a) SEM micrograph with 1000x magnification of biofilm-covered mortar before acidification; b \& c) SEM micrograph of biofilm-covered mortar specimen after exposure to $\mathrm{pH}$ of 5 ; b) $1000 \mathrm{x}$ magnification showing biofilm with less bacterial concentration, c) $5000 \times$ magnification showing high concentration of bacteria in biofilm. 


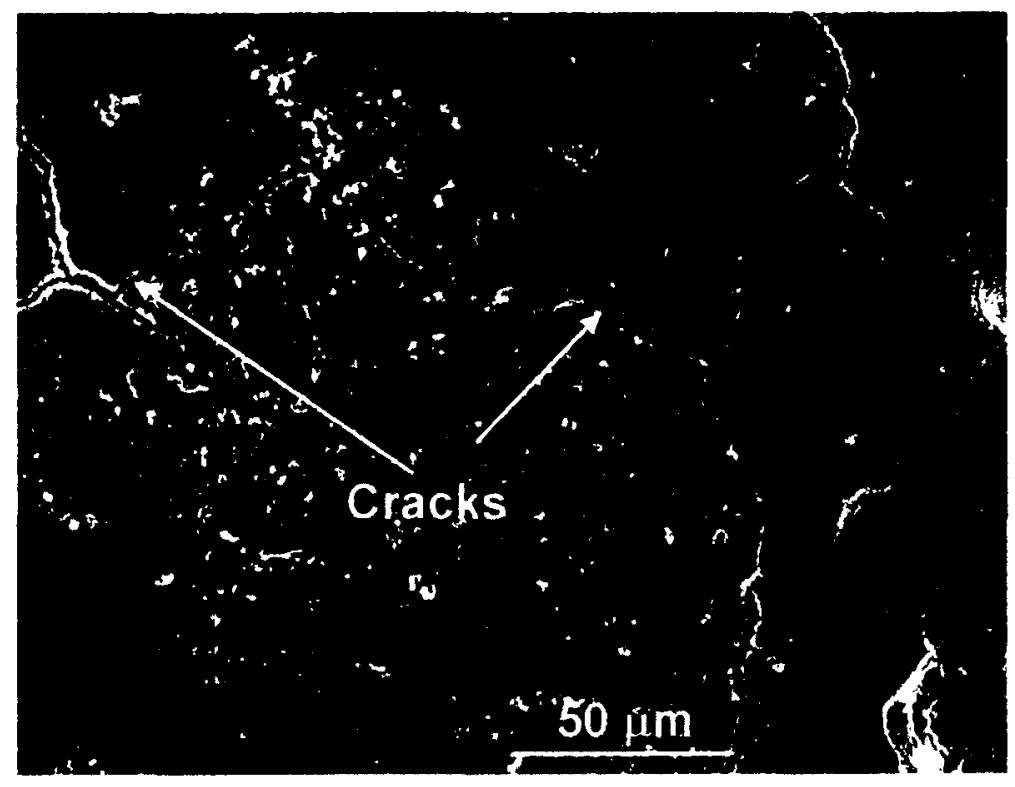

Figure 5.5: SEM image of mortar surface without biofilm after exposing to $\mathrm{pH} 5$ shows formation of cracks on the surface; $1000 x$ magnification.

Even after exposure to $\mathrm{pH}$ of 4 and 3 during the 2 week acidification period, the biofilm layer covering the mortar surface expanded which indicated that the bacteria could survive and continue to grow in this low pH environment (Figure 5.6a). The increase in the concentration of bacteria is likely due to the availability of enough nutrients for bacterial growth and their adoption to the low $\mathrm{pH}$ environment. According to Kubota et al. (2008), the higher EPS secretion increases the resistance of biofilm to the acidic environment; hence it is reasonable that they resist the high acidic environment by increasing the rate of EPS production. The higher buffering capacity of mortar surface due to the presence of calcium hydroxide also provided a good substrate for the biofilm growth during the acidification process resulting in more bacteria growth on the mortar surface. Focusing on the biofilm layer at higher magnification in Figure 5.6b showed some damages to the structure and morphology of the cells which was suspected to be due to the low $\mathrm{pH}$ environment. If the environmental conditions are altered beyond the 
normal limits, the cell membranes are often found to undergo gross structural changes. Exposure of the sample of mortar without biofilm to $\mathrm{pH}$ of 3 showed the presence of an amorphous layer covering the whole surface (Figure 5.7). The amorphous gelatinous layer is most likely hydrous silica gel resulting from the dissolution of C-S-H and is the consequence of sulphate attack as explained in the following paragraph.

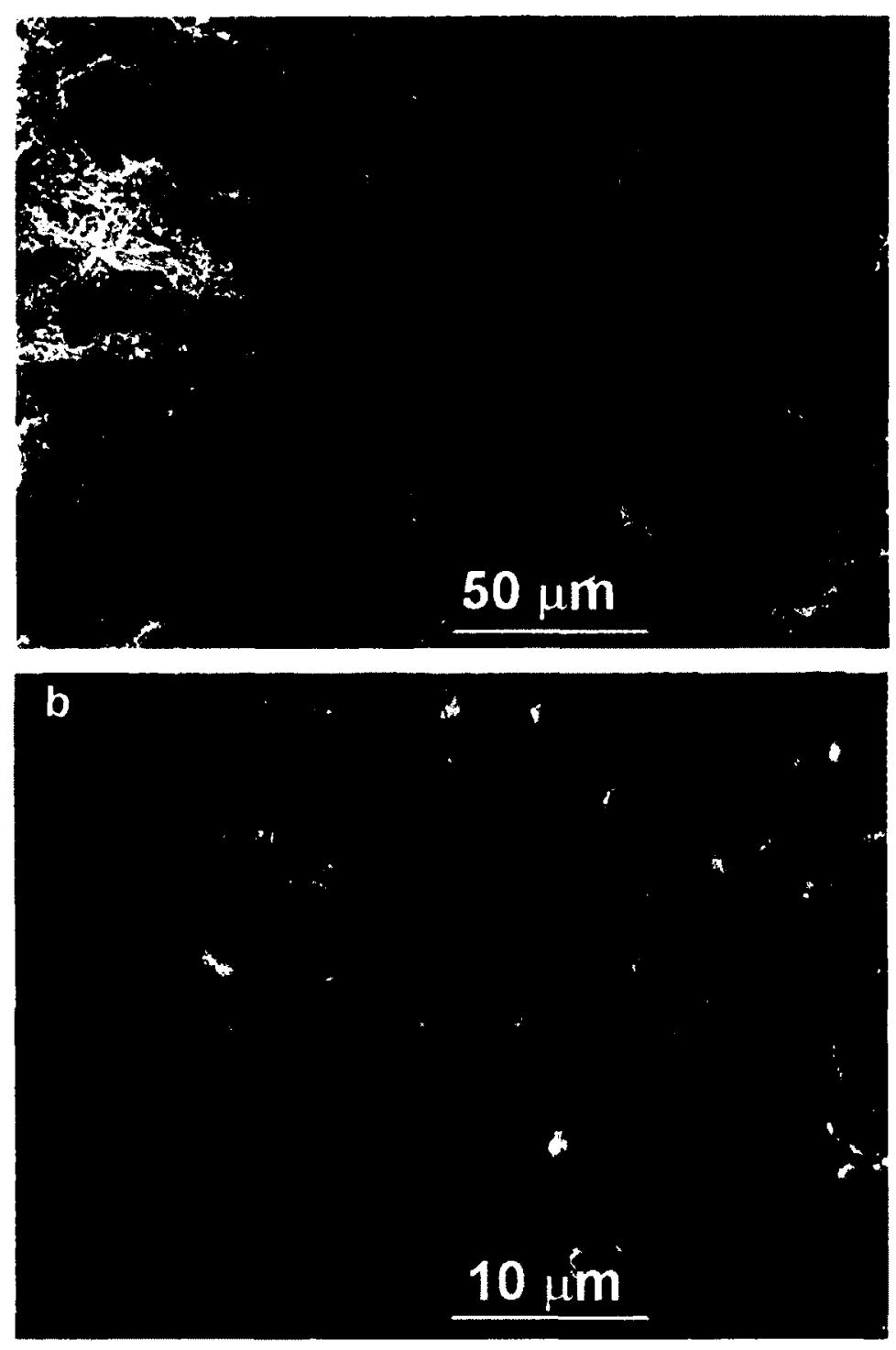

Figure 5.6: SEM image of biofilm-covered mortar surface after the last cycle of acidification; a) $1000 \mathrm{x}$ magnification of the mortar surface; b) $5000 \mathrm{x}$ magnification of the bacterial cell in biofilm. 


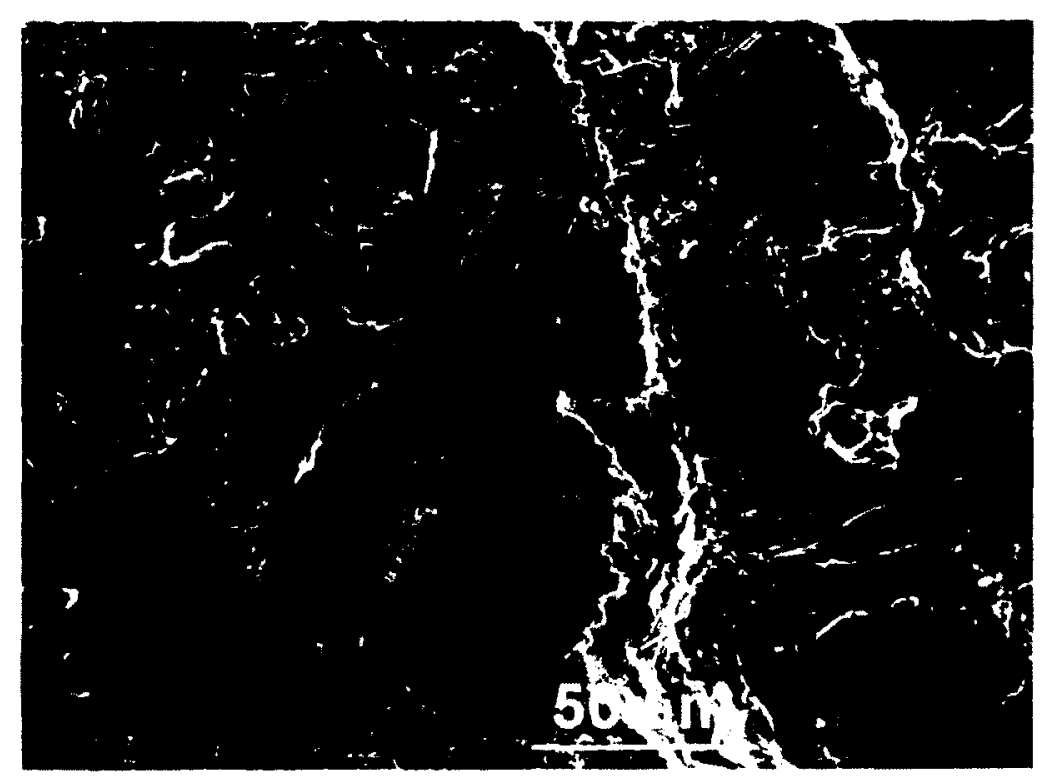

Figure 5.7: SEM image of control mortar surface without biofilm after exposure to $\mathrm{pH}$ value of 3 .

The increase in the atomic fraction of $\mathrm{Si}$ and $\mathrm{Al}$ on the mortar surface without biofilm after chemical acidification is an indicator of concrete deterioration. The increase in Si is an indication of formation of silica gel which is a consequence of decomposition of C-SH (Monteny et al., 2000; Skalny et al., 2001). Skalny et al. (2001) explains that under acidic conditions, the calcium sulfoaluminate hydrate phases (i.e., AFm and AFt) present in the hydrated paste lose their stability and convert to gypsum and aluminum; hence the increase in the atomic percentage of $\mathrm{Al}$ represents decomposition of the sulfoaluminate hydrate phases and initiation of sulphate attack. The EDS analysis results of $200 \mu \mathrm{m} \times 200$ $\mu \mathrm{m}$ area of mortar specimens before and after acidification are provided in Table 5.1. Similar results were also obtained when different $200 \mu \mathrm{m} \times 200 \mu \mathrm{m}$ areas on mortar specimens were analyzed. Comparing the EDS analysis of a mortar surface without biofilm showed that the two elements of $\mathrm{Al}$ and $\mathrm{Si}$ increased from 0.75 and $3.03 \%$ atomic fraction to 2.34 and $6.02 \%$, respectively (Table 5.1). Despite the increase of Al and $\mathrm{Si}$ on control specimen, the biofilm-covered mortar did not show any increase in the 
$\mathrm{Al}$ and $\mathrm{Si}$ elemental composition. Hence, the EDS analysis also indicated the deterioration of mortar without biofilm under the same acidification condition as the biofilm-covered mortar samples. The reduction in the elemental composition of $\mathrm{Al}$ and $\mathrm{Si}$ on the biofilm-covered mortar after acidification can be explained by the coverage of mortar surface by the biofilm layer which increased the atomic fraction of $P$ and reduced the atomic fraction of other present elements, respectively (Table 5.1).

Table 5.1: Percentage atomic fraction of elements on mortar surface under different conditions.

\begin{tabular}{c|cc|cc}
\hline & \multicolumn{2}{|c|}{ Before any acidification } & \multicolumn{2}{c}{ After chemical acidification } \\
Element & No biofilm & $\begin{array}{c}\text { After 8 days of } \\
\text { biofilm growth }\end{array}$ & No biofilm & With biofilm \\
& & 0 & 0 & \\
\hline $\mathrm{S}$ & 0 & 2.41 & 0 & 0 \\
$\mathrm{P}$ & 0 & 38.86 & 58.58 & 28.4 \\
$\mathrm{C}$ & 29.76 & 41.65 & 29.2 & 46.15 \\
$\mathrm{O}$ & 51.46 & 0 & 1.1 & 0 \\
$\mathrm{Na}$ & 0.39 & 0 & 0 & 0 \\
$\mathrm{Mg}$ & 0.14 & 0.56 & 2.34 & 0.23 \\
$\mathrm{Al}$ & 0.75 & 3.48 & 6.02 & 1.59 \\
$\mathrm{Si}$ & 3.03 & 0 & 0 & 0 \\
$\mathrm{~K}$ & 0 & 10.91 & 0.6 & 12.7 \\
$\mathrm{Ca}$ & 13.61 & 0 & 0 & 0 \\
$\mathrm{Fe}$ & 0.16 & 1.49 & 1.32 & 1.04 \\
$\mathrm{Pd}$ & 0.41 & 0.65 & 0.84 & 0.42 \\
$\mathrm{Au}$ & 0.29 & & & \\
\hline
\end{tabular}

\subsection{Confocal Laser Scanning MicRoscopy}

After chemical acidification, the biofilm on the mortar surface was observed using CLSM to evaluate the spatial distribution of bacterial viability and EPS coverage. In Table 5.2 , the relative proportion of biofilm components (i.e. live, dead cells and EPS) after chemical acidification is compared with the biofilm before acidification. The values in this table were obtained by analysing the projected CLSM images in at least 5 different 
fields of view. As shown in the table, the total number of cells and EPS coverage was increased from $10.9 \%$ and $60 \%$ to $16 \%$ and $73.5 \%$, respectively; hence it can be stated that the biofilm sustained itself and continued to grow during the acidification phase. The increase in EPS coverage during the acidification process was in agreement with the findings of Dogsa et al. (2005), who studied the behaviour of EPS structure at different pH values. Dogsa et al. (2005) describes EPS structure as a network of randomly coiled polymeric chains whose average size increases due to acidification, resulting in an increase in the surface area coverage. The increase in the average thickness of biofilm from $29 \mu \mathrm{m}$ to $56.9 \mu \mathrm{m}$ after chemical acidification process also confirms the biofilm growth in this phase. It should also be pointed out that the ratio of live to dead cells decreased from 2.7 to 1.1 showing the higher rate of bacterial death during the acidification period (Table 5.2).

Table 5.2: Live, dead and EPS coverage of biofilm on the mortar surface before and after chemical acidification.

\begin{tabular}{ccc}
\hline & $\begin{array}{c}\text { Before } \\
\text { acidification }\end{array}$ & $\begin{array}{c}\text { After chemical } \\
\text { acidification }\end{array}$ \\
\hline Live (\% area fraction) & $\mathbf{8 . 0 \pm 3 . 2}$ & $\mathbf{8 . 2 \pm 2 . 6}$ \\
Dead (\% area fraction) & $2.9 \pm 1.5$ & $7.8 \pm 2.8$ \\
EPS (\% area fraction) & $63.1 \pm 11.5$ & $73.5 \pm 4.19$ \\
Thickness $(\mu \mathrm{m})$ & $29 \pm 5.1$ & $56.9 \pm 16.2$ \\
\hline
\end{tabular}

The CLSM images of biofilm-covered mortar at different depths in a representative view are shown in Figure 5.8 and Figure 5.9. To clearly see the stained bacteria, the CLSM images of biofilm-covered mortar stained with calcofluor and Live/Dead are shown separately in Figure 5.8 and Figure 5.9, respectively. Supplementary CLSM images of biofilm-covered mortar after chemical acidification at different field of views are provided in Appendix B. 


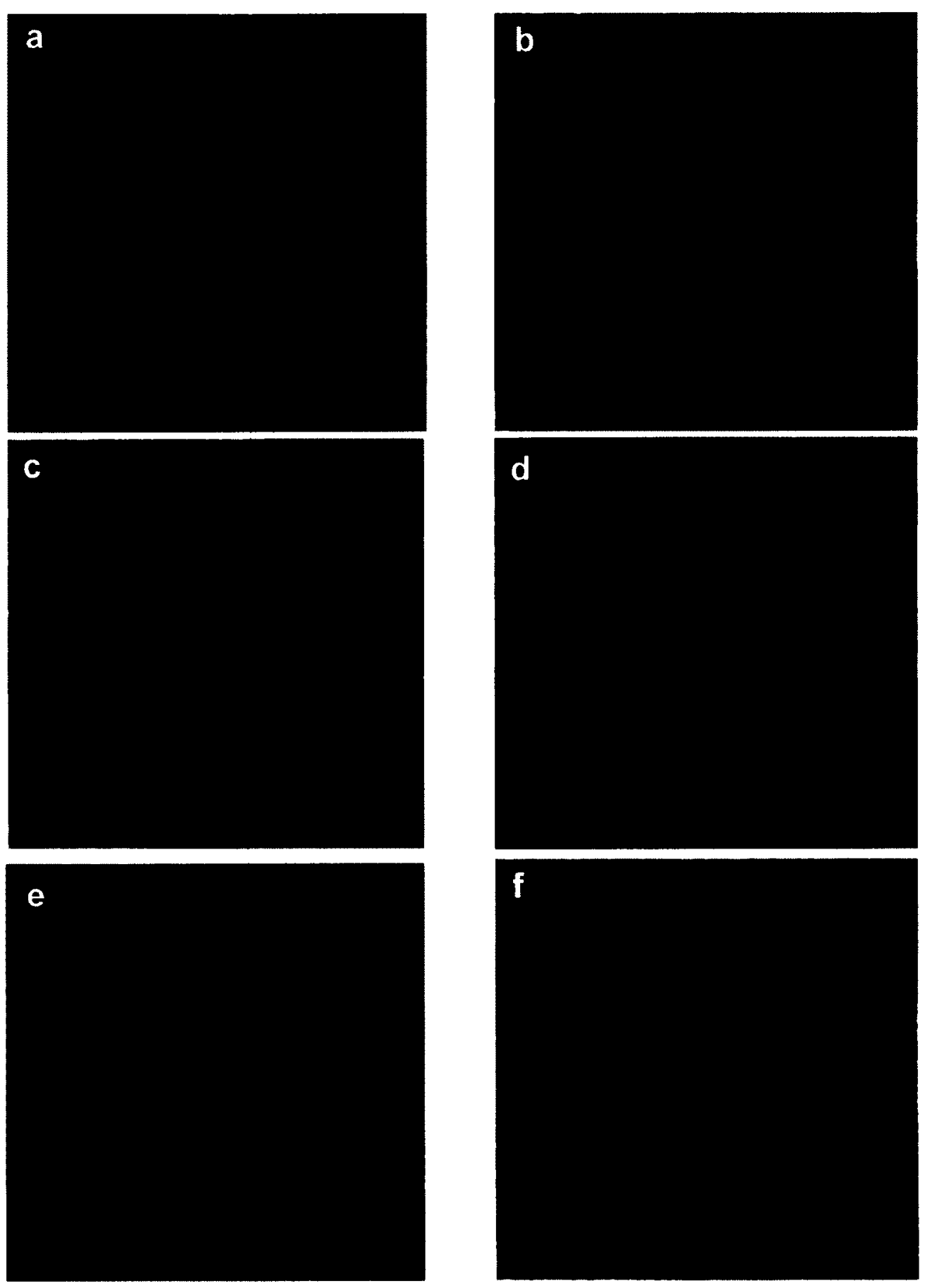

Figure 5.8: CLSM images of biofilm on mortar surface after chemical acidification stained with calcoflour for polysaccharide (cyan); image of biofilm at (a) $10 \mu \mathrm{m}$, (b) $20 \mu \mathrm{m}$, (c) $31 \mu \mathrm{m}$, (d) $45 \mu \mathrm{m}$, (e) $59 \mu \mathrm{m}$ distance from the mortar surface, f) projected image of all the subsections in the same view. Scale bar represents $10 \mu \mathrm{m}$. 

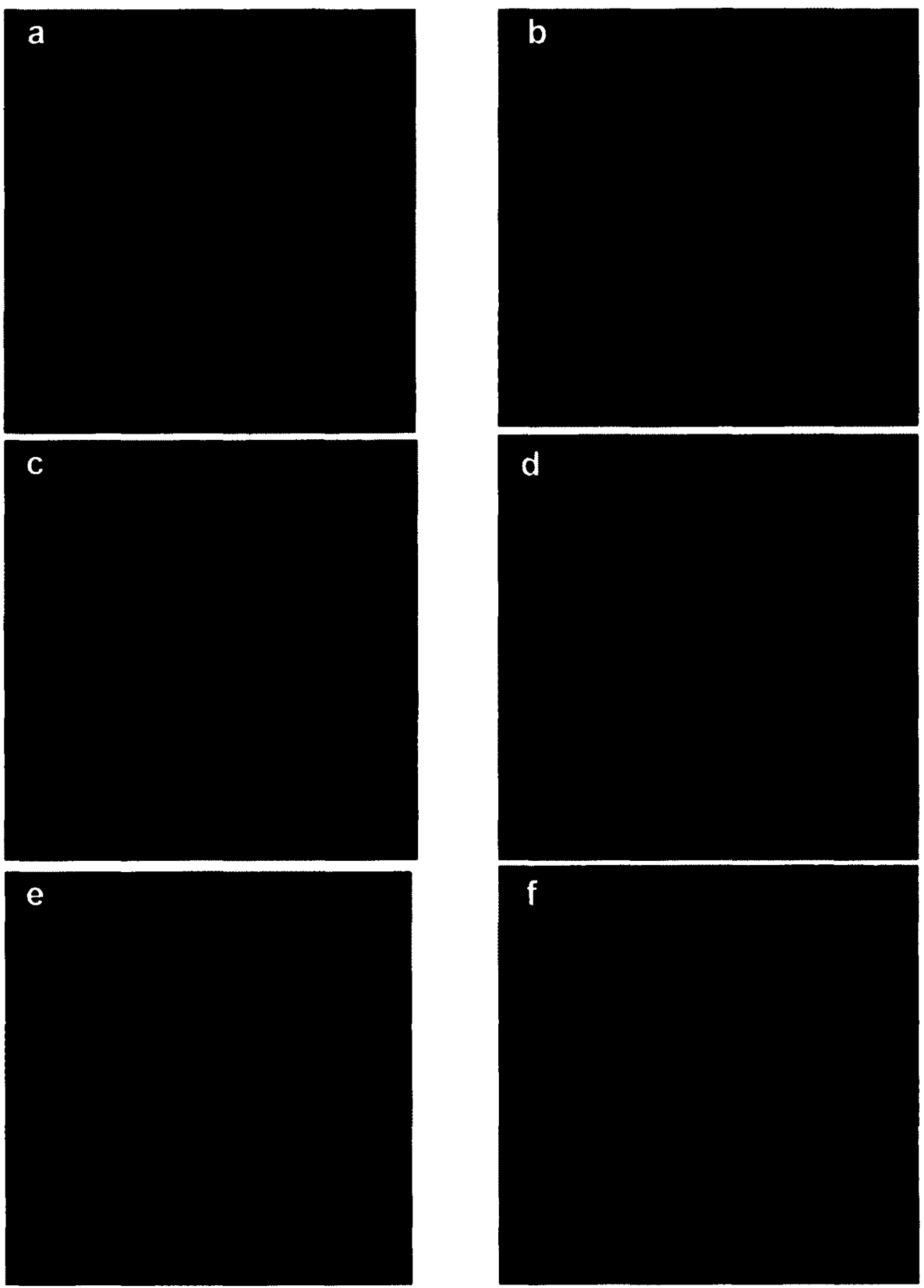

Figure 5.9: CLSM images of biofilm on mortar surface after chemical acidification stained for live cells (green) and dead cells (red); image of biofilm at (a) 10 $\mu \mathrm{m}$, (b) $20 \mu \mathrm{m}$, (c) $30 \mu \mathrm{m}$, (d) $40 \mu \mathrm{m}$, (e) $50 \mu \mathrm{m}$ distance from the mortar surface, $\mathrm{f}$ ) projected image of all the subsections in the same view. Scale bar represents $10 \mu \mathrm{m}$. 

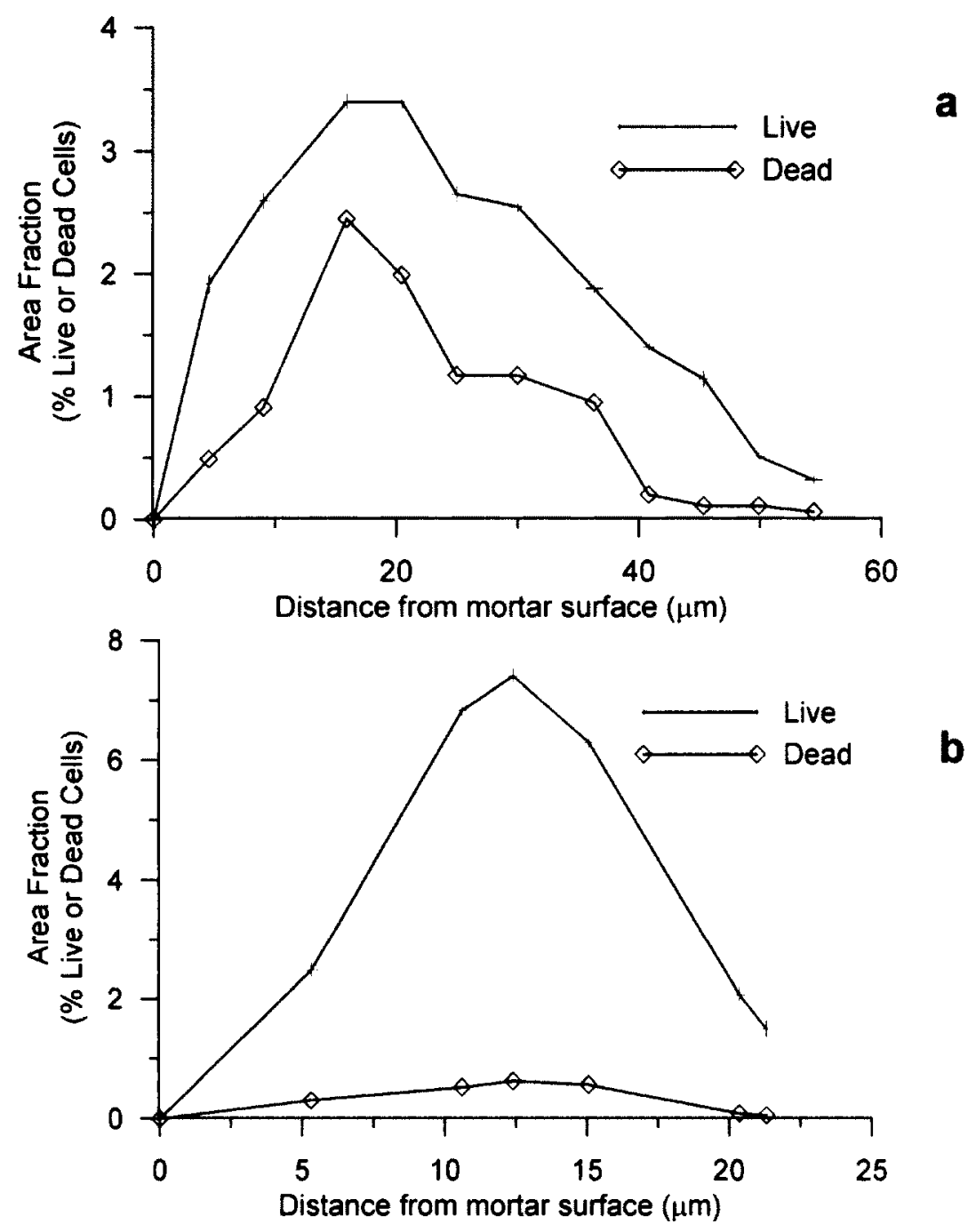

Figure 5.10: Spatial distribution of bacterial viability within the E.coli biofilm attached to mortar surface after chemical acidification; a) first field of view, b) second field of view.

The spatial distribution of biofilm viability after chemical acidification was obtained by analysing the CLSM images taken throughout the complete biofilm thickness (from the surface to its base). Figure $5.10 \mathrm{a}$ and $\mathrm{b}$ shows the biofilm viability profile at two field of views with different biofilm thicknesses. Figure 5.10 indicates the heterogeneity of the biofilm layer and its different viability profile at each field of view. For example, at the first field of view, the highest number of cells is closer to mortar-biofilm interface at 0.37 normalized depth of biofilm, but the second field of view shows the highest number of 
cells being closer to biofilm-liquid interface at 0.6 normalized depth (normalized depth is defined as the respected depth divided by the biofilm thickness).

Figure 5.11 shows the spatial distribution of EPS coverage in the biofilm layer before and after acidification process. This graph shows that after the acidification, the structure of the biofilm was changed with more EPS coverage in the middle of biofilm than the biofilm-liquid interface. It is suspected to be due to the low $\mathrm{pH}$ condition during the acidification process which increased the rate of biofilm detachment at the biofilm-liquid interface resulting in the decrease in EPS coverage at the biofilm-liquid interface (Figure 5.11). As illustrated in Figure 5.11, after acidification, the percentage of EPS coverage was reduced in different depths whitin the biofilm. For example at $20 \mu \mathrm{m}$ the percentage EPS coverage was reduced from $44 \%$ before the acidification to $24-26 \%$ coverage after the acidification (Figure 5.11); however, due to the biofilm growth during the acidification and the increase in thickness of biofilm, the overall EPS coverage was increased as reported in Table 5.2.

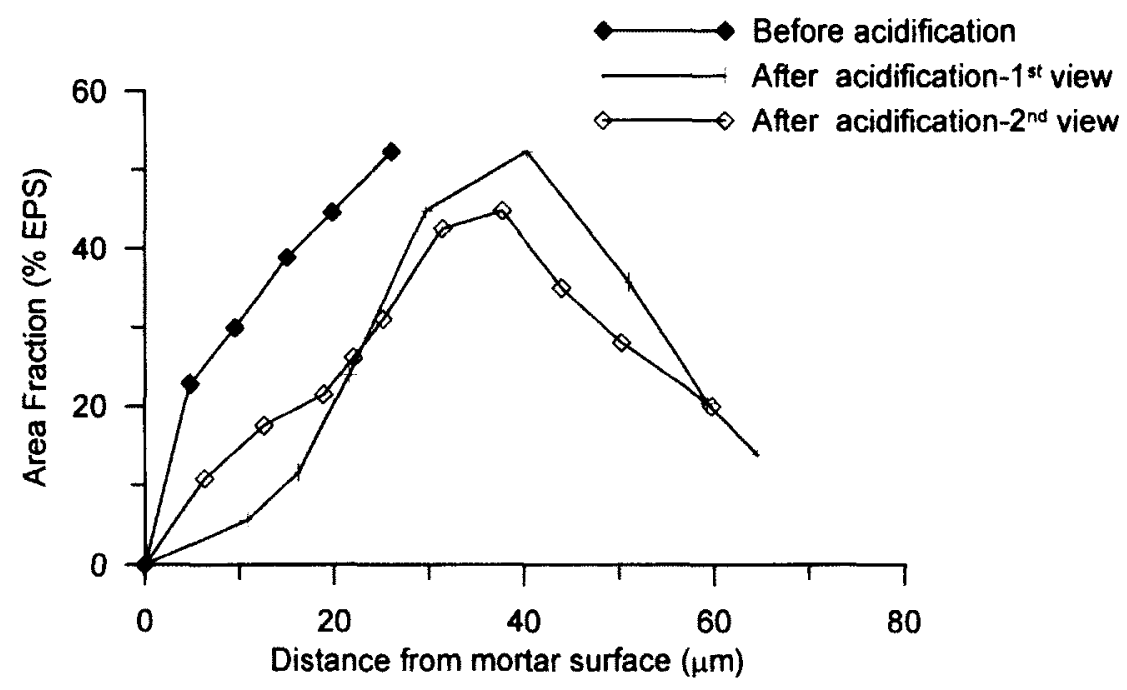

Figure 5.11: Comparison of spatial distribution of EPS coverage within the E.coli biofilm before and after chemical acidification. 


\subsection{Volatile SuSPENDEd Solids}

Volatile suspended solids of biomass attached on mortar specimens before and after chemical acidification were measured to quantify the changes in bacteria densities. As illustrated in Figure 5.12, VSS concentration on the biofilm-covered mortar samples increased from $16 \mathrm{mg} / \mathrm{cm}^{2}$ before the acidification to $80 \mathrm{mg} / \mathrm{cm}^{2}$ after the chemical acidification. The VSS measurements support the CLSM analyses that show an increase in biomass accumulation and confirm the growth of the biofilm layer during the acidification process.

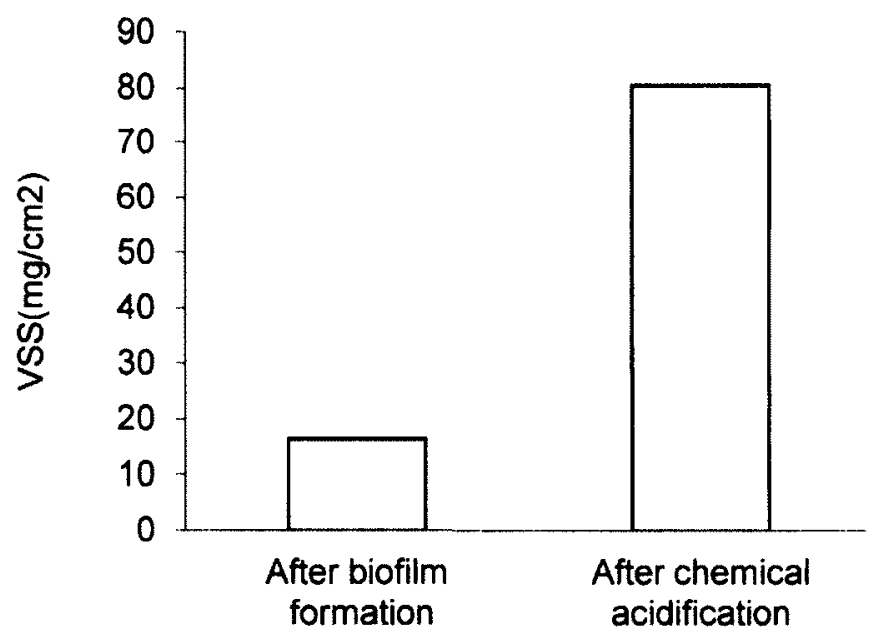

Figure 5.12: Volatile suspended solids measurement of biomass attached to mortar specimens (the values are the average of two VSS measurement on the surface of two mortar cubes).

\subsection{X-RAY Diffraction}

The main purpose of XRD analysis was to identify the presence of gypsum and ettrengite crystals known to be the indicators of sulphuric acid attack in concrete. The use of XRD to quantify the concentration of compounds and minerals is not recommended since in 
most of the cases it underestimates the quantities or does not detect the presence of substances as a result of the presence of crystal dislocations, embedment of materials in other phases or in gels and impurity of minerals (Ramachandran and Beaudoin, 2001). Therefore XRD technique is not used to quantify the amounts of the crystals in this study.

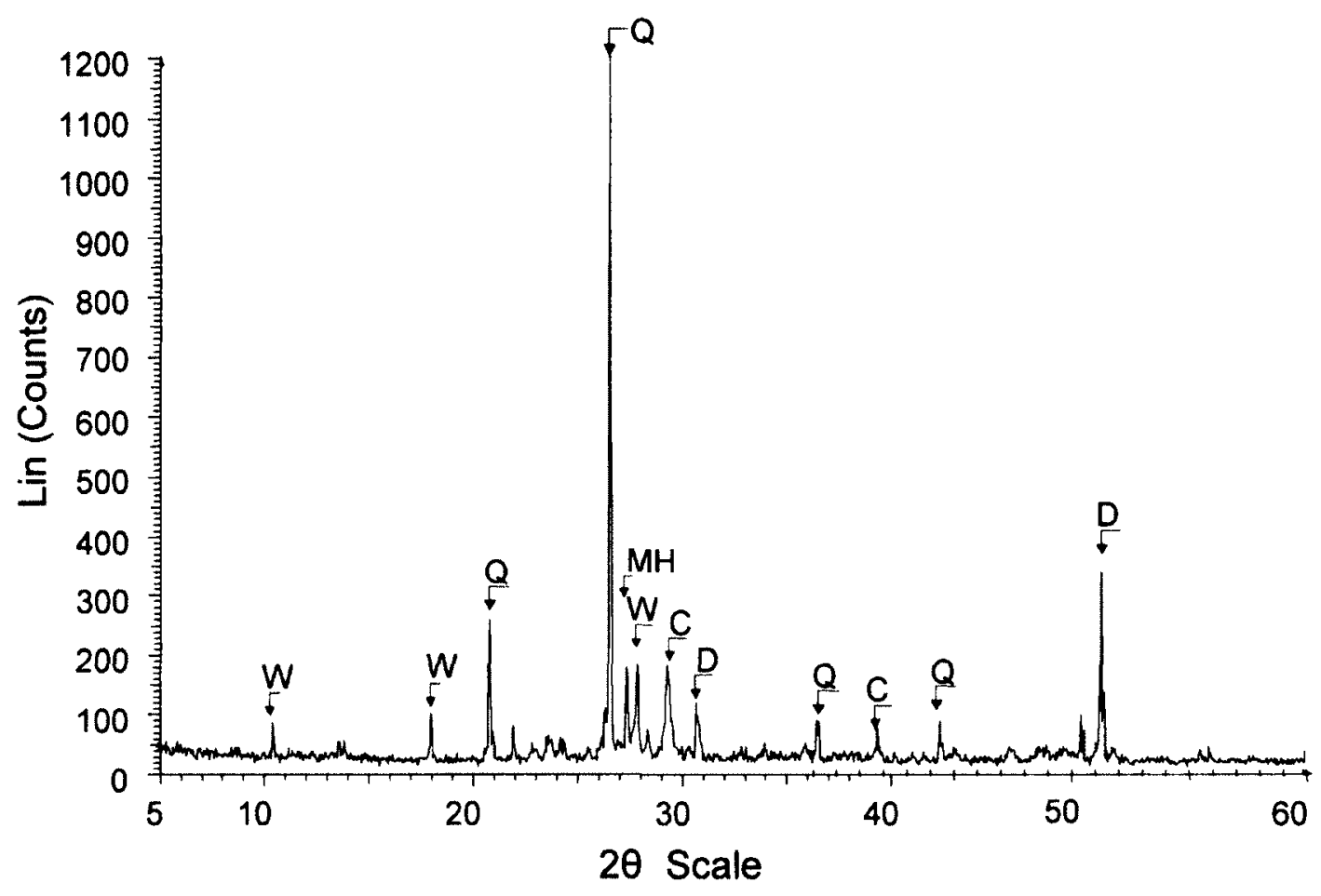

Figure 5.13: XRD of mortar powder taken from top $0.5 \mathrm{~mm}$ surface of mortar surface before any treatment; dolomite $(\mathrm{D})$, gypsum $(\mathrm{G})$, quartz $(\mathrm{Q})$, magnesium calcite $(\mathrm{C})$, winchitte potassium (W).

The XRD of powdered mortar samples taken from an untreated mortar specimen were compared with the chemically acidified mortar samples taken from specimens covered with biofilm and without biofilm. The XRD results of the top $0.5 \mathrm{~mm}$ layer of untreated mortar sample identified the presence of dolomite (D), quartz (Q), magnesium calcite (C), and winchitte potassium (W) (Figure 5.13). The XRD analysis of control mortar without biofilm and biofilm-covered mortar after chemical acidification is shown in 
Figure 5.14 and Figure 5.15, respectively. As illustrated in these figures, regardless of the presence of biofilm, the crystal composition of mortar specimens after chemical acidification were similar to the untreated mortar except for the increase in the formation of magnesium sulphate hydroxide (MH) (Figure 5.14 and Figure 5.15). The XRD analysis of control mortar after chemical acidification confirms the SEM findings in which no gypsum or ettrengite crystals were observed (Figure 5.7). As explained by Skalny (2002) and Allahverdi and Skvara (2000) during the sulphuric acid attack of cementitious materials, C-S-H and calcium hydroxide of the concrete will be ultimately converted to amorphous silica gel hence the peak of gypsum or ettrengite crystals were not present in the XRD pattern of the control mortar after acidification (Figure 5.14).

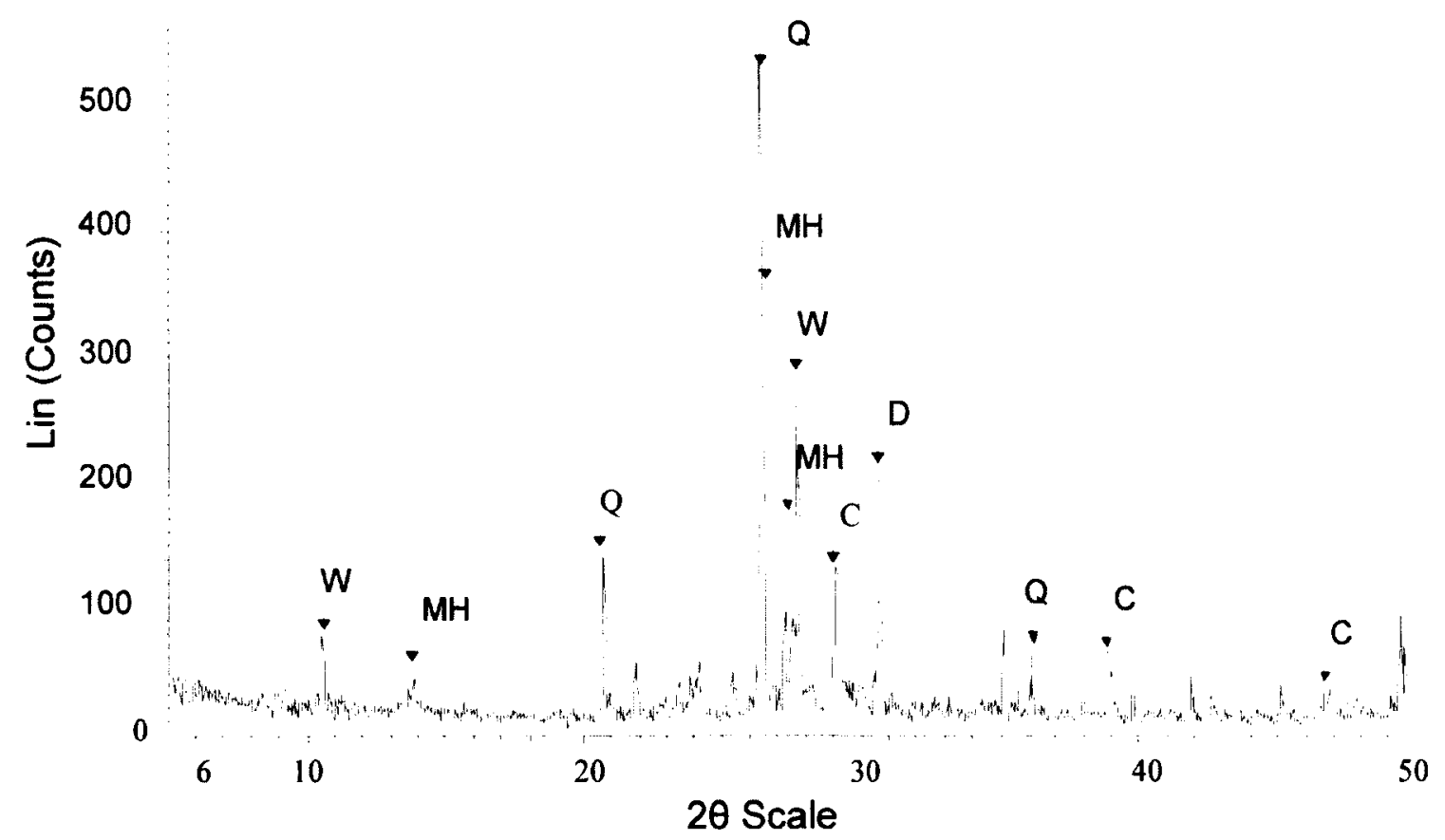

Figure 5.14: XRD of mortar powder taken from top $0.5 \mathrm{~mm}$ surface of mortar without biofilm after chemical acidification; dolomite (D), gypsum (G), quartz $(\mathrm{Q})$, magnesium calcite $(\mathrm{C})$, magnesium sulphate hydroxide $(\mathrm{MH})$, winchitte potassium (W). 


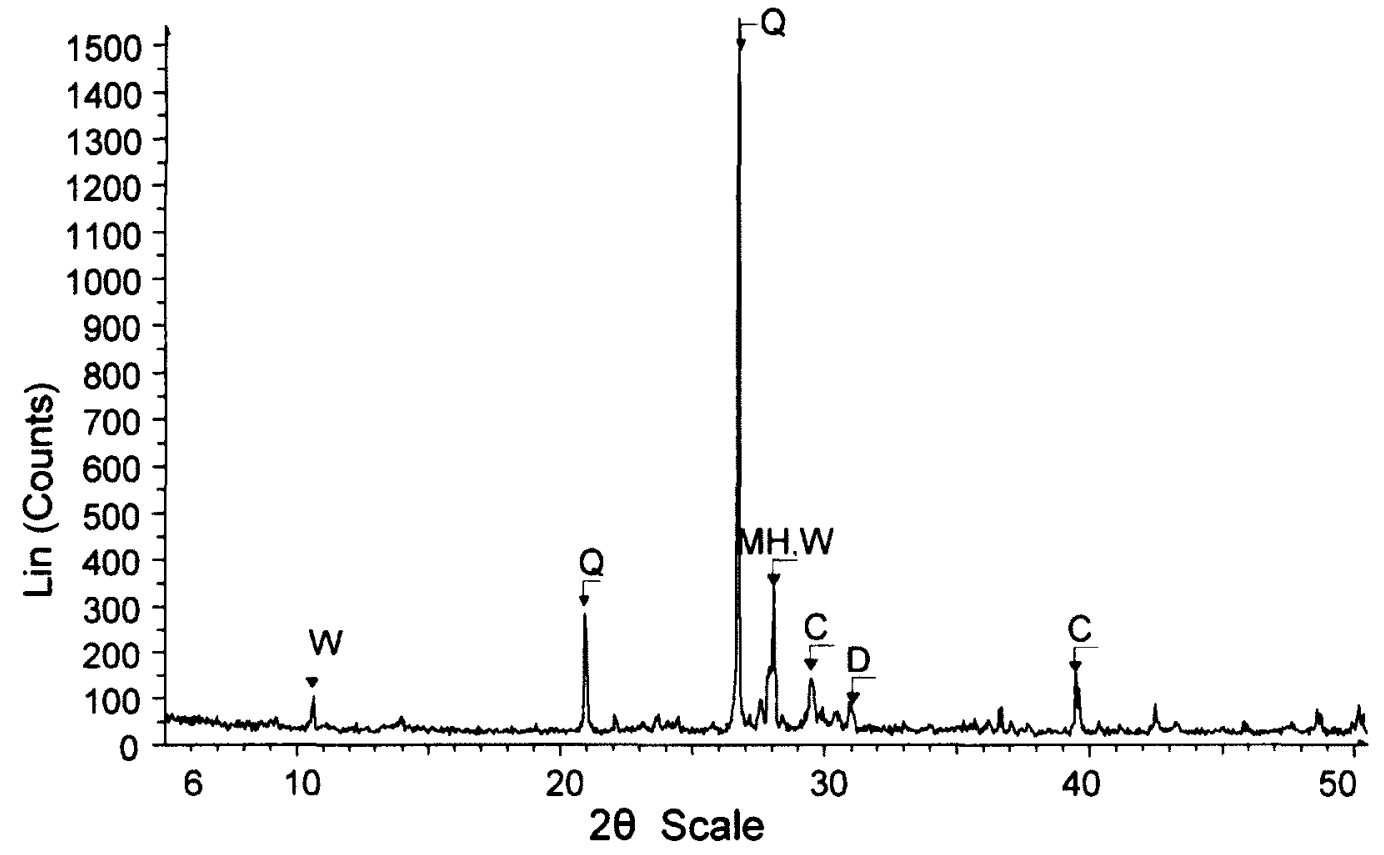

Figure 5.15: XRD of mortar powder taken from top $0.5 \mathrm{~mm}$ surface of biofilm-covered mortar after chemical acidification; calcium carbonate (CC), dolomite (D), gypsum $(\mathrm{G})$, quartz $(\mathrm{Q})$, magnesium calcite $(\mathrm{C})$, magnesium sulphate hydroxide $(\mathrm{MH})$, winchitte potassium $(\mathrm{W})$.

\subsection{CONCLUDING REMARKS}

The effectiveness of biofilm as a protective barrier against sulphuric acid attack in mortar was shown using sulphuric acid solutions. The data from calcium leach-out concentration, SEM and EDS analysis all suggest that the presence of biofilm helped to reduce the chemically induced mortar deterioration. The calcium concentration in control reactors without biofilm was $23-47 \%$ higher than the reactors with biofilm-covered mortar. This confirms a higher dissolution rate of calcium hydroxide and C-S-H from the control mortars than the biofilm-covered mortars.

SEM micrographs taken after the chemical acidification process showed the presence of silica gel on the mortar surface without biofilm which is an indication of sulphate attack. 
The presence of silica gel was also confirmed with the EDS analysis and increase in the atomic fraction of Si on the control mortar samples.

CLSM and VSS analysis both confirmed that the biofilm remained alive and continued to grow during the acidification process. 


\section{CHAPTER 6. BIOGENIC SULPHURIC ACID DETERIORATION}

\subsection{INTRODUCTION}

The effectiveness of biofilm against the biogenic sulphuric acid deterioration was evaluated in this chapter. In order to simulate the biogenic sulphuric acid deterioration, two strains of SOB, Thiobacillus thiooxidans and Thiobacillus neapolitanus, were grown in the modified broth at neutral $\mathrm{pH}$ to naturally reduce the $\mathrm{pH}$ of medium inside the reactor by their activities. The severity of the mortar deterioration was evaluated by measuring the concentration of calcium leach-out, microscopic analysis such as SEM and EDS, crystal analysis using XRD. FISH was employed to confirm the presence of E.coli biofilm and to distinguish the E.coli bacteria from the $\mathrm{SOB}$ on the mortar surface after the biogenic acidification. VSS measurement was employed to compare the concentration of biomass before and after acidification. The biofilm properties (i.e., live, dead and EPS coverage) and their spatial distribution was evaluated on the biofilm-covered specimens by CLSM. CLSM was also employed to identify the presence and viability of SOB bacteria attached to the control mortar surface without biofilm after the biogenic acidification. 


\subsection{SELECTION OF MEDIUM FOR SOB GROWTH}

Two different recipes of broth were evaluated in terms of their ability to grow a mixture of two SOB strains of Thiobacillus thiooxidans and Thiobacillus neapolitanus and to provide higher growth rate. Both broths have initial neutral $\mathrm{pH}$ to provide a solely biogenic acidification. In order to identify which modified broth is better in terms of promoting SOB growth and accelerating the acidification, the mixtures of SOB bacteria were grown for 12 days under at room temperature. The SOB were grown under static conditions in glassware that was open to air. The activity of the bacteria were analysed by measuring the $\mathrm{pH}$ and sulphate concentration in each container during the 12 days of growth. SOB use sulphur compounds as the substrate and oxidize them to sulphuric acid; hence it is expected to observe an increase in the sulphate concentration as the $\mathrm{pH}$ decreases during the SOB growth (Bielefeldt, 2010). The results of $\mathrm{pH}$ and sulphate measurements are shown in Figure 6.1 and Figure 6.2. These figures show that the MB2 is a better broth for the growth of the SOB mixture because the rate of $\mathrm{pH}$ reduction at the early stage of growth was higher for MB2. During the first five days of growth, MB2 showed a $46 \% \mathrm{pH}$ reduction compared to a $15 \% \mathrm{pH}$ reduction for $\mathrm{MB} 1$ (Figure 6.1). According to Figure 6.2, the rate of sulphate generation is higher in MB2 medium which is also indicating the higher activity of SOB mixture in this medium. Therefore, the MB2 was selected as the appropriate medium for the biogenic sulphuric acid deterioration experiment. 


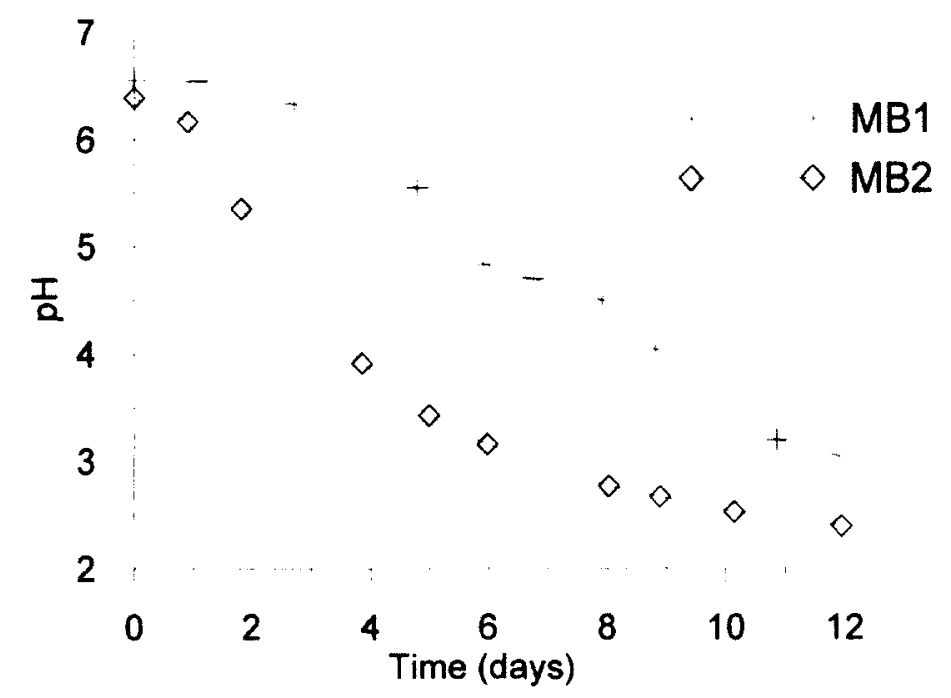

Figure 6.1: The $\mathrm{pH}$ decrease in different modified broths due to the growth of T.thiooxidans and T.neapolitanus.

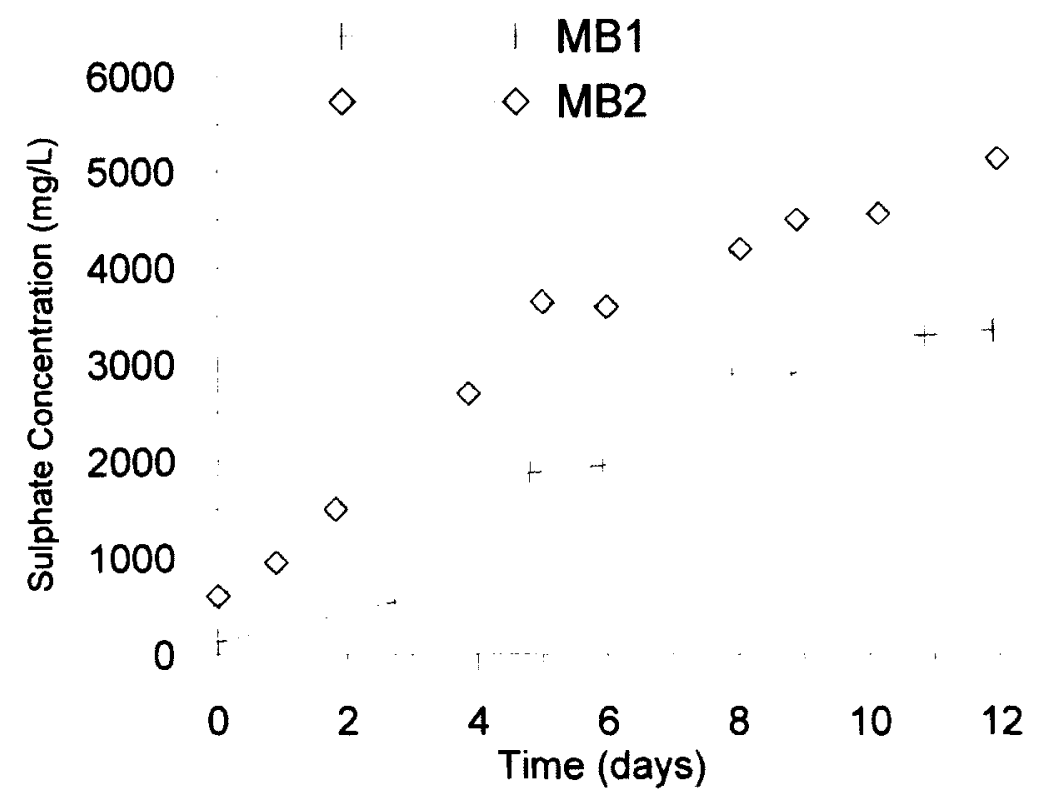

Figure 6.2: The sulphate generation in different modified broths due to the growth of T.thiooxidans and T.neapolitanus; data points are the average of three readings with the standard deviation of less than $250 \mathrm{mg} / \mathrm{L}$.

\subsection{Evaluation OF MORTAR Deterioration}

In this section, the severity of deterioration due to the biogenic acidification on the control mortar disks (i.e., mortar specimen without biofilm) and the biofilm-covered 
mortar disks is compared, and the effectiveness of the $E$. coli biofilm for control of biogenic acidification is evaluated.

\subsubsection{Chemical analysis}

To biologically acidify the mortar disks, two acidophilic and neutrophilic SOB strains of T.thiooxidans and T.neapolitanus were spiked into the reactor shown in Figure 3.1.To evaluate the effectiveness of biofilm against MICD, the biological acidification was carried out in two different reactors, one with the control mortar specimen without the biofilm and one with the biofilm-covered mortar specimen. The biological acidification of mortar specimens consisted of two 15-day cycles of exposure to the fresh broth and SOB bacteria at their exponential growth rate. During these cycles, the $\mathrm{pH}$, calcium and sulphate concentration of the medium inside the reactors were measured.

Figure 6.3, Figure 6.4 and Figure 6.5 are the results of the $\mathrm{pH}$, sulphate and calcium concentrations inside the two reactors with biofilm-covered mortar and control specimens, respectively. The profile of $\mathrm{pH}$ measurements, which serves as an indication of biological activity, shows that the SOB activity successfully reduced the $\mathrm{pH}$ to around 3.4 in the control reactor by day 10 . However, in the reactor with biofilm-covered specimen, the presence of E.coli biofilm was competing against the growth of SOB bacteria, hence no $\mathrm{pH}$ drop was observed in this reactor (Figure 6.3). This observation was also confirmed by measuring the sulphate concentration. As shown in Figure 6.4, the sulphate concentration increased in the control reactor representing a high growth rate of SOB and sulphate concentration remained the same in the reactor containing biofilmcovered mortar indicating the inhibition of $\mathrm{SOB}$ growth. On day 6 , the rate of sulphate production started to decrease which was likely caused by the diminishing food supply 
for the SOB and their slower growth rates. The decrease in sulphate production rate also explains the $\mathrm{pH}$ increase observed in the control reactor after day 10 (Figure 6.3). The $\mathrm{pH}$ increase after day 10 caused by the buffering capacity of $\mathrm{Ca}(\mathrm{OH})_{2}$ that is continuously being released from the mortar surface and was probably higher than the sulphate production rate. On day 15 , the growth medium was replaced with a fresh medium and new batch of SOB mixture to promote biogenic acidification in the second cycle. However, the growth and assimilation of SOB were not successful in the second cycle of acidification. As it is illustrated in Figure 6.3 and Figure 6.4, in the second cycle of acidification, no $\mathrm{pH}$ reduction or increase in the sulphate concentration was observed in any of the reactors. This may be explained by bacterial shock and their adoption to the new environment, and/or the presence of some contamination that was introduced during the evacuation of the reactors.,.

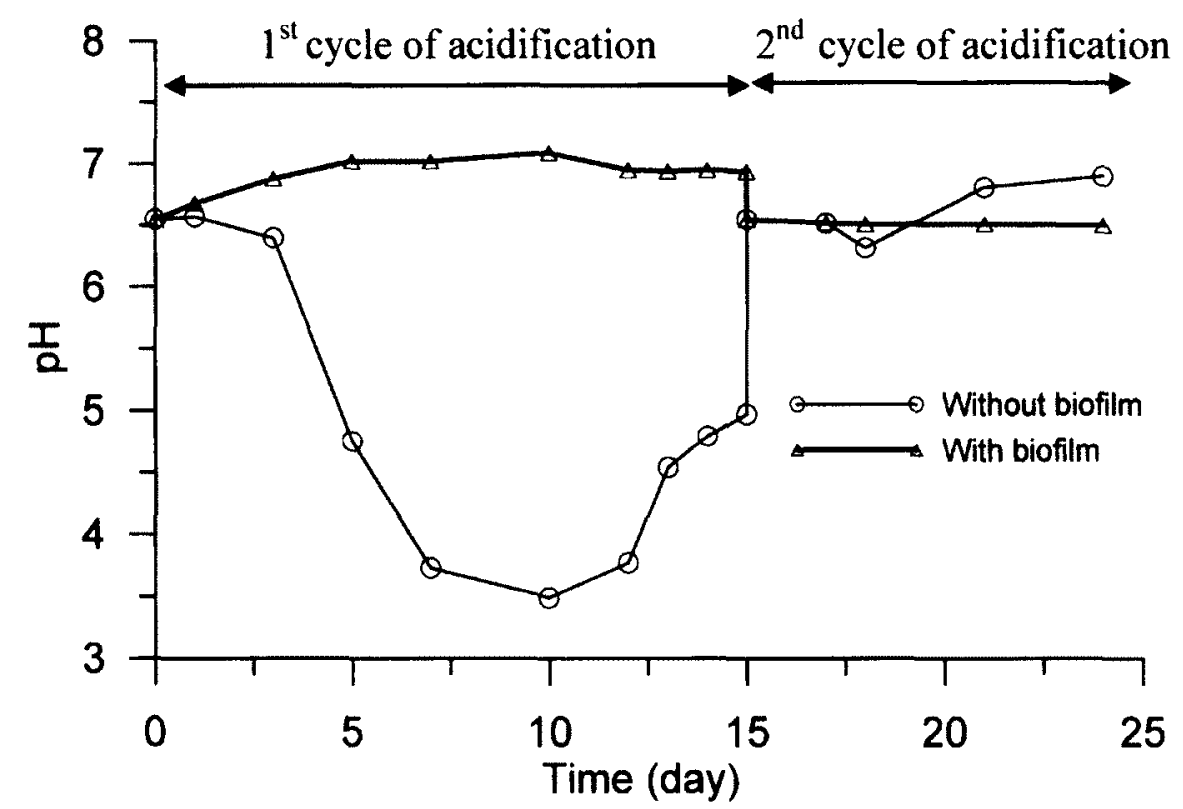

Figure 6.3: $\mathrm{pH}$ in the reactor with biofilm-covered mortar and control mortar specimen without biofilm under biogenic acidification. 
According to Figure 6.5, the calcium concentration in the control reactor increased to 69 $\mathrm{ppm}$ in the first cycle of acidification comparing to the maximum of $11 \mathrm{ppm}$ in the reactor with biofilm-covered mortar. This confirms that in the control reactor the SOB activity increased the dissolution of $\mathrm{Ca}(\mathrm{OH})_{2}$ from the mortar surface resulting in an increase in the calcium concentration and higher deterioration rate of the control mortar sample. Figure 6.5 also shows that the calcium concentration in the biofilm-covered reactor was decreased on the third day. This can be explained by the production of calcium carbonate due to the reaction of $\mathrm{Ca}(\mathrm{OH})_{2}$ with the carbon dioxide and removal of the calcium ion from the solution.

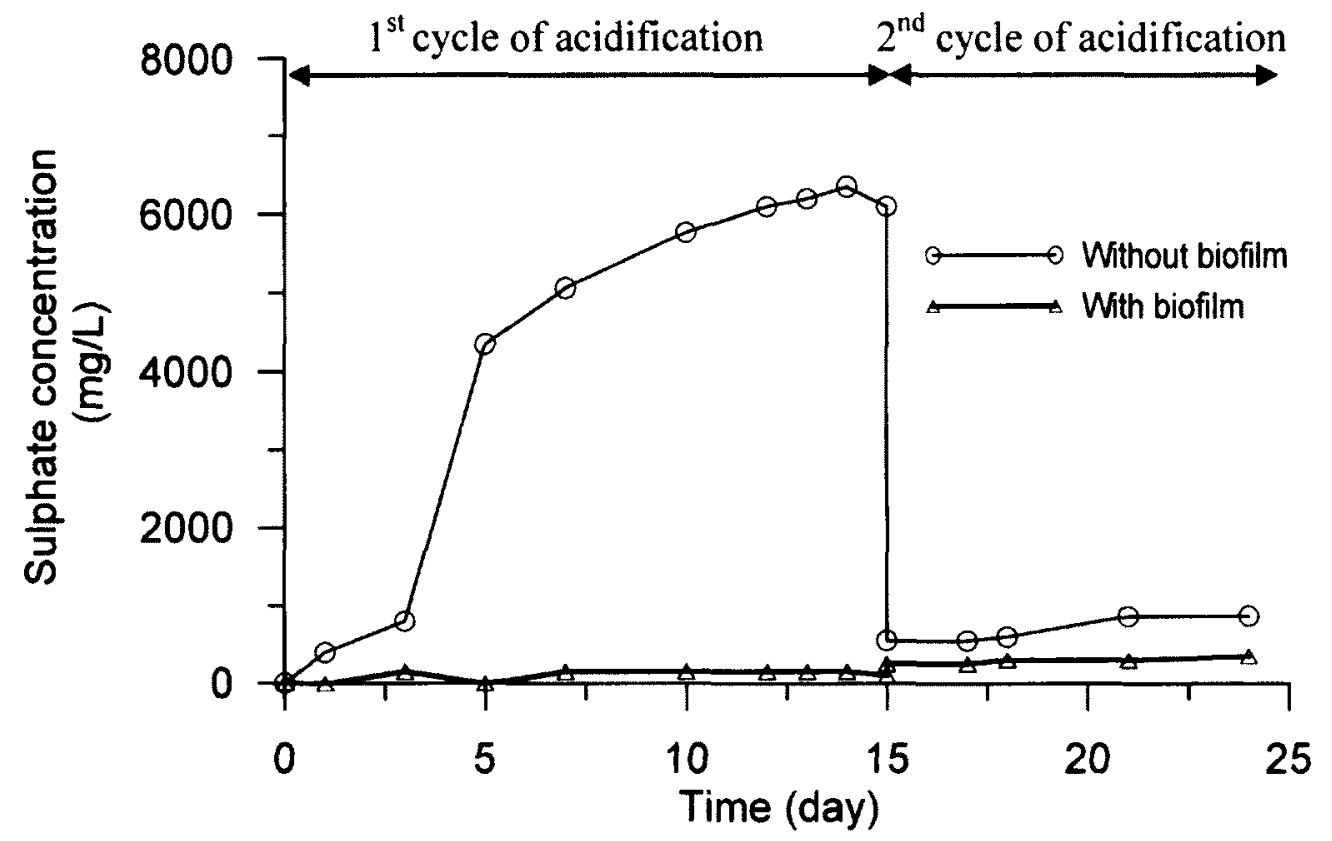

Figure 6.4: Sulphate concentration in the reactor with biofilm-covered mortar and reactor with control mortar specimen without biofilm. 


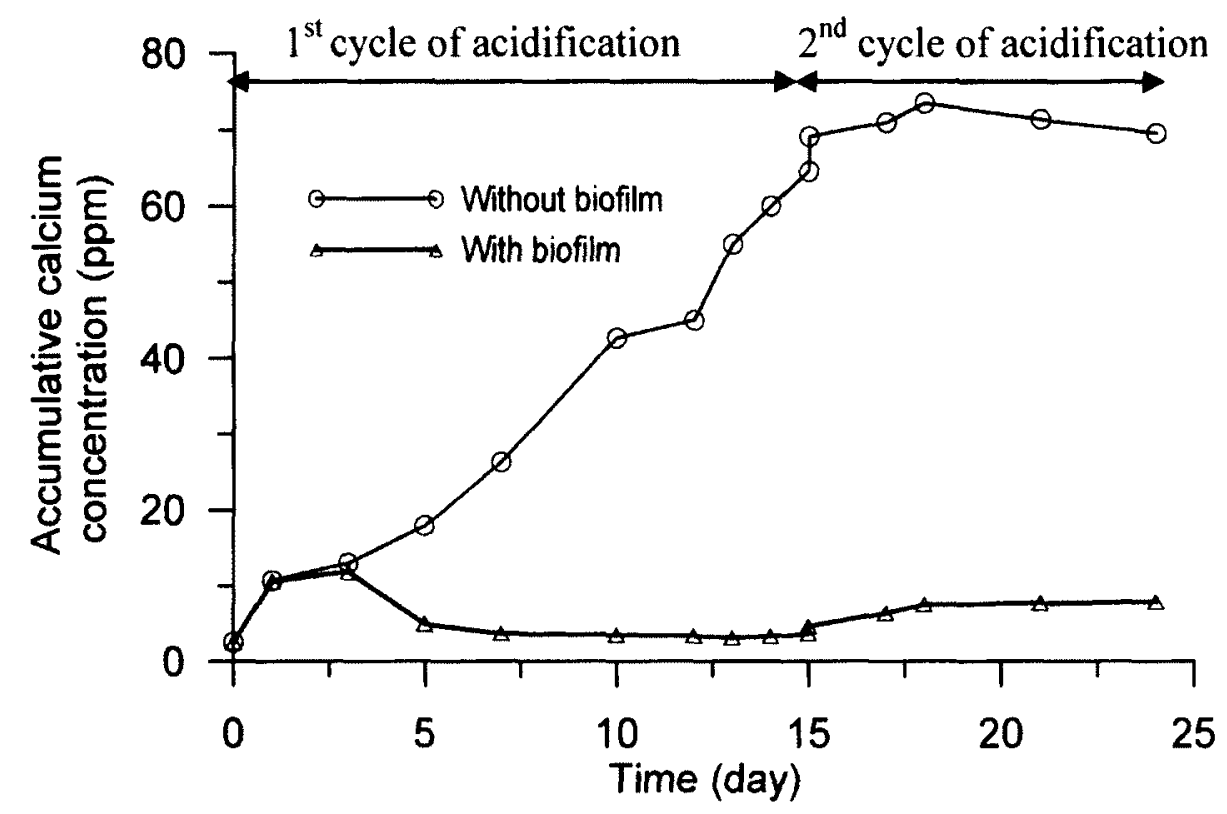

Figure 6.5: Accumulative calcium concentration in the reactor with biofilm-covered mortar and reactor with control mortar specimen without biofilm under biogenic acidification.

A duplicate set of experiments was performed to confirm the accuracy of the results and to see if the contamination issue in the second cycle can be eliminated. Figure 6.6, Figure 6.7 and Figure 6.8 are the results of $\mathrm{pH}$ measurement, sulphate and calcium concentration for the duplicate set of the experiments. As illustrated in Figure 6.6, the same trend was observed for $\mathrm{pH}$ of the solution as the $\mathrm{pH}$ decreased in the control reactor but remained constant without any decrease in the reactor with biofilm-covered mortar. However, in the duplicate experiments, the time of exposure to the low acidic environment was lower than the first set. For example, the time for the control reactor to reach the $\mathrm{pH}$ of 5.5 was 10 days in the duplicate experiment (Figure 6.6) compared to 4 days in the first set of experiments (Figure 6.3). This observation may be explained by less activity of the SOB in the duplicate experiment as compared to the first experiment. Comparing the sulphate concentration graphs (Figure 6.4 and Figure 6.7) also shows that the SOB had a higher growth rate in the first experiment and could increase the sulphate concentration to the 
maximum of $6350 \mathrm{mg} / \mathrm{L}$ in the control reactor. The maximum sulphate concentration in the first cycle of acidification for the duplicate experiment was $4400 \mathrm{mg} / \mathrm{L}$ indicating a lower SOB growth than the first set of experiments (Figure 6.7).

As expected, the trend of calcium leach-out was similar to the first set of experiments, in which higher calcium hydroxide dissolution was observed in the control reactor than the reactor with biofilm-covered mortar (Figure 6.8). The maximum calcium concentration achieved in the duplicate experiments was $38 \mathrm{ppm}$ in the control reactor compared with the $11 \mathrm{ppm}$ in the reactor with biofilm-covered mortar. Comparison of Figure 6.5 and Figure 6.8 shows that the maximum calcium concentration of the control reactor in the duplicate experiment was less than the first set of the experiment. It may be suggested that lower activity of SOB resulted in lower rate of $\mathrm{pH}$ reduction and calcium hydroxide leaching from the mortar. As shown in Figure 6.6 and Figure 6.7, in the duplicate experiment, the contamination was still inhibiting the growth of $\mathrm{SOB}$ and $\mathrm{pH}$ reduction in the second cycle. The biogenic acidification experiment was repeated for the third time with more caution to eliminate any contamination and to be able to see a $\mathrm{pH}$ reduction in the second cycle (the results of the third experiments are not shown). Unfortunately, the problem of contamination was not removed even though the opening and closing of the reactor and the measurement were done under a biological safety cabinet (1300 Series A2, Thermo Scientific). 


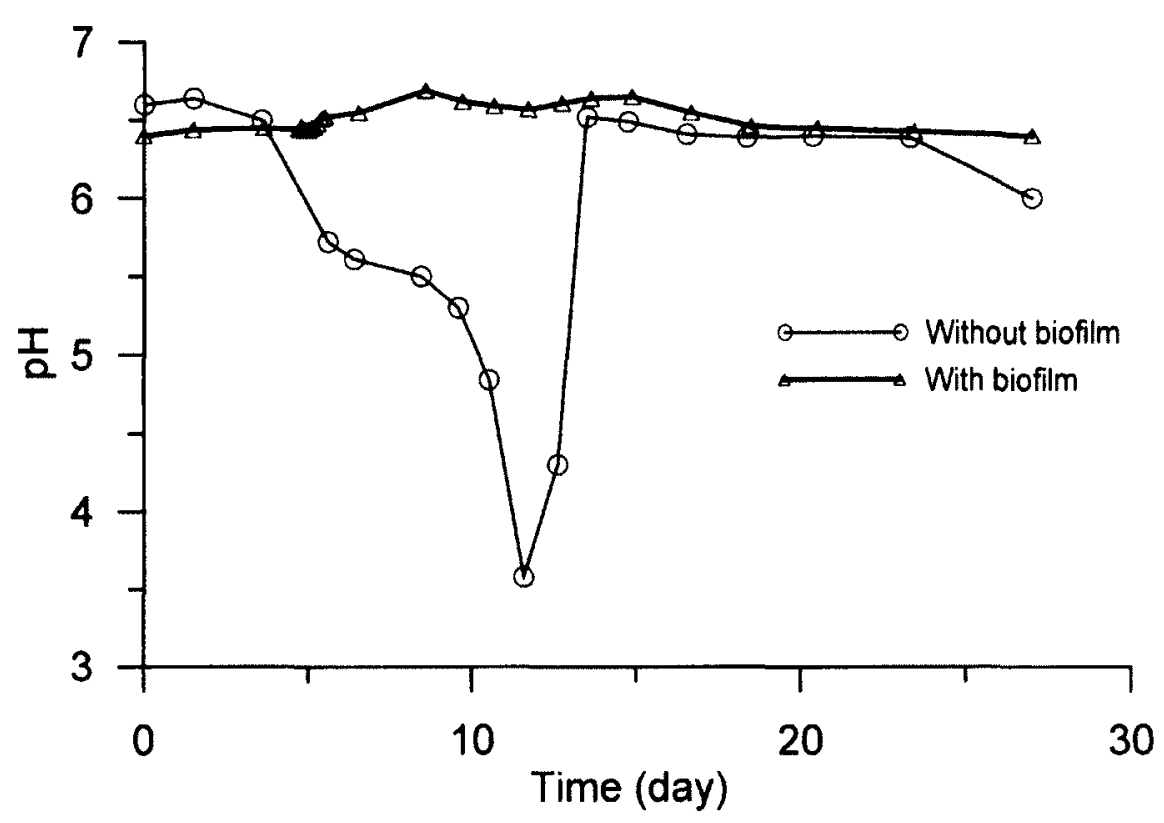

Figure 6.6: $\mathrm{pH}$ in the reactor with biofilm-covered mortar and control mortar specimen without biofilm under biogenic acidification for the duplicate set of experiment.

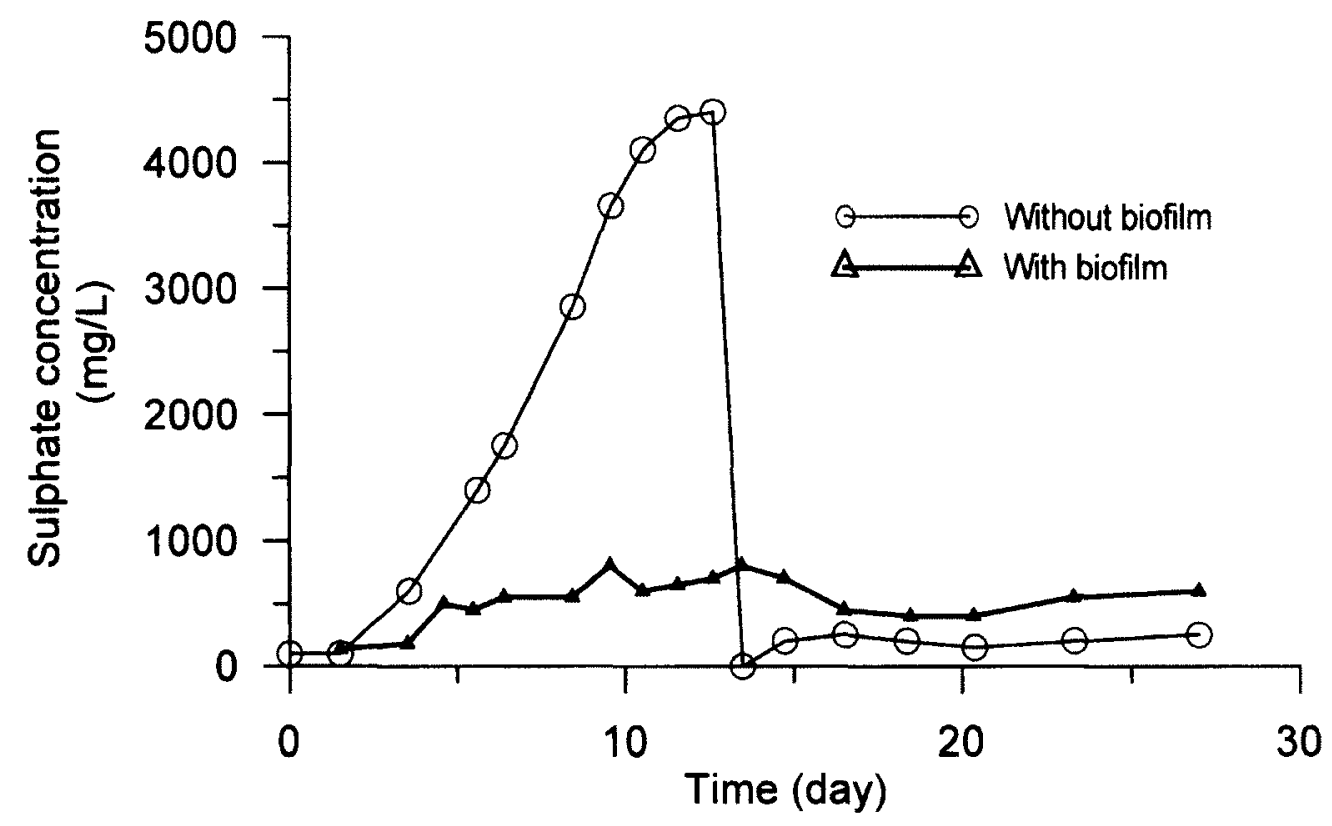

Figure 6.7: Sulphate concentration in the reactor with biofilm-covered mortar and reactor with control mortar specimen without biofilm for duplicate experiment. 


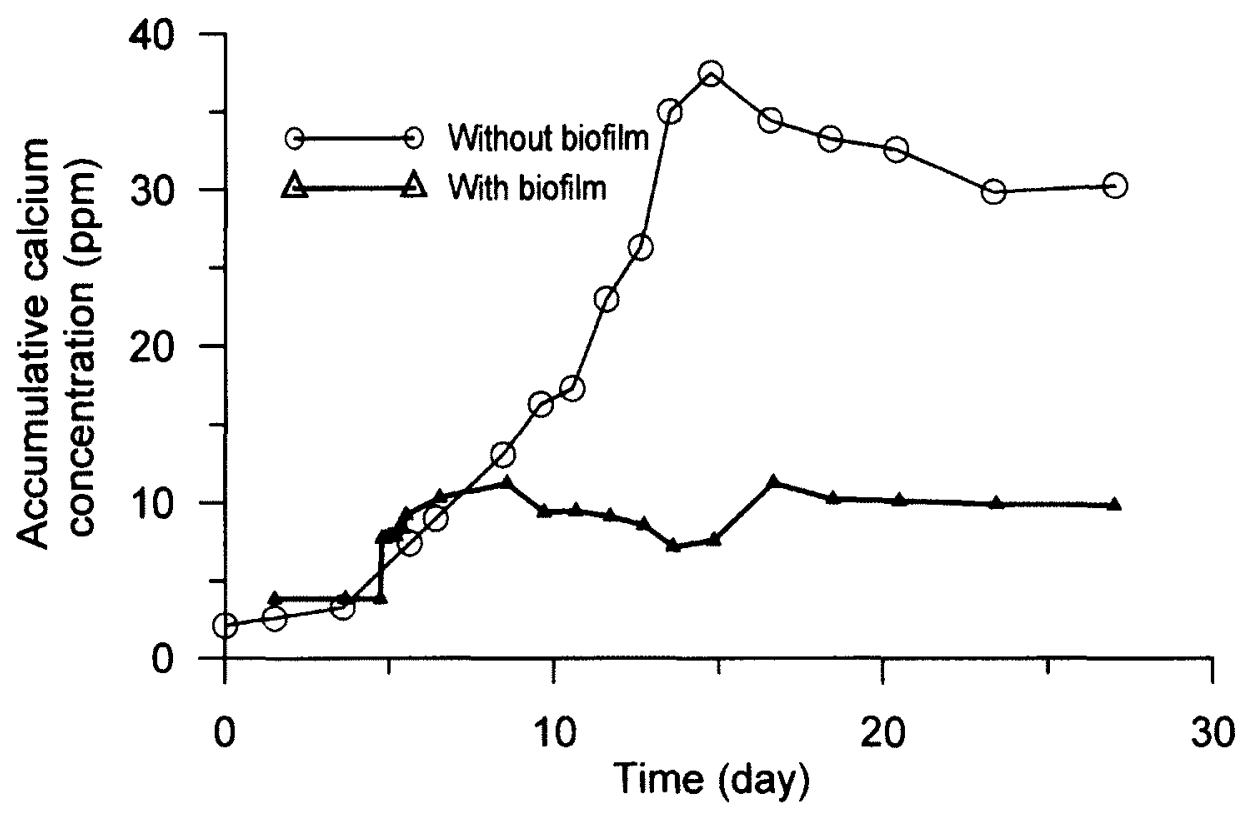

Figure 6.8: Accumulative calcium concentration in the reactor with biofilm-covered mortar and reactor with control mortar specimen without biofilm under biogenic acidification.

\subsubsection{X-ray diffraction}

The XRD analysis of an untreated mortar specimen was compared with the biologically acidified mortar samples covered with biofilm and without biofilm. For each mortar specimen, the XRD analysis was performed on the mortar powder collected from two layers, the top $0.5 \mathrm{~mm}$ layer and the $0.5-1 \mathrm{~mm}$ layer. In order to identify the origin of crystals on the untreated mortar sample, the XRD pattern of untreated mortar was compared with the XRD pattern of the sand used for making the cement mortar. As illustrated in Figure 6.9, the sand was mainly made of quartz $(\mathrm{Q})$, winchite potassium (W) and magnesium sulphate hydroxide (MH) crystals. The XRD pattern of hardened cement mortar also showed the presence of $\mathrm{Q}, \mathrm{W}$ and $\mathrm{MH}$ crystals but in different quantities (Figure 6.10). 


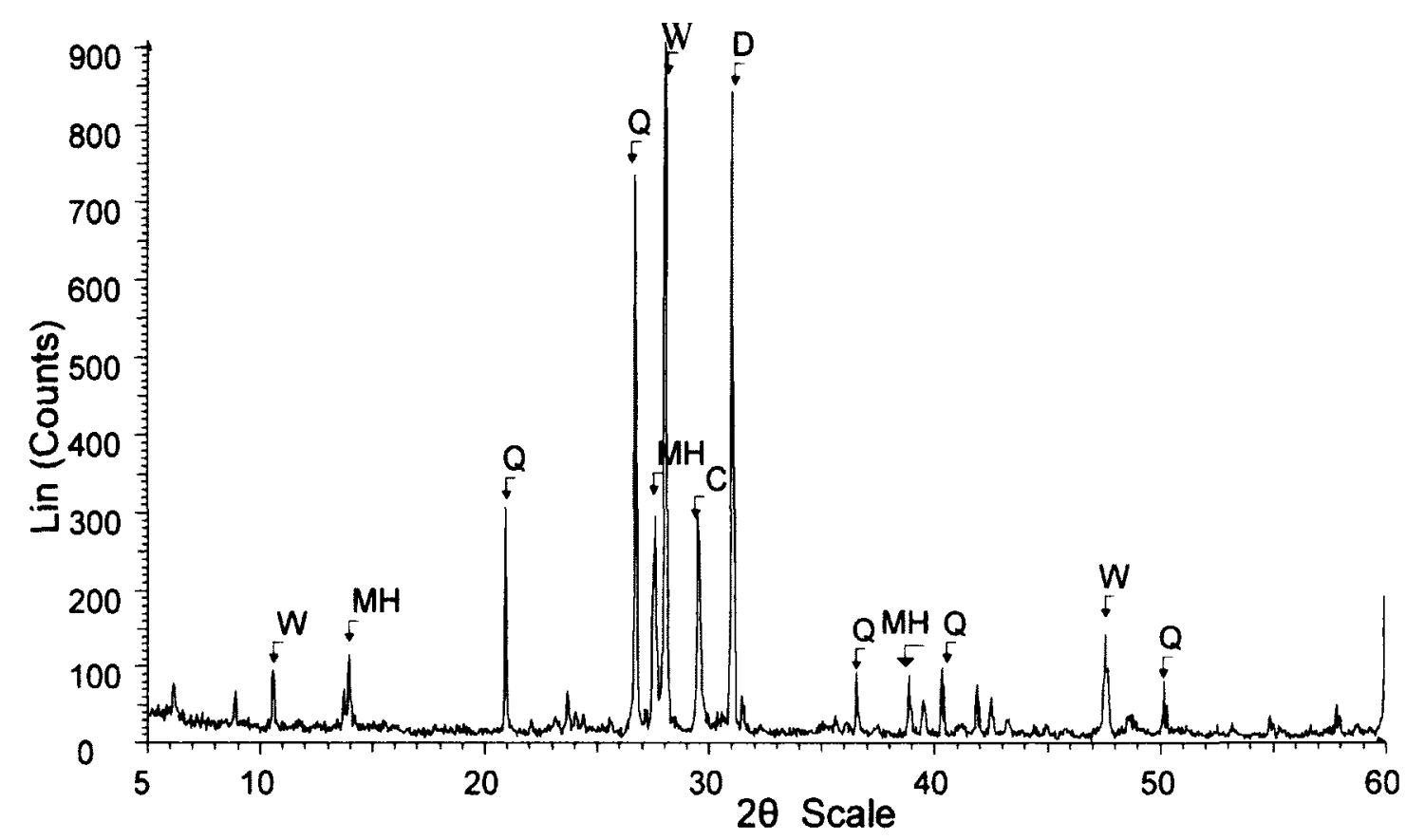

Figure 6.9: XRD pattern of sand sample used for constructing the mortar specimens; dolomite (D), quartz $(\mathrm{Q})$, magnesium calcite $(\mathrm{C})$, winchite potassium $(\mathrm{W})$, magnesium sulphate hydroxide (MH).

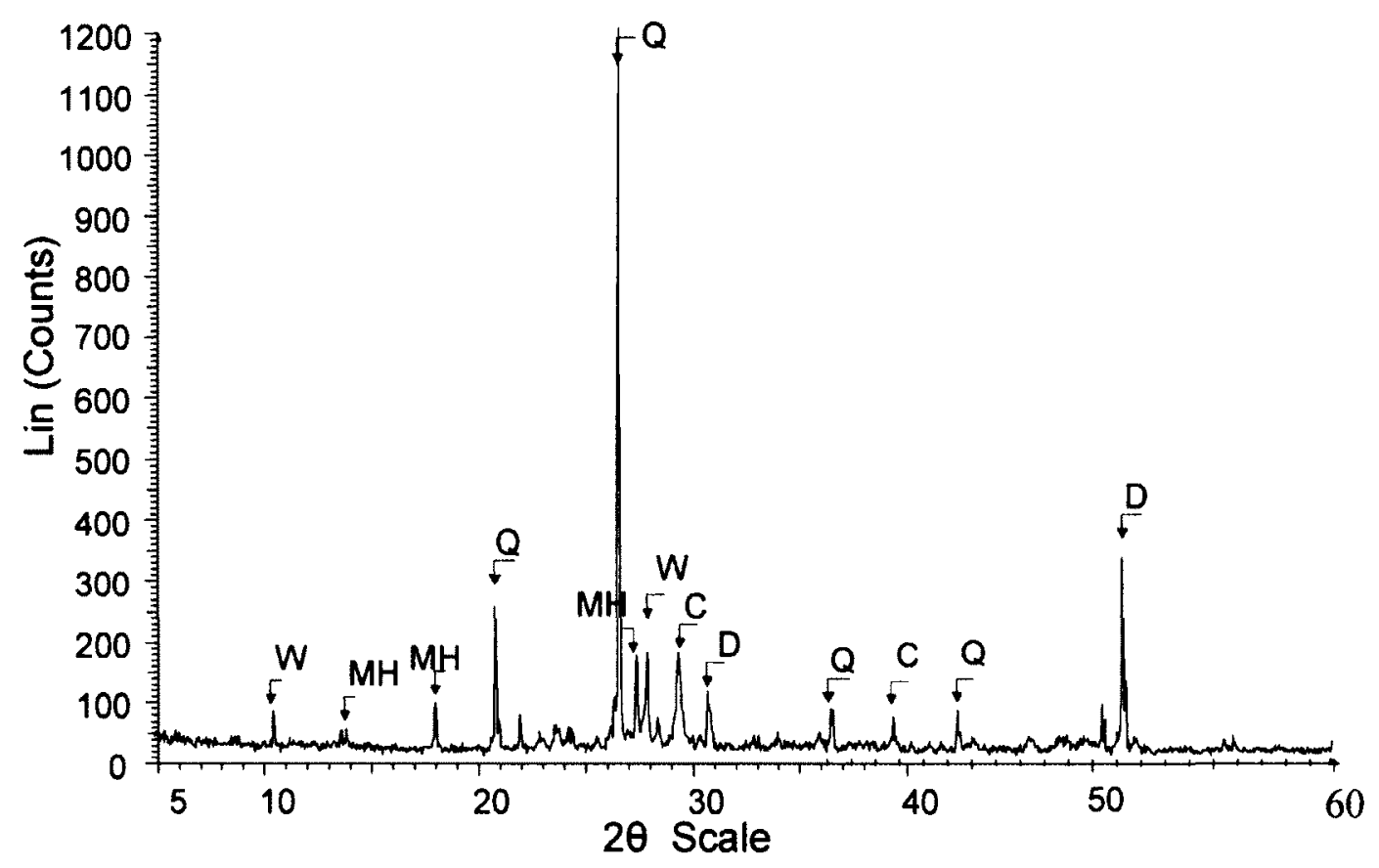

Figure 6.10: XRD of mortar powder taken from top $0.5 \mathrm{~mm}$ surface of mortar surface before any treatment; dolomite $(\mathrm{D})$, quartz $(\mathrm{Q})$, magnesium calcite $(\mathrm{C})$, winchite potassium (W), magnesium sulphate hydroxide $(\mathrm{MH})$. 
Comparing the XRD patterns of the top $0.5 \mathrm{~mm}$ layer of untreated mortar sample with the biogenically acidified mortar sample showed that the biogenic acidification caused gypsum formation (Figure 6.10 and Figure 6.11). According to the ICDD database (International Center for Diffraction Data), the first three main peaks for gypsum are at $2 \theta=20.7^{\circ}, 11.6$ and $29.9^{\circ}$ with the maximum XRD intensity at $2 \theta=20.7^{\circ}$. Since the gypsum peaks at $2 \theta=20.8^{\circ}$ and $23.5^{\circ}$ were interfering with the peaks of other present crystals, the formation of gypsum examined by the presence of the peak at $2 \theta=11.6^{\circ}$. As shown in Figure 6.10 and 6.11, the crystals that are present in the top layer of untreated mortars are dolomite (D), quartz $(\mathrm{Q})$, calcite $(\mathrm{MC})$, winchitte potassium $(\mathrm{W})$, and the crystal formed after biogenic acidification on the control mortar without biofilm was gypsum. However, based on Figure 6.12 which is the XRD pattern of the top layer of the biofilm-covered mortar after biogenic acidification, it may be suggested that the mortar deterioration due to the gypsum formation did not occur in the biofilm-covered mortar since there was no gypsum peak present in the XRD analysis of biofilm-covered mortar. Comparing the XRD pattern of the second layer (i.e., the powder that was collected from the top 0.5-1 $\mathrm{mm}$ of the mortar surface) of control mortar after biogenic acidification showed the same type of crystals as the top layer except that the intensities of XRD peaks reduced (Figure 6.12 and Figure 6.13). For example the peak intensity of gypsum at $2 \theta$ of 11.6 reduced from 220 at the top layer (Figure 6.11) to 70 at the second layer (Figure 6.13) for the control mortar specimen. Therefore, if the relative height of the XRD peaks is estimated as the quantity of the corresponding crystal, one can say that the less gypsum crystal has been produced in the second layer of control mortar specimen (Figure 6.13). 


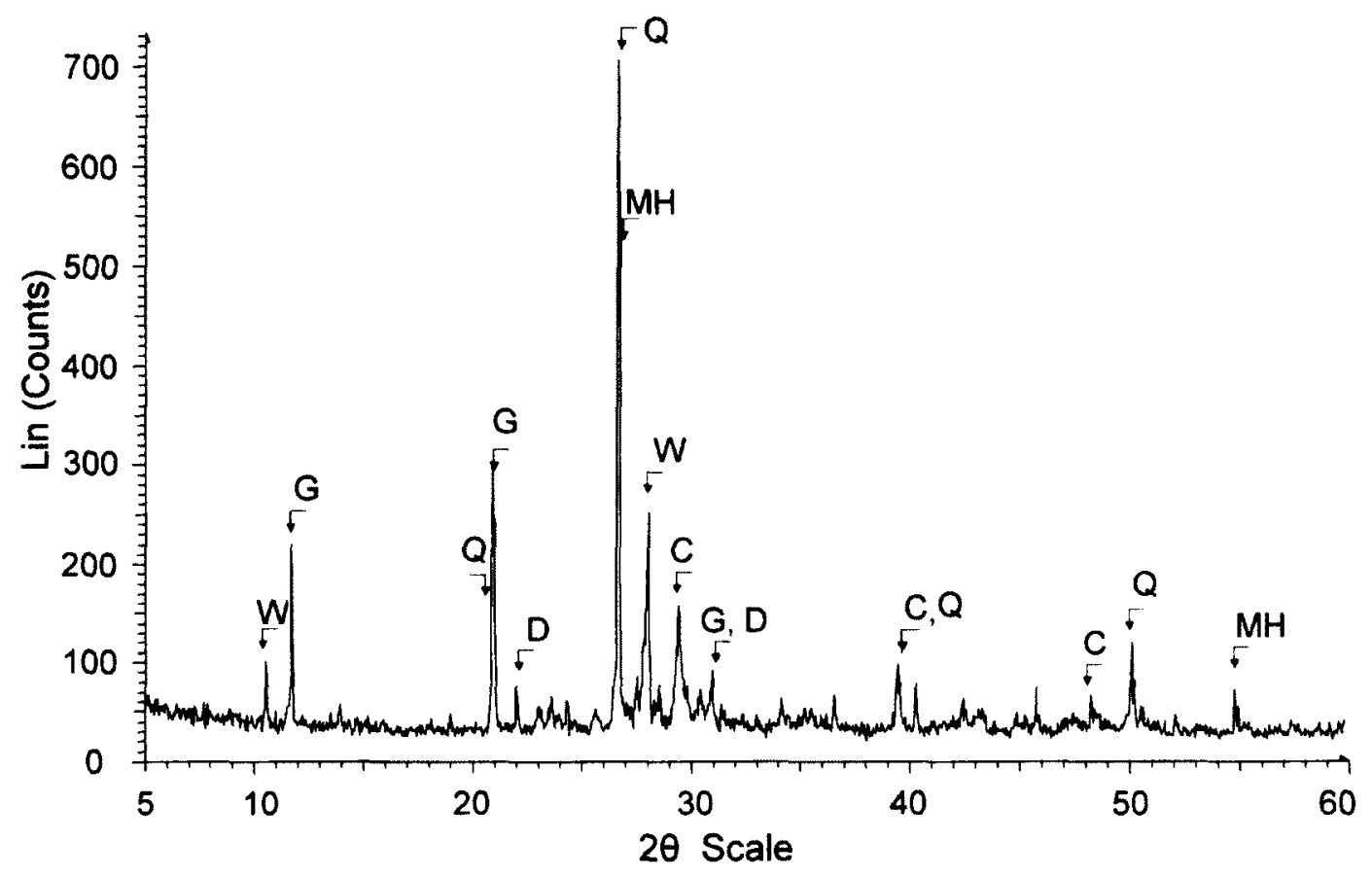

Figure 6.11: XRD analysis of top $0.5 \mathrm{~mm}$ surface of mortar without biofilm after biogenic acidification; dolomite (D), quartz (Q), calcite (C), winchite potassium $(\mathrm{W})$, magnesium sulphate hydroxide $(\mathrm{MH})$, gypsum $(\mathrm{G})$.

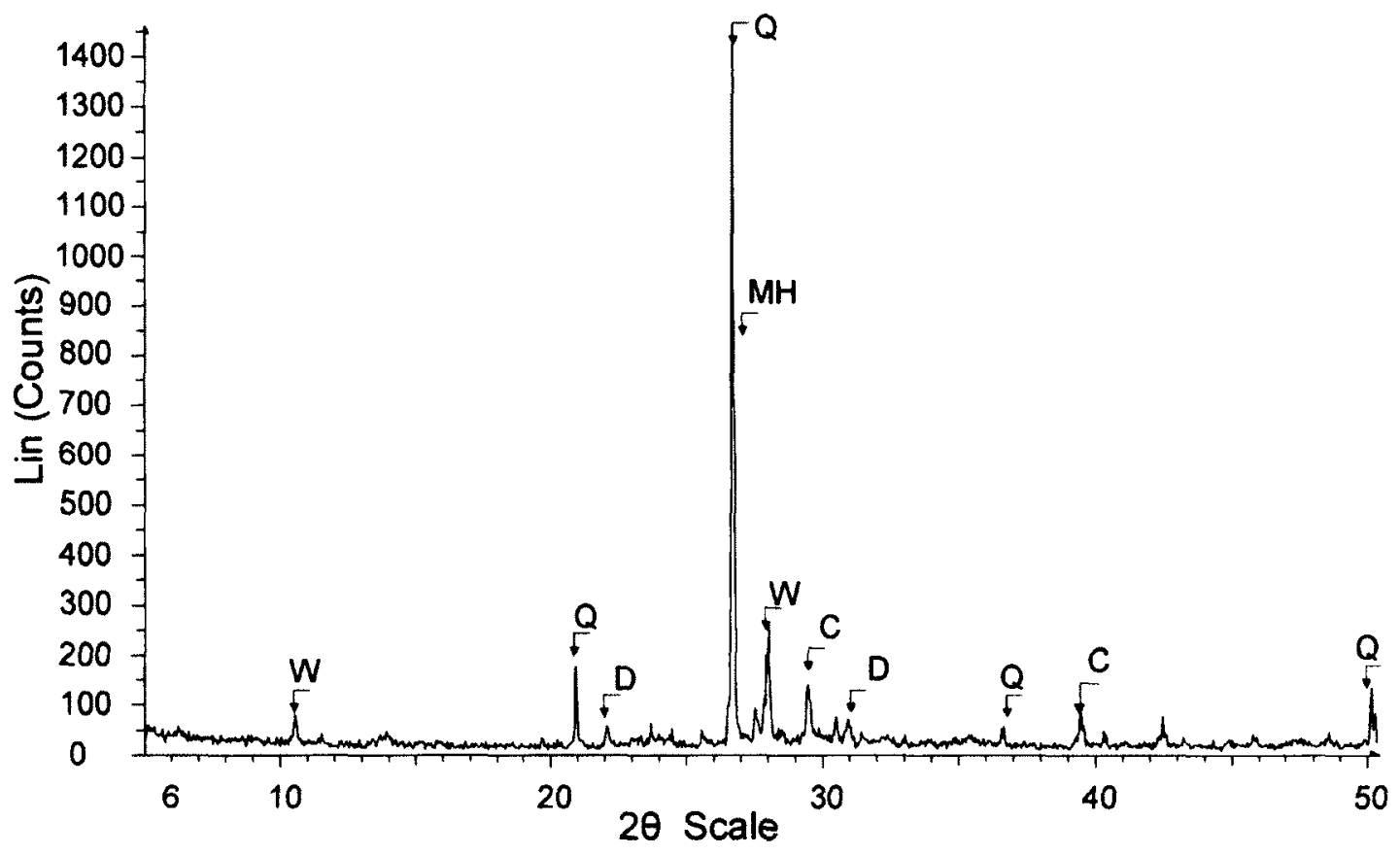

Figure 6.12: XRD analysis of top $0.5 \mathrm{~mm}$ surface of biofilm-covered mortar after biogenic acidification; dolomite (D), gypsum $(\mathrm{G})$, quartz $(\mathrm{Q})$, magnesium calcite $(\mathrm{C})$, magnesium sulphate hydroxide $(\mathrm{MH})$, winchitte potassium (W). 


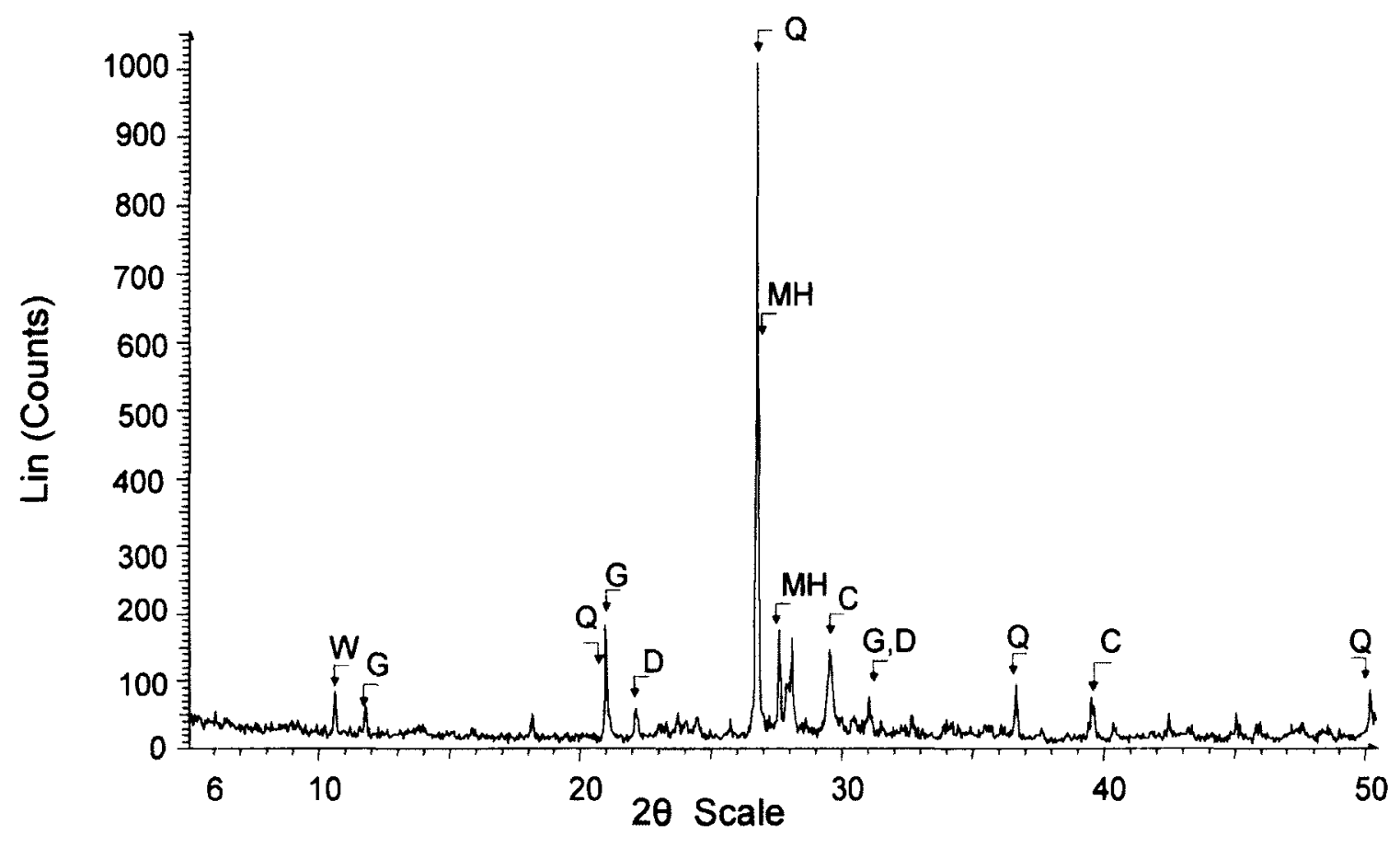

Figure 6.13: XRD analysis of second layer of mortar without biofilm after biogenic acidification; dolomite (D), gypsum $(\mathrm{G})$, quartz $(\mathrm{Q})$, magnesium calcite $(\mathrm{C})$, magnesium sulphate hydroxide(MH), winchitte potassium (W).

The XRD analysis of the second layer of biofilm-covered mortar which is presented in Appendix A indicates the presence of the same crystals as the first layer with no sign of gypsum formation.

\subsubsection{SEM/EDS}

Scanning electron micrograph of the mortar surface covered with E.coli biofilm showed the presence of biofilm after biogenic acidification (Figure 6.14a). However, as it is shown in Figure 6.14a, the biofilm was not uniformly covering the surface and patches of biofilm were observed on the surface. After the acidification, the surface of biofilmcovered mortar was brushed to remove the biofilm layer and to be able to see the crystal formation at the mortar-biofilm interface (Figure 6.14b). Figure $6.14 \mathrm{~b}$ revealed the 
presence of flower-like crystals of calcium carbonate but no evidence of gypsum or ettrengite formation.
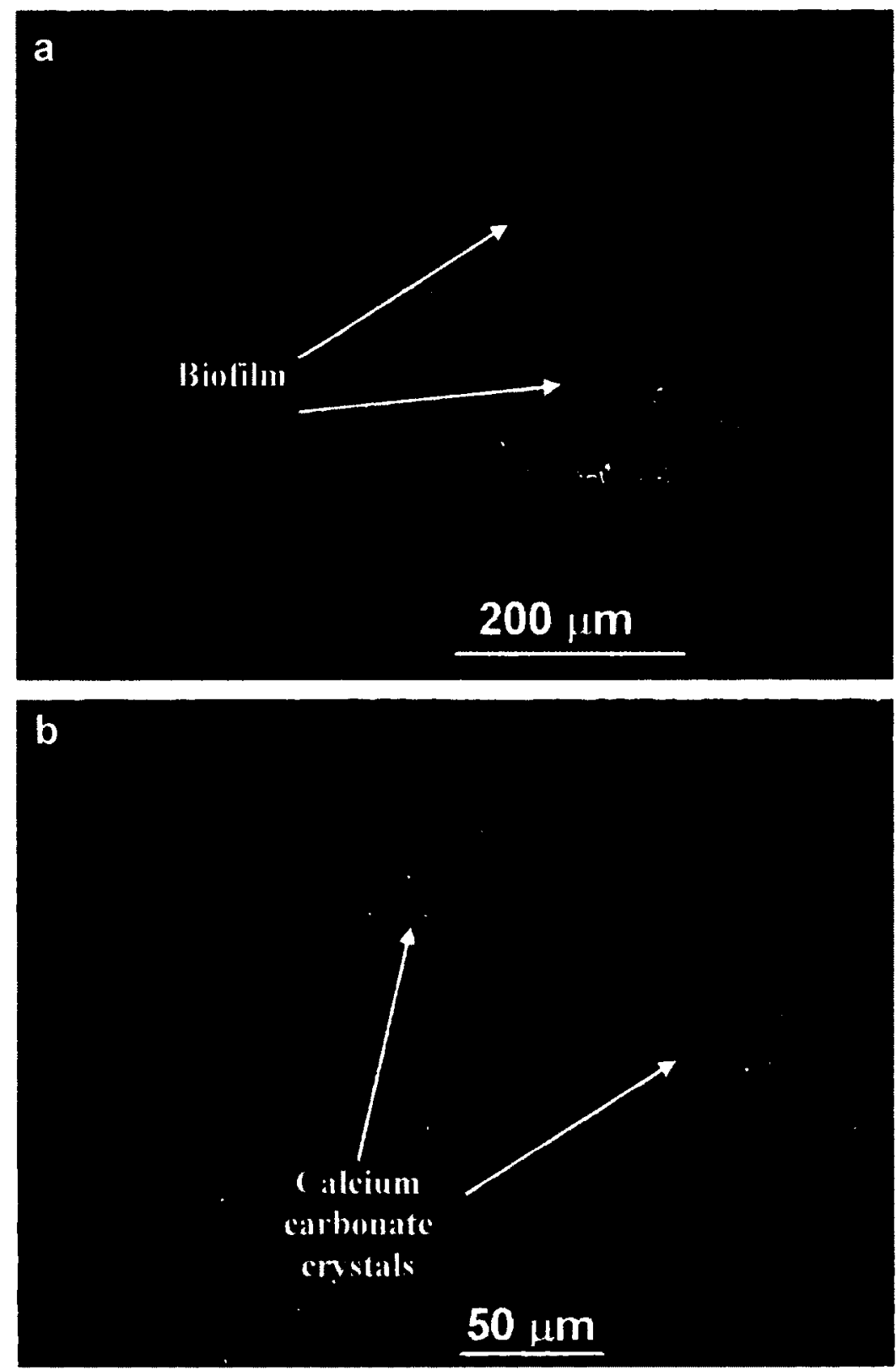

Figure 6.14: SEM micrographs of biofilm-covered mortar specimen after biogenic acidification; a) 200x magnification showing biofilm covering the surface in big patches, b) $500 \mathrm{x}$ magnification of biofilm-covered biofilm after removing the biofilm showing the formation of calcium carbonate crystals. 
The SEM images of the control mortar after biogenic acidification are shown in Figure 6.15. Figure 6.15a shows a layer of SOB bacteria forming biofilm on top of the mortar surface. It is also showing some crystal formation under the biofilm layer. The SOB biofilm layer was removed by a brush to be able to clearly see the mortar surface structure in Figure 6.15b. As illustrated in Figure 6.15b, the control mortar was deteriorated by crack formation, decomposition of cement and different types of crystal formation. This image visibly shows the gypsum crystals on top of the mortar surface and between the cracks. The presence of gypsum was also confirmed by XRD analysis (Figure 6.11).

The EDS analysis of mortar specimens before and after biogenic acidification also confirms the destruction of the control mortar specimens by showing an increase in the $\mathrm{Al}$ and Si compositions. The results provided in Table 6.1 are the representatives of the EDS analysis on $300 \mu \mathrm{m} \times 300 \mu \mathrm{m}$ area of mortar surface under different conditions (i.e., after biogenic acidification, with and without biofilm). Similar results were also obtained when different areas on mortar specimens were analyzed. As shown in Table 6.1, the atomic fraction of $\mathrm{Si}$ on the control mortar surface increased from 3.03 to $11.11 \%$ after biogenic acidification; this change suggests the decomposition of $\mathrm{C}-\mathrm{S}-\mathrm{H}$ in hydrated cement (Monteny et al., 2000; Skalny et al., 2001). 

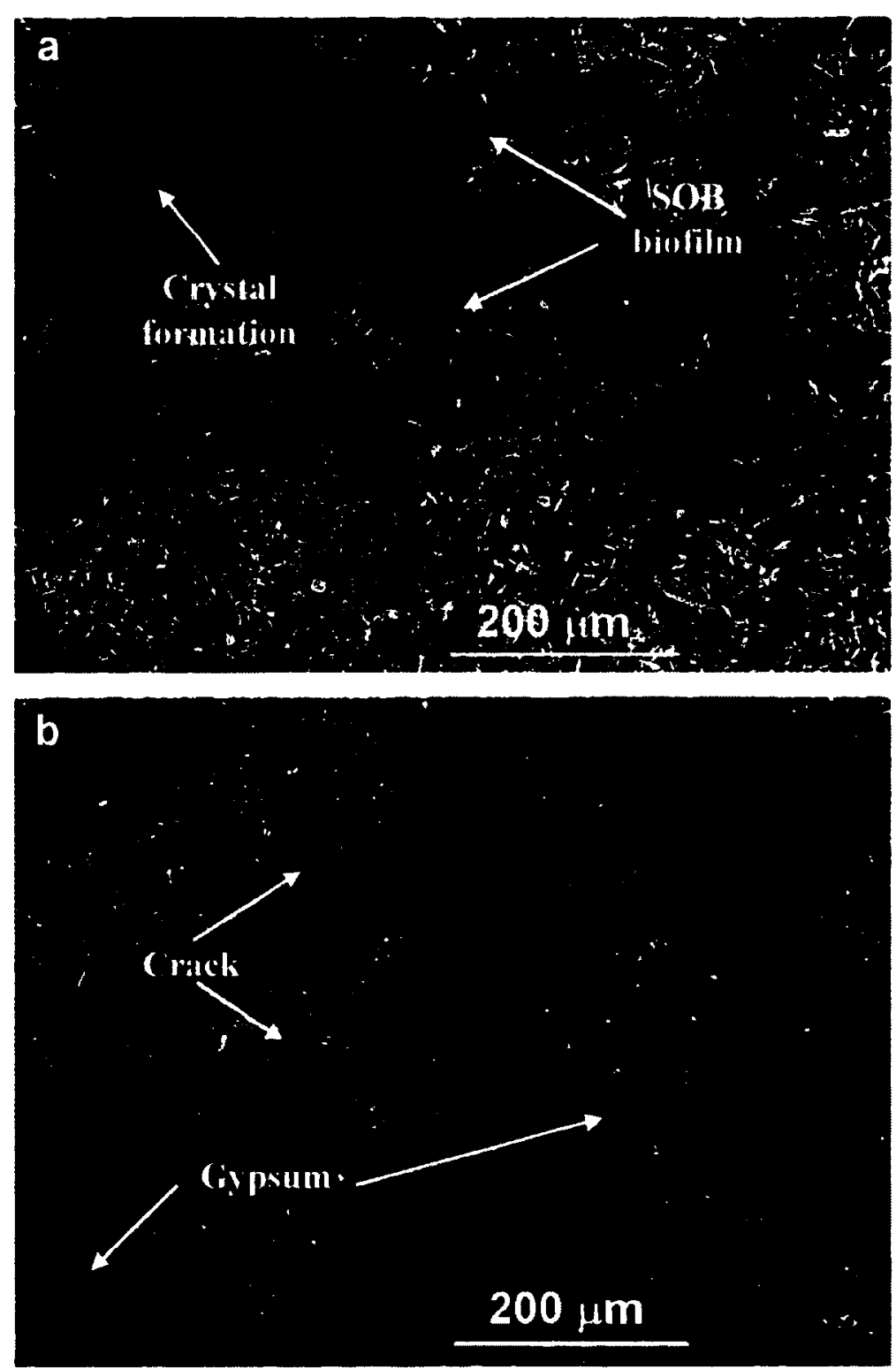

Figure 6.15: SEM micrographs of control mortar specimen after biogenic acidification; a) 200x magnification showing a layer of SOB bacterial film on top of some crystals , b) 200x magnification showing cracks and gypsum crystals.

It was also noticed that the biogenic acidification increased the amount of $\mathrm{Al}$ on the control mortar from 0.75 to $4.37 \%$ atomic fraction (Table 6.1 ). This may be explained by the decomposition of calcium sulfoaluminate hydrate phases (i.e., $\mathrm{AFm}$ and $\mathrm{AFt}$ ) and their conversion to gypsum in the acidic environment. On the contrary, the EDS analysis of biofilm-covered mortar did not show any increase in the atomic fraction of $\mathrm{Al}$ and $\mathrm{Si}$ 
after biogenic acidification (Table 6.1). The presence of phosphorous after biogenic acidification and its percentage weight increase from $2.41 \%$ to $6.3 \%$ suggests the sustainability of the biofilm during the acidification process. There was also an increase in the amount of phosphorous on the control mortar after biogenic acidification from 0 to $2.8 \%$ atomic fraction. This may be explained by the attachment of SOB bacteria to the mortar surface (Table 6.1).

Table 6.1: Percentage atomic fraction of elements on mortar surface as obtained by EDS analysis under different conditions.

\begin{tabular}{|c|c|c|c|c|}
\hline \multirow[b]{2}{*}{ Elements } & \multicolumn{2}{|c|}{ Before any acidification } & \multicolumn{2}{|c|}{ after biogenic acidification } \\
\hline & No biofilm & $\begin{array}{l}\text { After } 8 \text { days of } \\
\text { biofilm growth }\end{array}$ & No biofilm & With biofilm \\
\hline $\mathrm{S}$ & 0 & 0 & 0.18 & 3.07 \\
\hline $\mathbf{P}$ & 0 & 2.41 & 2.8 & 6.37 \\
\hline $\mathrm{C}$ & 29.76 & 38.86 & 18.2 & 10.28 \\
\hline $\mathrm{O}$ & 51.46 & 41.65 & 56.83 & 70.62 \\
\hline $\mathrm{Na}$ & 0.39 & 0 & 2.38 & 0 \\
\hline $\mathrm{Mg}$ & 0.14 & 0 & 0.29 & 0 \\
\hline $\mathrm{Al}$ & 0.75 & 0.56 & 4.36 & 0 \\
\hline $\mathrm{Si}$ & 3.03 & 3.48 & 11.11 & 0 \\
\hline $\mathrm{K}$ & 0 & 0 & 0.69 & 0 \\
\hline $\mathrm{Ca}$ & 13.61 & 10.91 & 2.62 & 9.66 \\
\hline $\mathrm{Fe}$ & 0.16 & 0 & 0.54 & 0 \\
\hline $\mathrm{Pd}$ & 0.41 & 1.49 & 0 & 0 \\
\hline $\mathrm{Au}$ & 0.29 & 0.65 & 0 & 0 \\
\hline
\end{tabular}

\subsection{Biofilm Properties After Biogenic Acidification}

In this section, first the continuing presence of E.coli biofilm on the mortar surface after biogenic acidification was confirmed. Then, the biofilm on the mortar was evaluated in terms of its bacterial viability, thickness and biofilm coverage. The results were obtained by CLSM and FISH and confirmed with VSS analysis. 


\subsubsection{Fluorescence in situ hybridization}

Florescence in situ hybridization was employed to confirm the presence of E.coli biofilm on the biofilm-covered mortar after the biogenic acidification and to determine whether SOB can compete with the E.coli for surface attachment. Figure 6.16 is the image of bacteria collected from the biofilm-covered mortar after biogenic acidification. The collected bacteria were stained with DAPI to identify all the bacteria and hybridized with the E.coli FISH probe (green) to identify only the E.coli bacteria. Bacteria that were stained with DAPI but not seen with the E. coli probe would be the SOB.
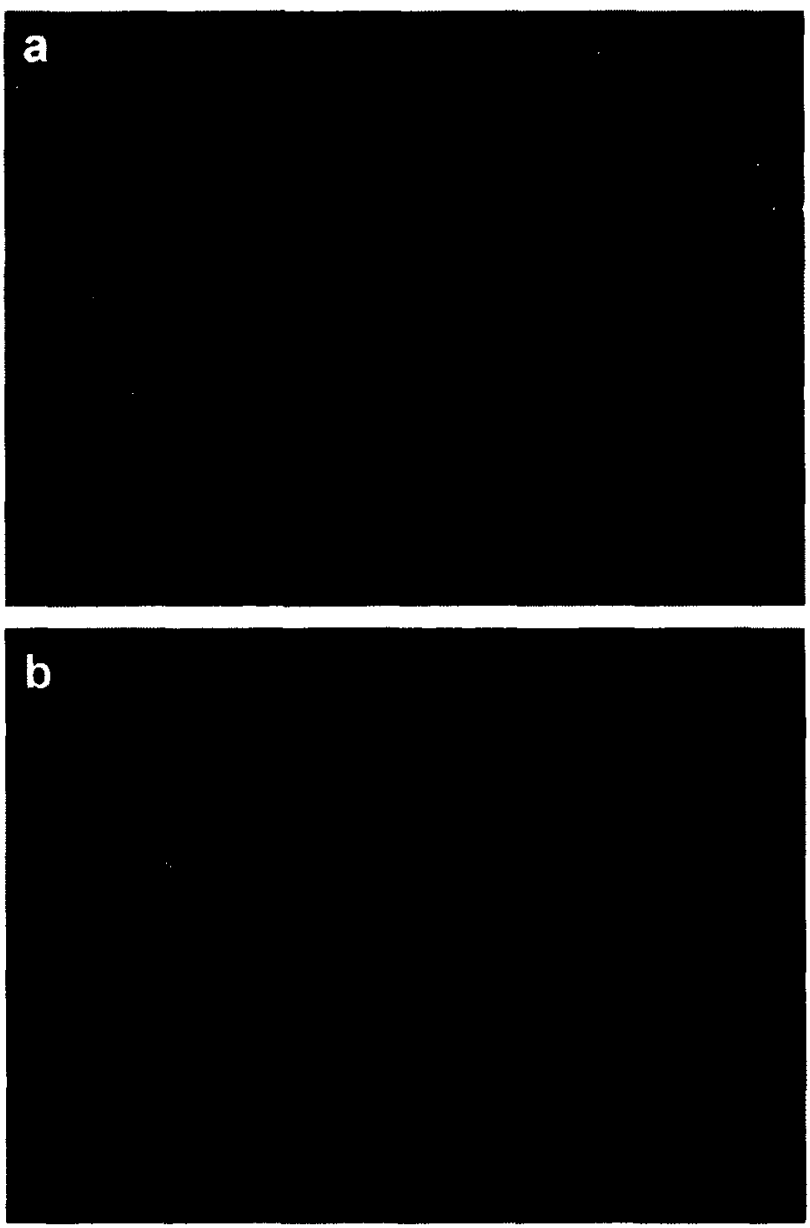

Figure 6.16: Image of bacteria collected from biofilm-covered mortar specimen after biogenic acidification a) DAPI stained image showing all the present bacteria in blue b) FISH image of the same view showing only the E.coli bacteria in green. 
Therefore, using these two stains simultaneously provided the ability to differentiate E.coli from SOB in the biofilm. Comparing Figure 6.16a showing all the bacteria in blue with Figure $6.16 \mathrm{~b}$ which is the image of the same view showing just the E.coli bacteria in green elucidate that $E$. coli was the main bacteria forming the biofilm since the blue cells aligned with the green cells very well. The purity of E.coli biofilm was also confirmed by analysis five other FISH images taken at other locations which are not shown in this thesis for brevity.

\subsubsection{Confocal laser scanning microscopy}

CLSM was used to evaluate the spatial distribution of bacterial viability and EPS coverage of biofilm-covered mortar after biogenic acidification. It was also employed to analyse SOB viability on the control mortar sample after biogenic acidification. Figure 6.17 compares the bacterial viability and the EPS coverage on the mortar surface before and after biogenic acidification. The values in this figure were obtained by analysing the projected CLSM images in at least 5 different fields of view. According to Figure 6.17, the live cells, dead cells and EPS coverage were increased in the biofilm-covered mortar after biogenic acidification. The live and dead cell coverage on the biofilm-covered mortar was increased from $8 \%$ and $2.9 \%$ to $19.2 \%$ and $11.5 \%$ after biogenic acidification, respectively. The EPS coverage on the biofilm-covered mortar specimens was also increased from $59.6 \%$ to $75.6 \%$ after biogenic acidification. It was also interesting to see the attachment of SOB on the control mortar specimen after biogenic acidification. This observation was in accordance with the SEM images showing a thin layer of bacterial coverage (Figure 6.15). However, the SOB bacteria was not able to produce as much EPS as the E.coli bacteria as the EPS coverage of the control mortar 
was $7.5 \%$ compared to the $75.6 \%$ EPS coverage for the biofilm-covered mortar specimens.
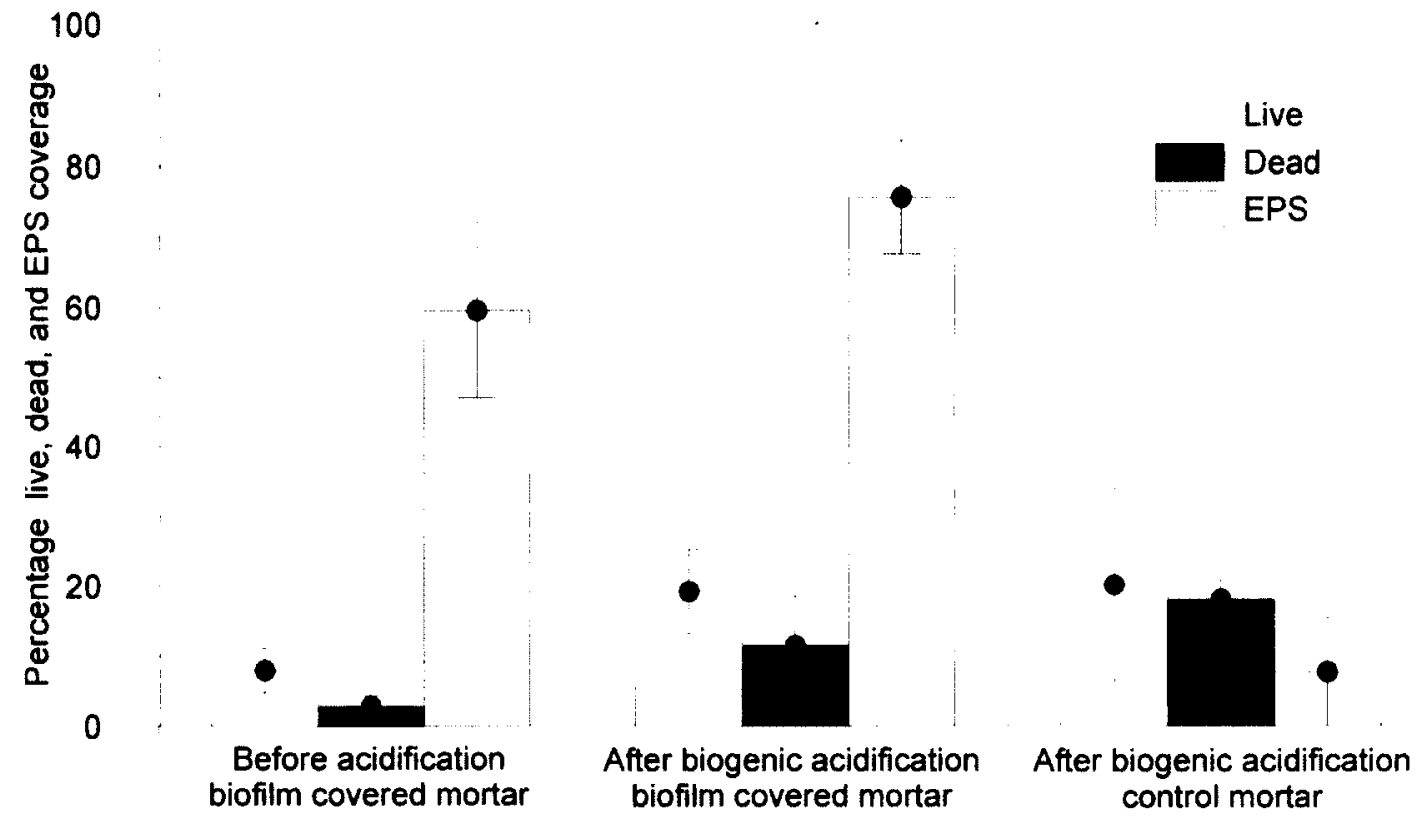

Figure 6.17: Bacterial viability analysis and the percent EPS coverage of biofilm before and after biogenic acidification experiment.

As per FISH analysis of biofilm-covered mortar sample, almost all attached bacteria after biogenic acidification was E.coli, and there was no significant SOB attachment (Figure 6.16). Since the only bacteria present on the biofilm-covered mortar was E.coli bacteria, it can be suggested that the higher number of live and dead cell attachment on the control mortar specimen shows that the SOB cells have a higher ability to attach to the mortar surface. This might be due to the ability of $\mathrm{SOB}$ to produce acid and eliminate the high alkali environment on the mortar surface hence preparing a better substrate for their attachment.

The effect of biogenic acidification on biofilm thickness, live to dead cell ratio and the total number of attached cells is reported in Table 6.2. According to this table, during the 
acidification process, the total amount of bacterial coverage and the average thickness of biofilm on the biofilm-covered mortar increased from $10.9 \%$ and 29 to $30.7 \%$ and 78.9 $\mu \mathrm{m}$, respectively (Table 6.2). The increase in the average thickness and the total cel] coverage during biogenic acidification process confirms the continuous growth of E.coli biofilm and its sustainability on the mortar surface during this process. It is also pointed out that the ratio of live to dead cells on the biofilm-covered mortar decreased from 2.7 to 1.7 showing the higher rate of bacterial decay during the acidification which might be due to the acidic environment (Table 6.2). According to Table 6.2, after biogenic acidification, the total amount of cell coverage on the control specimen was $38.1 \%$ which was higher than the biofilm-covered mortar with $30.7 \%$ cell coverage. Having lower cell coverage in the biofilm-covered mortar indicates that the E.coli bacteria were competing with the SOB in terms of their attachment to the mortar surface and did not let the SOB attach to the mortar.

Table 6.2: Biofilm thickness, live to dead cell ratio and total cell coverage on the mortar surface before and after biogenic acidification.

\begin{tabular}{|c|c|c|c|}
\hline & \multirow{2}{*}{$\begin{array}{c}\text { Before } \\
\text { acidification }\end{array}$} & \multicolumn{2}{|c|}{ After biogenic acidification } \\
\hline & & $\begin{array}{c}\text { biofilm-covered } \\
\text { mortar }\end{array}$ & $\begin{array}{l}\text { control } \\
\text { mortar }\end{array}$ \\
\hline Total cell ( $\%$ area fraction) & $10.9 \pm 3.2$ & $30.7 \pm 13$ & $38.1 \pm 26$ \\
\hline Thickness $(\mu \mathrm{m})$ & $29 \pm 5.1$ & $78.6 \pm 18$ & $\cdots$ \\
\hline Live/Dead & 2.7 & 1.7 & 1.1 \\
\hline
\end{tabular}

The CLSM images of biofilm-covered mortar of one representative view at different depths and the projected image of all the layers are shown in Figure 6.18 and Figure 6.19. To clearly see the stained bacteria, the CLSM images of biofilm-covered mortar stained with calcofluor and Live/Dead are shown separately in Figure 6.18 and Figure 6.19, respectively. Supplementary CSLM images of biofilm-covered mortar at different field of 
views are provided in Appendix B.
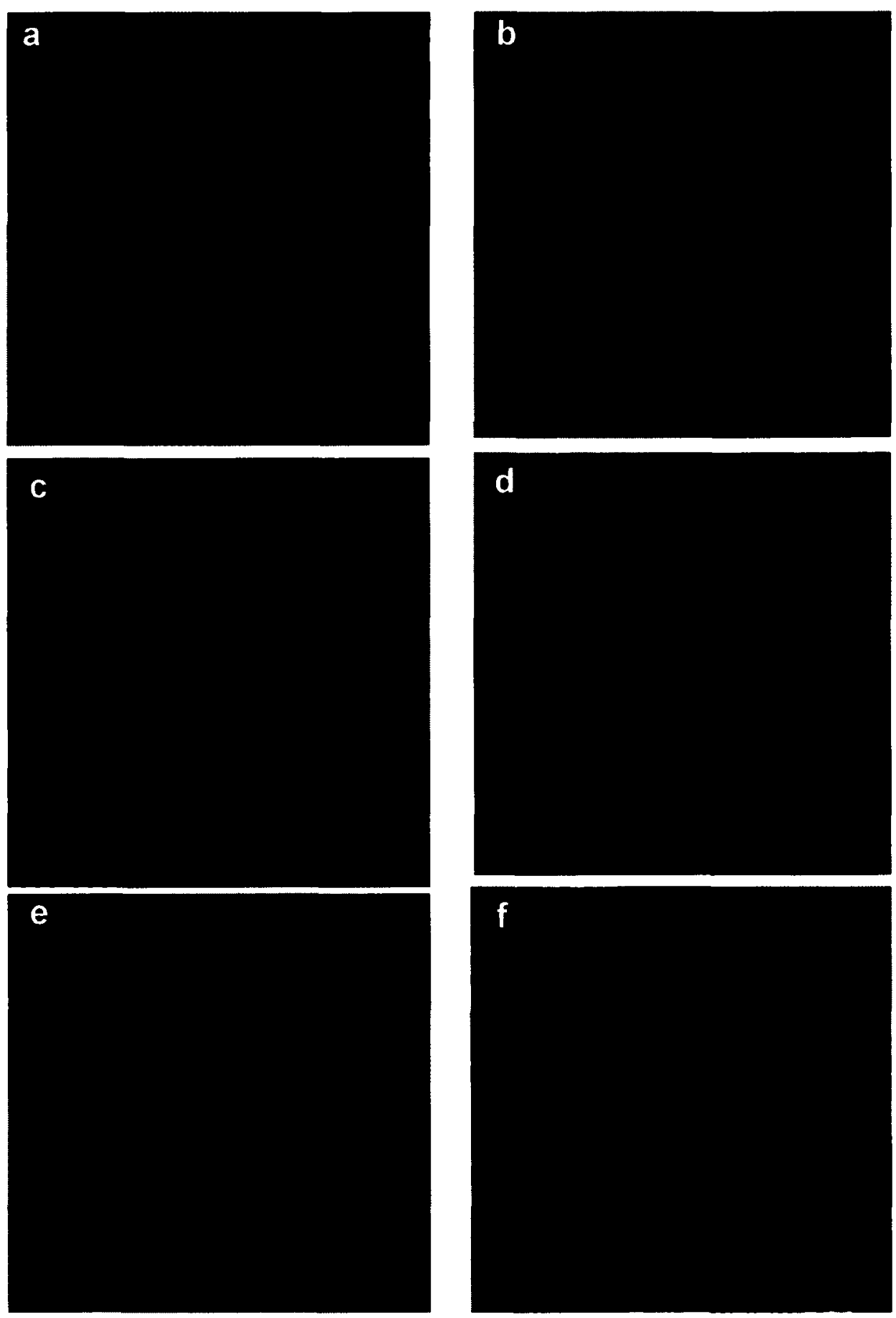

Figure 6.18: CLSM images of biofilm on mortar surface after biogenic acidification stained with calcoflour for polysaccharide (cyan); image of biofilm at (a) $20 \mu \mathrm{m}$, (b) $30 \mu \mathrm{m}$, (c) $40 \mu \mathrm{m}$, (d) $55 \mu \mathrm{m}$, (e) $70 \mu \mathrm{m}$ distance from the mortar surface, f) projected image of all the subsections in the same view. Scale bar represents $10 \mu \mathrm{m}$. 

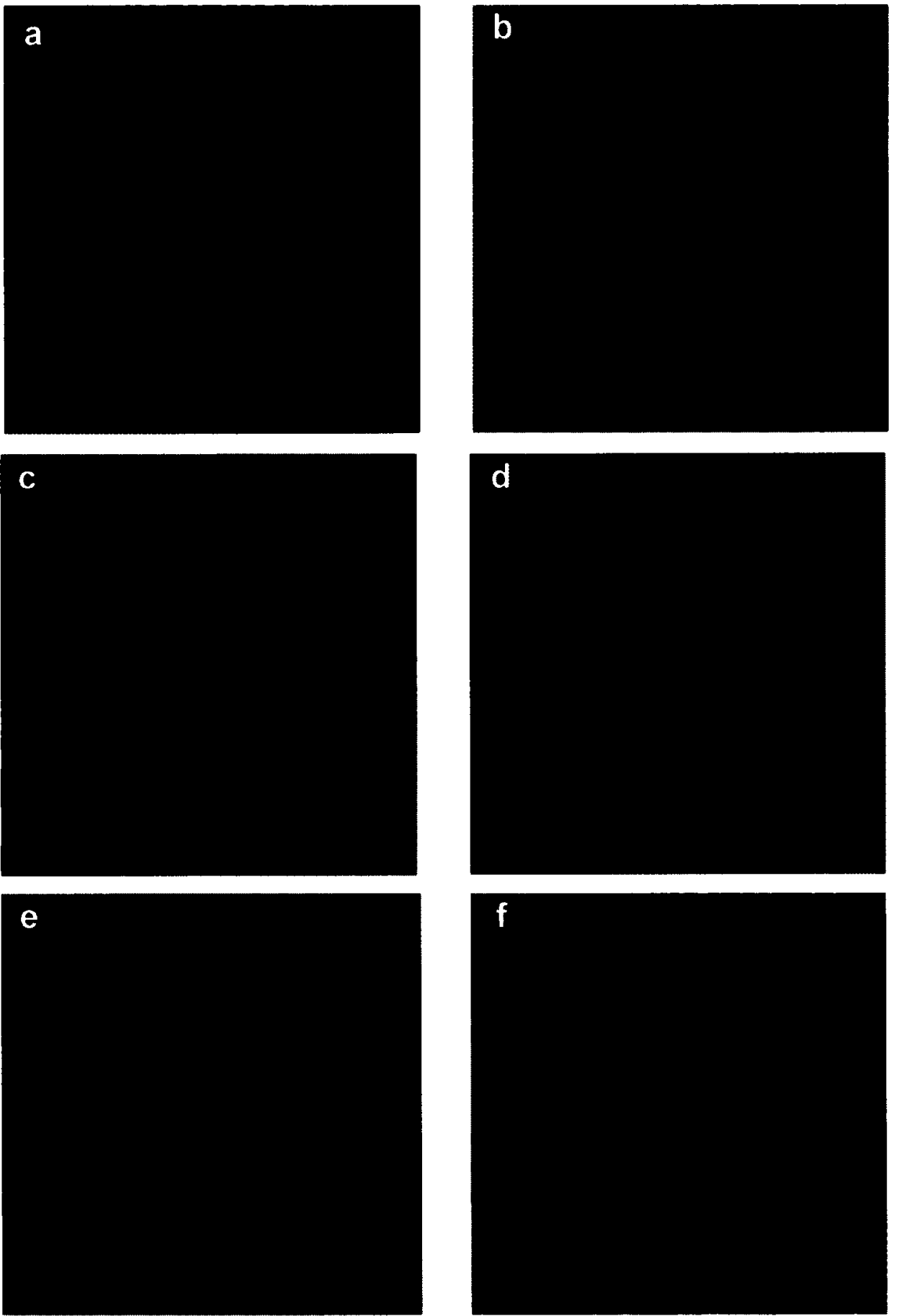

Figure 6.19: CLSM images of biofilm on mortar surface after biogenic acidification stained for live cells (green) and dead cells (red); image of biofilm at (a) $20 \mu \mathrm{m}$, (b) $30 \mu \mathrm{m}$, (c) $40 \mu \mathrm{m}$, (d) $55 \mu \mathrm{m}$, (e) $70 \mu \mathrm{m}$ distance from the mortar surface, $f$ ) projected image of all the subsections in the same view. Scale bar represents $10 \mu \mathrm{m}$. 

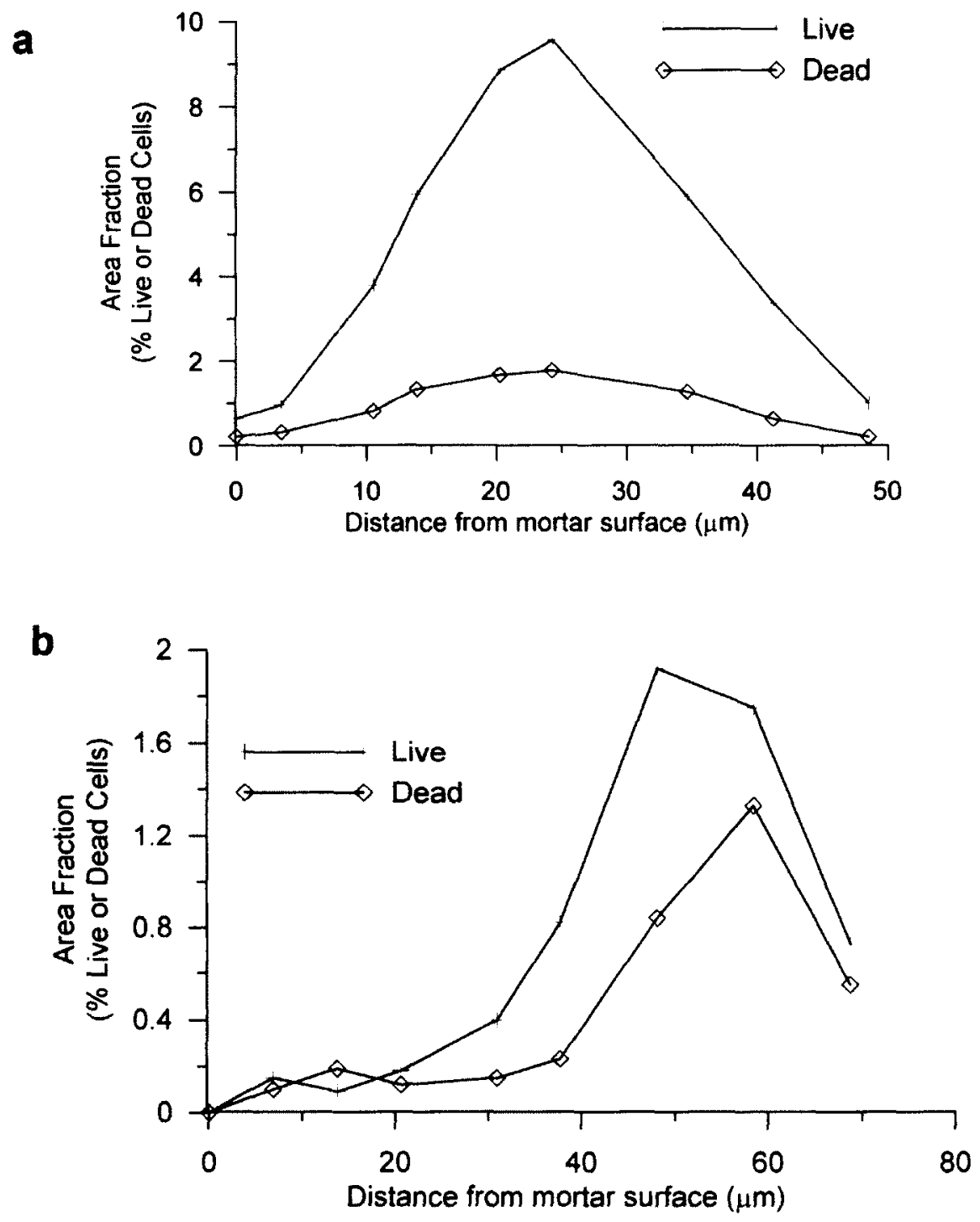

Figure 6.20: Spatial distribution of bacterial viability within the E.coli biofilm attached to mortar surface after biogenic acidification at two different location.

The spatial distribution of biofilm viability after biogenic acidification which was obtained by analysing the CLSM images are shown in Figure 6.20 for two different positions with different biofilm thicknesses. Comparing the viability profiles in Figure $6.20 \mathrm{a}$ and $\mathrm{b}$ indicates the heterogeneity of the biofilm layer and its differences at each field of view. For example, at the first field of view, the highest number of cells is at the middle of biofilm layer, but the second field of view shows the highest number of cells 
being closer to the biofilm-liquid interface. In both profiles, the percentage of live is higher than the percentage of dead cells at all depths. However, the ratio of live/dead cells is more in the first field of view than the second field of view (Figure 6.20).

Comparison of the EPS profiles before and after acidification also shows that the structure and organization of the biofilm were changed due to the acidification (Figure 6.21 ). It is suspected to be due to the presence of $\mathrm{SOB}$ and their competition with E.coli for surface attachment resulting in an increase in the rate of biofilm detachment and decrease in EPS coverage at the biofilm-liquid interface (Figure 6.21). As illustrated in Figure 6.21, after acidification, the percentage of EPS coverage was reduced at different depths of the biofilm. For example at $20 \mu \mathrm{m}$ the percentage EPS coverage was reduced from $44 \%$ before the acidification to $31 \%$ and $6 \%$ coverage after the acidification (Figure 6.17); however, due to the biofilm growth during the acidification and the increase in thickness of biofilm, the overall EPS coverage was increased as reported in Figure 6.17.

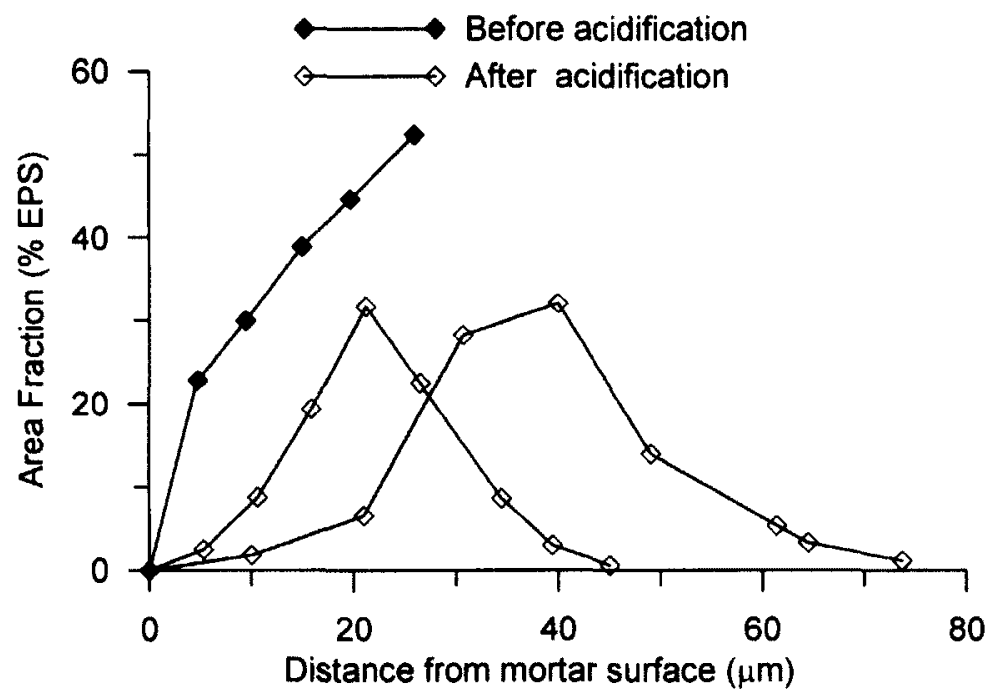

Figure 6.21: Comparison of profile of EPS coverage within the E.coli biofilm before and after biogenic acidification. 


\subsubsection{Volatile suspended solids}

Volatile suspended solids of the biomass attached on mortar specimens before and after biogenic acidification were measured to confirm the results of the CLSM analysis. According to Figure 6.22, VSS concentration on the biofilm-covered mortar sample increased from $16 \mathrm{mg} / \mathrm{cm}^{2}$ before the acidification to $60 \mathrm{mg} / \mathrm{cm}^{2}$ after the biogenic acidification. The VSS concentration of $92 \mathrm{mg} / \mathrm{cm}^{2}$ was obtained for the control mortar specimen which was higher than the biofilm-covered sample with the VSS of $60 \mathrm{mg} / \mathrm{cm}^{2}$. This was likely due to the higher tendency of SOB for attachment to the mortar surface and E.coli bacteria preventing SOB attachment. The VSS finding was in accordance with the CLSM analysis showing an increase in biomass accumulation and confirming the growth and sustainability of a biofilm layer during the biogenic acidification.

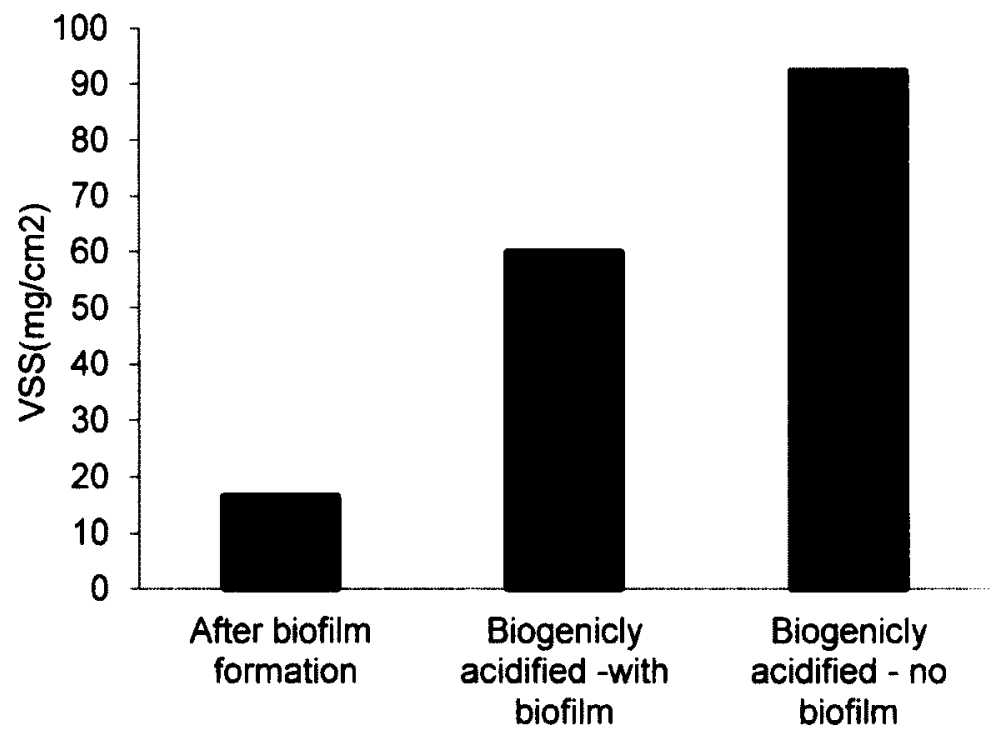

Figure 6.22: Volatile suspended solids measurement of biomass attached to mortar specimens after biogenic acidification (the values are the average of two VSS measurement on the surface of two mortar cubes). 


\subsection{Concluding Remarks}

The effectiveness of biofilm as a protective barrier against biogenic sulphuric acid was evaluated by simulating the acidification using two types of SOB to naturally reduce the solution $\mathrm{pH}$. The evidence from calcium leach-out concentration, SEM and EDS analyses suggests that the presence of biofilm prevented or controlled the biologically induced mortar deterioration. The $\mathrm{pH}$ of the solution in the reactor containing biofilm-covered mortar could not decrease as the $\mathrm{SOB}$ were not able to grow in the respective reactor. However, the growth of SOB in the control reactor increased the sulphate concentration to as high as $6350 \mathrm{mg} / \mathrm{L}$ and consequently increased the calcium leach-out to $69 \mathrm{ppm}$. The maximum calcium concentration in the biofilm-covered mortar reactor was $11 \mathrm{ppm}$ which was lower than the control reactor and suggests a higher dissolution rate of calcium hydroxide and C-S-H from the control mortars than the biofilm-covered mortars.

SEM micrographs taken after the biogenic acidification process showed the presence of gypsum crystals and cracks or spalling of the control mortar surface without the biofilm. The presence of gypsum crystals on the control mortar sample as the main indicator of mortar deterioration due to sulphate attack was also indicated by XRD analysis. There was no sign of gypsum crystals on the biofilm-covered mortar surface. EDS analysis also showed that after the biogenic acidification, higher amounts of $\mathrm{Al}$ and $\mathrm{Si}$ were present on the control mortar compared with the biofilm-covered mortar. This observation suggests the decomposition of sulfoaluminate hydrate phases and their conversion to gypsum in the control mortar specimens. Presence of silica gel was also indicated in the EDS analysis and increase in the atomic fraction of $\mathrm{Si}$ on the control mortar samples. 
FISH analysis showed that the SOB did not attach to the surface of biofilm-covered mortar. The CLSM and VSS analyses both indicated that the biofilm was sustained and was growing during the acidification process. CLSM also showed the higher tendency of SOB bacteria for attachment to a mortar surface than the E.coli bacteria; hence after acidification, higher cell coverage was observed on the control mortar than the biofilmcovered mortar in which the E.coli biofilm prevented the SOB attachment. 


\section{CHAPTER 7. EFFECT OF HIGH TEMPERATURE AND MECHANISMS OF DETERIORATION}

\subsection{INTRODUCTION}

In this chapter, the effectiveness of biofilm against the biogenic sulphuric acid deterioration at an elevated temperature was evaluated. Since some of the treatment processes with high probability of concrete structure deterioration such as anaerobic digesters, are operated at the elevated temperature, it is importance to evaluate the effectiveness of biofilm as MICD prevention strategy at a higher temperature. The severity of the mortar deterioration was evaluated by measuring the concentration of calcium leach-out, and crystal analysis using XRD.

Also in this chapter, the mechanism of mortar deterioration was investigated, and the mechanism of biogenic sulphuric acid deterioration was compared with the chemically induced sulphuric acid deterioration.

\subsection{EFFECT OF TEMPERATURE}

The biogenic sulphuric acid deterioration was performed at the elevated temperature of $37 \pm 1^{\circ} \mathrm{C}$ to evaluate the effect of temperature on the mortar deterioration. The effectiveness of biofilm for the control of biogenic acidification was also evaluated using 
calcium leach-out measurement and XRD analysis. The results are then compared with the previous experiments which were carried out at room temperature.

\subsubsection{Chemical analysis}

The biogenic acidification was carried out at the elevated temperature of $37 \pm 1^{\circ} \mathrm{C}$ by injecting two SOB strains of T.thiooxidans and T.neapolitanus into the reactors. The results of $\mathrm{pH}$, calcium concentration, and sulphate concentration of medium inside two reactors containing the biofilm-covered mortar and the control mortar without biofilm were compared to evaluate the effectiveness of biofilm to control MICD at elevated temperature. The acidification consisted of two cycles of exposure to the fresh broth and SOB at their exponential growth rate. Despite the 15-day period selected for each acidification cycle for biogenic acidification at room temperature, the length of the acidification cycle during the high temperature experiments was identified as the time SOB could keep the $\mathrm{pH}$ of the solution low. SOB bacteria use sulphur compounds as the substrate and oxidize them to sulphuric acid hence it is expected to observe an increase in the sulphate concentration as the $\mathrm{pH}$ decreases during the SOB growth (Bielefeldt, 2010).

Figure 7.1, Figure 7.2 and Figure 7.3 are the results of the $\mathrm{pH}$, sulphate and calcium concentration of the solution inside the two reactors with biofilm-covered mortar and control specimens, respectively. As indicated in Figure 7.1, during the first cycle of acidification, the activity of $\mathrm{SOB}$ could reduce the $\mathrm{pH}$ of the solution in the control reactor to as low as 4.1 after 16 days of growth compared with the biofilm-covered reactor in which the lowest $\mathrm{pH}$ achieved was 5.5 after 12 days. The solution in the reactor with biofilm-covered mortar had higher buffering capacity since there were two sources increasing the alkalinity of the solution: 1) the alkalinity due to the calcium hydroxide 
leaching, 2) buffering capacity of E.coli cells. The bacteria that grow in an acidic environment have a tendency to keep their internal $\mathrm{pH}$ at a more alkaline $\mathrm{pH}$ than that of the environment by controlling the movements of cations through their membrane and increasing the extracellular buffering capacity (Booth, 1999). Having a higher buffering capacity in the reactor containing the biofilm-covered mortar resulted in a lower $\mathrm{pH}$ reduction, hence one can conclude that the biofilm was controlling the biogenic acidification to some extent.

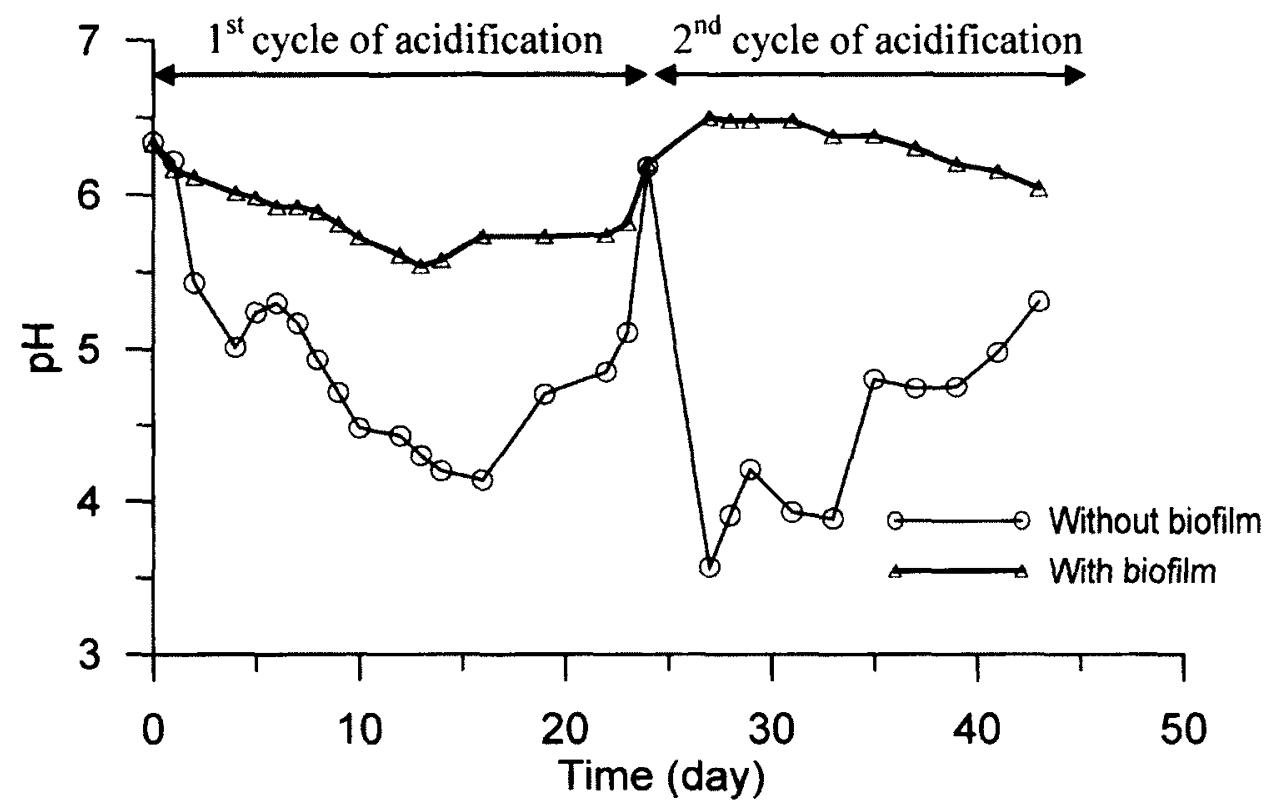

Figure 7.1: $\mathrm{pH}$ in the reactor with biofilm-covered mortar and control mortar specimen without biofilm under biogenic acidification at elevated temperature of $37 \pm 1^{\circ} \mathrm{C}$.

The graph of sulphate concentration as shown in Figure 7.2 also supported the higher sulphate concentration representing a higher rate of SOB growth in the control reactor compared with reactor containing the biofilm-covered mortar. After 23 days of exposure to SOB during the first cycle of acidification, the highest sulphate concentration was $6350 \mathrm{mg} / \mathrm{L}$ and $3550 \mathrm{mg} / \mathrm{L}$ in the control reactor and reactor containing the biofilmcovered mortar, respectively (Figure 7.2). Therefore, achieving a lower $\mathrm{pH}$ in the control 
reactor compared to the reactor containing biofilm-covered mortar may also be due to the higher activity of SOB in the control reactor, which was impeded in the biofilm-covered reactor due to the E.coli activity. The decalcification of mortar was observed in both reactors by an increase in the calcium concentration of the solution; the amount of calcium leach-out was 4.9 times higher in the control reactor than the reactor with biofilm-covered mortar: As illustrated in Figure 7.3, the calcium concentration after the first cycle of acidification was $136 \mathrm{ppm}$ in the control reactor compared with $28 \mathrm{ppm}$ in the reactor with the biofilm-covered mortar.

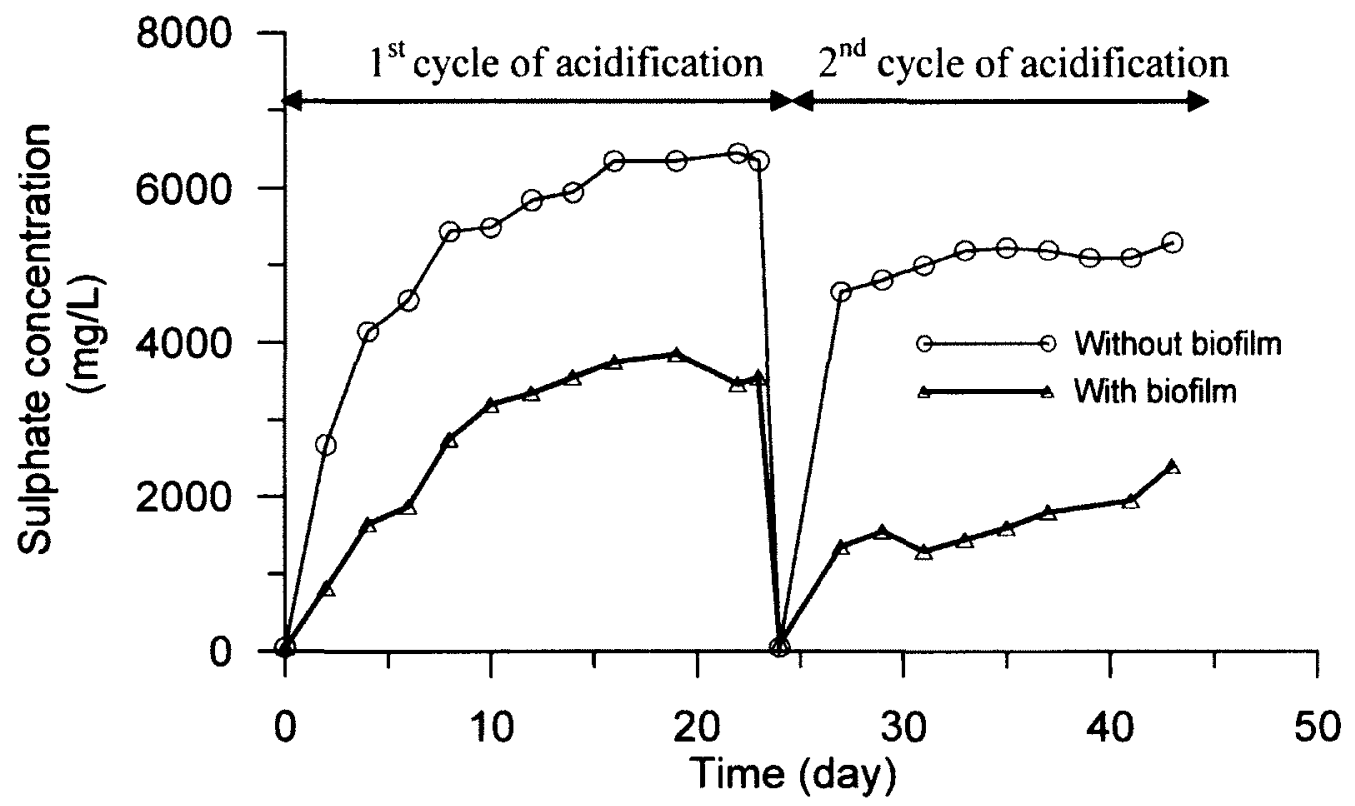

Figure 7.2: Sulphate concentration in the reactor with biofilm-covered mortar and control mortar specimen without biofilm under biogenic acidification at elevated temperature of $37 \pm 1^{\circ} \mathrm{C}$ (data points are the average of at least 3 readings with the maximum standard deviation of $225 \mathrm{mg} / \mathrm{L}$ ).

In the second cycle of acidification, after refreshing the broth containing SOB, the SOB growth rate increased drastically in the control reactor resulting in a sudden decrease in the $\mathrm{pH}$. As shown in Figure 7.2, the sulphate generation of $4650 \mathrm{mg} / \mathrm{L}$ was observed after one day, causing a $\mathrm{pH}$ drop to 3.5. The sudden increase in sulphate concentration of the 
reactor with control mortar can be explained by the presence of higher number of SOB originating from the attached SOB to the mortar and addition of new SOB. Overall, the rate of SOB growth in the second cycle of acidification was less than the first cycle in both reactors. As illustrated in Figure 7.2, the maximum sulphate concentration in the control reactor and biofilm-covered reactor was 5300 and $2400 \mathrm{mg} / \mathrm{L}$ in the second cycle of acidification, compared to the first cycle with 6350 and $3550 \mathrm{mg} / \mathrm{L}$ sulphate generation, respectively. Having a lower SOB growth in the second cycle of acidification and most likely higher buffering capacity of E.coli biofilm due to the biofilm growth during the acidification cycles resulted in slight increase in the $\mathrm{pH}$ at the beginning of the second cycle in the reactor with the biofilm-covered mortar (Figure 7.1). The pH in this reactor then decreased over time to the $\mathrm{pH}$ of 6 .

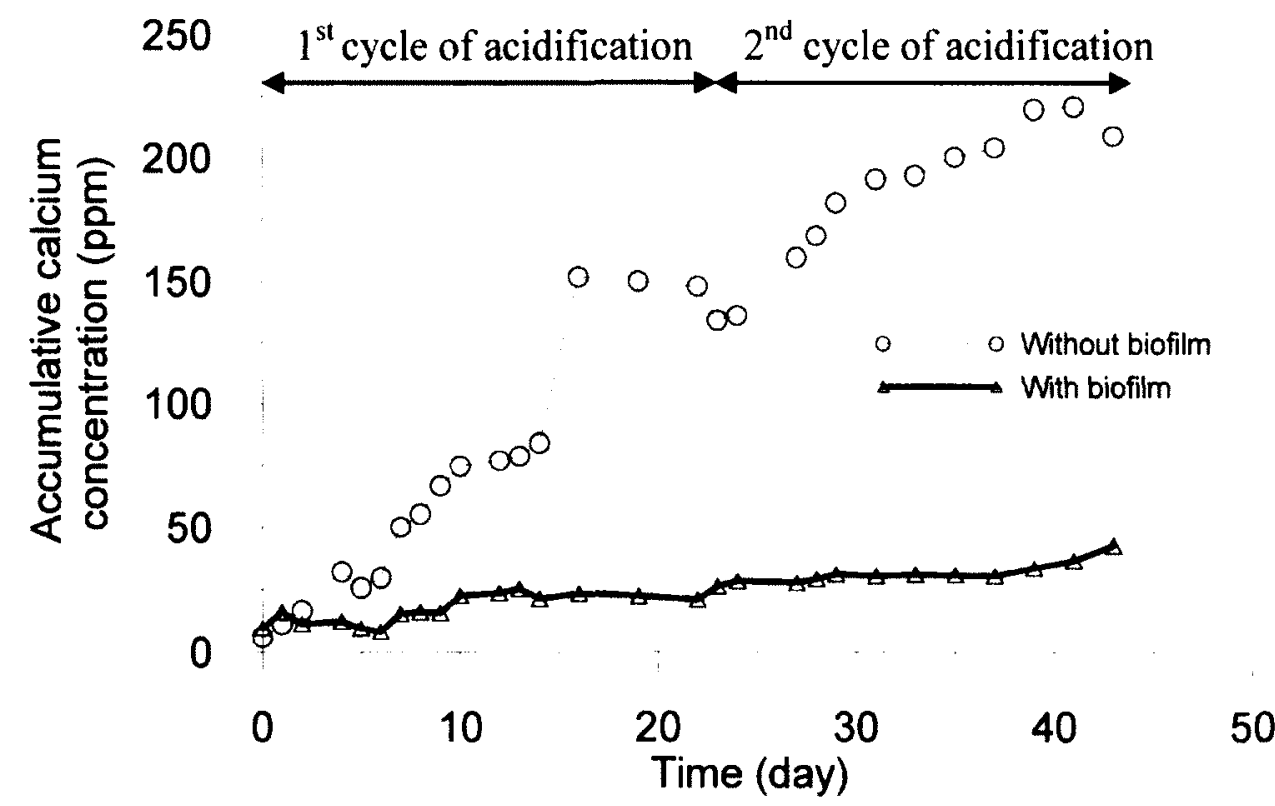

Figure 7.3: Accumulative calcium concentration in the reactor with biofilm-covered mortar and control mortar specimen without biofilm under biogenic acidification at elevated temperature of $37 \pm 1^{\circ} \mathrm{C}$.

A duplicate set of experiment consisting of the biogenic acidification at elevated temperature in control reactor and reactor containing biofilm-covered mortar was 
performed to confirm the accuracy of the results. Based on the observations in Figure 7.4, Figure 7.5 and Figure 7.6, which are respectively the results of $\mathrm{pH}$ measurement, sulphate and calcium concentration of the second replica, the same trend was observed for $\mathrm{pH}$, sulphate and calcium concentration in the control reactor. However, the reactor containing biofilm-covered mortar showed more protective characteristics compared to the first set of the experiment as the $\mathrm{pH}$ did not drop to below the initial $\mathrm{pH}$ in this reactor (Figure 7.4). There was also lower SOB activity with less sulphate generation in the biofilm-covered reactor of the second replica. As shown in Figure 7.5, the highest sulphate concentration in biofilm-covered reactor of replica experiment was $1200 \mathrm{mg} / \mathrm{L}$ compared with the first replica with the maximum sulphate concentration of $3550 \mathrm{mg} / \mathrm{L}$ (Figure 7.2). The results from these experiments confirmed again the protective properties of the E.coli biofilm against biogenic acidification with SOB even under elevated temperatures $\left(37^{\circ} \mathrm{C}\right)$.

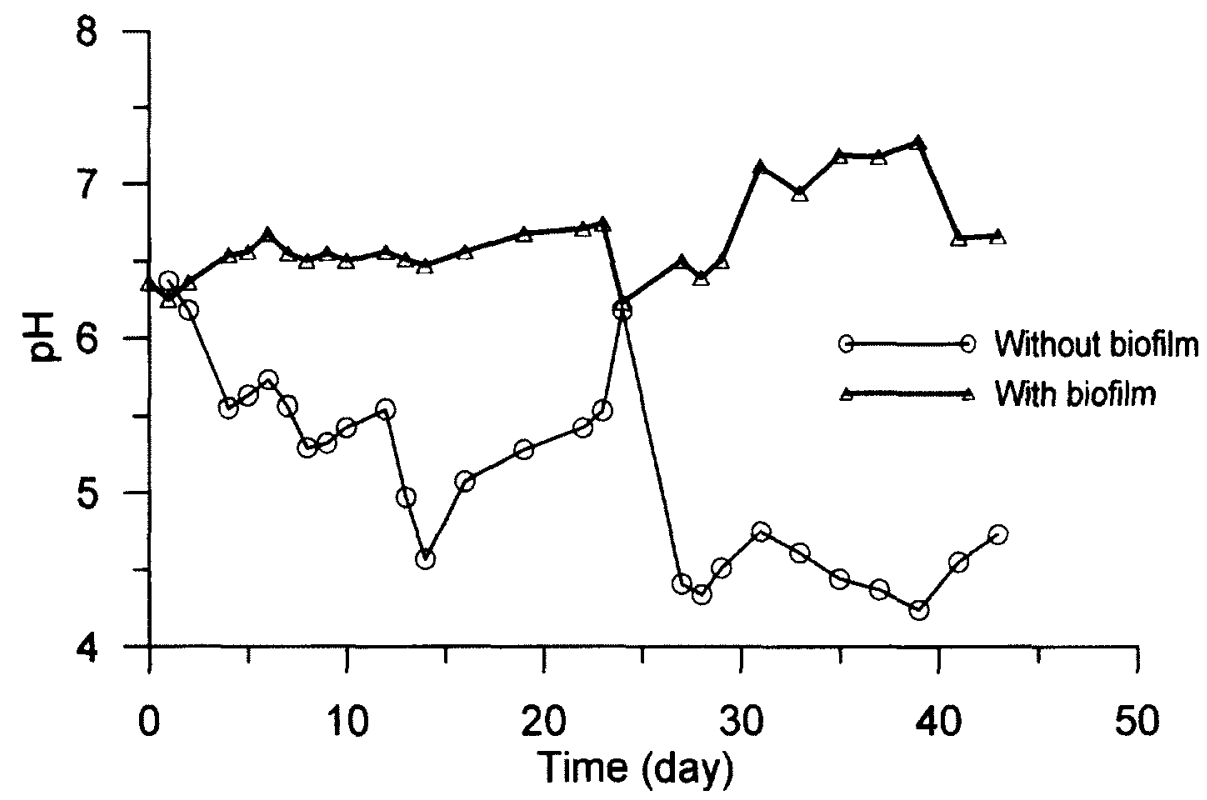

Figure 7.4: $\mathrm{pH}$ in the reactors of the second replica experiment under biogenic acidification at an elevated temperature of $37 \pm 1^{\circ} \mathrm{C}$. 


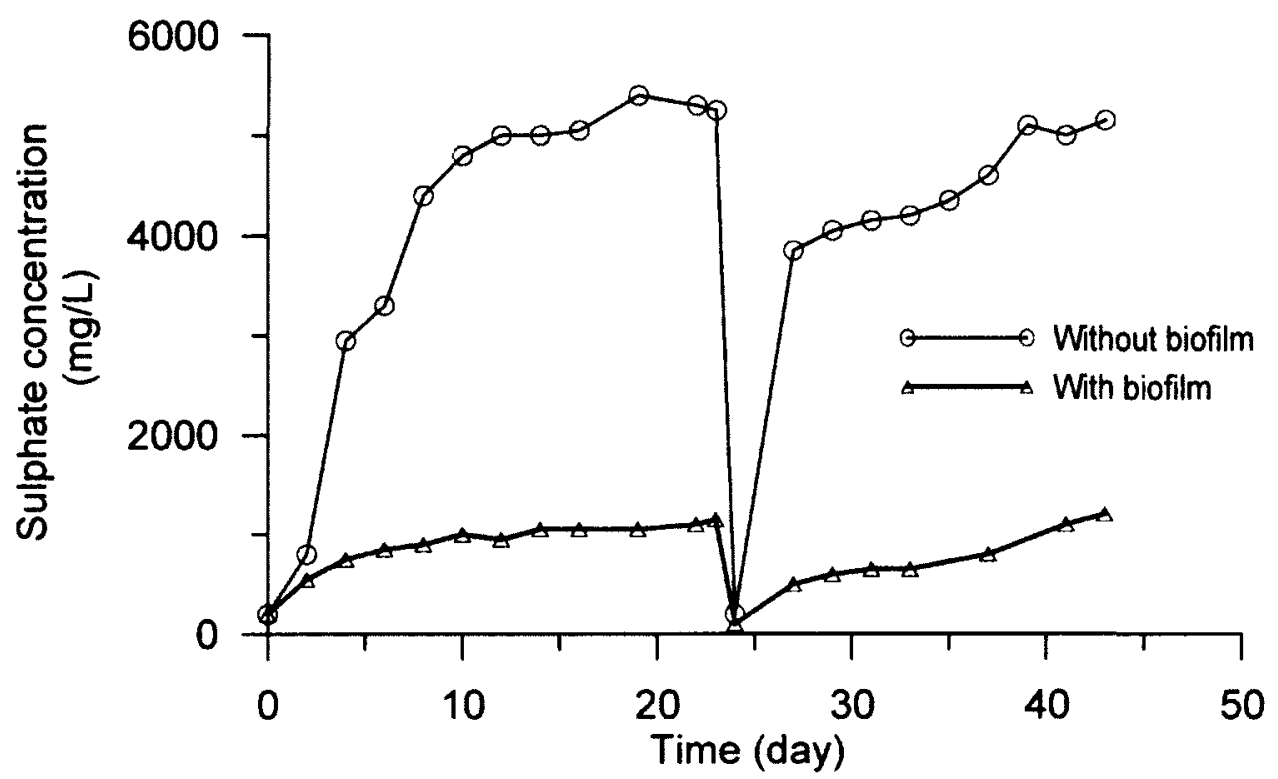

Figure 7.5: Sulphate concentration in the reactors in second replica experiment under biogenic acidification at an elevated temperature of $37 \pm 1^{\circ} \mathrm{C}$ (data points are the average of at least 3 readings with the maximum standard deviation of $200 \mathrm{mg} / \mathrm{L}$ ).

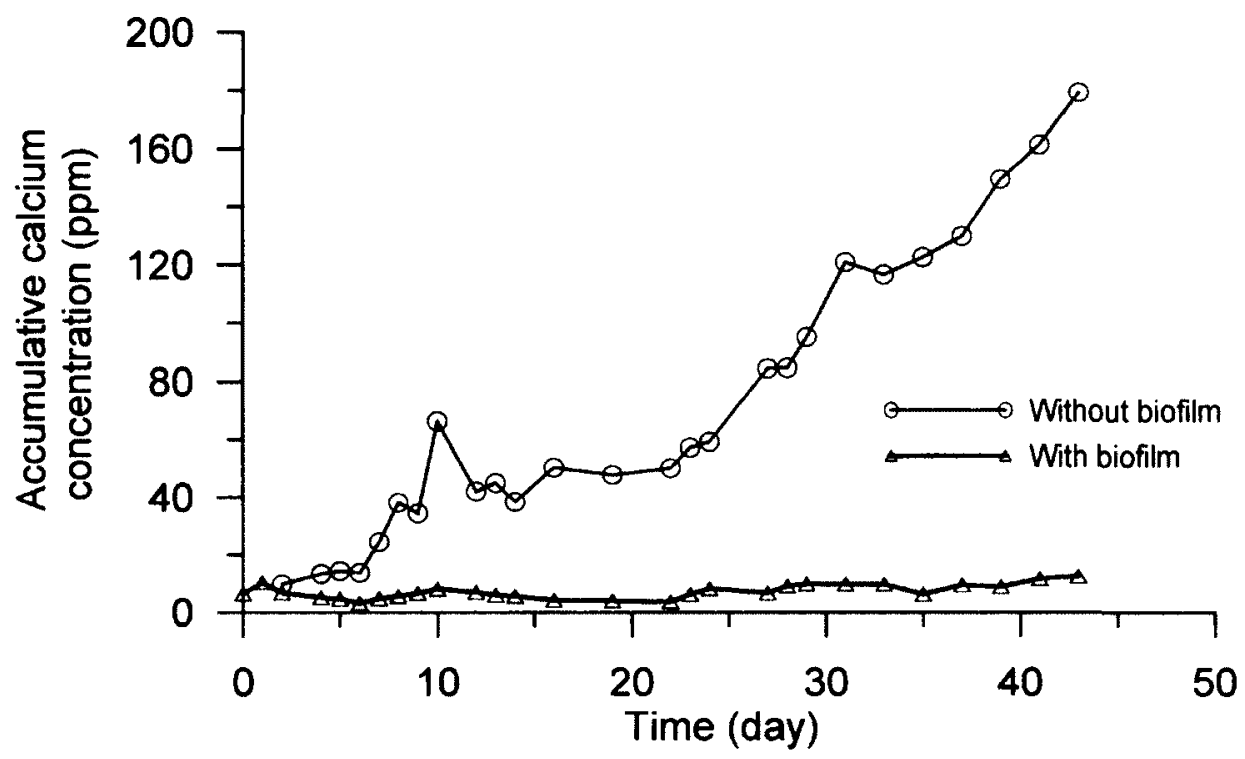

Figure 7.6: Accumulative calcium concentration of reactors in duplicate experiments under biogenic acidification at an elevated temperature of $37 \pm 1^{\circ} \mathrm{C}$.

\subsubsection{Crystal formation}

The XRD analysis was performed on the powder sample taken from control mortar and biofilm-covered mortar in two 0.5 -mm-thick layers of mortar surface to identify the type 
of crystal formations. Comparisons of the XRD pattern of the top $0.5-\mathrm{mm}$ layer of control mortar with the biofilm-covered mortar in Figure $7.7 \mathrm{a}$ and $\mathrm{b}$ showed almost the same type of crystal formation in both cases, which contained mainly quartz, calcite, dolomite and gypsum. In the control mortar aluminate formation was also observed. The presence of gypsum which was observed in both control mortar and biofilm-covered mortar indicates that the biofilm was not very effective in controlling the gypsum formation at elevated temperature (Figure 7.7). The XRD analysis of the second layer of control mortar (i.e., powder was taken from the $0.5-1 \mathrm{~mm}$ top layer of mortar surface) showed the presence of ettrengite in addition to gypsum (Figure 7.8a). In Figure 7.8a, the ettrengite formation was confirmed by the presence of all three main peaks of ettrengite (i.e., 20=9.1, 15.8 and 22.9). As explained by Wang (1994) ettrengite is not stable at low $\mathrm{pH}$ and is converted to gypsum, hence its presence was only observed at deeper sections with higher alkalinity (Figure 7.8a). In the top layer with the lower $\mathrm{pH}$, ettrengite most likely converted to gypsum and some aluminate phases since both gypsum and aluminate were present in the XRD of top layer (Figure 7.7a). As observed in Figure 7.8a, the intensity of the aluminate peak decreased as the ettrengite was more stable in the deeper section with higher alkalinity. The XRD analysis of second layer of biofilm-covered mortar did not show any sign of gypsum or ettrengite (Figure 7.8). This observation indicates that even though the gypsum formation was observed in the top surface layer, mortar deterioration in biofilm-covered mortar was not as severe as the control mortar sample in which the gypsum as well as ettrengite formation penetrated deeper into the control mortar sample indicating deeper mortar deterioration. 

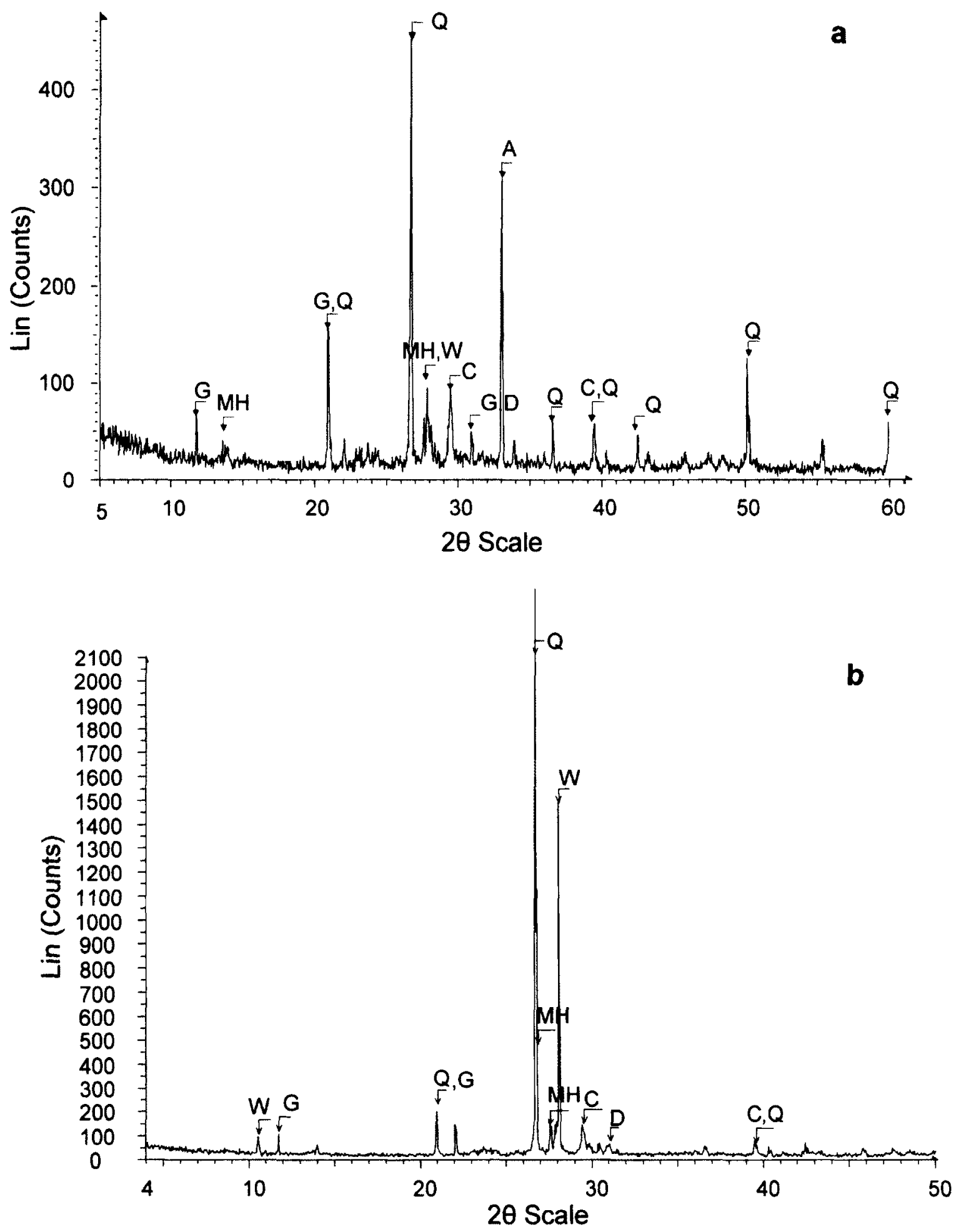

Figure 7.7: XRD pattern of mortar powder taken from top $0.5 \mathrm{~mm}$ surface after biogenic acidification at elevated temperature; a) control mortar, b) biofilmcovered mortar; dolomite (D), gypsum $(\mathrm{G})$, quartz $(\mathrm{Q})$, magnesium calcite (C), magnesium sulphate hydroxide(MH), winchitte potassium (W), aluminate (A). 

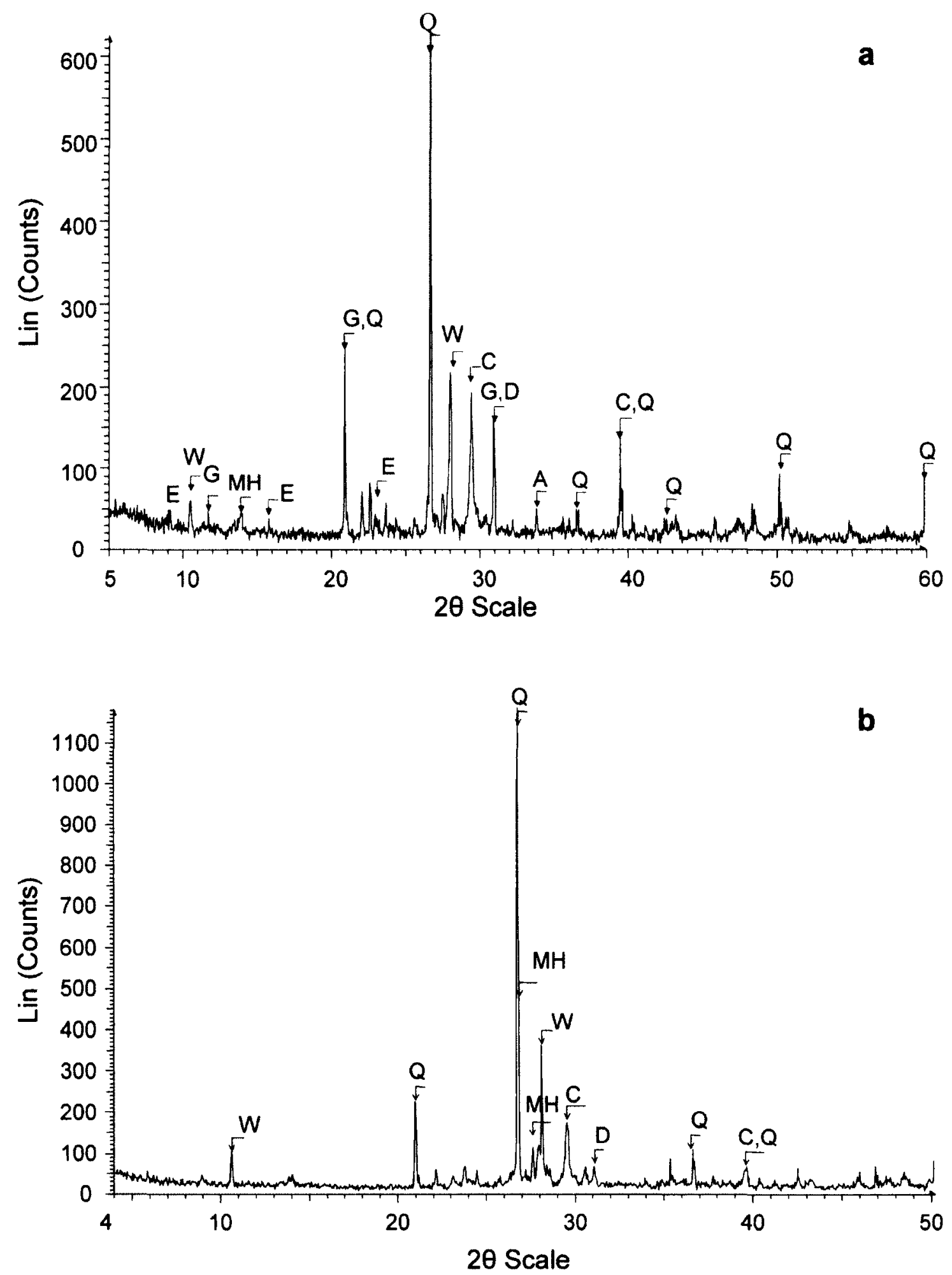

Figure 7.8: XRD pattern of second layer of mortar powder after biogenic acidification at elevated temperature; a) control mortar, b) biofilm-covered mortar; dolomite (D), gypsum $(\mathrm{G})$, quartz $(\mathrm{Q})$, magnesium calcite $(\mathrm{C})$, magnesium sulphate hydroxide $(\mathrm{MH})$, winchitte potassium $(\mathrm{W})$, aluminate $(\mathrm{A})$. 


\subsubsection{Visual inspection}

The photographs of the mortar surface taken after biogenic acidification at elevated temperatures are shown in Figure 7.9. Figure 7.9a and $\mathrm{b}$ are the photographs of control mortar surface without biofilm. These two images show the mortar surface structure became rougher with larger pore formation and some black spots appearing most likely due to the microstructure changes.

The photograph of the biofilm-covered mortar from the first replicate is shown in Figure $7.9 \mathrm{c}$ and showed the non-uniform biofilm layer covering the mortar surface. In Figure $7.9 \mathrm{~d}$, the biofilm layer was brushed away to be able to see the mortar surface structure. As illustrated in Figure $7.9 \mathrm{~d}$, due to the abrasion caused by brushing, the mortar surface spalled away at the weak locations. Comparing Figure $7.9 \mathrm{c}$ with Figure $7.9 \mathrm{~d}$ showed that the location with no biofilm coverage were the weakest locations which spalled away during the brushing of the sample.

In Figure $7.9 \mathrm{e}$, the image of the biofilm-covered mortar in the replica experiment is shown. This image shows very good biofilm coverage on the mortar surface. The removal of biofilm layer from the surface also showed an intact mortar surface with no sign of damage or spalling (Figure 7.9f). 

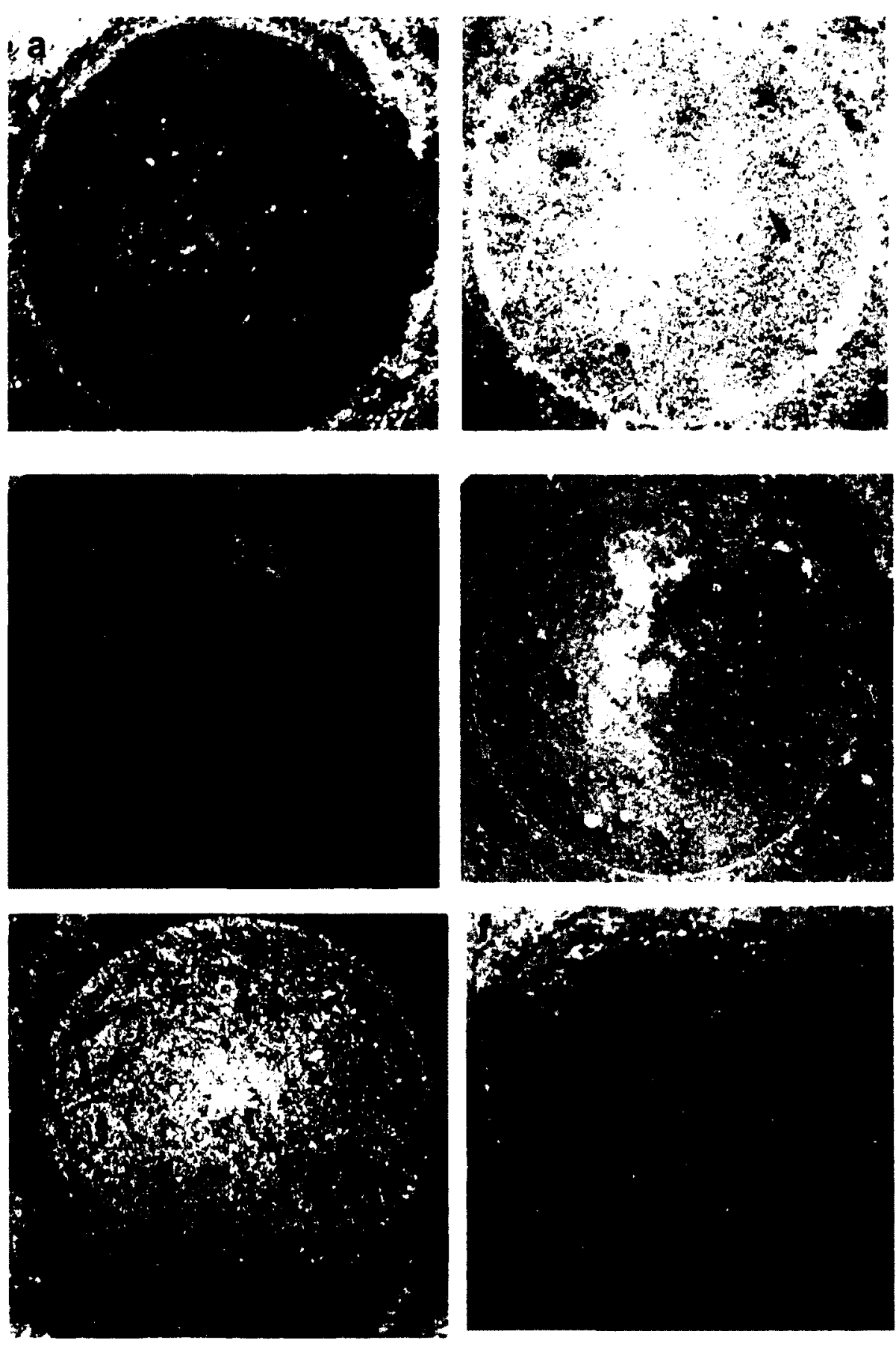

Figure 7.9: Visual inspection of mortar surface after biogenic acidification at elevated temperature; a) first control mortar without biofilm, b) second control mortar without biofilm c) first biofilm-covered mortar showing the attached biofilm, d) first biofilm-covered mortar after removing the biofilm layer, e) second biofilm-covered mortar showing the attached biofilm, f) second biofilm-covered mortar after removing the biofilm layer. 


\subsection{Mechanisms of Deterioration: Chemical vs. BiogeniC ACIDIFICATION}

Due to the complexity of simulation of biogenic sulphuric acid attack, extensive studies performed on assessing the resistance of concrete to biogenic sulphuric acid attack usually consider simulating the deterioration with chemical acidification (Attiogbe and Rizkalla, 1988; O'Connell et al. 2010). However, the mechanism of chemical acidification may be different from the biogenic acidification since it does not consider the bacterial aspects of the deterioration and may lead to unrealistic conclusions. Hence, the differences of the mechanism of mortar deterioration under chemical acidification and biogenic acidification at room temperature were investigated in this study.

As illustrated in Figure 7.10a, the decalcification of mortar, which is described by the dissolution of calcium hydroxide and C-S-H in hydrated cement systems and estimated by measuring the calcium concentration of the solution, was observed in both mortars exposed to chemical and biogenic acidification. Decalcification reduces the bulk density and porosity of the cement paste, hence resulting in a decrease of the mechanical strength of the cement-based material (Glasser et al., 2007). The decalcification was 6.7 times higher under chemically induced acidification, even though the $\mathrm{pH}$ of the solution was generally higher than the $\mathrm{pH}$ in biogenic acidification process (Figure $7.10 \mathrm{a}$ and $\mathrm{b}$ ). For example, after 12 days of exposure, and having a higher $\mathrm{pH}$ for $67 \%$ of the time (i.e., 8 days out of 12 days) in the chemical acidification reactor than the biogenic reactor, the amount of calcium leached out was $200 \mathrm{ppm}$ in the chemical reactor compared to $45 \mathrm{ppm}$ in the biogenic reactor (Figure $7.10 \mathrm{a}$ and $\mathrm{b}$ ). The higher rate of decalcification of the 
chemically acidified mortar initiated the dissolution of C-S-H which usually occurs after depletion of calcium hydroxide (Taylor and Gollop, 1997).
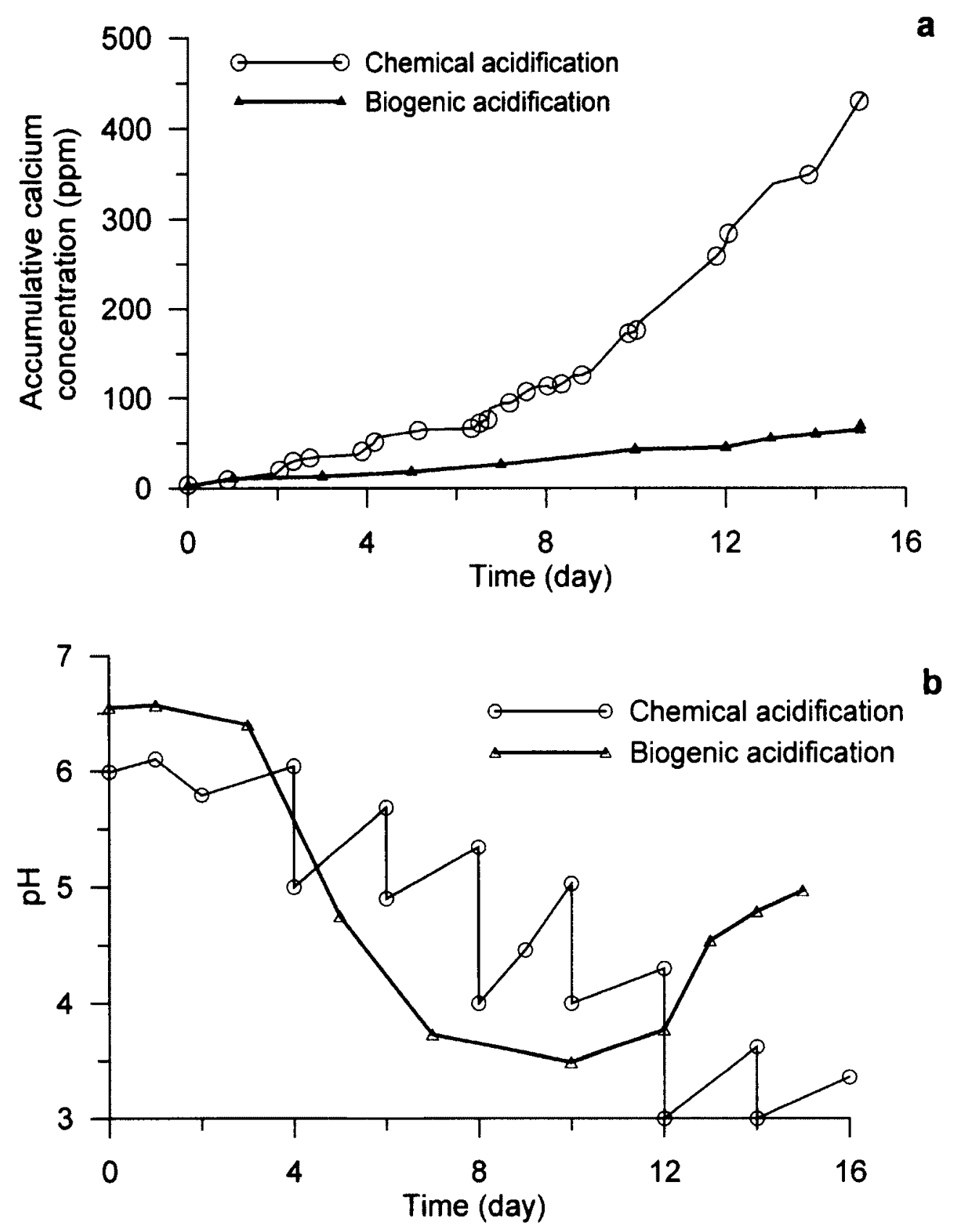

Figure 7.10: Comparison of mortar deterioration due to biogenic acidification with chemical acidification as measured by calcium concentration and $\mathrm{pH}$ measurement; a) calcium concentration and, b) $\mathrm{pH}$ measurement in reactors under chemical and biogenic acidification at room temperature. 
The dissolution of C-S-H in the chemically acidified mortar was also observed by SEM analysis indicating the formation of silica gel which is formed by loss of $\mathrm{Ca}$ ion from $\mathrm{C}$ S-H (Figure 7.11a). On the other hand, the SEM image of mortar under biogenic acidification revealed the formation of gypsum crystals, spalling and cracking of the mortar (Figure 7.11b). According to Glasser et al. (2007), the formation of gypsum and ettringite may lead to expansion, loss of cement-aggregate binding and consequent surface cracking, the phenomena which were all observed on the surface of biogenicly acidified mortar (Figure 7.11b). The XRD analysis of the top surface of mortar under biogenic and chemical acidification also revealed the formation of gypsum crystals due to the biogenic acidification which was not the case under chemical acidification (Figure 7.12). 

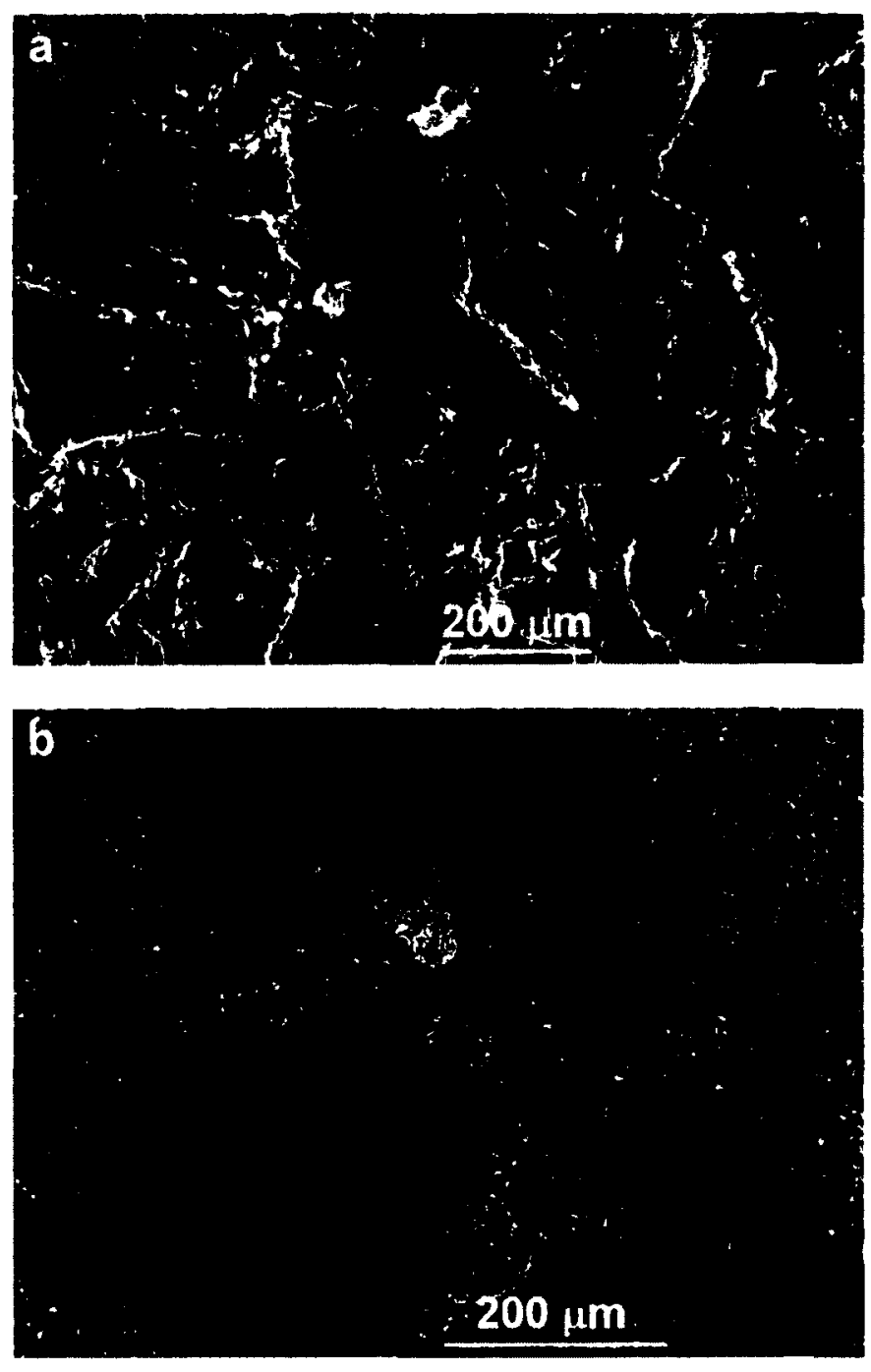

Figure 7.11: SEM micrographs of mortar surface; a) after chemical acidification (1000x magnification), b) after biogenic acidification (200x magnification). 


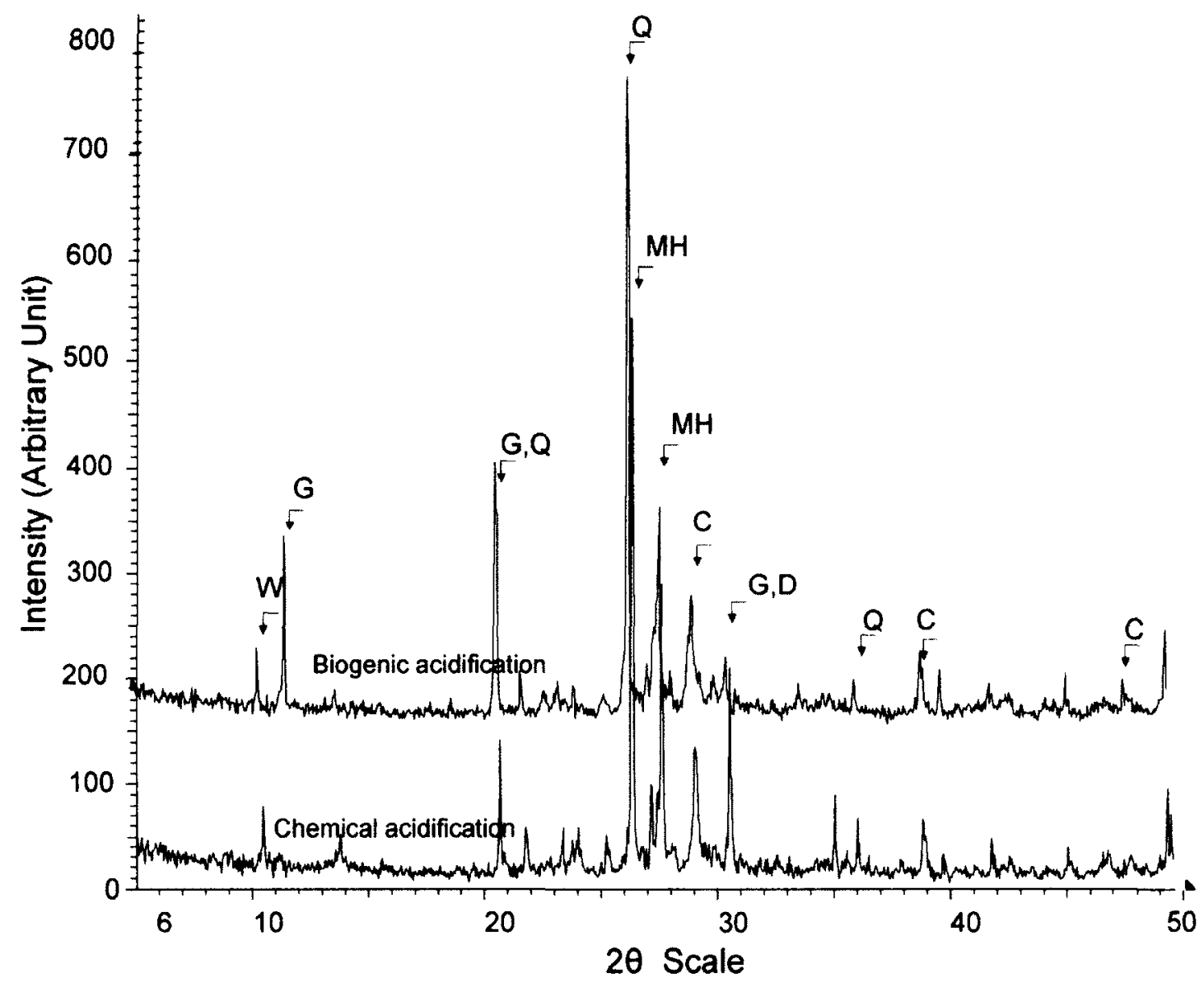

Figure 7.12: XRD analysis of powder taken from the top $0.5 \mathrm{~cm}$ surface of mortar under chemical (bottom XRD pattern) and biogenic (top XRD pattern) acidification.

\subsection{CONCLUDING REMARKS}

The effectiveness of biofilm as a protective barrier against biogenic sulphuric acid at elevated temperature of $37 \pm 1^{\circ} \mathrm{C}$ was evaluated. Evidence of calcium leaching showed that the biofilm layer was protective to some extent. As observed by visual inspection, the formation of a uniform biofilm after an 8-day period was a challenging task and if the biofilm was grown for longer times, the protective characteristics of the biofilm would be enhanced. It was also revealed that the biogenic acidification at elevated temperature is a more severe deterioration compared with the room temperature biogenic acidification. As 
shown by the XRD analysis, the biogenic acidification at elevated temperatures resulted in the formation of gypsum in the biofilm-covered mortar which was not a case for the room temperature experiment. $\mathrm{XRD}$ analysis also confirmed that gypsum formation was reduced to some extent in the biofilm-covered mortar because gypsum was not present in the deeper section.

Comparing the mechanism of chemical sulphuric acid deterioration with the biogenic sulphuric acid deterioration illustrated that the chemical acidification changes the pore structure of the mortar by the dissolution of C-S-H; however, biogenic acidification causes cracking, spalling and loss of coherence due to gypsum formation and expansion. 


\section{CHAPTER 8. BIOFILM PERFORMANCE EVALUATION USING AN ENZYME ELECTRODE}

\subsection{INTRODUCTION}

In this chapter, an enzyme electrode that measures the sulphide concentration was used to evaluate the effectiveness of a biofilm as a protective barrier for inhibition of microbiologically influenced corrosion caused by the presence of sulphide. Reduction and oxidation of sulphur is one of the major microbial activities that occur during wastewater treatment and transport. Sulphate ion is naturally present in most water supplies and wastewater. Under anaerobic conditions, sulphate ion is biologically reduced to sulphide by sulphate reducing bacteria (SRB) and is converted to hydrogen sulphide in the presence of hydrogen. Sulphide or hydrogen sulphide is responsible for the microbial corrosion of metals (Booth 1964) and concrete deterioration (Vincke et al., 2001). Hence, an effective biofilm against MIC would reduce or prevent the passage of sulphide ions.

The steady-state amperometric measurement of sulphide is performed by an enzyme electrode which was prepared using sulphide oxydase (SO) enzyme (Papavinasam et al. 2004). During the amperometric measurement, the SO enzyme oxidizes sulphides and sulphur compounds to elemental sulphur resulting in an electric current as: 


$$
\mathrm{H}_{2} \mathrm{~S} \stackrel{\text { Sulphide oxidase }}{\longrightarrow} \mathrm{S}+2 \mathrm{H}^{+}+2 \mathrm{e}^{-}
$$

The electric current is proportional to the sulphide concentration in the solution; therefore, by amperometric measurement of electric current, one can investigate the sulphide concentration and subsequently the severity of microbial corrosion. In order to develop a redox reaction (Eqs. 8-1 and 8-2) in the enzyme electrode, a mediator needs to be added to the SO enzyme paste. A ferrocene derivative (1,1' dimethylferrocene) was used as the mediator to accomplish the oxidation reaction (Eq. 8-3) (Sooknah et al., 2008 a, b):

$$
\text { Sulphide }+\mathrm{SO}_{[\mathrm{ox}]} \longrightarrow \text { sulphur }+\mathrm{SO} \text { [red] }
$$

$\mathrm{SO}_{[\text {red }]}+2$ ferricinium ${ }^{+} \longrightarrow \mathrm{SO}_{[\mathrm{ox}]}+2$ ferrocence $+2 \mathrm{H}^{+}$

The enzyme electrode was used to assess Escheria coli DH5 $\alpha$ biofilm for its ability to inhibit the sulphide passage. If the tip of the enzyme electrode is covered with a biofilm, the decrease observed in the electric current density with the biofilm compared to the current density without the biofilm would be an indicator for the performance of the biofilm. This simple method would enable the comparison of several microbial biofilms in less than a day and selection of the best performing one against MIC. The method would also eliminate the need for expensive, difficult and long-term testing of biofilms in microbial studies. 


\subsection{Materials ANd Methods}

\subsubsection{Microorganisms}

A tetracycline-resistant enteric bacterium, Escheria coli DH5 $\alpha$ (pKMY319) was used, based on its ability to form biofilms (Jayaraman et al. 1997 a, b). The strain was cultivated in $10 \mathrm{~mL}$ of Luria-Bertani (LB) medium with $0.25 \%$ tetracycline in a test tube by streaking from the agar plate. The bacteria were grown overnight at $30^{\circ} \mathrm{C}$ under static conditions (no mixing) while exposed to air. A $0.1 \% \mathrm{v} / \mathrm{v}$ inoculum from the overnight grown sample was used as the seed for biofilm growth.

A sulphide oxidase-producing actinomycetes strain which belongs to the Arthrobacter species, FR-3, was isolated from a swamp sediment and used for the production of SO enzyme (Mohapatra et al., 2006). The Arthrobacter species, FR-3, was routinely cultivated from an agar slant and revived on glucose-yeast extract (GY) broth containing $1 \%(\mathrm{w} / \mathrm{v})$ glucose and $1 \%(\mathrm{w} / \mathrm{v})$ yeast extract. The selection of FR-3 as a potential SO producing microorganism and its isolation was performed according to the procedures outlined in Mohapatra et al. (2006).

\subsubsection{Biofilm growth}

A bacterial biofilm was grown on a dialysis membrane with a molecular weight cut off (MWCO) of 3,000 kD (Spectrum Laboratories, CA, US). The membrane was placed on the bottom of a $60 \mathrm{~mL}$ glass bottle (QorPak, PA, USA) with a foam stopper. The biofilm was grown in $10 \mathrm{~mL}$ of $\mathrm{LB}$ under static conditions with no agitation at $30^{\circ} \mathrm{C}$. The $\mathrm{LB}$ medium was replenished on a daily basis to provide enough nutrients for the growth and seeded with a $0.1 \%(\mathrm{v} / \mathrm{v})$ inoculum from an overnight grown culture. The membrane was 
removed after 7 days and attached to the tip of the enzyme electrode with a rubber band (Figure 8.1).

\subsubsection{Production and purification of sulphide oxidase enzyme}

For production of SO enzyme, FR-3 was cultivated in a $1,000 \mathrm{~mL}$ flask with a foam stopper containing $500 \mathrm{~mL}$ of GY medium. After incubation for 7 days in an orbital shaker at $100 \mathrm{rpm}$ and $30^{\circ} \mathrm{C}, 1 \%(\mathrm{v} / \mathrm{v})$ of $1 \mathrm{mM} \mathrm{Na} \mathrm{Na}_{2} \mathrm{~S}$ was added to the cultivation medium in order to increase the production of SO. The bacteria were harvested by centrifuging the medium at $6,000 \mathrm{rpm}$ for 10 minutes on Day 8 and were washed three times with $50 \mathrm{mM}$ Tris-HCL buffer ( $\mathrm{pH}$ 7.5). The SO enzyme was released by sonification of the harvested cells at a power of $130 \mathrm{~W}$. The lysed cells were centrifuged at $1,000 \mathrm{rpm}$ for 20 minutes and the supernatant of the centrifuged lysate was used as the cell-free extract of SO.

The molecular weight of the SO enzyme is $43 \mathrm{kD}$ (Mohapatra et al., 2006); therefore the enzyme was purified with membranes that have MWCO of $10 \mathrm{kD}$. The cell-free extract of SO was purified by diafiltration using a Minimate Tangential Flow Filtration Capsule (Pall Corporation, $\mathrm{MWCO}=10 \mathrm{kD}$ ), and further purified by gel filtration using a HiLoad X16/60 (Sephadex 75 Prep. grade) gel filtration column. The purified enzyme was concentrated after each purification step by ultrafiltration using Macrosep Centrifugal Device (Pall Corporation, $\mathrm{MWCO}=10 \mathrm{kD}$ ). Detailed information on the preparation and purification of enzyme can be found in Mohapatra et al. (2006, 2007). 


\subsubsection{Enzyme electrode preparation}

To improve the shelf life of SO, the purified enzyme was stabilized by adding $5 \%(w / v)$ lactitol and 1\%(w/v) DEAE-dextran (Sooknah et al., 2008 a). The enzyme electrode (EE) was developed by immobilization of the stabilized SO in 1,1' dimethylferrocene and carbon/graphite paste. The immobilized enzyme paste was placed on a commercially available electrode body shown in Figure 8.1 (BioAnalytical Systems Instruments Company, USA), which is made of a solvent-resistant plastic $(7.5 \mathrm{~cm}$ length $\times 6 \mathrm{~mm}$ outer diameter). The bottom of the electrode was perforated for a $3.0 \mathrm{~mm}$ inner diameter to house the enzyme paste. A metal pin $(0.75 \mathrm{~cm})$ mounted in the plastic body of the electrode was used to connect the electrode to a potantiostat for current density reading.

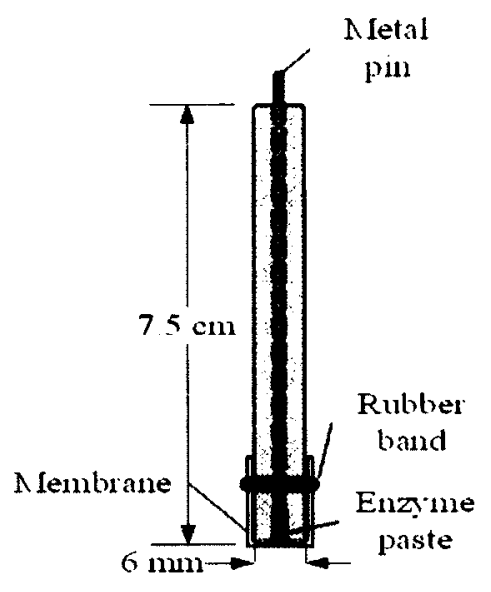

Figure 8.1: Body of the electrode used for placement of enzyme paste; the tip of the electrode is covered with the biofilm-covered membrane where needed.

\subsubsection{Electrochemical measurements}

All of the amperometric measurements were carried out at room temperature using 50 $\mathrm{mM}$ Tris-HCL buffer $(\mathrm{pH}=7.5)$ as the electrolyte and sodium sulphide solution as the electroactive species. Standard sodium sulphide solution was prepared in an anaerobic 
chamber by dissolving the $\mathrm{Na}_{2} \mathrm{~S}$ salt in nitrogen-saturated $50 \mathrm{mM}$ Tris- $\mathrm{HCl}$. The solution was standardized by the modified iodometric method followed by titration. Since sodium sulphide is not stale in presence of air, a setup was designed to maintain anaerobic conditions (Figure 8.2). This setup consisted of a reservoir for holding the Tris-HCL buffer, a $100 \mathrm{~mL}$ mixing cell for mixing the buffer with the sulphide solution and a 50 $\mathrm{mL}$ test cell. The test cell incorporated three electrodes: the EE as the working electrode, an SCE (Standard Calomel Electrode) $\mathrm{Ag} / \mathrm{AgCl}$ reference electrode, and a steel rod as counter electrode. The electrodes were connected to a potentiostat (Solartron SI 1287 interface controlled by CorrWare $\mathrm{V} 1.3$ software). A potential of $+0.3 \mathrm{~V}$ against the reference electrode was applied to achieve the oxidation of sodium sulphide. A small amount of sodium sulphide ( 1 to $5 \mathrm{~mL}$ ) was withdrawn from the $25 \mathrm{~mL}$ glass vial containing the standard sodium sulphide solution and injected in $100 \mathrm{~mL}$ deaerated Tris$\mathrm{HCl}$ in the mixing reservoir to give a final concentration of $20-350 \mathrm{mg} / \mathrm{L} \mathrm{S}^{2-}$. After mixing, the sulphide solution was transferred to the test cell by pressurizing the mixing cell by argon gas. The current density was monitored as a function of time and the stabilized current density was reported as the corresponding current density to the sulphide concentration. 


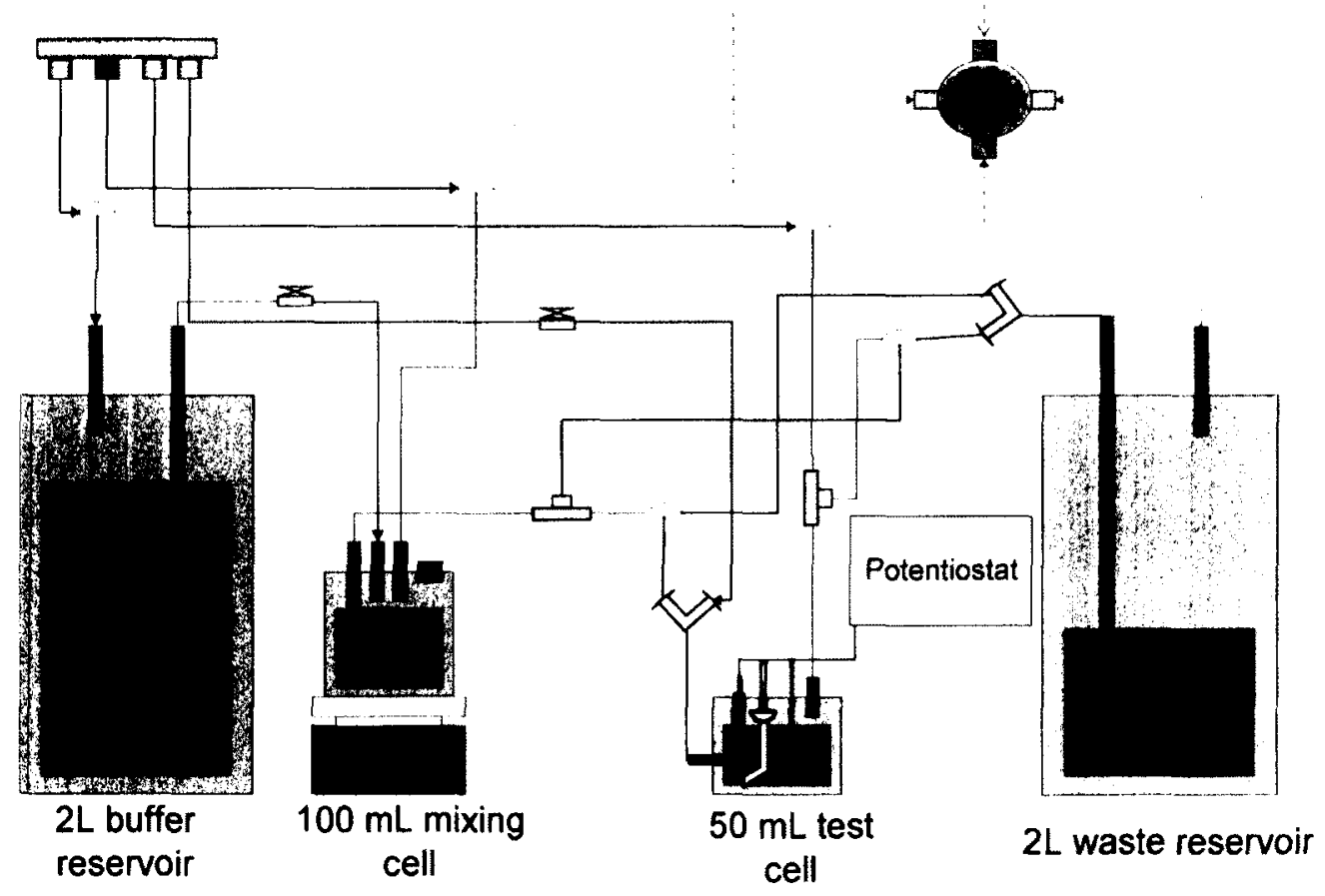

Figure 8.2: Schematic of the setup for amperometric measurements.

\subsection{RESUlts AND DiscuSSION}

The effectiveness of the E. coli DH5 $\alpha$ biofilm was evaluated using the SO enzyme electrode and amperometric measurements. Due to the challenges faced growing the biofilm directly on the enzyme electrode, the biofilm was grown on a membrane and the membrane was used to cover the tip of the enzyme electrode. The steady-state current response of EE with the membrane was compared to the response of $E E$ covered with the biofilm-covered membrane in order to evaluate the performance of the biofilm against passage of sulphide ion. Amperometric measurements were also conducted for the EE with no membrane to provide a baseline reading.

\subsubsection{Electrochemical measurements}

Amperometric measurements were carried out using the SO EE as the working electrode 
at increasing concentrations of sulphide. Figure 8.3, Figure 8.4, and Figure 8.5 illustrate the results obtained without the membrane, with the membrane (no biofilm), and with the biofilm-covered membrane, respectively. The initial current density measured at zero concentration of sulphide took a longer time to stabilize in Figure 8.4 and Figure 8.5 due to the presence of membrane which delayed the penetration of sulphide ions into the enzyme paste. The EE that did not have a membrane was more sensitive to sulphide and provided higher peak values at the same sulphide concentration (Figure 8.3 and Figure 8.4). For example, EE without the membrane showed a current density difference of $1 \times 10^{-5}\left(\mathrm{Amps} / \mathrm{cm}^{2}\right)$ between $0.06 \mathrm{mg} / \mathrm{mL}$ and $0.09 \mathrm{mg} / \mathrm{mL}$ sulphide concentration (Figure 8.3) but the EE with the membrane showed a current density difference of $0.1 \times 10^{-5}$ between 0.07 and $0.1 \mathrm{mg} / \mathrm{mL}$ sulphide concentration (Figure 8.4). As a result, a lower sulphide concentration range ( 0 to $0.18 \mathrm{mg} / \mathrm{mL}$ ) was used to calibrate the $\mathrm{EE}$ with no membrane, and a higher concentration range was used to calibrate the EE with the membrane ( 0 to $0.33 \mathrm{mg} / \mathrm{mL}$ ) and with the biofilm-covered membrane ( 0 to 0.26 $\mathrm{mg} / \mathrm{mL}$ ). The EE with biofilm-covered membrane was not responsive to sulphide concentration changes, and there was not a significant change in current density within the concentration range tested (Figure 8.5). The results indicated that the biofilm was effective in blocking the sulphide ions.

The calibration line representing the steady-state response of the EE was obtained from the difference of the steady-state current density reading corresponding to a particular sulphide concentration and the current density at zero sulphide concentration when the experiments were run with the Tris-HCL buffer only (Sooknah et al. $2008 \mathrm{~b}$ ). The current was monitored as a function of time and the stabilized current density was reported as the 
corresponding current density to the sulphide concentration. The calibration lines of the EE with and without the membrane and with the biofilm grown membrane are provided in Figure 8.6. The data illustrate that the EE with the membrane had a lower sensitivity than the EE without the membrane. The sensitivity of the EE with the membrane, which is defined as the slope of the calibration line (Sooknah et al., $2008 \mathrm{~b}$ ), was 51.73 $\mu \mathrm{A} . \mathrm{mL} / \mathrm{mg}$ compared to $186.7 \mu \mathrm{A} . \mathrm{mL} / \mathrm{mg}$ for the EE without the membrane (Figure 8.6). Most importantly, the steady-state response of EE with the biofilm grown membrane stayed at around zero, and no significant increase in current density was observed with increasing sulphide concentration. This indicates that the biofilm was successful as a barrier against the sulphide ions and almost completely prevented the transport of the sulphide ions.

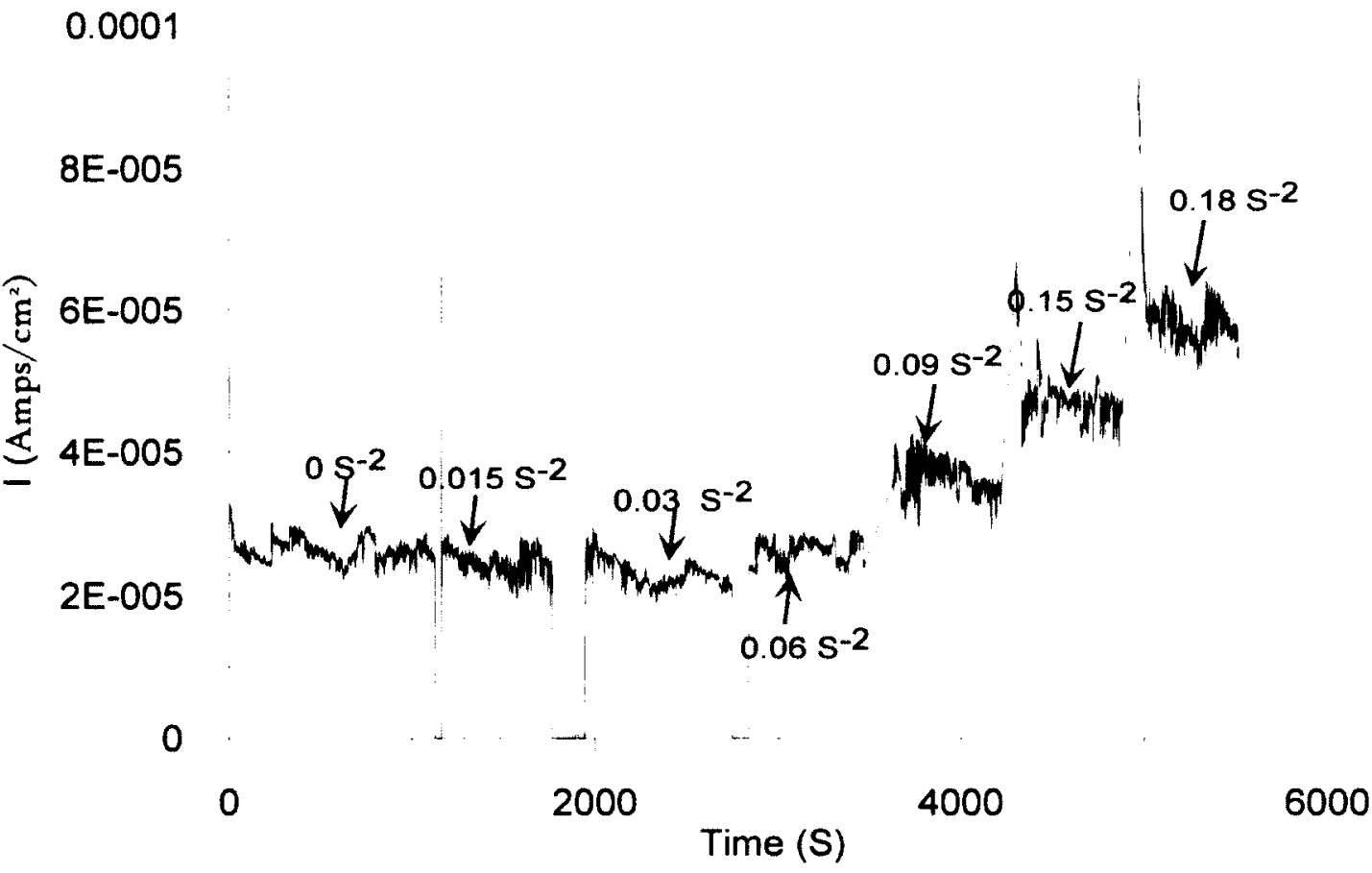

Figure 8.3: Current densities measured using a sulphide oxidase enzyme electrode, at ambient temperature, with a potential hold of $0.3 \mathrm{~V}$ (vs. SCE); concentration of sulphide reported on the graph as $\mathrm{mg} / \mathrm{mL}$. 
$8 \mathrm{E}-005$

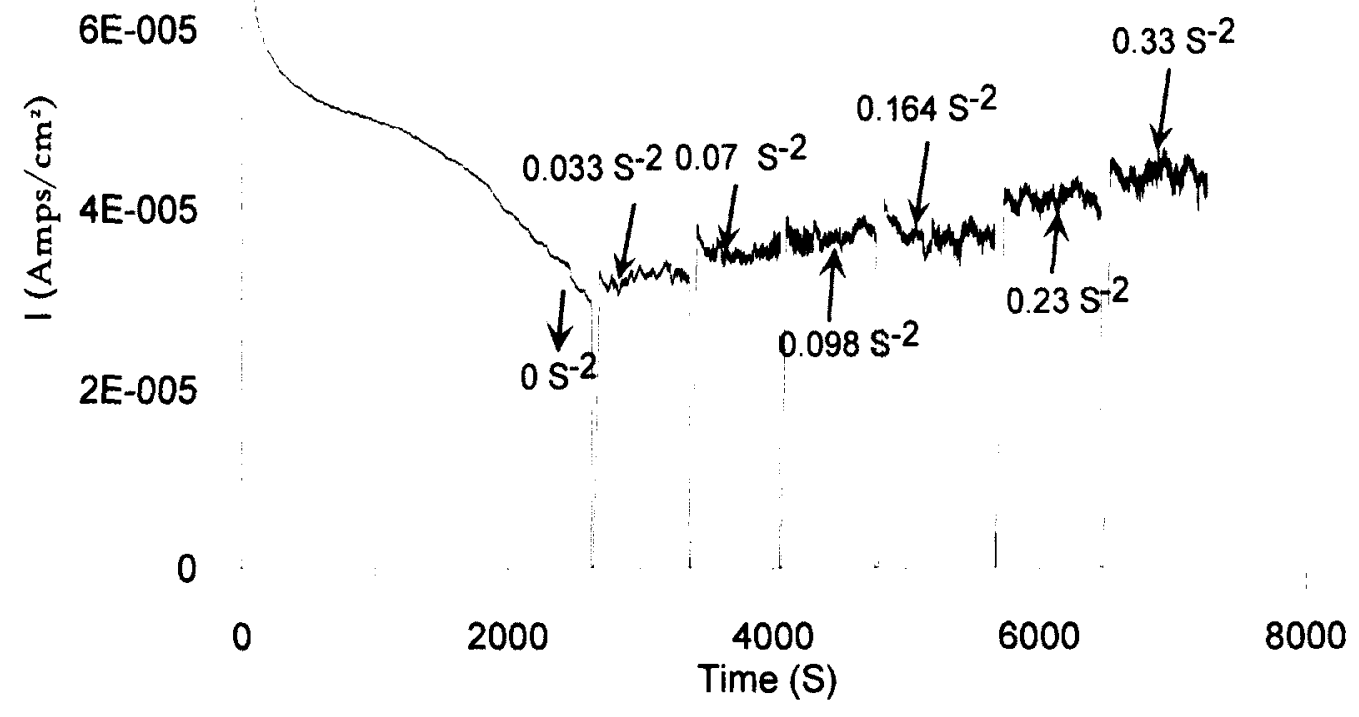

Figure 8.4: Current densities measured using a sulphide oxidase enzyme electrode with a membrane on the tip, at ambient temperature, with a potential hold of 0.3 $\mathrm{V}$ (vs. SCE); concentration of sulphide reported on the graph as $\mathrm{mg} / \mathrm{mL}$.

8E-005

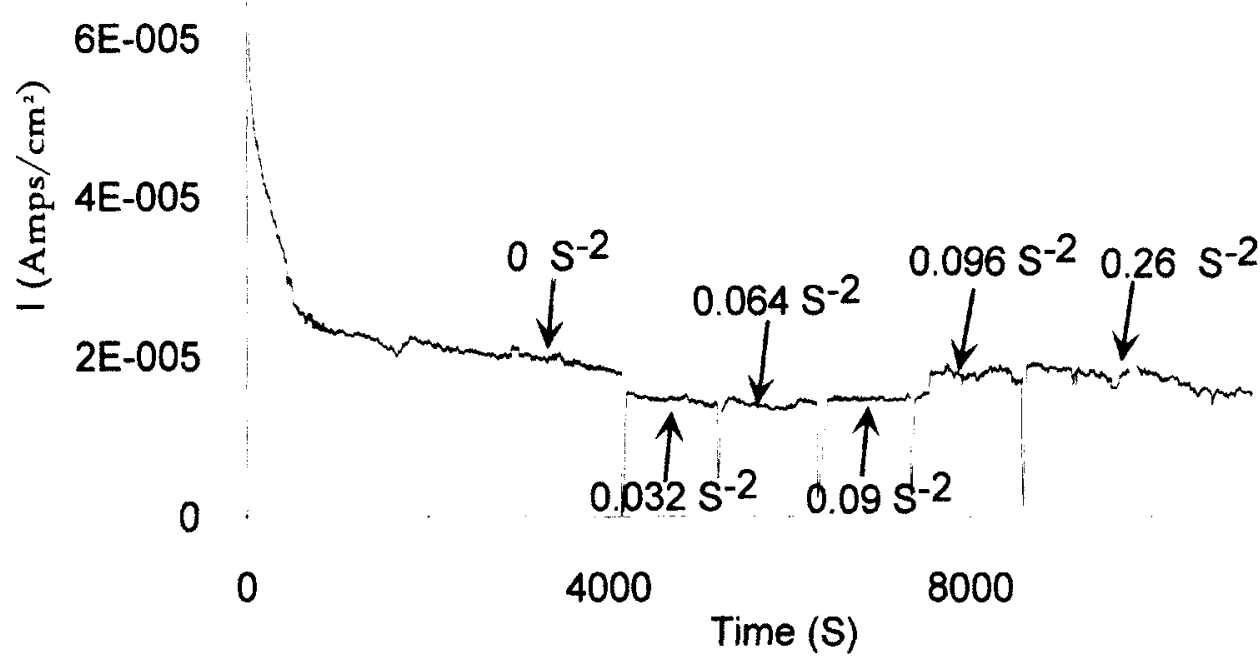

12000

Figure 8.5: Current densities measured using a sulphide oxidase enzyme electrode with a biofilm grown membrane on the tip, at ambient temperature, with a potential hold of $0.3 \mathrm{~V}$ (vs. SCE); concentration of sulphide reported on the graph as $\mathrm{mg} / \mathrm{mL}$. 


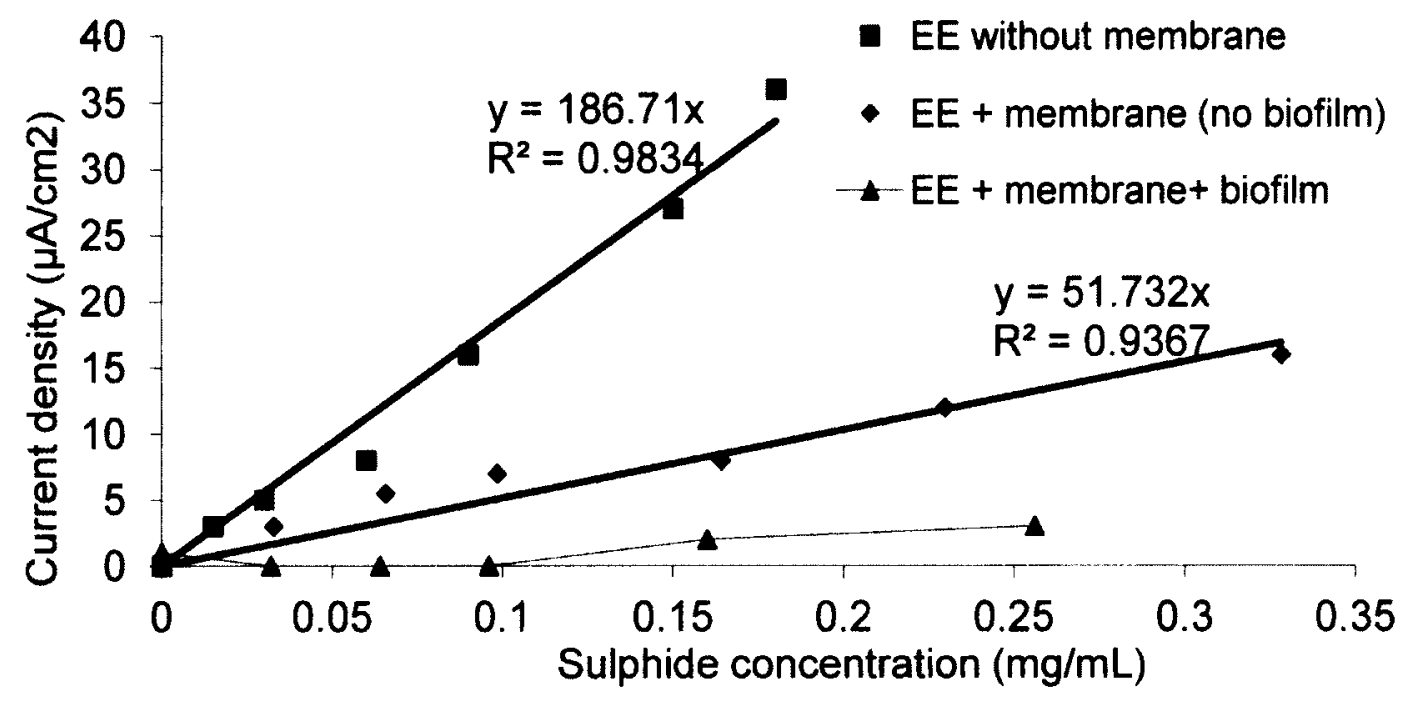

Figure 8.6: Calibration lines for enzyme electrodes with and without the membrane and steady-state current density reading for the enzyme electrode with the biofilm grown membrane.

\subsection{CONCLUding REMARKS}

Biofilm performance as a protective barrier against sulphide passage was evaluated using a sulphide oxidase enzyme electrode. The simple method presented herein was shown to be valuable in rapidly determining the effectiveness of a biofilm as a protective barrier. Results from amperometric measurements showed that E.coli DH5 $\alpha$ biofilm was successful in blocking the sulphide ions and provided an effective barrier against MICD and MIC. 


\section{CHAPTER 9. CONLUSIONS AND FUTURE WORK}

\subsection{Conclusions}

This project was designed to investigate the possibility of using E.coli biofilm as a protective barrier against microbial influenced concrete deterioration in wastewater structures. The detailed discussion and specific conclusions for each part of the thesis were presented in the relevant chapters and summarized as follows:

In Chapter 4, a setup was designed to grow biofilm on the mortar specimens. Using CLSM and SEM image analysis, a non-uniform biofilm formation was observed on the mortar surface. CLSM images also provided insight on quantification of the biofilm thickness and relative proportions of live cells, dead cells, and EPS coverage. The purity of the E.coli biofilm was confirmed by FISH analysis through comparison of the FISH images with the DAPI stained images.

Chapter 5 presented the results of the performance of biofilm and its effectiveness as a protective barrier against chemically induced sulphuric acid attack. The data from calcium leach-out concentration, SEM and EDS analyses all suggest that the presence of biofilm helped to reduce the chemically induced mortar deterioration. The calcium concentration in control reactors without biofilm was $23-47 \%$ higher than the reactors 
with biofilm-covered mortar. The formation of silica gel as an indication of sulphate attack was only observed on control mortar specimens without biofilm. CLSM and VSS analysis both confirmed that the biofilm remained alive and continued to grow during the acidification process.

Chapter 6 presented the results of the effectiveness of biofilm as a protective barrier against biogenic sulphuric acid attack by naturally reducing the $\mathrm{pH}$ using two SOB. It was shown that the presence of biofilm prevented or controlled the biologically induced mortar deterioration. The $\mathrm{pH}$ of the solution in the reactor containing biofilm-covered mortar did not decrease as the SOB were not able to grow in the respective reactor. However, the growth of $\mathrm{SOB}$ in the control reactor increased the sulphate concentration to as high as $6350 \mathrm{mg} / \mathrm{L}$ and consequently increased the calcium leach-out to $69 \mathrm{ppm}$. The presence of gypsum crystals as an indication of concrete deterioration was only observed on the control mortar by SEM and XRD analyses. FISH analysis showed that SOB did not attach to the surface of biofilm-covered mortar. The CLSM and VSS analyses both indicated that the biofilm was sustained and growing during the acidification process.

In Chapter 7, the performance of biofilm as a protective barrier against biogenic sulphuric acid at elevated temperature of $37 \pm 1^{\circ} \mathrm{C}$ was evaluated. The evidence of the calcium leaching measurement and XRD analysis showed that the biofilm layer was protective to some extent. It was also revealed that the biogenic acidification at the elevated temperature led to a more severe deterioration in comparison with the deterioration at room temperature. At the end of this chapter a comparison of the mechanisms of chemical sulphuric acid deterioration with the biogenic sulphuric acid deterioration was 
provided. The comparative analysis showed that chemical acidification deteriorates mortar by dissolution of C-S-H whereas biogenic acidification causes gypsum and ettrengite formation resulting in the destruction of mortar.

In Chapter 8, the E.coli biofilm was evaluated in terms of its capability to prevent the passage of ions, specifically, sulphide ion as the main cause of MICD and MIC. As shown in the chapter, the biofilm was capable of preventing sulphide ion passage and hence can be used as a protective barrier.

Based on the above observations, the most important general achievements of the current study are described as follows:

1. The simulation of accelerated biogenic sulphuric acid attack of concrete is a controversial subject as it is important to identify the role of bacteria in the deterioration process and distinguish the deterioration caused by purely chemical acidification from the biogenic acidification. In this study, biogenic sulphuric acid was simulated successfully by growing two strains of SOB, Thiobacillus thiooxidans and Thiobacillus neapolitanus in a modified broth at neutral $\mathrm{pH}$ to naturally reduce the $\mathrm{pH}$ inside the reactor by their activities and producing sulphuric acid.

2. This is the first study of its kind to grow E.coli DH5a biofilm on a cement mortar surface. Biofilm formation on the mortar surface was a challenge due to the high surface $\mathrm{pH}$ of mortars. The calcium hydroxide leach-out from the mortar specimens leading to an increase in the $\mathrm{pH}$ of the solution was another obstacle for the bacterial growth. However, these difficulties were eliminated to some extend and it was possible to grow a fairy well biofilm in a short period of time. 
3. Attachment of E.coli DH5a biofilm on the surface of metals have shown some promising results in terms of corrosion inhibition of metals. In this study, for the first time, E.coli DH5 $\alpha$ biofilm was applied on a mortar surface to evaluate its effectiveness in controlling microbial influenced concrete deterioration. It was shown that E.coli biofilm can be used as an effective, environmental friendly alternative for inhibition and control of concrete deterioration in existing and new wastewater structures and sewer pipelines.

\subsection{RECOMMENDATIONS FOR FUTURE WORK}

Despite the potential ability of the biofilm to prevent corrosion of metals and MICD as shown in this study, various aspects of the characteristics and behavior of biofilm still need to be addressed before it can be used in larger scale structures to predictably prevent MICD. The growth rate of the bacterial biofilm depends on the available nutrients, substrate and temperature; therefore, small perturbations in the environmental conditions may change the response of the bacteria in the biofilm. Bacteria can grow on all types of engineering materials and form biofilm. However, the structure of the biofilm changes over time as the cells inside the biofilm die or slough from the surface which can convert a more uniform biofilm to a patchy-like biofilm. On the other hand, for concrete material, the mechanism of concrete deterioration and the interaction of bacteria involved with the deterioration are other complicated phenomena that need to be studied more thoroughly. A couple of relevant investigations to advance the knowledge of MICD and the use of biofilm as a prevention alternative in the future are suggested as follows:

1. The biogenic sulphuric acid deterioration test developed in the current thesis is using the pure culture of two SOB to simulate the accelerated biogenic acidification. It is more 
realistic if a real wastewater solution is exposed to concrete to understand the interaction of SOB with other bacteria present in the wastewater. Investigating MICD by exposing the concrete samples to a wastewater solution can also help to understand if wastewater can provide enough nutrients for the growth and sustainability of E.coli biofilm or if there is a natural competence for attachment of other bacteria to the concrete surface which can alter the microbial constituents of the biofilm.

2. Estimating the remaining service life of structures exposed to wastewater and under biogenic sulphuric acid deterioration is important in order to develop repair and maintenance schedules for such structures. The prediction of the expected long-term performance of concrete is difficult as it is affected by a large number of parameters. There is a good advancement in the modelling of the sulphate attack to investigate the service life of the structure. It is also necessary to couple the Monod equation for modelling bacterial growth into the respected models to consider the attachment of SOB and the resultant deterioration caused by the production of sulphate due to the growth of SOB.

3. The current study indicated the potential ability of E.coli biofilm as a protective barrier to control MICD. However, as it was shown in the results, it is important to form a uniform E.coli biofilm on the mortar surface since the mechanism of protection is by providing a physical barrier. Since, it is not an easy task to grow a uniform biofilm; it is also interesting to look into the application of other types of biofilm forming bacteria with a different mechanism of protection. Such bacteria can be Bacillus Brevis with the ability to produce antimicrobial agents. Biofilm in real systems are usually made of 
many different bacterial species, hence it is also useful to look at the ability of multispecies biofilm to prevent MICD.

4. The current study demonstrated the potential ability of E.coli biofilm to mitigate MICD using the bench-scale experiments. It is acknowledged that in order to use beneficial biofilms to resist concrete deterioration caused by biogenic acidification in real-life applications, large-scale experiments and demonstration projects are required to address the practical issues related to the growth and maintenance of healthy biofilm on a large scale concrete structure. To perform this task, it is recommended that the biofilmcovered mortar specimens are placed inside an actual sewer pipe or a wastewater treatment structure under the biogenic attack and investigate the performance of these specimens over time.

5. The attachment of E.coli biofilm to concrete surfaces might have a secondary benefit in treating wastewater during the collection process. The presence of biofilm on the surface of wastewater collection pipes can help degrade organic matters and improve wastewater treatment. It is recommended to investigate this hypothesis by applying a real wastewater solution to the biofilm-covered concrete and measuring the treatment indexes such as VSS, biological oxygen demand and total carbon inside the wastewater over time.

6. Surface cracking of concrete is a major contributor to deterioration of structures. The use of different bacteria in a concrete mixture for the remediation of cracks and enhancement of compressive strength was reported by Ramachandran et al. (2001) and Van Tittelboom (2009). Therefore, it is believed that E.coli biofilm (or others that are not studied in this thesis) is not only effective in inhibiting MICD but might also have potential for promoting self-healing of concrete by filling the cracks. Hence, it is 
recommended to study this hypothesis in a more detailed experimental plan to investigate the influence of biofilms to enhance the self-healing properties of concrete. 


\section{REFERENCES}

Abdelmseeh, V. A., Jofriet, J. C., Negi, S. C., \& Hayward, G. (2006). Sulphide, sulphate and sulphuric acid corrosion of concrete in laboratory tests. Solid Mechanics and Its Applications, 140: 55-65.

Abdelmseeh, V. A., Jofriet, J. C., Negi, S. C., \& Hayward, G. L. (2005). Corrosion of reinforced concrete specimens exposed to hydrogen sulfide and sodium sulfate. Agricultural Engineering International: The CIGR EJournal.

ACI Committee 201,(2008). Guide to durable concrete. ACI Manual of Concrete Practice. 201.2R-08.

Akid, R., Wang, H., Smith, T. J., \& Greenfield, D. E., Earthman, J.C. (2008). Biological functioning of a sol-gel coating for the mitigation of microbial-induced corrosion. Advanced Functional Materials, 18: 203-211.

Allahverdi, A., \& Skvara, F. (2000). Acidic Corrosion of Hydrated Cement based Materials-PART 1. - Mechanism of the Phenomenon. Ceramics-Silkaty, 44, no.4: 114-120.

Alunno Rossettia, V., Chiocchioa, G. and Paolinia, A.E. (1982). Expansive properties of the mixture C4A $\overline{\mathrm{S}} \mathrm{H} 12-2 \mathrm{C} \overline{\mathrm{S}}, 1$. An hypothesis on the expansion mechanism. Cement and Concrete Research 12, no. 5: 577-585.

Amann, R. I. (1995). In situ identification of micro-organisms by whole cell hybridization with rRNA-targeted nucleic acid probes. Molecular Microbial Ecology Manual, Kluwer Academic Publishers, Netherlands: 1-15.

Attiogbe, E. K., and Rizkalla, S. H. (1988). Response of concrete to sulfuric acid. $A C I$ Materials Journal 85, no. 6: 481-488.

Barton, L. L., and Shively, J. M. (1968). Thiosulfate utilization by Thiobacillus thiooxidans ATCC 8085. Journal of Bacteriology 95, no.2: 720. 
Basu, S., McAuley, J., White, N., Lamb, S. and Pitt, P. (2001). Microbiologically influenced corrosion in a wastewater treatment plant. Materials Performance 40, no. 7: 52-57.

Beeldens, A., Monteny, J., Vincke, E., De Belie, N., Van Gemert, D., Taerwe, L., and Verstraete, W. (2001). Resistance to biogenic sulphuric acid corrosion of polymermodified mortars. Cement and Concrete Composites, 23, no.1: 47-56.

Beyenal, H. and Lewandowski Z. (2002). Internal and external mass transfer in biofilms grown at various flow velocities. Biotechnology progress 18, no. 1: 55-61.

Bielefeldt, A., Gutierrez-Padilla, M.D., Ovtchinnikov, S., Silverstein, J., and Hernandez, M. (2010). Bacterial kinetics of sulfur oxidizing bacteria and their biodeterioration rates of concrete sewer pipe samples. Journal of Environmental Engineering 136, no. $7: 731-738$.

Bonen, D., and Cohen, M. D. (1992). Magnesium of sulfate attack on Portland cement paste- I. microstructural analysis. Cement and Concrete Research, 22, no. 1: 169180.

Booth, G. H. and Tiller, A. K. 1960. Polarization studies of mild steel in cultures of sulphate-reducing bacteria. Transactions of the Faraday Society 56: 1689-1696.

Booth, I.R. (1999). The regulation of interacellular $\mathrm{pH}$ in bacteria. (1999). In Bacterial responses to $\mathrm{pH}$, Novartis Foundation, John Wiley\& Sons.

Borenstein, S. W. (1994). Microbiologically influenced corrosion handbook, Woodhead Publication Ltd.

Bruce, S.M. and Freitag, S. A. (2005). Concrete durability in wastewater reticulation and treatment facilities and its sensitivity to small changes in exposure conditions. Corrosion \& Prevention proceedings, January $1^{\text {st }}, 2005$.

Cao, H., Bucea, L., Ray, A., \& Yozghatlian, S. (1997). The effect of cement composition and $\mathrm{pH}$ of environment on sulfate resistance of portland cements and blended cements. Cement and Concrete Composites, 19, no.2: 161-171.

Cohen, M. D., and Mather, B. (1991). Sulfate attack on concrete- research needs. $A C I$ Materials Journal 88, no. 1:62-69.

De Belie, N., J. Monteny, A. Beeldens, E. Vincke, D. Van Gemert, and W. Verstraete (2004). Experimental research and prediction of the effect of chemical and biogenic 
sulfuric acid on different types of commercially produced concrete sewer pipes. Cement and Concrete Research 34, no. 12: 2223-2236.

De Lomas, J. G., Corzo, A., Gonzalez, J. M., Andrades, J. A., Iglesias, E. and Montero, M. J. (2006). Nitrate promotes biological oxidation of sulfide in wastewaters: Experiment at plant-scale. Biotechnology and bioengineering 93, no. 4: 801-811.

De Muynck, W., De Belie, N. and Verstraete, W. (2009). Effectiveness of admixtures, surface treatments and antimicrobial compounds antimicrobial compounds. Cement \& Concrete Composites 31: 163-170.

Diercks, M., Sand, W. and Bock, E. (1991). Microbial corrosion of concrete. Cellular and Molecular Life Sciences 47, no. 6: 514-516.

Dogsa, I., Kriechbaum, M., Stopar, D., \& Laggner, P. (2005). Structure of bacterial extracellular polymeric substances at different $\mathrm{pH}$ values as determined by SAXS. Biophysical Journal 89, no.4:2711-2720.

APHA (2005) by Eaton, A. D., \& Franson, M. A. H., Standard methods for the examination of water \& wastewater. American Public Health Association.

Estoup, J. M., Cabrillac, R. (1997). Corrosion of biological origin observed on concrete digestors. Construction and Building Materials 11, no. 4: 225-232.

Geoghegan, M., Andrews, J. S., Biggs, C. A., Eboigbodin, K. E., Elliott, D. R., Rolfe, S., Scholes, J., Ojeda, J. J., Romero-González, M. E., and Edyvean R. G. J. (2008). The polymer physics and chemistry of microbial cell attachment and adhesion. Faraday discussions 139: 85-103.

Gollop, R., \& Taylor, H. (1995). Microstructural and microanalytical studies of sulfate attack III. sulfate-resisting portland cement: Reactions with sodium and magnesium sulfate solutions. Cement and Concrete Research, 25, no.7: 1581-1590.

Gollop, R., and Taylor, H. (1992). Microstructural and microanalytical studies of sulfate attack. I. ordinary portland cement paste. Cement and Concrete Research, 22, no.6: 1027-1038.

Gu, J. D., Ford, T. E., Berke, N. S., and Mitchell, R. (1998). Biodeterioration of concrete by the fungus Fusarium. International Biodeterioration \& Biodegradation 41, no. 2 : 101-109. 
Guiamet, P. S. and Gómez de Saravia, S. G. (2005). Laboratory studies of biocorrosion control using traditional and environmentally friendly biocides: An overview. Latin American Applied Research 35: 295-300.

Guiamet, P. S., Saravia, S. G. G., and Videla, H. A. (1999). An innovative method for preventing biocorrosion through microbial adhesion inhibition. International Biodeterioration \& Biodegradation 43, no. 1-2: 31-35.

Haile, T., Nakhla, G. Allouche, E. and Vaidya, S. (2009). Evaluation of the bactericidal characteristics of nano-copper oxide or functionalized zeolite coating for biocorrosion control in concrete sewer pipes. Corrosion Science 50: 713-720.

Haile, T., Nakhla, G. and Allouche E. (2008). Evaluation of the resistance of mortars coated with silver bearing zeolite to bacterial-induced corrosion. Corrosion Science 50, no. 3: 713-720.

Hamilton, W. (1985). Sulphate-reducing bacteria and anaerobic corrosion. Annual Reviews in Microbiology, 39, no.1: 195-217.

Hernandez, G., Kucera, V., Thierry, D., Hermansson, M. and Pedersen A. (1994). Corrosion inhibition of steel by bacteria. Corrosion 50, no. 08: 603-608.

Hormann, K., Hofmann, F. and Schmidt, M. (1997). Stability of concrete against biogenic sulfuric acid corrosion, a new method for determination. In Proceedings of the 10 th international congress on the chemistry of cement, gothenburg.

Hubert, C., Nemati, M., Jenneman, G. and Voordouw G. (2005). Corrosion risk associated with microbial souring control using nitrate or nitrite. Applied Microbiology and Biotechnology 68, no. 2: 272-282.

Idriss, A. F., Negi, S. C., Jofriet, J. C. and Hayward, G. L. (2001). Corrosion of steel reinforcement in Mortar specimens exposed to hydrogen sulphide, Part 1: Impressed voltage and electrochemical potential tests. Journal of Agricultural Engineering Research 79, no. 2: 223-230.

Islander, R. L., Mansfeld, F., Postyn, A. and Shih, H. (1991). Microbial ecology of crown corrosion in sewers. Journal of Environmental Engineering 117: 751.

Jayaraman, A., Cheng, E. T., Earthman, J. C., and Wood T. K. (1997 b). Axenic aerobic biofilms inhibit corrosion of SAE 1018 steel through oxygen depletion. Applied Microbiology and Biotechnology 48, no. 1: 11-17. 
Jayaraman, A., D. Ornek, D. A. Duarte, C. C. Lee, F. B. Mansfeld, and T. K. Wood. (1999 b). Axenic aerobic biofilms inhibit corrosion of copper and aluminum. Applied Microbiology and Biotechnology 52, no. 6: 787-790.

Jayaraman, A., Earthman, J. C., and Wood T. K. (1997 a). Corrosion inhibition by aerobic biofilms on SAE 1018 steel. Applied Microbiology and Biotechnology 47, no. 1: 62-68.

Jayaraman, A., Hallock, P. J., Carson, R. M., Lee, C. C., Mansfeld, F. B. and Wood, T. K. $(1999$ c). Inhibiting sulfate-reducing bacteria in biofilms on steel with antimicrobial peptides generated in situ. Applied Microbiology and Biotechnology 52, no. 2: 267-275.

Jayaraman, A., Mansfeld, F. B. and Wood, T. K. (1999 a). Inhibiting sulfate-reducing bacteria in biofilms by expressing the antimicrobial peptides indolicidin and bactenecin. Journal of Industrial Microbiology and Biotechnology 22, no. 3: 167175.

Jayaraman, A., Sun, A. K. and Wood T. K. (1998). Characterization of axenic Pseudomonas fragi and Escherichia coli biofilms that inhibit corrosion of SAE 1018 steel. Journal of applied microbiology 84, no. 4: 485-492.

Kuenen, J.G., Robertson, L.A. and Tuovinen, O.H. (1992). The Genera Thiobacillus, Thiomicrospira, and Thiosphaera. In Chapter 138 of The Prokaryotes, edited by A. Balows et al., Vol. III, 2nd Edition, 1992.

Kulpa, C. F. and Baker, C. J. (1990). Involvement of sulfur-oxidizing bacteria in concrete deterioration. Special Publication 122: 313-322.

Little, B. J., and Lee J. S. (2007). Microbiologically influenced corrosion. WileyInterscience.

Little, B., Lee, J. and Ray R. (2007). A review of green strategies to prevent or mitigate microbiologically influenced corrosion. Biofouling 23, no. 2: 87-97.

Mehta, K. (2000). Sulfate attack on concrete: Separating myths from reality. Concrete International 22, no. 8: 57-61.

Mehta, P. K. (1983). Mechanism of sulfate attack on portland cement concrete-another look. Cement and Concrete Research, 13, no.3: 401-406. 
Mehta, P.K. (1973). Effect of lime on hydration of pastes containing gypsum and calcium aluminates or calcium sulfoalurninate. Journal of The Amrican Ceramic Society 56, no. $6: 315-319$.

Metcalf and Eddy, Inc. (2003). Chobanoglous, G., Burton, F. L. and Stensel, H. D. Wastewater Engineering, Treatment and Reuse, 4th edition, McGraw-Hill Edition.

Min, D., \& Mingshu, T. (1994). Formation and expansion of ettringite crystals. Cement and Concrete Research, 24, no.1: 119-126.

Mohapatra, B. R., Gould, W. D., Dinardo, O., Papavinasam, S., and Revie. R. W. (2006). Optimization of culture conditions and properties of immobilized sulfide oxidase from Arthrobacter species. Journal of Biotechnology 124, no. 3: 523-531.

Mohapatra, B. R., Gould, W. D., Dinardo, O., Papavinasam, S., Koren, D. W. and Revie, R. W. (2007). Enhanced biosynthesis of sulfide oxidase by Arthrobacter species using response surface methodology. Engineering in Life Sciences 7, no. 3: 241-246.

Monteny, J., De Belie, N., Vincke, E., Verstraete, W. and Taerwe L. (2001). Chemical and microbiological tests to simulate sulfuric acid corrosion of polymer-modified concrete. Cement and Concrete Research 31, no. 9: 1359-1365.

Monteny, J., Vincke, E., Beeldens, A., De Belie N., Taerwe L., Van Gemert, D., and Verstraete, W. (2000). Chemical, microbiological, and in situ test methods for biogenic sulfuric acid corrosion of concrete. Cement and Concrete Research 30, no. 4: 623-634.

Mori, T., Nonaka, T., Tazaki, K., Koga, M., Hikosaka, Y. and Noda S. (1992). Interactions of nutrients, moisture and $\mathrm{pH}$ on microbial corrosion of concrete sewer pipes. Water research(Oxford) 26, no. 1: 29-37.

NACE International (2002). Corrosion costs and preventive strategies in the United States. Report FHWA-RD-01-156. available at: http://www.nace.org/uploadedFiles/Publications/ccsupp.pdf (accessed 10 March 2012)

Neville, A. (2004). The confused world of sulfate attack on concrete. Cement and Concrete Research 34, 1275-1296.

Nica, D., Davis, J. L., Kirby, L., Zuo, G. and Roberts D. J. (2000). Isolation and characterization of microorganisms involved in the biodeterioration of concrete in sewers. International Biodeterioration \& Biodegradation 46, no. 1: 61-68. 
O'Connell, M., McNally, C., and Richardson, M. G. (2010). Biochemical attack on concrete in wastewater applications: A state of the art review. Cement and Concrete Composites, 32, no.7, 479-485.

O'Dea, V. (2007). Coatings \& linings - understanding biogenic sulfide corrosion. Materials Performance 46, no. 11: 36-39.

Okabe, S., Odagiri, M., Ito, T. and Satoh, H. (2007). Succession of sulfur-oxidizing bacteria in the microbial community on corroding concrete in sewer systems. Applied and Environmental Microbiology 73, no. 3: 971.

Örnek, D., Jayaraman, A., Syrett, B. C., Hsu, C. H., Mansfeld, F. B. and Wood, T. K. (2002a). Pitting corrosion inhibition of aluminum 2024 by Bacillus biofilms secreting polyaspartate or $\gamma$-polyglutamate. Applied Microbiology and Biotechnology 58, no. 5: 651-657.

Örnek, D., Wood, T. K., Hsu, C. H. and F. Mansfeld (2002b). Corrosion control using regenerative biofilms (CCURB) on brass in different media. Corrosion Science 44, no. 10: 2291-2302.

Papavinasam, S., Gould, W.D., Macleod, A., Revie, R.W., Attard, M., (2004). Biosensor development for monitoring of activity of sulfate-reducing bacteria in oil and natural gas pipelines. US Patent No 6673222.

Parande, A. K., Ramsamy, P. L., Ethirajan, S., Rao., C. R. K and Palanisamy N. (2006). Deterioration of reinforced concrete in sewer environments. Municipal Engineer 159, no. 1: 11-20.

Parker C. (1945). The corrosion of concrete: Isolation of a species of bacterium associated with the corrosion of concrete exposed to atmospheres containing hydrogen sulphide. Australian Journal of Experimental Biology \& Medical Science 23, no. 3: 14-17.

Pedersen, A. and Hermansson, M. (1989). The effects on metal corrosion by Serratia marcescens and a Pseudomonas sp. Biofouling 1, no. 4: 313-322.

Pedersen, A., Kjelleberg, S. and Hermansson, M. (1988). A screening method for bacterial corrosion of metals. Journal of microbiological methods 8, no. 4: 191-198.

Perego, P., Fabiano, B., Pastorino, R. and Randi G. (1997). Microbiological corrosion in aerobic and anaerobic waste purification plants: safety and efficiency problems. Bioprocess and Biosystems Engineering 17, no. 2: 103-109. 
Peyton, B. M. (1996). Effects of shear stress and substrate loading rate on Pseudomonas aeruginosa biofilm thickness and density. Water research 30, no. 1: 29-36.

Potekhina, J., Sherisheva, N., Povetkina, L., Pospelov, A., Rakitina, T., Warnecke, F., \& Gottschalk, G. (1999). Role of microorganisms in corrosion inhibition of metals in aquatic habitats. Applied Microbiology and Biotechnology, 52, no.5: 639-646.

Ramachandran, V. S. and Beaudoin, J. J. (2001). Handbook of analytical techniques in concrete science and technology: Principles, Techniques and Applications. Williams Anderw publishing.

Ramachandran, S. K., Ramakrishnan, V. and Bang, S. S. (2001). Remediation of concrete using micro-organisms. ACI Materials Journal-American Concrete Institute 98, no. 1:3-9.

Roberts, D. J., Nica, D., Zuo, G. and Davis, J. L. (2002). Quantifying microbiologically induced deterioration of concrete: initial studies. International Biodeterioration \& Biodegradation 49, no. 4: 227-234.

Sand, W. and Bock, E. (1987). Biotest system for rapid evaluation of concrete resistance to sulfur-oxidizing bacteria. Materials Performance 26, no. 3: 14-17.

Sand, W., Dumas, T., \& Marcdargent, S. (1994). Accelerated biogenic sulfuric acid corrosion test for evaluating the performance of calcium-aluminate based concrete in sewage applications. ASTM Special Technical Publication, 1232: 234-234.

Santo Domingo, J. W., Revetta, R. P., Gomez-Alvarez, B., Iker, G. Garcia J., Sullivan, J. and Weast, J. (2011). Molecular survey of concrete sewer biofilm microbial communities. Biofouling 27, no. 9: 993-1001.

Satoh, H., Odagiri, M., Ito, T., and Okabe S. (2009). Microbial community structures and in situ sulfate-reducing and sulfur-oxidizing activities in biofilms developed on mortar specimens in a corroded sewer system. Water Resources 43 , no. 18, 47294739.

Sezonov, G., Joseleau-Petit, D., \& D' Ari, R. (2007). Escherichia coli physiology in luriabertani broth. Journal of Bacteriology, 189, no. 23: 8746-8749.

Sheng, X., Ting, Y. P., and Pehkonen, S. O. (2007). The influence of sulphate-reducing bacteria biofilm on the corrosion of stainless steel AISI 316. Corrosion Science 49, no. 5: 2159-2176. 
Shock, W. E., L. W. Bell (2003). Corrosion control in concrete pipe and manholes. Water Environmental Federation, Orlando, Florida.

Skalny, J., Marchand, J. and Odler, I. (2002). Sulfate attack on concrete. London \& New York: Taylor \& Francis, 2002.

Slonczewski, J. L., Fujisawa, M., Dopson, M., \& Krulwich, T. A. (2009). Cytoplasmic $\mathrm{pH}$ measurement and homeostasis in bacteria and archaea. Advances in Microbial Physiology, 55:1-79.

Sooknah R, Papavinasam, S, Revie, R.W. (2008 a) A sulfide oxidase biosensor for monitoring sulfide. Corrosion 2008 Conference, New Orleans, LA.

Sooknah, R., Papavinasam, S., Attard, M., Revie, R. W., Gould, W. D. and Dinardo, O. (2008 b). Performance of an enzyme electrode designed for a sulfide monitoring biosensor. Journal of ASTM International 5, no. 6.

Stark, D. (2002). Performance of concrete in sulfate environments. Research and Development Bulletin, RD 129, Portland Cement Association

Starkey, R. L. (1925). Concerning the physiology of thiobacillus thiooxidans, an autotrophic bacterium oxidizing sulfur under acid conditions. Journal of Bacteriology, 10, no.2: 135.

Stott, J. F. D. (1993). What progress in the understanding of microbially induced corrosion has been made in the last 25 years? A personal viewpoint. Pergamon Press Inc., Corros.Sci.(United States) 35, no. 1-4: 667-673.

Taylor, H.F.W. and Gollop, R.S. (1997). Some chemical and microstructural aspects of concrete durability. In Mechanisms of Chemical Degradation of Cement-based Systems (Eds: Scrivener, K.L., and J.F.Young, Publisher: E \& FN Spon, 177-184).

Todar, K. (2008-2012). Online Textbook of Bacteriology: http://www.textbookofbacteriology.net/

Torii, K. and Kawamura, M. (1994). Effects of fly ash and silica fume on the resistance of mortar to sulfuric acid and sulfate attack. Cement and Concrete Research, 24, no. 2: $361-370$.

USEPA (2004). Primer for municipal wastewater treatment systems. United state Environmental Protection Agency, EPA 832-R-04-001, September 2004. 
Van Tittelboom, K., De Belie, N., De Muynck, W., \& Verstraete, W. (2010). Use of bacteria to repair cracks in concrete. Cement and Concrete Research 40, no.1:157166.

Videla, H. A. (1996). Manual of biocorrosion. CRC.

Videla, H. A. (2002). Prevention and control of biocorrosion. International Biodeterioration \& Biodegradation 49, no. 4: 259-270.

Videla, H. A. and Characklis, W. G. (1992). Biofouling and microbially influenced corrosion. International Biodeterioration \& Biodegradation, 29, no.3-4: 195-212.

Videla, H. A., Herrera, L. K. (2005). Microbiologically influenced corrosion: looking to the future. International microbiology 8: 169-180.

Vincke, E., Boon, N. and Verstraete, W. (2001). Analysis of the microbial communities on corroded concrete sewer pipes-a case study. Applied Microbiology and Biotechnology 57, no. 5: 776-785.

Vincke, E., Van Wanseele, E.; Monteny, J., Beeldens, A., De Belie, N., Taerwe, L., Van Gemert, D., Verstraete, W. (2002). Influence of polymer addition on biogenic sulfuric acid attack of concrete. International Biodeterioration \& Biodegradation 49: 283-292.

Vincke, E., Verstichel, S., Monteny, J. and Verstraete, W. (1999). A new test procedure for biogenic sulfuric acid corrosion of concrete. Biodegradation 10, no. 6: 421-428.

Vishniac, W., \& Santer, M. (1957). The thiobacilli. Microbiology and Molecular Biology Reviews, 21, no.3: 195.

Waksman, S. A., \& Joffe, J. S. (1922). The chemistry of the oxidation of sulfur by microorganisms to sulfuric acid and transformation of insoluble phosphates into soluble forms. Journal of Bioliological Chemistry, 50: 35-45.

Wang, J.G. (1994). Sulfate attack on hardened cement paste. Cement and concrete research 24, no. 4: 735-742.

Yamanaka, T., Aso, I., Togashi, S., Tanigawa, M., Shoji, K., Watanabe, T., et al. (2002). Corrosion by bacteria of concrete in sewerage systems and inhibitory effects of formates on their growth. Water Research, 36, no.10: 2636-2642. 
Zarda, B., Hahn, D., Chatzinotas, A., Schönhuber, W., Neef, A., Amann, R. I., \& Zeyer, J. (1997). Analysis of bacterial community structure in bulk soil by in situ hybridization. Archives of Microbiology, 168, no. 3: 185-192.

Zivica, V., \& Bajza, A. (2001). Acidic attack of cement based materials-a review: Part 1. Principle of acidic attack. Construction and Building Materials, 15, no.8: 331-340.

Zuo, R. (2007). Biofilms: strategies for metal corrosion inhibition employing microorganisms. Applied Microbiology and Biotechnology 76, no. 6 (Oct): 12451253.

Zuo, R., Kus, E., Mansfeld, F. and Wood, T. K. (2005). The importance of live biofilms in corrosion protection. Corrosion Science 47, no. 2: 279-287.

Zuo, R., Örnek, D., Syrett, B. C., Green, R. M., Hsu, C. H., Mansfeld, F. B., and Wood, T. K. (2004). Inhibiting mild steel corrosion from sulfate-reducing bacteria using antimicrobial-producing biofilms in Three-Mile-Island process water. Applied Microbiology and Biotechnology 64, no. 2: 275-283.

Zuo, R., Wood., T. K. (2004). Inhibiting mild steel corrosion from sulfate-reducing and iron-oxidizing bacteria using gramicidin-S-producing biofilms. Applied Microbiology and Biotechnology 65, no. 6: 747-753. 


\section{APPENDIX A: SUPPLEMENTARY XRD ANALYSIS}

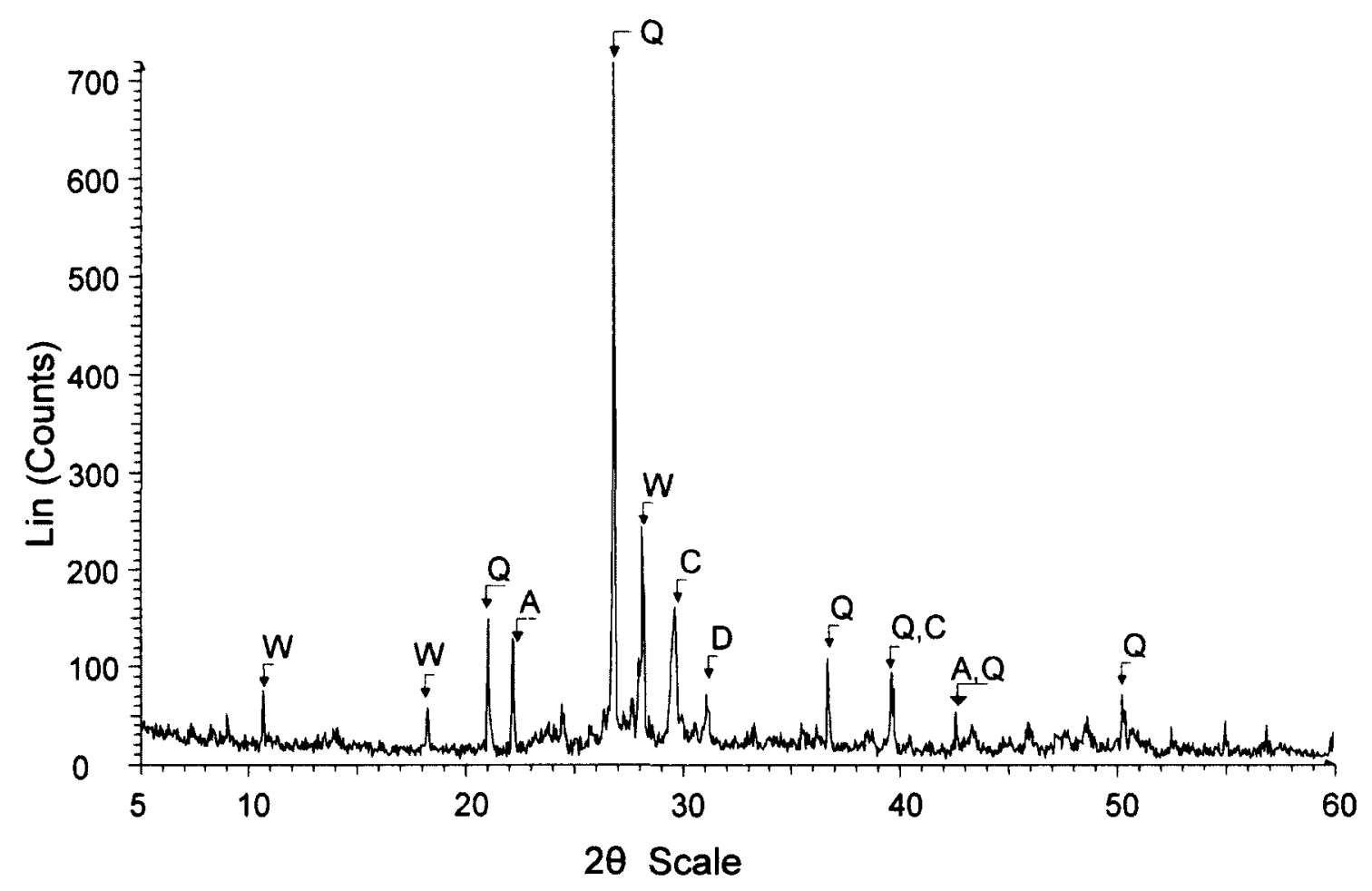

Figure A.1: XRD of mortar powder taken from second layer of mortar surface (the powder was collected from the top $0.5-1 \mathrm{~mm}$ of the mortar surface) before any treatment; dolomite (D), gypsum $(\mathrm{G})$, quartz $(\mathrm{Q})$, magnesium calcite $(\mathrm{MC})$, winchitte potassium $(\mathrm{W})$, aluminate phase $(\mathrm{A})$ 


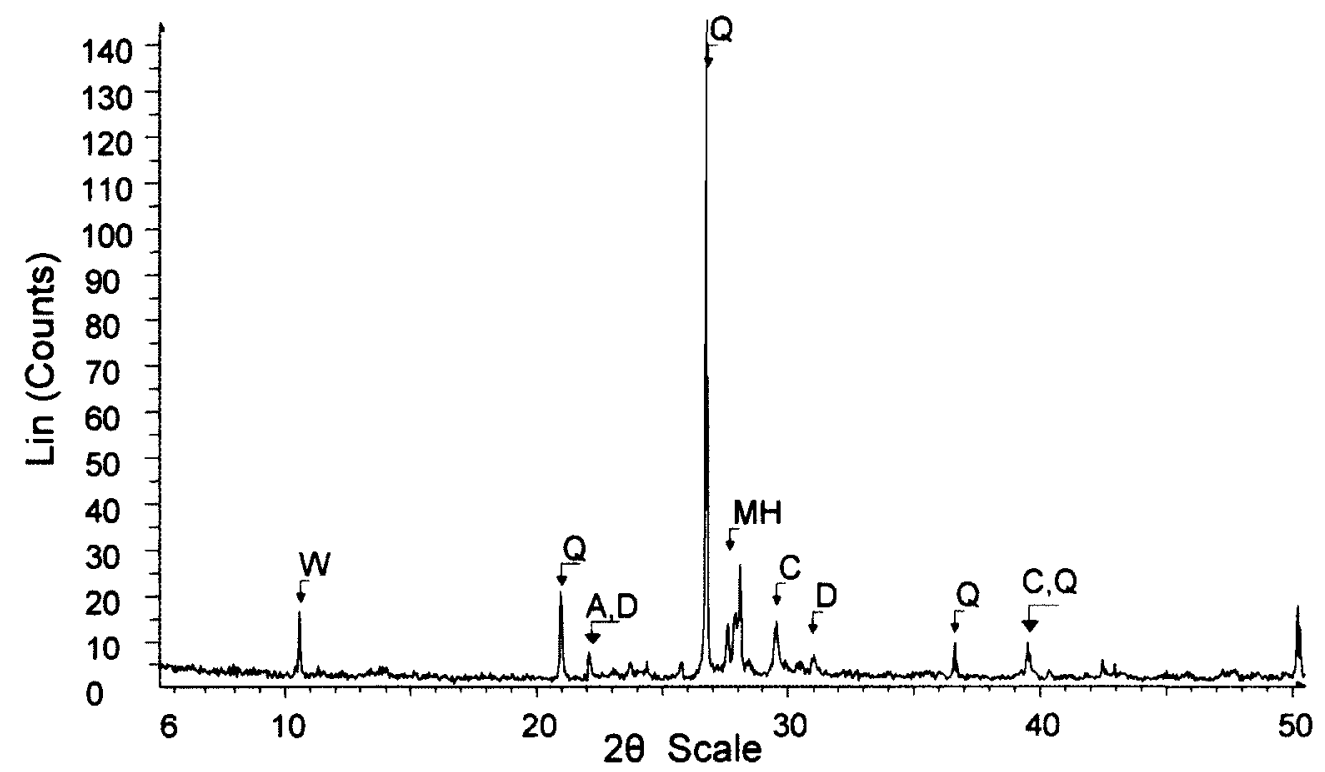

Figure A.2: XRD analysis of second layer of mortar with biofilm after biogenic acidification; dolomite (D), gypsum (G), quartz (Q), magnesium calcite (C), magnesium sulphate hydroxide $(\mathrm{MH})$, winchitte potassium $(\mathrm{W})$, aluminate phase (A).

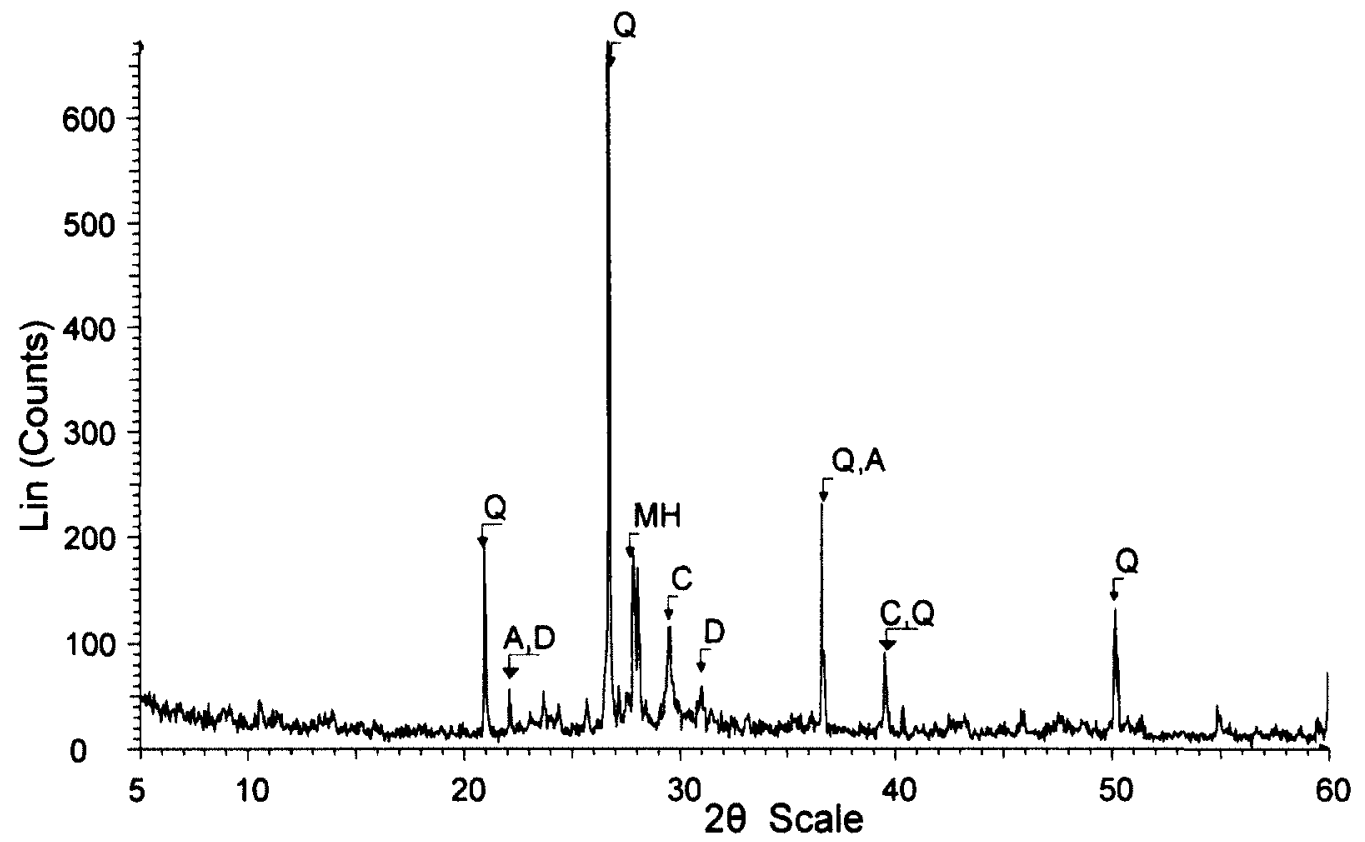

Figure A.3: XRD analysis of second layer of mortar without biofilm after chemical acidification; dolomite (D), gypsum (G), quartz (Q), magnesium calcite (C), magnesium sulphate hydroxide $(\mathrm{MH})$, winchitte potassium $(\mathrm{W})$, aluminate phase (A). 


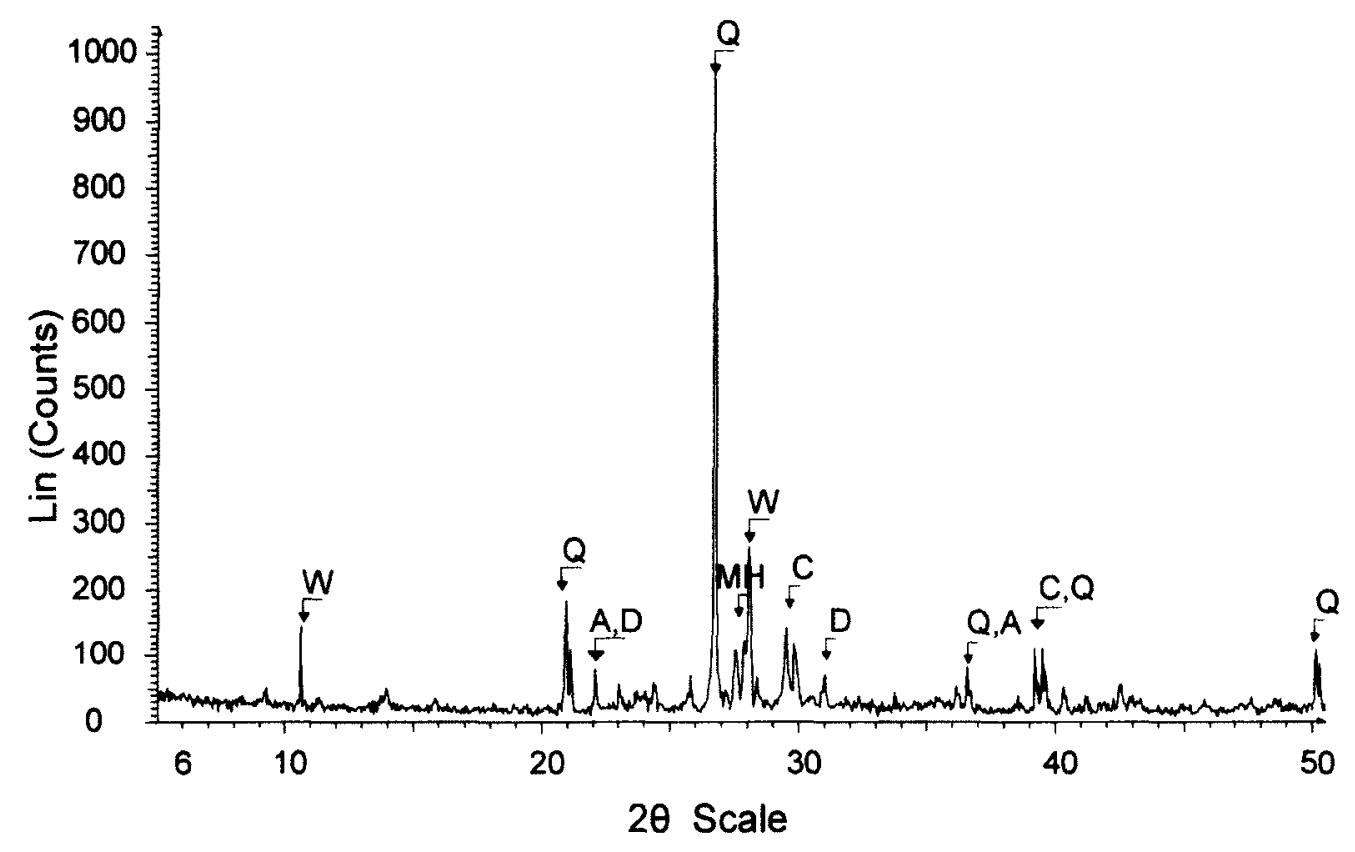

Figure A.4: XRD analysis of second layer of mortar with biofilm after chemical acidification; dolomite (D), gypsum $(\mathrm{G})$, quartz $(\mathrm{Q})$, magnesium calcite $(\mathrm{C})$, magnesium sulphate hydroxide $(\mathrm{MH})$, winchitte potassium $(\mathrm{W})$, aluminate phase (A).

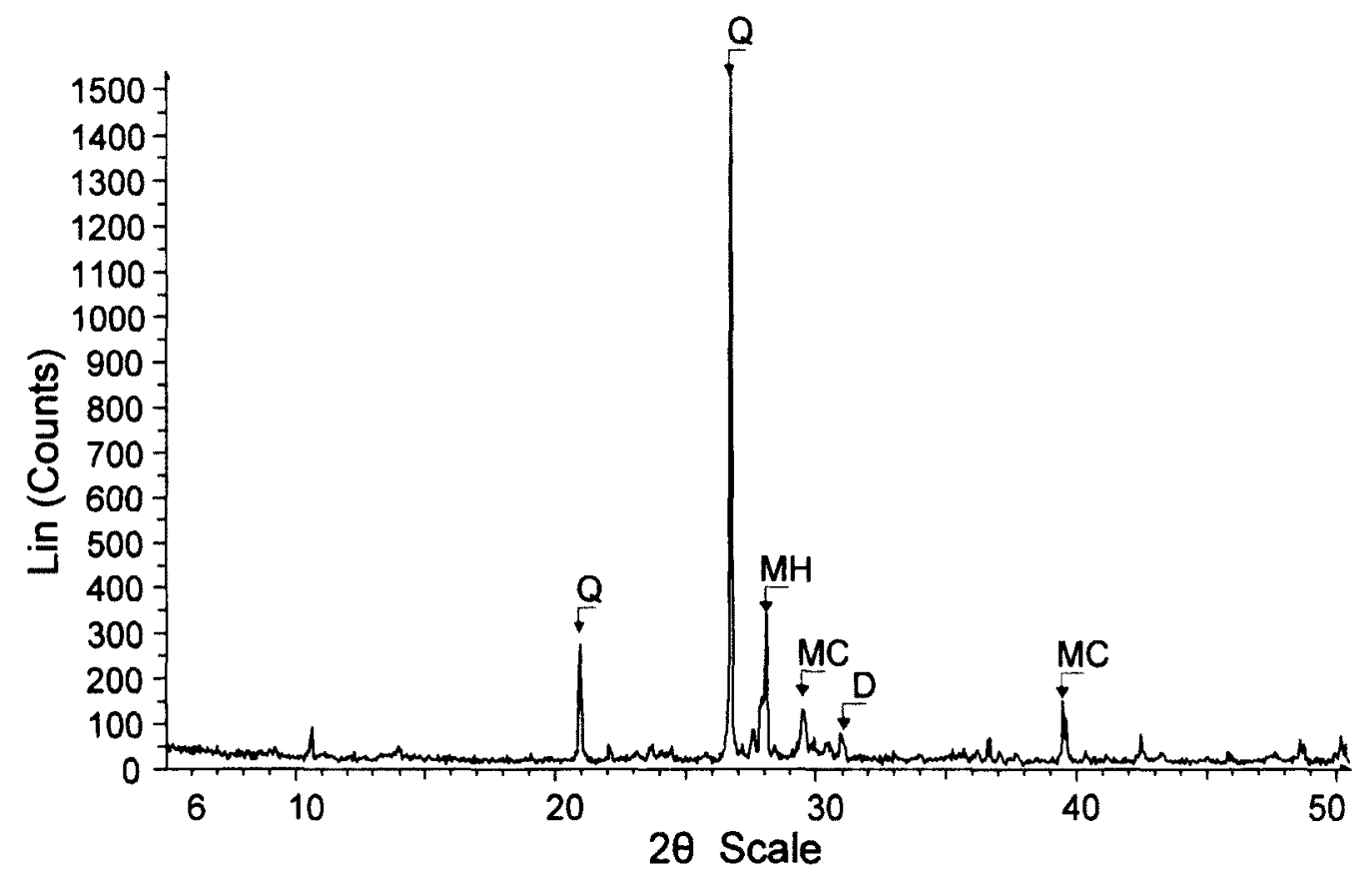

Figure A.5: XRD of concrete powder taken from top $0.5 \mathrm{~cm}$ surface of biofilm-covered mortar after chemical acidification; calcium carbonate (CC), dolomite (D), gypsum $(\mathrm{G})$, quartz $(\mathrm{Q})$, magnesium calcite $(\mathrm{C})$, magnesium sulphate hydroxide $(\mathrm{MH})$, winchitte potassium $(\mathrm{W})$. 


\section{APPENDIX B: SUPPLEMENTARY CLSM IMAGES}
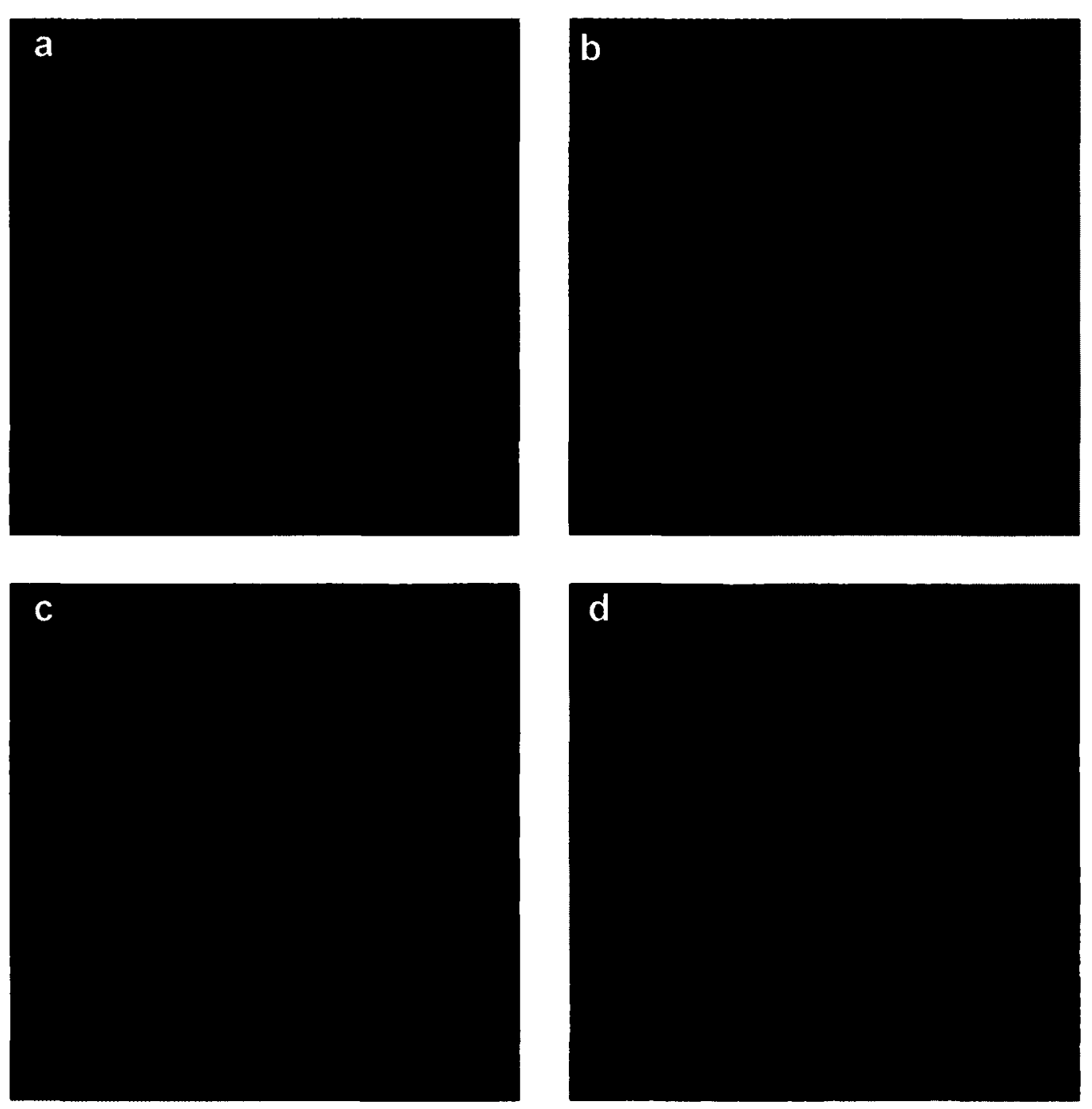

Figure B.1: CLSM images of biofilm-covered mortar before acidification stained with calcoflour for polysaccharide (cyan); image of biofilm at, a) $10 \mu \mathrm{m}$, b) 20 $\mu \mathrm{m}, \mathrm{c)} 26 \mu \mathrm{m}$ distance from the mortar surface, d) projected image of all the subsections in the same view. Scale bar represents $10 \mu \mathrm{m}$. 

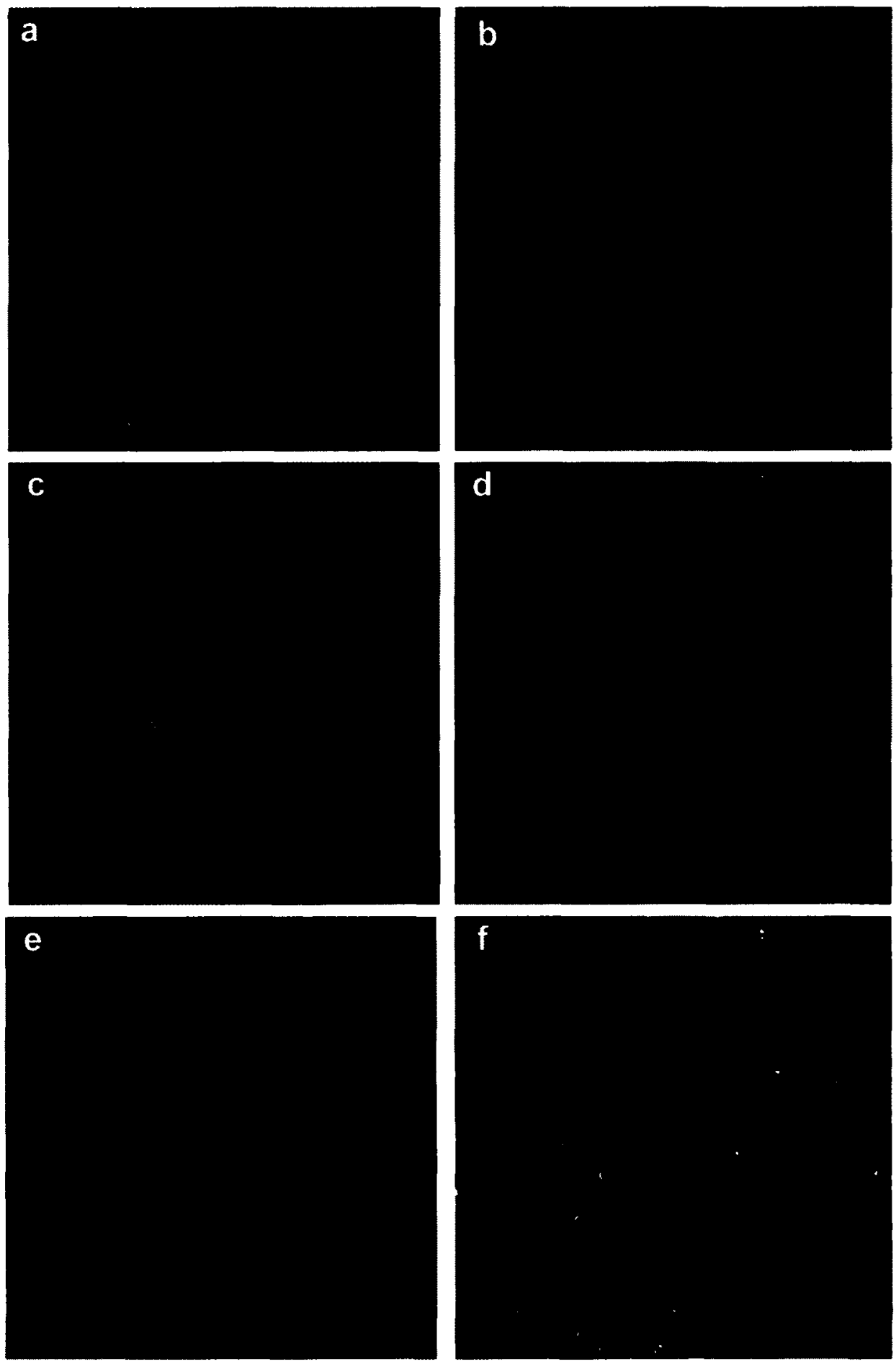

Figure B.2: CLSM images of biofilm-covered mortar before acidification stained for live cells (green) and dead cells (red); image of biofilm at, a) $5 \mu \mathrm{m}$, b) 10 $\mu \mathrm{m}$, c) $15 \mu \mathrm{m}$, d) $20 \mu \mathrm{m}$, e) $26 \mu \mathrm{m}$ distance from the mortar surface, f) projected image of all the subsections in the same view. Scale bar represents $10 \mu \mathrm{m}$. 

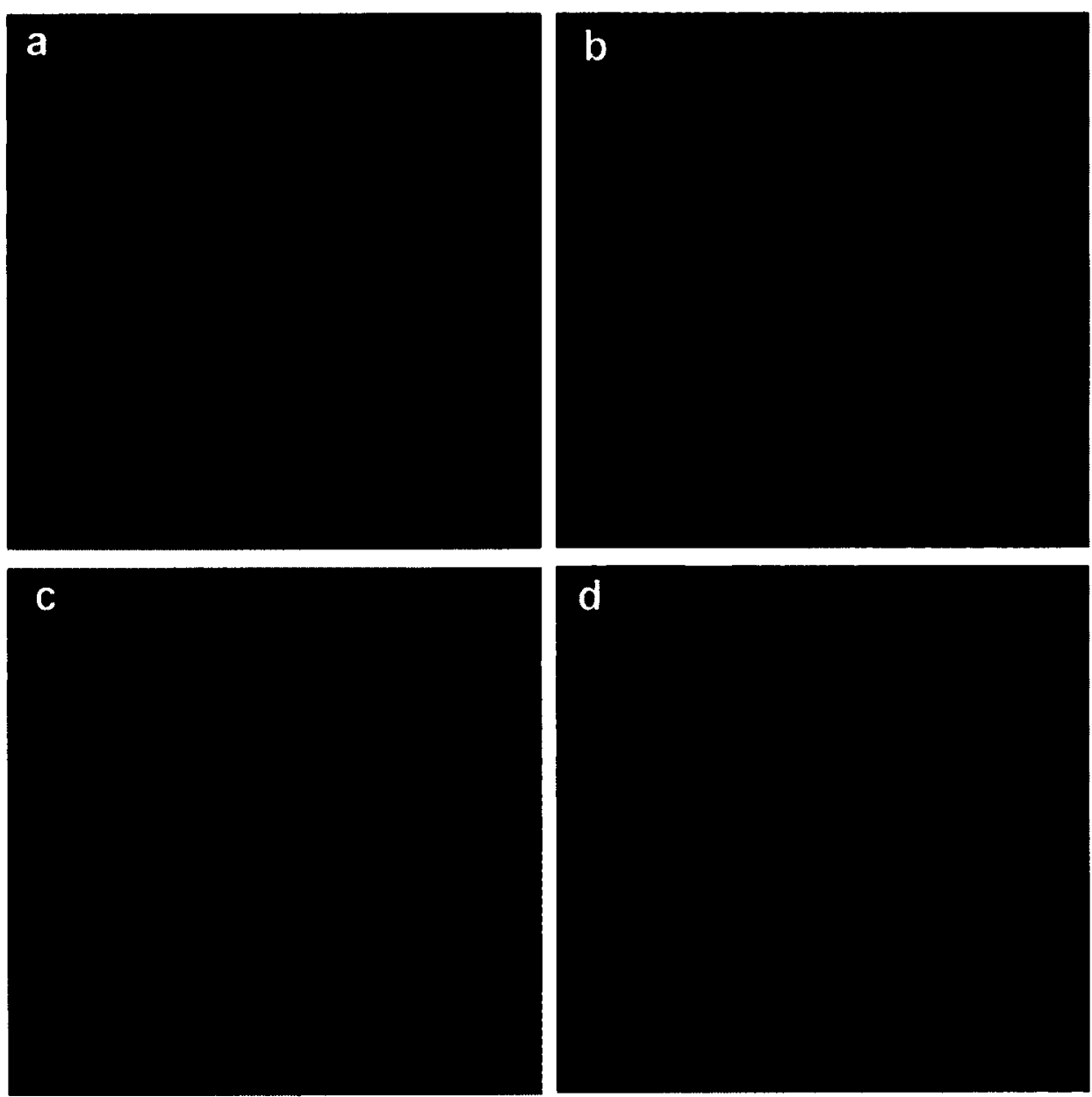

e

Figure B.3: CLSM images of biofilm-covered mortar after chemical acidification stained with calcoflour for polysaccharide (cyan); image of biofilm at, a) 20 $\mu \mathrm{m}$, b) $40 \mu \mathrm{m}$, c) $60 \mu \mathrm{m}$, d) $82 \mu \mathrm{m}$, e) $110 \mu \mathrm{m}$ distance from the mortar surface, f) projected image of all the subsections in the same view. Scale bar represents $10 \mu \mathrm{m}$. 

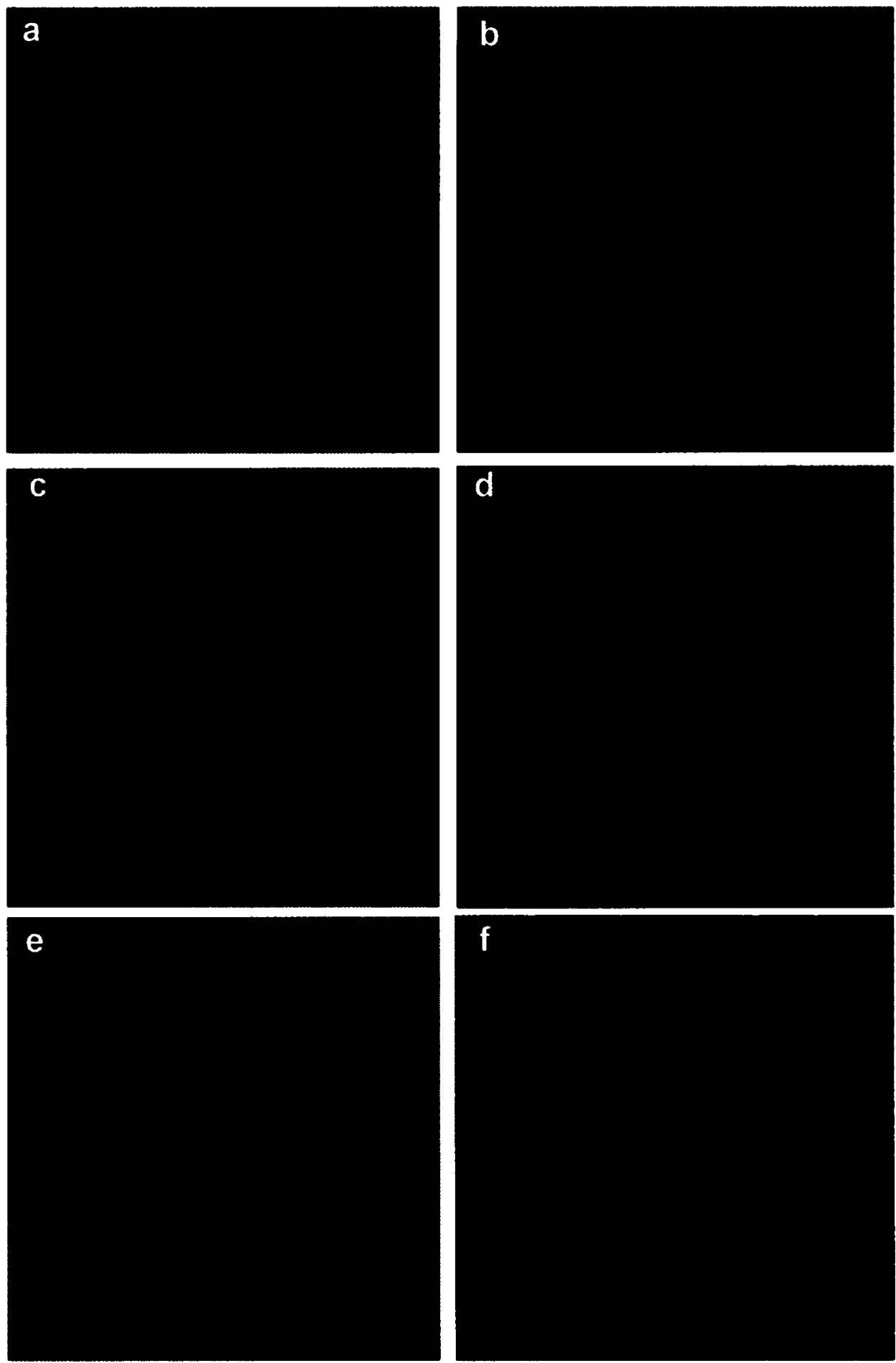

Figure B.4: CLSM images of biofilm-covered mortar after chemical acidification stained for live cells (green) and dead cells (red); image of biofilm at, a) 5 $\mu \mathrm{m}$, b) $10 \mu \mathrm{m}$, c) $15 \mu \mathrm{m}$, d) $20 \mu \mathrm{m}$, e) $22 \mu \mathrm{m}$ distance from the mortar surface, f) projected image of all the subsections in the same view. Scale bar represents $10 \mu \mathrm{m}$. 

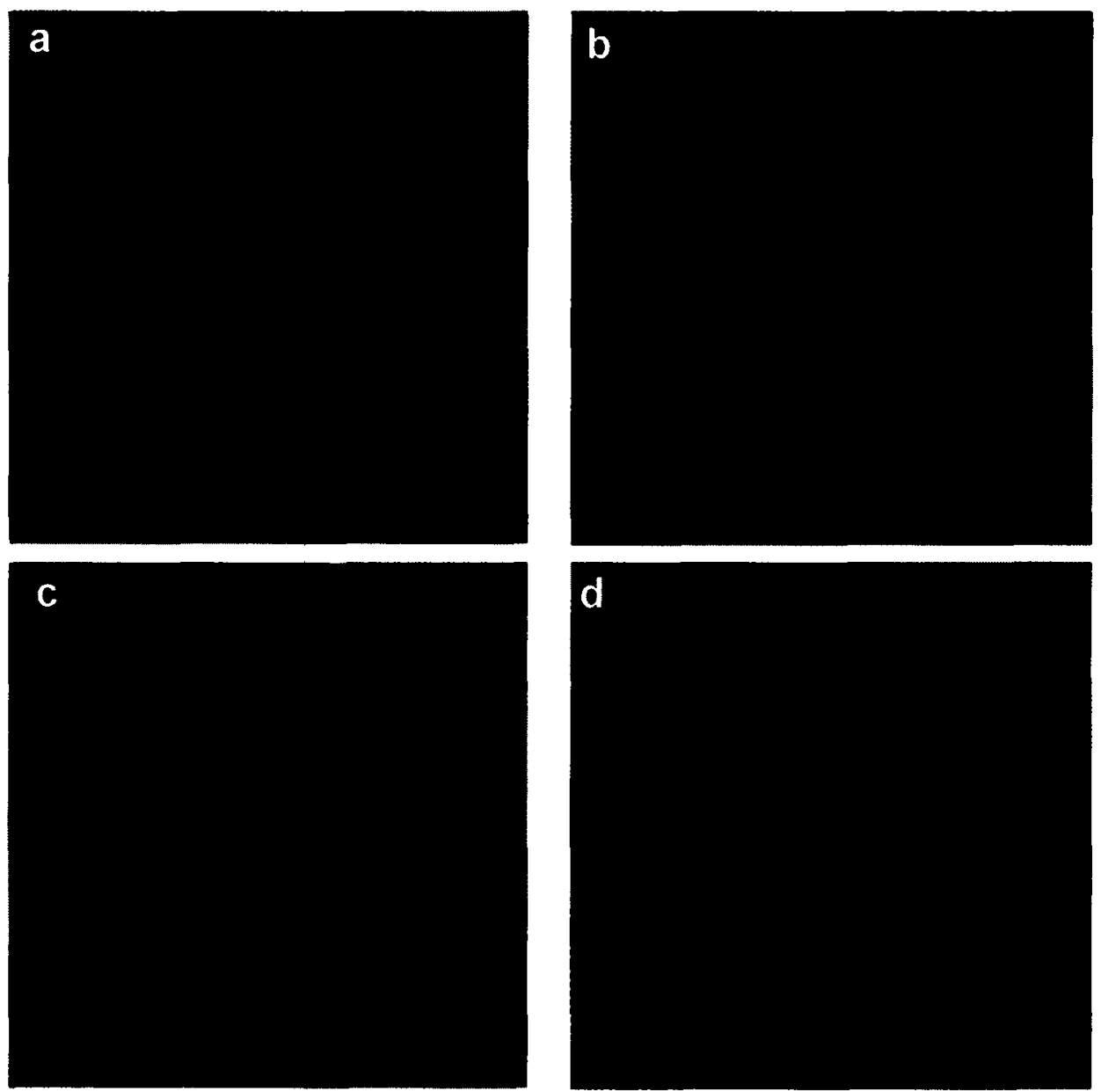

e

Figure B.5: CLSM images of biofilm-covered mortar after biogenic acidification stained with calcoflour for polysaccharide (cyan); image of biofilm at, a) $11 \mu \mathrm{m}, \mathrm{b}$ ) $15 \mu \mathrm{m}$, c) $20 \mu \mathrm{m}$, d) $30 \mu \mathrm{m}$ distance from the mortar surface, e) projected image of all the subsections in the same view. Scale bar represents $10 \mu \mathrm{m}$. 

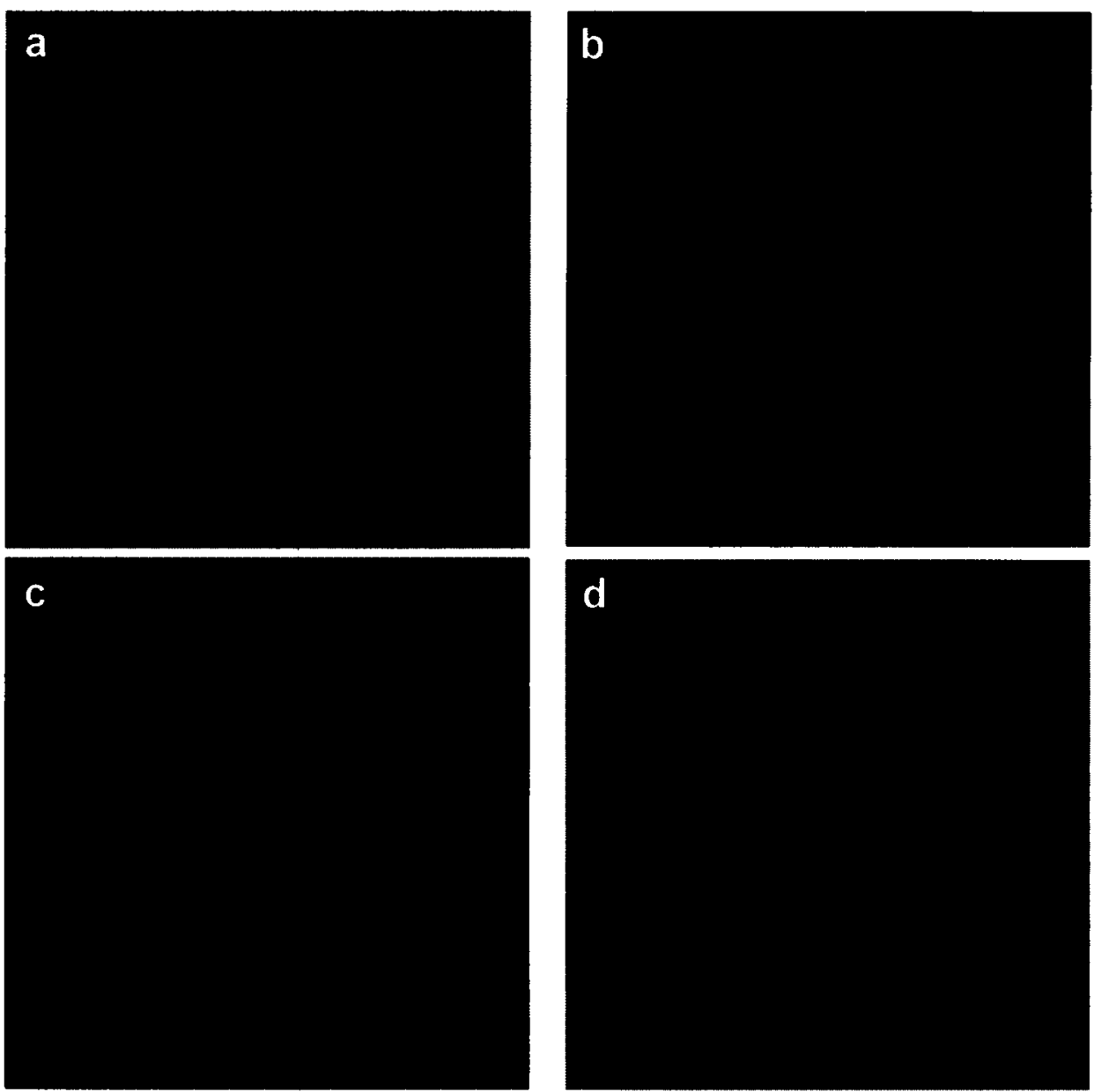

e

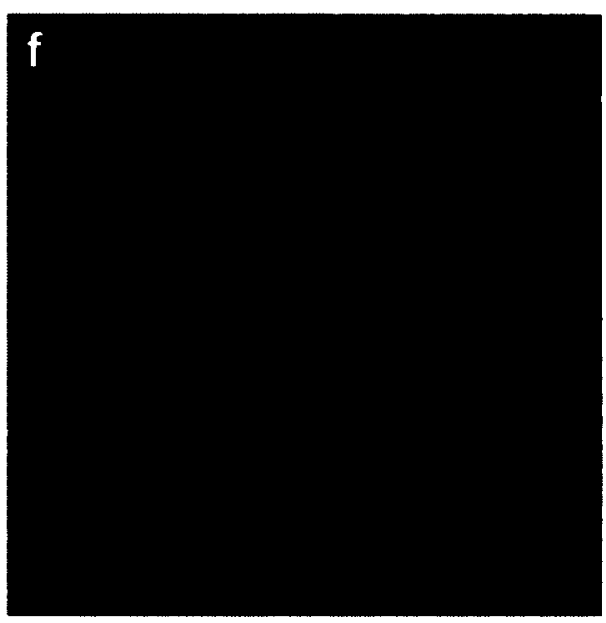

Figure B.6: CLSM images of biofilm-covered mortar after chemical acidification stained for live cells (green) and dead cells (red); image of biofilm at, a) 20 $\mu \mathrm{m}$, b) $32 \mu \mathrm{m}$, c) $51 \mu \mathrm{m}$, d) $64 \mu \mathrm{m}$, e) $91 \mu \mathrm{m}$ distance from the mortar surface, $f$ ) projected image of all the subsections in the same view. Scale bar represents $10 \mu \mathrm{m}$. 


\section{APPENDIX C: TABULAR DATA USED FOR DRAWING GRAPHS}

Table C.1: Data points of Figure 4.1; bacterial growth at elevated temperature of $37 \pm 1^{\circ}$ C.

\begin{tabular}{ccccc}
\hline $\begin{array}{c}\text { Time } \\
\text { (day) }\end{array}$ & $\begin{array}{c}\text { Average } \\
\text { reading }\end{array}$ & $\begin{array}{c}\text { Spectrophotometer reading } \\
\text { First }\end{array}$ & Second & $\begin{array}{c}\text { at } \\
\text { Third }\end{array}$ \\
\hline 0.00 & 0.049 & 0.049 & 0.049 & 0.492 \\
0.99 & 0.724 & 0.722 & 0.726 & 0.726 \\
1.01 & 0.758 & 0.761 & 0.757 & 0.756 \\
1.99 & 0.811 & 0.810 & 0.812 & 0.812 \\
3.01 & 1.150 & 1.154 & 1.152 & 1.143 \\
4.01 & 1.300 & 1.300 & 1.400 & 1.200 \\
5.00 & 1.355 & 1.355 & 1.350 & 1.360 \\
5.99 & 1.525 & 1.530 & 1.522 & 1.523 \\
7.00 & 1.735 & 1.733 & 1.737 & 1.736 \\
8.00 & 1.747 & 1.748 & 1.748 & 1.745 \\
\hline
\end{tabular}

Table C.2: Data points of Figure 4.1; bacterial growth at room temperature.

\begin{tabular}{c|c|ccc}
\hline $\begin{array}{c}\text { Time } \\
\text { (day) }\end{array}$ & $\begin{array}{c}\text { Average } \\
\text { reading }\end{array}$ & \multicolumn{3}{|c}{ Spectrophotometer reading at $600 \mathrm{~nm}$} \\
\hline 0.00 & 0.1094 & 0.0749 & Second & Third \\
0.99 & 0.5649 & 0.5793 & 0.5788 & 0.1092 \\
2.00 & 0.522 & 0.5297 & 0.5306 & 0.5245 \\
3.00 & 0.58 & 0.505 & 0.5032 & 0.4914 \\
4.01 & 0.7479 & 0.7474 & 0.7466 & 0.7507 \\
4.99 & 0.9356 & 0.9185 & 0.9223 & 0.9349 \\
6.01 & 0.9959 & 1.0323 & 1.0343 & 0.9953 \\
6.99 & 1.2527 & 1.2461 & 1.2496 & 1.2567 \\
8.00 & 1.2536 & 1.2712 & 1.2706 & 1.2523 \\
\hline
\end{tabular}


Table C.3: Data points of Figure 4.2; biomass concentration as measured by membrane filtration.

\begin{tabular}{c|ccc|cc}
\hline Time & \multicolumn{2}{|c|}{ Number of colonies on agar plates } & \multicolumn{2}{c}{ Average colony counts } \\
& first & second & Third & CFU/ml & CFU/cm ${ }^{2}$ \\
\hline Day 3 & 100 & 0 & 0 & 4 & 3.08 \\
Day 5 & $2.1 \mathrm{E}+07$ & $1.5 \mathrm{E}+07$ & $2.7 \mathrm{E}+07$ & $8.4 \mathrm{E}+05$ & $6.45 \mathrm{E}+05$ \\
Day 8 & $6.0 \mathrm{E}+07$ & $2.0 \mathrm{E}+07$ & $1.6 \mathrm{E}+08$ & $3.2 \mathrm{E}+06$ & $2.5 \mathrm{E}+06$ \\
\hline
\end{tabular}

Table C.4: Data points of Figure 4.3; biomass concentration as measured by ATP analysis.

\begin{tabular}{|c|c|c|c|c|}
\hline Time & \multicolumn{3}{|c|}{$\begin{array}{l}\text { Average } R_{\text {LUTP }} \text { of } \\
\text { two readings }\end{array}$} & $\begin{array}{c}\text { Average tATP } \\
\left(\frac{\text { pg ATP }}{\mathrm{cm}^{2}}\right)\end{array}$ \\
\hline Day 3 & 2569 & 2867 & 7340 & 1587 \\
\hline Day 5 & 36824 & 30212 & 8438 & 33518 \\
\hline Day 8 & 33018 & 34678 & 5742 & 43401 \\
\hline
\end{tabular}

Table C.5: Data points of Figure 4.10; live/dead cell coverage on biofilm-covered mortar.

\begin{tabular}{c|cccc|cc}
\hline \multirow{2}{*}{ Depth $(\mu \mathrm{m})$} & \multicolumn{2}{|c|}{ First location } & \multicolumn{2}{c|}{ Second location } & \multicolumn{2}{c}{ Average } \\
& Live & Dead \% & Live \% & Dead \% & \% Live & \% Dead \\
& $\%$ & & & & & \\
\hline 5 & 0.44 & 0.17 & 0.48 & 0.22 & 0.46 & 0.20 \\
10 & 0.77 & 0.25 & 0.60 & 0.31 & 0.69 & 0.28 \\
15 & 0.92 & 0.24 & 0.75 & 0.36 & 0.84 & 0.30 \\
20 & 0.85 & 0.22 & 1.00 & 0.45 & 0.93 & 0.34 \\
25 & 0.61 & 0.14 & 1.10 & 0.52 & 0.86 & 0.33 \\
27 & 0.42 & 0.10 & 0.95 & 0.42 & 0.69 & 0.26 \\
\hline
\end{tabular}


Table C.6: Data points of Figure 4.11; EPS and void space coverage on biofilmcovered mortar.

\begin{tabular}{c|cc|cc}
\hline \multirow{2}{*}{$\begin{array}{c}\text { Depth } \\
(\mu \mathrm{m})\end{array}$} & \multicolumn{2}{|c|}{ \% EPS } & \multicolumn{2}{c}{ Averages } \\
First view & Second view & \% EPS & \% Void \\
\hline 0 & 0.0 & 0.0 & 0.0 & 100.0 \\
5 & 33.5 & 12.0 & 22.8 & 77.3 \\
9 & 48.1 & 11.7 & 29.9 & 70.1 \\
15 & 61.5 & 16.1 & 38.8 & 61.2 \\
20 & 69.0 & 20.2 & 44.6 & 55.4 \\
26 & 66.8 & 37.8 & 52.3 & 47.7 \\
\hline
\end{tabular}

Table C.7: Data points of Figure 5.1 and 5.2; accumulative calcium and $\mathrm{pH}$ measurement in biofilm-covered and control reactors after chemical acidification.

\begin{tabular}{c|cc|cc}
\hline & \multicolumn{2}{|c|}{ Biofilm-covered mortar } & \multicolumn{2}{c}{ Control mortar } \\
Time (day) & Accum. Ca (ppm) & $\mathrm{pH}$ & Accum. Ca (ppm) & $\mathrm{pH}$ \\
\hline 0 & 2 & 5.99 & 2 & 5.99 \\
1 & 2.79 & 6.47 & 15 & 6.1 \\
2 & 4 & 7.45 & 20 & 5.79 \\
2 & 7 & 5.8 & 20 & 5.79 \\
4 & 13.3 & 7.58 & 34.3 & 6.04 \\
4 & 15.3 & 5 & 36.8 & 5 \\
6 & 16.72 & 6.83 & 72.3 & 5.68 \\
6 & 23.3 & 4.9 & 72.3 & 4.9 \\
8 & 34.9 & 6.31 & 76.4 & 5.34 \\
8 & 36.9 & 4 & 78.4 & 4 \\
9 & 53.4 & 4.81 & 99.7 & 4.46 \\
10 & 91.9 & 5.59 & 156 & 5.03 \\
10 & 99.9 & 4.08 & 176.4 & 4 \\
12 & 124.9 & 4.9 & 200.4 & 4.3 \\
12 & 126.9 & 3 & 202.4 & 3 \\
14 & 209.5 & 3.8 & 317.4 & 3.62 \\
14 & 234.9 & 3.08 & 370.4 & 3 \\
16 & 306.9 & 3.75 & 432.4 & 3.36 \\
19 & 329.9 & 5.32 & 500.4 & 4.39 \\
\hline
\end{tabular}


Table C.8: Data points of Figure 5.10; live/dead cell coverage on biofilm-covered mortar after chemical acidification.

\begin{tabular}{ccc|ccc}
\hline \multicolumn{3}{c|}{ First field of view } & \multicolumn{3}{c}{ Second field of view } \\
Depth $(\mu \mathrm{m})$ & \% Live & \% Dead & Depth $(\mu \mathrm{m})$ & \% Live & \% Dead \\
\hline 0 & 0 & 0 & 0 & 0 & 0 \\
4.54 & 1.92 & 0.49 & 5.31 & 2.47 & 0.31 \\
9.04 & 2.6 & 0.91 & 10.6 & 6.83 & 0.53 \\
15.87 & 3.4 & 2.45 & 12.4 & 7.4 & 0.63 \\
20.41 & 3.4 & 1.99 & 15.05 & 6.3 & 0.57 \\
24.94 & 2.65 & 1.17 & 20.36 & 2.06 & 0.09 \\
29.98 & 2.55 & 1.17 & 21.3 & 1.5 & 0.06 \\
36.28 & 1.88 & 0.95 & & & \\
40.82 & 1.4 & 0.2 & & & \\
45.35 & 1.14 & 0.11 & & & \\
49.89 & 0.51 & 0.11 & & & \\
54.42 & 0.32 & 0.06 & & & \\
\hline
\end{tabular}

Table C.9: Data points of Figure 5.11; comparison of EPS coverage on biofilm-covered mortar.

\begin{tabular}{cccc|cc}
\hline \multicolumn{5}{c|}{ After acidification } & \multicolumn{2}{c}{ Before acidification } \\
\multicolumn{2}{c}{ First field of view } & \multicolumn{2}{c}{ Second field of view } & & \\
Depth $(\mu \mathrm{m})$ & \%EPS & Depth $(\mu \mathrm{m})$ & \%EPS & Depth $(\mu \mathrm{m})$ & $\%$ EPS \\
\hline 0 & 0 & 0 & 0 & 0 & 0.0 \\
6.28 & 10.86 & 10.76 & 5.6 & 5 & 22.8 \\
12.55 & 17.54 & 16.14 & 11.6 & 9 & 29.9 \\
18.83 & 21.47 & 21.5 & 23.9 & 15 & 38.8 \\
21.97 & 26.09 & 29.6 & 44.8 & 20 & 44.6 \\
25.11 & 31 & 40.3 & 52.3 & 26 & 52.3 \\
31.38 & 42.5 & 51 & 35.7 & & \\
37.66 & 44.8 & 59.2 & 20.4 & & \\
43.93 & 35 & 64.5 & 13.9 & & \\
50.21 & 28 & & & & \\
59.69 & 20 & & & & \\
\hline
\end{tabular}


Table C.10: Data points of Figure 6.1 and $6.2 ; \mathrm{pH}$ and sulphate concentration of SOB growth media, MB1.

\begin{tabular}{|c|c|c|c|c|c|}
\hline \multirow{2}{*}{$\begin{array}{l}\text { Time } \\
\text { (day) }\end{array}$} & \multirow[t]{2}{*}{$\mathrm{pH}$} & \multicolumn{3}{|c|}{$\begin{array}{l}\text { Sulfate concentration in } 30 \mathrm{x} \\
\text { diluted samples }(\mathrm{mg} / \mathrm{L})\end{array}$} & \multirow[t]{2}{*}{$\begin{array}{c}\text { Average } \\
(\mathrm{mg} / \mathrm{L})\end{array}$} \\
\hline & & $\# 1$ & $\# 2$ & $\# 3$ & \\
\hline 0 & 6.55 & \multirow[t]{2}{*}{3} & \multirow[t]{2}{*}{6} & \multirow[t]{2}{*}{4.5} & \multirow[t]{2}{*}{135} \\
\hline 1.06 & 6.54 & & & & \\
\hline 2.71 & 6.33 & 18 & 18 & 18 & 540 \\
\hline \multirow[t]{2}{*}{4.79} & 5.55 & 65 & 60 & 63 & 1880 \\
\hline & & \multicolumn{3}{|c|}{ change dilution factor to $100 \mathrm{x}$} & \\
\hline 5.91 & 4.83 & 19 & 20 & 19.5 & 1950 \\
\hline 6.74 & 4.7 & & & & \\
\hline 7.91 & 4.5 & 29 & 29 & 29 & 2900 \\
\hline 8.81 & 4.0 & 28 & 30 & 29 & 2900 \\
\hline 10.85 & 3.2 & 31 & 35 & 33 & 3300 \\
\hline 11.89 & 3.05 & 33 & 34 & 34 & 3367 \\
\hline
\end{tabular}

Table C.11: Data points of Figure 6.1 and 6.2; pH and sulphate concentration of SOB growth media, MB2.

\begin{tabular}{|c|c|c|c|c|c|}
\hline \multirow{2}{*}{$\begin{array}{l}\text { Time } \\
\text { (day) }\end{array}$} & \multirow[t]{2}{*}{$\mathrm{pH}$} & \multicolumn{3}{|c|}{$\begin{array}{l}\text { Sulfate concentration in } 100 \mathrm{x} \\
\text { diluted samples }(\mathrm{mg} / \mathrm{L})\end{array}$} & \multirow{2}{*}{$\begin{array}{l}\text { sulfate } \\
\mathrm{mg} / \mathrm{L}\end{array}$} \\
\hline & & $\# 1$ & $\# 2$ & $\# 3$ & \\
\hline 0 & 6.39 & 6 & 6 & 6 & 600 \\
\hline 0.90 & 6.16 & 9.5 & 9 & 10 & 950 \\
\hline 1.82 & 5.35 & 15 & 16 & 14 & 1500 \\
\hline 3.86 & 3.91 & 37 & 37 & 37 & 2700 \\
\hline 4.98 & 3.43 & 36 & 37 & 36 & 3650 \\
\hline 5.97 & 3.16 & 36 & 36 & 36 & 3600 \\
\hline 8.03 & 2.77 & 41 & 42 & 43 & 4200 \\
\hline 8.89 & 2.67 & 42 & 45 & 48 & 4500 \\
\hline 10.14 & 2.53 & 48 & 45 & 44 & 4567 \\
\hline 11.95 & 2.4 & 52 & 50 & 52 & 5133 \\
\hline
\end{tabular}


Table C.12: Data points of Figure 6.3 and 6.5; accumulative calcium and $\mathrm{pH}$ measurement in biofilm-covered and control reactors during biogenic acidification.

\begin{tabular}{c|cc|cc}
\hline & \multicolumn{2}{|c|}{ Biofilm covered mortar } & \multicolumn{2}{|c}{ Control mortar } \\
Time & $\begin{array}{c}\text { Accum. Ca } \\
\text { (day) }\end{array}$ & pH & Accum. Ca & $\mathrm{pH}$ \\
\hline 0.01 & 2.50 & 6.55 & 2.50 & 6.55 \\
1.01 & 10.60 & 6.68 & 10.70 & 6.57 \\
3.00 & 11.80 & 6.88 & 13.00 & 6.40 \\
5.00 & 4.95 & 7.02 & 17.90 & 4.75 \\
7.00 & 3.65 & 7.02 & 26.30 & 3.73 \\
9.99 & 3.47 & 7.09 & 42.70 & 3.49 \\
12.01 & 3.36 & 6.95 & 45.00 & 3.77 \\
13.01 & 3.08 & 6.94 & 55.00 & 4.54 \\
14.01 & 3.30 & 6.95 & 60.00 & 4.79 \\
15.00 & 6.95 & 6.94 & 64.60 & 4.97 \\
15.00 & 4.64 & 6.55 & 69.17 & 6.55 \\
17.01 & 6.37 & 6.52 & 71.02 & 6.52 \\
18.00 & 7.51 & 6.51 & 73.53 & 6.32 \\
21.01 & 7.71 & 6.51 & 71.40 & 6.81 \\
24.00 & 7.90 & 6.50 & 69.60 & 6.90 \\
\hline
\end{tabular}

Table C.13: Data points of Figure 6.4; sulphate concentration in biofilm-covered and control reactors during biogenic acidification; units are in $\mathrm{mg} / \mathrm{L}$.

\begin{tabular}{c|cccc|cccc}
\hline & \multicolumn{3}{|c|}{ Biofilm-covered mortar } & \multicolumn{4}{c}{ Control mortar } \\
Time & \multicolumn{2}{|c|}{$\begin{array}{c}\text { Sulfate concentration in } \\
\text { (day) }\end{array}$} & $\begin{array}{c}\text { 100x diluted samples } \\
\# 1\end{array}$ & $\# 2$ & $\# 3$ & & Average & \multicolumn{3}{c}{ Sulfate concentration in } & Average \\
(mg/L) & \multicolumn{2}{c}{ 100x diluted samples } & (mg/L) \\
\hline 0.0 & 0 & 0 & 0 & 0 & 0 & 0 & 0 & 0 \\
1.0 & 0 & 0 & 0 & 0 & 4 & 4 & 4 & 400 \\
3.0 & 1.5 & 1 & 2 & 150 & 8 & 8 & 8 & 800 \\
5.0 & 1 & 0 & 0 & 0 & 43 & 44 & 43 & 4350 \\
7.0 & 1.5 & 2 & 1 & 150 & 50 & 51 & 51 & 5067 \\
10.0 & 1.5 & 1 & 2 & 150 & 58 & 57 & 58 & 5767 \\
12.0 & 1.5 & 1 & 2 & 150 & 61 & 61 & 61 & 6100 \\
14.0 & 1.5 & 1 & 2 & 150 & 63 & 64 & 63.4 & 6350 \\
15.0 & 1 & 1 & 1 & 100 & 60 & 62 & 61 & 6100 \\
15.0 & 2 & 3 & 2 & 250 & 6 & 5 & 5.4 & 550 \\
17.0 & 3 & 2 & 3 & 250 & 5 & 5 & 5 & 500 \\
18.0 & 3 & 3 & 3 & 300 & 7 & 5 & 6 & 600 \\
21.0 & 3 & 3 & 3 & 300 & 9 & 8 & 9 & 867 \\
24.0 & 3 & 4 & 3.5 & 350 & 9 & 8 & 9 & 867 \\
\hline
\end{tabular}


Table C.14: Data points of Figure 6.17; comparison of biofilm components at different condition.

\begin{tabular}{l|ccc}
\hline & $\begin{array}{c}\text { Before acidification- } \\
\text { biofilm covered } \\
\text { mortar }\end{array}$ & $\begin{array}{c}\text { After biogenic } \\
\text { acidification, biofilm } \\
\text { covered mortar }\end{array}$ & $\begin{array}{c}\text { After biogenic } \\
\text { acidification, control } \\
\text { mortar }\end{array}$ \\
\hline \% Live & $8.0 \pm 3.2$ & $19.2 \pm 6.0$ & $20.1 \pm 13.8$ \\
$\%$ Dead & $2.9 \pm 1.5$ & $11.5 \pm 7.1$ & $18 \pm 12.2$ \\
$\%$ EPS & $63.1 \pm 11.5$ & $75.6 \pm 8.0$ & $7.7 \pm 7.7$ \\
Thickness $(\mu \mathrm{m})$ & $29 \pm 3.2$ & $78.6 \pm 18.7$ & $65.3 \pm 14.2$ \\
live/dead & 2.8 & 1.7 & 1.1 \\
total cells & 10.9 & 30.7 & 38.1 \\
\hline
\end{tabular}

Table C.15: Data points of Figure 6.20 ; biofilm viability profile after biogenic acidification.

\begin{tabular}{ccc|ccc}
\hline \multicolumn{3}{c|}{ First field of view } & \multicolumn{3}{c}{ Second field of view } \\
Depth $(\mu \mathrm{m})$ & \%Live & \%Dead & Depth $(\mu \mathrm{m})$ & \%Live & \%Dead \\
\hline 0 & 0.645 & 0.22 & 0 & 0 & 0 \\
3.46 & 0.977 & 0.326 & 6.9 & 0.15 & 0.1 \\
10.53 & 3.803 & 0.823 & 13.8 & 0.09 & 0.19 \\
13.87 & 5.95 & 1.343 & 20.64 & 0.18 & 0.12 \\
20.23 & 8.875 & 1.681 & 30.96 & 0.4 & 0.15 \\
24.23 & 9.573 & 1.781 & 37.74 & 0.82 & 0.23 \\
34.61 & 5.897 & 1.284 & 48.15 & 1.92 & 0.84 \\
41.23 & 3.379 & 0.642 & 58.47 & 1.75 & 1.33 \\
48.53 & 1.014 & 0.215 & 68.8 & 0.73 & 0.55 \\
\hline
\end{tabular}

Table C.16: Data points of Figure 6.21; comparison of EPS coverage on biofilm-covered mortar after biogenic acidification.

\begin{tabular}{cc|cc|cc}
\hline \multicolumn{4}{c|}{ After acidification } & \multicolumn{2}{c}{ Before acidification } \\
\multicolumn{2}{c|}{ First field of view } & \multicolumn{2}{c}{ Second field of view } & & \\
Depth $(\mu \mathrm{m})$ & \%EPS & Depth $(\mu \mathrm{m})$ & \%EPS & Depth $(\mu \mathrm{m})$ & $\%$ EPS \\
\hline 0 & 0 & 0 & 0 & 0 & 0.0 \\
5.3 & 2.5 & 10 & 1.8 & 5 & 22.8 \\
10.6 & 8.72 & 21 & 6.5 & 9 & 29.9 \\
15.9 & 19.3 & 30.7 & 28.16 & 15 & 38.8 \\
21.21 & 31.6 & 40 & 32 & 20 & 44.6 \\
26.51 & 22.4 & 49.1 & 13.9 & 26 & 52.3 \\
34.46 & 8.57 & 61.4 & 5.35 & & \\
39.44 & 3 & 64.5 & 3.33 & & \\
45.04 & 0.6 & 73.7 & 1.15 & & \\
\hline
\end{tabular}


Table C.17: Data points of Figure 7.1 and 7.3 ; accumulative calcium and $\mathrm{pH}$ measurement in biofilm-covered and control reactors during biogenic acidification at an elevated temperature.

\begin{tabular}{|c|c|c|c|c|}
\hline \multirow{2}{*}{$\begin{array}{l}\text { Time } \\
\text { (day) }\end{array}$} & \multicolumn{2}{|c|}{ Control mortar } & \multicolumn{2}{|c|}{ Biofilm-covered mortar } \\
\hline & $\begin{array}{l}\text { Accum. Ca } \\
\text { (ppm) }\end{array}$ & $\mathrm{pH}$ & $\begin{array}{c}\text { Accum. } \mathrm{Ca} \\
(\mathrm{ppm})\end{array}$ & $\mathrm{pH}$ \\
\hline 0 & 6.06 & 6.34 & 9.64 & 6.33 \\
\hline 1 & 11.2 & 6.22 & 16.3 & 6.16 \\
\hline 2 & 16.7 & 5.43 & 11.4 & 6.11 \\
\hline 4 & 32.2 & 5.01 & 12.4 & 6.01 \\
\hline 5 & 25.8 & 5.24 & 9.65 & 5.98 \\
\hline 6 & 29.8 & 5.3 & 8.45 & 5.92 \\
\hline 7 & 50.3 & 5.17 & 15.5 & 5.92 \\
\hline 8 & 55.6 & 4.93 & 16.2 & 5.89 \\
\hline 9 & 66.9 & 4.71 & 15.9 & 5.81 \\
\hline 10 & 74.8 & 4.48 & 22.8 & 5.72 \\
\hline 12 & 77.1 & 4.43 & 23.7 & 5.61 \\
\hline 13 & 78.9 & 4.3 & 25.5 & 5.54 \\
\hline 14 & 84.2 & 4.2 & 21.6 & 5.58 \\
\hline 16 & 152 & 4.14 & 23.6 & 5.73 \\
\hline 19 & 150 & 4.7 & 22.5 & 5.73 \\
\hline 22 & 148 & 4.85 & 21.1 & 5.74 \\
\hline 23 & 134 & 5.11 & 26.4 & 5.82 \\
\hline 24 & 136 & 6.18 & 28.4 & 6.2 \\
\hline 27 & 159.6 & 3.57 & 27.66 & 6.5 \\
\hline 28 & 168.5 & 3.91 & 29.2 & 6.48 \\
\hline 29 & 182 & 4.21 & 31.11 & 6.48 \\
\hline 31 & 191.4 & 3.93 & 30.52 & 6.48 \\
\hline 33 & 192.9 & 3.89 & 31.08 & 6.38 \\
\hline 35 & 200.4 & 4.8 & 30.77 & 6.38 \\
\hline 37 & 204.3 & 4.74 & 30.43 & 6.3 \\
\hline 39 & 219.7 & 4.75 & 33.5 & 6.2 \\
\hline 41 & 220.8 & 4.98 & 36.7 & 6.15 \\
\hline 43 & 209.1 & 5.31 & 42.7 & 6.04 \\
\hline
\end{tabular}


Table C.18: Data points of Figure 7.2; sulphate concentration in biofilm-covered and control reactors during biogenic acidification at an elevated temperature; units are in $\mathrm{mg} / \mathrm{L}$.

\begin{tabular}{c|cccc|cccc}
\hline & \multicolumn{4}{|c|}{ Control Mortar } & \multicolumn{5}{c}{ Biofilm-covered mortar } \\
Time & \multicolumn{3}{|c}{ Sulfate concentration in } & Average & \multicolumn{3}{c}{ Sulfate concentration in } & Average \\
& \multicolumn{2}{|c|}{100 d diluted sample } & & \multicolumn{4}{c}{ 100 diluted sample } \\
(day) & $\# 1$ & $\# 2$ & $\# 3$ & & $\# 1$ & $\# 2$ & $\# 3$ & \\
\hline 0 & 0 & 1 & 1 & 66.7 & 0 & 0 & 1 & 33.3 \\
2 & 28 & 28 & 27 & 2766.7 & 10 & 9 & 7 & 866.7 \\
4 & 44 & 41 & 39 & 4133.3 & 15 & 16 & 18 & 1633.3 \\
6 & 46 & 45.5 & 45 & 4550.0 & 20 & 17 & 22 & 1966.7 \\
8 & 53 & 56 & 57 & 5533.3 & 28 & 27.5 & 27 & 2750.0 \\
10 & 53 & 56 & 56 & 5500.0 & 32 & 32 & 32 & 3200.0 \\
12 & 58 & 58.5 & 59 & 5850.0 & 33 & 33.5 & 34 & 3350.0 \\
14 & 60 & 59 & 59 & 5933.3 & 36 & 35.5 & 35 & 3550.0 \\
16 & 63 & 63 & 64 & 6333.3 & 38 & 37.5 & 37 & 3750.0 \\
19 & 64 & 63 & 63 & 6333.3 & 38 & 38.5 & 39 & 3850.0 \\
22 & 65 & 64 & 64 & 6433.3 & 36 & 35 & 33 & 3466.7 \\
23 & 63 & 64 & 64 & 6366.7 & 36 & 35.5 & 35 & 3550.0 \\
24 & 1 & 1 & 0 & 66.7 & 1 & 1 & 1 & 100.0 \\
27 & 46 & 47 & 47 & 4666.7 & 13 & 13.5 & 14 & 1350.0 \\
29 & 48 & 48 & 48 & 4800.0 & 15 & 15 & 16 & 1533.3 \\
31 & 52 & 50 & 48 & 5000.0 & 13 & 13 & 13 & 1300.0 \\
33 & 52 & 52 & 52 & 5200.0 & 14 & 15 & 15 & 1466.7 \\
35 & 54 & 52 & 51 & 5233.3 & 15 & 16 & 17 & 1600.0 \\
37 & 52 & 52 & 52 & 5200.0 & 18 & 18 & 18 & 1800.0 \\
39 & 52 & 51 & 50 & 5100.0 & & & & \\
41 & 50 & 51 & 52 & 5100.0 & 18 & 19 & 21 & 1933.3 \\
43 & 54 & 53 & 52 & 5300.0 & 23 & 24 & 25 & 2400.0 \\
\hline
\end{tabular}

